UII norden

\title{
Invasive Alien Species
}

Pathway Analysis and Horizon Scanning for Countries in Northern Europe

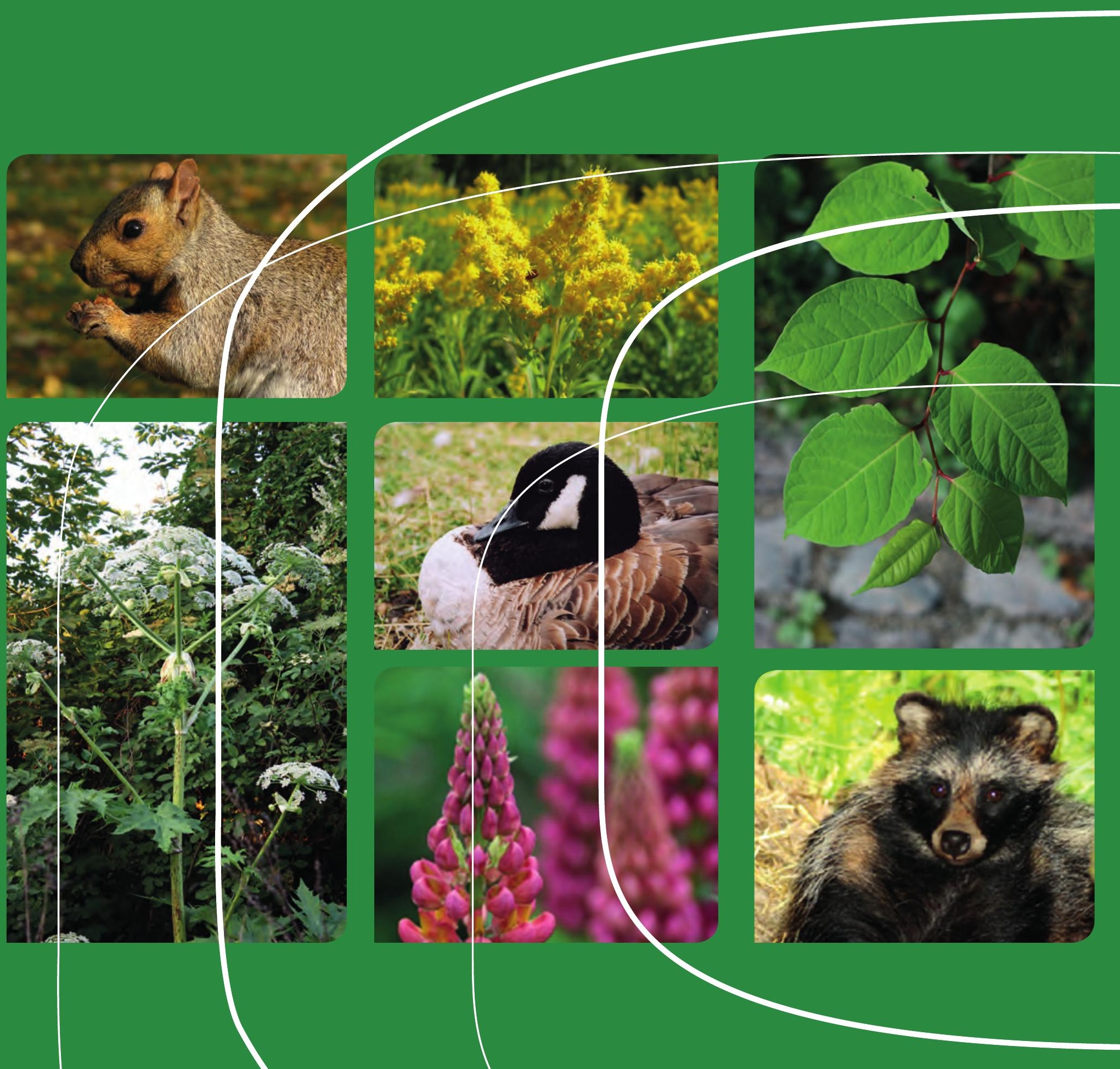



2 norden 



\section{Invasive Alien Species}

Pathway Analysis and Horizon Scanning for Countries in Northern Europe

NOBANIS 
Invasive Alien Species

Pathway Analysis and Horizon Scanning for Countries in Northern Europe NOBANIS

ISBN 978-92-893-3982-7 (PRINT)

ISBN 978-92-893-3984-1 (PDF)

ISBN 978-92-893-3983-4 (EPUB)

http://dx.doi.org/10.6027/TN2015-517

TemaNord 2015:517

ISSN 0908-6692

(C) Nordic Council of Ministers 2015

Layout: Hanne Lebech

Cover photo:

Arion lusitanicus by Hans Erik Svart; Solidago canadensis by Hans Erik Svart; Heracleum mantegazzianum by Helene Nyegaard Hvid; Rosa rugosa by Helene Nyegaard Hvid; Trachemys scripta elegans by Henrik Bringsøe; Branta canadensis by Inger Weidema; Lupinus polyphyllus by Merike Linnamägi; Pacifastacus leniusculus by Merike Linnamägi; Reynoutria japonica by Merike Linnamägi; Nyctereutes procyonoides by Merike Linnamägi; Sciurus carolinensis by Merike Linnamägi

Print: Rosendahls-Schultz Grafisk

Printed in Denmark

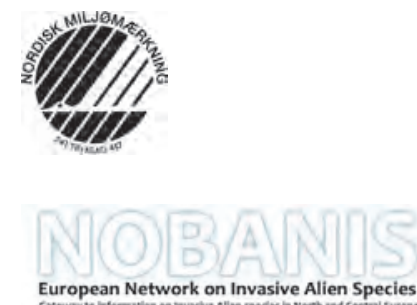

This publication has been published with financial support by the Nordic Council of Ministers. However, the contents of this publication do not necessarily reflect the views, policies or recommendations of the Nordic Council of Ministers.

\section{www.norden.org/en/publications}

\section{Nordic co-operation}

Nordic co-operation is one of the world's most extensive forms of regional collaboration, involving Denmark, Finland, Iceland, Norway, Sweden, and the Faroe Islands, Greenland, and Åland.

Nordic co-operation has firm traditions in politics, the economy, and culture. It plays an important role in European and international collaboration, and aims at creating a strong Nordic community in a strong Europe.

Nordic co-operation seeks to safeguard Nordic and regional interests and principles in the global community. Common Nordic values help the region solidify its position as one of the world's most innovative and competitive.

\section{Nordic Council of Ministers}

Ved Stranden 18

DK-1061 Copenhagen K

Phone (+45) 33960200

\section{www.norden.org}




\section{Content}

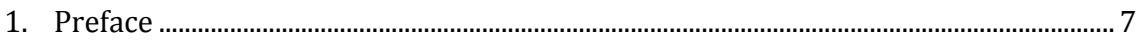

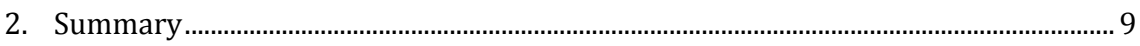

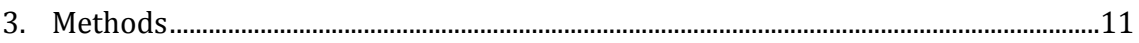

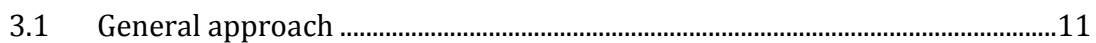

3.2 Pathway analysis ............................................................................................13

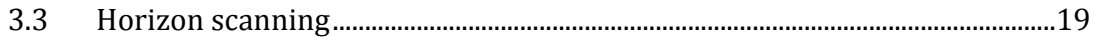

3.4 Prioritisation of pathways ...........................................................................25

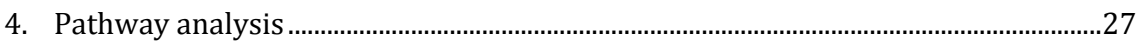

4.1 Pathways of introduced species .....................................................................28

4.2 Invasiveness of introduced species......................................................................

4.3 Taxonomic groups of introduced species...........................................................50

$4.4 \quad$ Temporal development of pathways................................................................97

4.5 Species origin and the pathway of introduction.............................................. 104

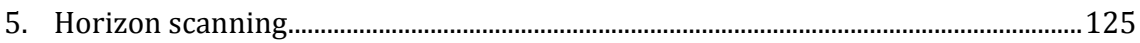

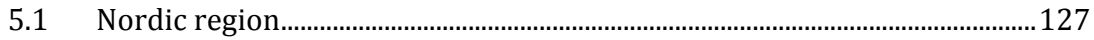

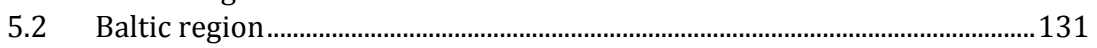

5.3 Islands of the North Atlantic Ocean ...............................................................134

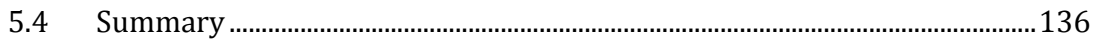

6. Discussions ....................................................................................................................139

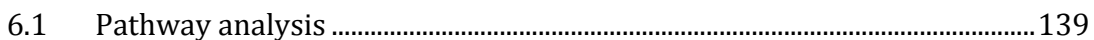

6.2 Horizon scanning ............................................................................................... 144

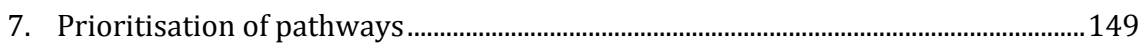

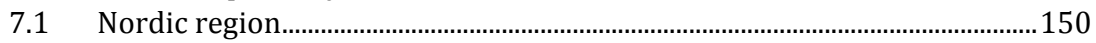

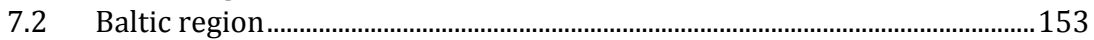

7.3 Islands of the North Atlantic Ocean ...............................................................157

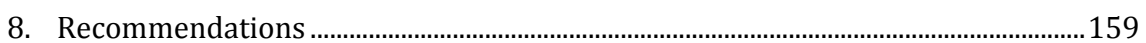

8.1 Pathways of concern ........................................................................................ 159

8.2 Early warning system ...................................................................................... 161

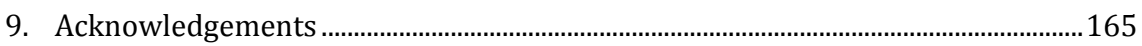

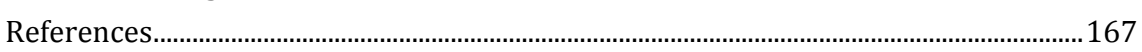

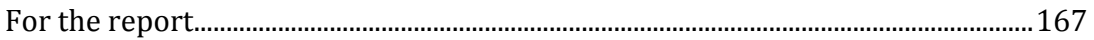

For the information search on Angiosperms, Coleoptera and Diptera..................168

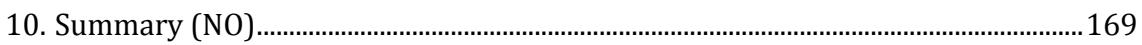

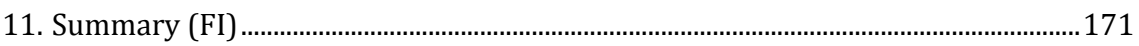


Appendices

Appendix 1: Classification of pathways in Norway ...................................................173

Appendix 2: List of experts ......................................................................................175

Appendix 3: Assessment scores and criteria .............................................................177

Appendix 4: Temporal development of pathways in the Nordic region ................178

Appendix 5: Temporal development of pathways in the Baltic region...................179

Appendix 6: High risk species for all regions.............................................................180

Appendix 7: Medium risk species for all regions .......................................................183

Appendix 8: Species not assessed...........................................................................187

Appendix 9: High risk species for the Nordic region..................................................189

Appendix 10: Medium risk species for the Nordic region..............................................192

Appendix 11: High risk species for the Baltic region.................................................196

Appendix 12: Medium risk species for the Baltic region ...........................................199

Appendix 13: High risk species for the Islands of the North Atlantic Ocean ........202

Appendix 14: Medium risk species for the Islands of the North Atlantic

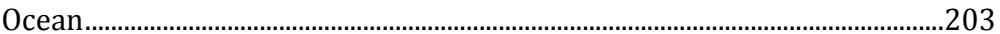

Appendix 15: Low risk species for the Nordic region ...............................................204

Appendix 16: Low risk species for the Baltic region .................................................209

Appendix 17: Low risk species for the Islands of the North Atlantic Ocean.........214

Appendix 18: List of potential door knocker species ................................................220 


\section{Preface}

Invasive alien species are one of the main drivers of biodiversity loss, due to their ability to disperse and cause negative effects on native species and the environment. To reduce the introduction of invasive alien species in the future, preventive measures need to be implemented, and knowledge about pathways of introduction of new and potentially invasive alien species can facilitate tailor-made measures.

This report is the product of a collaboration between the Nordic Council of Ministers and ten participating countries and territories (Denmark, Estonia, Finland, the Faroe Islands, Iceland, Latvia, Lithuania, Norway, Svalbard \& Sweden), all part of the NOBANIS network. The project extended from April 1st 2014 to February 28th 2015 and was funded through the Terrestrial Ecosystem Group (TEG) of the Nordic Council of Ministers.

The aim of the project is to contribute to the fulfilment of obligations in Aichi target 9 under the Convention on Biological Diversity, CBD and the EU Biodiversity Strategy 2020 target 5 . This is done by identifying and prioritising the most significant pathways of introduction for invasive alien species to the regions. This identification and prioritisation is done to assist the participating countries and territories in minimising and preventing further introductions and establishment of invasive alien species through pathways of concern.

This report contains a pathway analysis and a horizon scanning. The pathway analysis examines the pathways of introduction for alien species into the Nordic region: Denmark (DK), Finland (FI), Norway (NO), Svalbard (SJ) \& Sweden (SE), Baltic region: Estonia (EE), Lithuania (LT) \& Latvia (LV) and the Islands of the North Atlantic Ocean represented by Iceland (IS) and the Faroe Islands (FO). The horizon scanning identifies species that may potentially become invasive in the participating countries or territories. Later in the report, guidelines and general recommendations on measures to control pathways of interest and advice on development of an early warning system for invasive alien species are presented.

Copenhagen, January 2015 



\section{Summary}

One of the main drivers of biodiversity loss is invasive alien species (IAS), and in order to plan cost-effective measures to prevent the introduction of harmful invasive alien species, we need to know in what manner they are introduced. Until now, the measures to prevent harm to native environments and biodiversity by invasive alien species in the Nordic and Baltic countries, incl. Iceland and the Faroe Islands, have mainly been reactive methods based on knowledge of the invasive alien species already present. This approach has proven to be a costly and ineffective way to manage invasive alien species.

The prevention of introduction of new invasive alien species to the countries can be improved by gathering new knowledge on invasive and potentially invasive species and their pathways of introduction, as well as planning and implementing appropriate measures of control. Appropriate measures of control are: surveillance, early warning, detection and immediate control of the species.

The purpose of this project was to conduct a pathway analysis and a horizon scanning. The pathway analysis was done to identify and prioritise pathways of introductions by which alien species (particularly invasive alien species) were introduced in the Nordic and Baltic region, along with Iceland and the Faroe Islands. The horizon scanning was conducted to identify potential door knocker species that may be introduced in the future through the most significant pathways identified.

The NOBANIS network was initiated with funding by the Nordic Council of Ministers. The NOBANIS database contains information on alien species in 20 countries and territories in Northern and Central Europe, which have cooperated by sharing information on alien species in the countries. 10 of these countries and territories have participated in this project: Denmark, Estonia, the Faroe Islands, Finland, Iceland, Latvia, Lithuania, Norway (including Svalbard) and Sweden. The data in the NOBANIS database has formed the basis for the pathway analysis, and each country updated their national data with relevant information available using relevant literature and articles and by consulting national experts. 
In this project we conducted the pathway analysis and the horizon scanning on a regional level, where the participating countries and territories were divided into three regions:

- A Nordic region consisting of Denmark, Finland, Norway and Sweden (for the pathway analysis also Svalbard).

- A Baltic continental region consisting of Estonia, Latvia and Lithuania.

- A region consisting of the islands in the North Atlantic Ocean represented by Iceland and the Faroe Islands.

The pathway analysis contains the following subanalyses:

- Pathways of introduced species.

- Invasiveness of introduced species.

- Taxonomic groups of introduced species.

- Temporal development of pathways.

- Species origin and the pathway of introduction.

The pathway analysis showed that the main pathway of introduction was horticulture, followed by agriculture, transport, forestry and ballast water \& sediments, but there were variations between the regions.

To examine which new species may be introduced and established in the three regions in the future, a number of potential door knocker species was assessed.

The list of 414 potential door knocker species was assessed by experts across the participating countries and territories. Of the 414 species, 43 were evaluated as high risk species and 78 as medium risk species for the regions combined.

In this report a prioritised list of pathways of concern is also presented, along with guidelines and general recommendations on measures to control pathways of interest in the regions and advice on an early warning system. 


\section{Methods}

In this chapter the methods of the analyses are described. The first analysis is the Pathway analysis, which identifies which human activities have caused the introduction of alien species already present in the participating countries.

The second analysis is the Horizon scanning, which examines the risk of new alien species arriving, establishing and causing damage. In this horizon scanning the knowledge collected in the pathway analysis will be applied to highlight the most immediate threats.

Guidelines and general recommendations on measures to control pathways of interest are presented, along with advice on the development of an early warning system for invasive alien species in the region.

\subsection{General approach}

\subsubsection{The NOBANIS database}

The NOBANIS database has formed the basis for identifying pathways of introduction for non-native species in Denmark (DK), Estonia (EE), Finland (FI), the Faroe Island (FO), Iceland (IS), Latvia (LV), Lithuania (LT), Norway (NO), Svalbard (SJ) and Sweden (SE). The database was also used to make the list for the horizon scanning, by searching the database on invasive alien species in the NOBANIS network.

The database includes all alien species, i.e. all species that have been introduced as a result of human activities intentionally or unintentionally. This means that the database covers both invasive alien species (causing harm to native biodiversity) and non-invasive alien species (not causing harm to native biodiversity).

The database includes organisms from the agricultural landscape, forestry and animal husbandry, when the species are found in natural or seminatural ecosystems, or on native animal or plants. Species native to some part of a country, but alien in other parts are also included in the database. 
The species included in the database are organisms that are:

- naturalized (established) in natural or semi-natural ecosystems

- only present from time to time (incidental)

- non-naturalized (not established) in natural or semi-natural ecosystems, but introduced regularly.

\subsubsection{Regional level}

In this study we will conduct the pathway analysis and the horizon scanning on a regional level. The participating countries and territories were divided into three different regions:

- A Nordic region consisting of DK, FI, NO \& SE (for the Pathway analysis also SJ).

- A Baltic continental region consisting of EE, LT \& LV.

- A region consisting of the islands in the North Atlantic Ocean represented by IS and FO.

The division of the countries and territories into the different regions was based on several differences. Differences in the geographical position of the countries and territories can cause variations in climate, topography etc. There are also differences in how species are introduced, especially to islands as opposed to the continents. Furthermore, the countries' or territories' political history can affect how the import and trade of goods have developed and are being handled.

By dividing the countries and territories into regions in the analysis, we might be able to see if the pathways of introduction can vary in the different regions.

There are also large geographical differences within some of the countries' and territories' terrestrial and aquatic environments. The database only has information about the presence of a species within a country or territories and therefore we are not able to take this into account in this analysis.

In the Pathway analysis Svalbard is analysed as a separate territory, even through it is a part of Norway. This is due to the data in the NOBANIS database being separated for Svalbard. In the Horizon scanning Svalbard is not analysed separately, but considered as part of Norway. 


\subsection{Pathway analysis}

The pathway analysis identifies which human activities have caused the introduction of alien species already present in the participating countries and territories. It also examines the taxonomy, invasiveness and origin of the introduced species, along with the changes of the introductions over time.

\subsubsection{Approach}

Prior to the pathway analysis, each participating country and territory was asked to update and fill in the blanks for the data available in the NOBANIS database. This should be done by consulting experts and search for literature to acquire the data.

All the participating countries and territories except for Lithuania and the Faroe Islands managed to update the data in the NOBANIS database for this project, with the relevant information available for the species listed.

The data used for the pathway analysis from Lithuania was last updated in 2006, and the data used from the Faroe Islands was last updated in 2012.

In the analysis the results are presented in processed form. Raw data with species lists for the regions is available by request to the NOBANIS secretariat.

For the Norwegian data some information regarding pathway of introduction is missing due to differences in classification of pathways between NOBANIS and the Norwegian ArtsDatabanken (see the Norwegian classification in appendix 1).

In connection to this project, ArtsDatabanken in Norway has matched some of their pathway classifications with the NOBANIS classification, but for some species matching was inadequate. In such cases the pathway of introduction is classified as not known in the pathway analysis.

In the NOBANIS database some species are registered with a pathway that is not suited for that group of organism. Some species of angiosperms are registered with ornamental as their pathway, even though that pathway is designed for animals. Therefore, where ornamental is registered as a pathway for an angiosperm, the pathway has been changed to horticulture in the data for this analysis. The pathway horticulture is suited for ornamental plants among others. 


\subsubsection{Subanalyses}

The pathway analysis contains the following subanalyses:

- Pathways of introduced species.

- Invasiveness of introduced species.

- Taxonomic groups of introduced species.

- Temporal development of pathways.

- Species origin and the pathway of introduction.

In the first three subanalyses (pathway, invasiveness and taxonomic groups), species appearing in more than one country or territory are only represented once for each pathway. As an example, Giant hogweed (Heracleum mantegazzianum) was introduced to Denmark, Finland, Norway and Sweden by horticulture only, and will therefore only count as one species introduced to the Nordic region. But if a species is introduced by more than one pathway, it will count as one species with the actual number of pathways, e.g. the Warty comb jelly (Mnemiopsis leidyi) introduced by ballast water \& sediment and secondary introduction.

In the same three subanalyses, species without data on both pathway and invasiveness were taken out of the dataset. This is due to the lack of information contributed.

\section{Pathway for introduced species}

Here we examine the number of species introduced through the different pathways, to find the most active pathways used by alien species in the three regions. The used pathways are presented for each region in both absolute numbers and as a percentage distribution.

\section{Invasiveness of introduced species}

A pathway of introduction can be used frequently by many non-native species. Whether or not the species using the pathway has a negative impact, controlling the pathway can be time consuming and expensive. To prioritize management of the pathways that pose the greatest risk in the regions, we conducted an analysis for the different type of invasiveness for each pathway. The types of invasiveness used by the NOBANIS database are:

- Invasive.

- Potentially invasive.

- Not invasive. 
Also, invasive alien species from all taxonomic groups are a major threat to native biodiversity, and it is possible that some taxonomic groups could include more invasive species than others (both relative and absolute). Therefore, this analysis also examines the type of invasiveness for each taxonomic group.

The results are presented in two ways. Firstly, the invasiveness of the taxonomic groups of species is shown in both absolute numbers and percentage distribution. The percentage distribution is the number of species in each invasiveness category relative to the total number of species in the taxonomic group (N). Secondly, the invasiveness of species using the different pathways is presented.

\section{Taxonomic groups of introduced species}

When dealing with non-native species it is relevant to see if the main pathway of introductions is the same across the different taxonomic groups, or if different taxonomic groups use different pathway of introduction when entering a region. For that reason we conducted this subanalysis where both pathway and type of introduction (intentional or unintentional) is presented for each taxonomic group for each region.

\section{Temporal development of pathways}

When looking at the development of pathways over time, some pathways may have been active earlier, but not in recent times, and new pathways may have developed due to globalisation etc. Therefore, in order to make contemporary management plans for invasive alien species and their pathway of introduction, we need to know which pathways are relevant. This subanalysis examines the active pathways over an extensive period of time.

In this analysis the development of the use of pathways over time is presented for all three regions. The time length of registration of arrival of alien species differs amongst the countries. For some countries and territories some species is registered as being introduced early (pre 1200), while other countries and territories only have registrations from a couple of hundred years ago. In order to have comparable data for all countries and territories, we conducted the analysis using data from the age of enlightenment around the 1700s and until today. Note that the data from the year 2000 and forward only contains data from the last 14 years.

The year of introduction and year of first report are registered for many alien species in Iceland. The same information is not available for the Faroe Islands, so the analysis is only based on the Icelandic data. 


\section{Species origin and the pathway of introduction}

In order to get an overview of where in the world most of the non-native species are introduced from, an analysis regarding the origin of the nonnative species was conducted. This was done for the non-native species identified in the NOBANIS database for all of the participating countries and territories. This knowledge can be useful in relation to control and management of non-native species when dealing with trading goods entering the regions from all around the world.

Before conducting the analysis Species origin and the pathway of introduction the data concerning the species' natural distribution area was unified for all the participation countries and territories. The species without information on both origin and pathway of introduction were taken out of this subanalysis.

The NOBANIS database works with 14 different natural distribution areas (see table 1), which are the basis for this subanalysis.

Table 1: Natural distribution areas of alien species. From the technical manual for the NOBANIS database

\begin{tabular}{|c|c|}
\hline Areas & Explanation \\
\hline \multicolumn{2}{|l|}{ Continents } \\
\hline Africa & The African continent \\
\hline Antarctica & The Antarctic continent \\
\hline Asia & Divides Asia from Europe along Ural/Kazakhstan, Black Sea \\
\hline Europe & Divides Europe from Asia along Ural/Kazakhstan \\
\hline N. America & Canada, USA and Mexico \\
\hline Oceania & Australia, New Zealand, Tasmania and a number of small islands \\
\hline S. America & All countries on the S. American continent south of Mexico \\
\hline \multicolumn{2}{|l|}{ Oceans } \\
\hline Arctic Ocean & The ocean surrounding the North Pole \\
\hline Indian Ocean & The Ocean south of India to the southern tip of Africa and to the northern tip of Australia \\
\hline N. Atlantic Ocean & Upper part of the Atlantic Ocean divided by the equator \\
\hline S. Atlantic Ocean & The lower part of the Atlantic Ocean divided by the equator \\
\hline N. Pacific Ocean & The upper part of the Pacific Ocean divided by the equator \\
\hline S. Pacific Ocean & The lower part of the Pacific ocean divided by the equator \\
\hline Southern Oceans & The ocean surrounding the South Pole \\
\hline
\end{tabular}

For a number of species establishing the origin was challenging. This is due to the registrations of different areas of origin from the participating countries and territories. In this analysis we used the origin that was registered the most for each species. When different areas of origin for a species was registered an equal number of times, all areas were used in the analysis. 


\subsubsection{Pathway categories}

Pathways are the dispersal mechanisms for which alien species can enter a country or territory. The importance of knowledge concerning pathways of introduction for invasive alien species has been addressed by several authors (NISC 2007, ISCC 2013, Kelly et al. 2013,) and a need for a common terminology has been pointed out. Currently the EU COST Action TD1209 "Alien Challenge" is working on a common terminology for identifying pathways of introduction for alien species. In the following sections the NOBANIS terminology is described.

\subsubsection{Type of introduction}

The term Type of introduction refers to whether the introduction is intentional or unintentional.

- Intentional introduction refers to the deliberate movement and/or release by humans of an alien species outside its natural range.

- Unintentional introduction refers to all other introductions which are not intentional.

\subsubsection{Pathway of introduction}

The pathways are based on the categories used by NOBANIS (see table 2). The categories used are based on the framework that NOBANIS uses for the database, and the definition of pathways that NOBANIS uses is based on the European Strategy on invasive alien species.

The European Strategy on invasive alien species works with three definition of a pathway:

1. The geographic route by which a species moves outside its natural range (past or present).

2. The corridor of introduction (e.g. road, canal, tunnel).

3. The human activity that gives rise to an intentional or unintentional introduction.

NOBANIS has focused on the definition for pathways of introduction regarding human activity (option 3). 
Table 2: Descriptions of the pathways of introduction for alien species. From the technical manual for the NOBANIS database

\begin{tabular}{|c|c|}
\hline Pathway & Explanation \\
\hline Agriculture & $\begin{array}{l}\text { Plants for production of food for human and animal consumption, incl. crops and } \\
\text { contaminants of hay, grain, fodder }\end{array}$ \\
\hline Angling/sport & Live bait or dispersal via fishing gear and/or boats or as a consequence of aqua sports \\
\hline Animal husbandry & $\begin{array}{l}\text { Animals for production of food for humans, including the pest species introduced via } \\
\text { the animal hosts }\end{array}$ \\
\hline Aquaculture & $\begin{array}{l}\text { Fish/crayfish/algae/shellfish/seafood farming, or consequences of stocking of species } \\
\text { (pest species) - including marine cultures, animals escaping from aquaculture }\end{array}$ \\
\hline Aquaria & Garden ponds and aquariums \\
\hline $\begin{array}{l}\text { Ballast water and } \\
\text { sediments }\end{array}$ & $\begin{array}{l}\text { Ballast water and sediments in tanks, as well as solid ballast, incl. also the dispersal via } \\
\text { shipping in general (e.g. Brown rat) }\end{array}$ \\
\hline Biological control & Introduced as a putative bio control agent/pest of another species \\
\hline Escapes & $\begin{array}{l}\text { Fur farming, pet-animals escapes from captivity, laboratory animals, animal escapes, } \\
\text { pet trade }\end{array}$ \\
\hline Fisheries & Commercial fishing \\
\hline Forestry & $\begin{array}{l}\text { Timber and tree production, including the pest species introduced via tree hosts or } \\
\text { products thereof }\end{array}$ \\
\hline Horticulture & Plants used for ornamental purpose, gardening \\
\hline Hull fouling & Fouling of ships hulls \\
\hline Hunting & Released as hunting quarry or prey \\
\hline Landscaping & $\begin{array}{l}\text { The use of plants in the landscape (such as hedge plantings, binding of silt, erosion } \\
\text { control) }\end{array}$ \\
\hline Medicinal & Plants or animals used for this purpose \\
\hline Reintroduction & Re-introduction of species that have previously died out in the country \\
\hline Ornamental & Animals used for ornamental purposes such as colourful slugs and birds in parks, etc. \\
\hline $\begin{array}{l}\text { Secondary introdu- } \\
\text { ction }\end{array}$ & $\begin{array}{l}\text { Introduced species where populations have been introduced from a nearby coun- } \\
\text { try/sea area - which are not the natural distribution area }\end{array}$ \\
\hline Transport & $\begin{array}{l}\text { Infrastructure, translocation of machinery, transportation along roads and rails, } \\
\text { planes, package material etc. }\end{array}$ \\
\hline
\end{tabular}




\subsection{Horizon scanning}

In the horizon scanning the risk of new alien species arriving, establishing and causing damage is examined. The potentially invasive species are called potential door knocker species, which refers to their potential introduction and impact in the participating countries and territories in the near future.

In the analysis the results are presented in processed form. Raw data used for the analysis (regional level) and expert evaluations is available by request. Please contact the NOBANIS secretariat for further information.

\section{Door knocker species}

Door knocker species are defined as an alien species which has not yet arrived and established in any of the participating countries and territories (DK, EE, FI, FO, IS, LT, LV, NO \& SE), but can be expected to be introduced in the near future.

This might be an alien species which is already established in a neighbouring country, and which unaided can manage to cross national boundaries into any of the participating countries and territories. This is called secondary introduction (Gederaas et al. 2012). It could also be a species with a natural range in other geographical areas that can potentially spread to the participating countries and territories by using a pathway of introduction e.g. by horticulture, transport, forestry etc.

In this report a door knocker species can also include alien species already present but not established in the wild with a sustainable population, in any of the participating countries and territories. This can apply to species which initially only survive indoors, in greenhouses or in compost heaps (Gederaas et al. 2012).

\subsubsection{Approach}

A list of potential door knocker species was compiled using:

- The NOBANIS database to search and list invasive or potentially invasive species established in non-participating countries (Austria, Belarus, Belgium, Czech Republic, Germany, Greenland, Ireland, the Netherlands, Poland, Slovakia and the European part of Russia) that are part of the NOBANIS network.

- Data from alert lists made by Denmark (Pathway for non-native species in Denmark, 2014), Norway (Alien Species in Norway, 2012), Germany (Warnliste, 2013) and Ireland (Risk analysis and prioritisation, 2013). 
All species already present in the 10 countries and territories participating in the project were excluded from the analysis. These species were identified by using the NOBANIS database. Species that are present, but not yet established in the wild, were kept on the list.

When categorising the species on the list, the taxonomic groups used in NOBANIS were applied. Some of the taxonomic groups were divided into subgroups to give more information about the kind of organism, e.g. Arthropods were divided into Coleoptera etc.

An assessment criteria table was then made - based on other horizon scanning projects (Sutherland et al. 2008, Kelly et al. 2013 and Roy et al. 2014). The assessment criteria table and the door knocker species list were sent to experts in different taxonomic groups across Scandinavia and the Baltic. See appendix 2 for the list of experts.

The assessment criteria table (see appendix 3) consists of three different factors and associated questions. The factors and questions are based on horizon scanning projects by Sutherland et al. (2008), Kelly et al. (2013) and Roy et al. (2014):

- Arrival.

$\circ$ What is the possibility that the species will arrive?

- Establishment.

- What is the possibility that the species will become established?

- Impact assessment.

- Does the species pose a threat to biodiversity?

- Does the species pose a risk to human health?

- Does the species pose a risk regarding socio-economic concerns?

The answers to these questions were one of four assessment scores for the experts to choose (see table 3). Each question was answered for each species in each region.

\begin{tabular}{|c|c|}
\hline Score & Description \\
\hline 0 & Not possible to evaluate \\
\hline 1 & Low risk \\
\hline 2 & Medium risk \\
\hline 3 & High risk \\
\hline
\end{tabular}




\subsubsection{Final risk assessment}

In the final risk assessment, the results from the expert assessments mentioned above were calculated into three risk categories: high, medium or low risk species. This was done for all three regions separately and the high and medium risk species are highlighted in the results. The method of the final risk assessment is described in the following sections.

\section{Calculations}

For each species the score for establishment was added to the mean score of the impact (establishment + mean impact) (see appendix 3). The mean impact was calculated with the scores of the three categories: biodiversity, human health and socio-economic concerns. The result of the "establishment + mean impact" is the ranking value seen in table 4 . This ranking was then held against the assessments score (ranking) for the species ability to arrive, by plotting the results against each other using table 4 .

By using this method, the species assessed by experts were categorised into three groups: High risk species (A), medium risk species (B) and low risk species (C). A description of the categories is found in the next section.

\begin{tabular}{|c|c|c|c|c|}
\hline \multirow[t]{2}{*}{ Final risk categorisation } & & \multicolumn{3}{|c|}{ Arrival } \\
\hline & Score & 3 & 2 & 1 \\
\hline & $5-6$ & High risk species & High risk species & Medium risk species \\
\hline \multirow{5}{*}{$\begin{array}{l}\text { Establishment + } \\
\text { mean impact } \\
\text { (impact on biodiversity, } \\
\text { human health and socio } \\
\text { economic concerns) }\end{array}$} & & $A$ & A & $\mathrm{B}$ \\
\hline & $4-4.9$ & High risk species & Medium risk species & Low risk species \\
\hline & & $A$ & B & $\mathrm{C}$ \\
\hline & $2-3.9$ & Medium risk species & Low risk species & Low risk species \\
\hline & & B & C & C \\
\hline
\end{tabular}

\section{Risk categorisation}

High risk species (A): species that were assessed as having one of these two scenarios:

- A high risk of arrival in the region of concern, and a medium risk of establishing and having a negative impact.

- A medium or high risk of arrival in the region of concern, and a high risk of establishing and having a negative impact. 
Medium risk species (B): species that were assessed as having one of three scenarios:

- A high risk of arrival in the region of concern, but a low risk of establishing and having an impact.

- A medium risk of arrival in the region of concern, and a medium risk of establishing and having an impact.

- A low risk of arrival in the region of concern, but a high risk of establishing and having an impact.

Low risk species (C): species that were assessed as having one of these two scenarios:

- A low risk of establishing and having an impact, and a low or medium risk of arrival in the region of concern.

- A medium risk of establishing and having an impact, but a low risk of arrival in the region of concern.

Species categorised to be high or medium risk species are discussed further, while low risk species will not be thoroughly discussed in this report.

There may be some uncertainty for a number of species in this analysis, due to either limitation in knowledge about the species or the unpredictability of climate change, species survival and behaviour in new environments etc.

\section{Risk categorisation}

The risk categorisation has three cells for each of the categories (see table 4). This causes some of the species that score in the medium range in one of the parameters (i.e. arrival), to be assessed as high risk species due to high risk of the other parameter (i.e. establishment+mean impact). This is also the case with a species scoring in the low range of one parameter, which can be assessed to a medium risk species due to a high risk in the other risk parameter.

As an example of the "low+high=medium"-scenario mentioned above, we might have a species that has a high risk of arrival, but a low risk of establishment and impact. This species is therefore likely to have several opportunities to establish, and might have a wider habitat range than currently known and higher survival rate in the absence of natural predators and parasites and therefore scores as a medium risk species.

In another scenario we can have a species with a high risk of establishment and impact, but with a low risk of arrival. If only a few of these individuals manage to arrive they can have considerable impact and therefore score as medium risk species. 


\subsubsection{Species not included}

Some species are not included in the horizon scanning:

- Species native to any of the participating countries and territories.

- Alien species already established with sustainable populations in the wild in any of the participating countries and territories.

- Subspecies or lower taxa (except vascular plants and macroalgae).

\subsubsection{Expert evaluations}

In order to make a validated assessment of the potential door knocker species on the horizon scanning list, NOBANIS contacted experts in different taxonomic groups from universities, scientific research centres, associations inside the scientific community etc. across Scandinavia and the Baltic region.

We attempted to consult more than one expert for each taxonomic group (and for arthropods also for individual order) on the list, but for many of the taxonomic groups and orders this was not possible, due to the lack of experts in that particular field.

All experts used for the horizon scanning originated from one of the participating countries and territories. We chose only to use expert from the three regions, due to their expert knowledge of the geographical region that forms the framework for this project.

The experts assessed the species for the region as a whole, except for the Baltic region. In the Baltic region it was not possible for the experts to assess the taxonomic group of non-parasitic fungi for the entire region, so each country was assessed separately for that specific group. In order to achieve results for the region as a whole, the results from the three countries were combined. This was done by taking the mean of the scores for each species of fungus. For paracitic species of fungi, we were not able to find experts to conduct the assessment for the Baltic region and the Islands of the North Atlantic Ocean. Therefore, door knocker species of paracitic fungi are only assessed for the Nordic region in this report.

For some taxonomic groups more than one expert assessed the species ability to arrive, establish and have an impact. For those species where the experts did not agree on the assessments, the assessments with the highest risk were used in the final results. 


\subsubsection{Challenging taxa}

Finding experts on some taxonomic groups for the horizon scanning proved to be a difficult task. Many experts were reluctant to do the assessments for other countries and territories than their own, but also the short time frame, limited information on the door knocker species and the lack of experts in some taxonomic groups, made it difficult to find experts for all the species on the door knocker list.

The groups of organisms especially challenging to obtain assessments for were some insects (Coleoptera, Diptera and Hemiptera), crustacean (Isopods and Copepods), microorganisms, flatworms, phytoplankton, annelids and angiosperms.

For some taxonomic groups (angiosperms and orders of arthropods (Coleoptera and Diptera)) we provided additional information regarding the individual species in those groups, by searching relevant literature. Each species was searched for in one or more sources, until the adequate data was obtained. The data obtained is related to the species' native range, distribution, reproduction, ecology, negative effects etc. The purpose of finding that information was to help experts make the assessments.

Some of the accessible data collected was not from recent years, which means that the data obtained on the species distribution may have changed. The data collected for the species are available by contacting the NOBANIS secretariat.

For some groups and orders of species it was not possible to find experts that could do the assessments for the horizon scanning (see table 5).

\begin{tabular}{|c|c|}
\hline \multicolumn{2}{|c|}{ Groups not assessed in the Horizon scanning } \\
\hline Arthropods & $\begin{array}{l}\text { Hemiptera } \\
\text { Opiliones } \\
\text { Copepods (Cladocera, Calanoida \& Poecilostomatoida) } \\
\text { Isopods }\end{array}$ \\
\hline Flatworms & All \\
\hline Microorganisms & $\begin{array}{l}\text { Bacteria } \\
\text { Vira }\end{array}$ \\
\hline Annelids & All \\
\hline Phytoplankton & All \\
\hline Protists & All \\
\hline
\end{tabular}




\subsection{Prioritisation of pathways}

In the process of prioritising pathways of concern, we looked at the results from the pathway analysis. Here, the prioritisation was done based on:

- Number of introduced invasive species by the pathway.

- Number of introductions through the pathway.

Subsequently, other parametres from the pathway analysis and the horizon scanning were taken into account to make ajustments to the prioritisation of the pathways:

- Percentage of invasive introductions. ${ }^{1}$

- Number of high risk (A) door knocker species that is assigned to the pathway.

- Number of medium risk (B) door knocker species that is assigned to the pathway.

- Number of potentially invasive introductions.

- Temporal development of pathways.

Pathways with less than 25 registrations of introduction were not considered to be pathways of concern in this report, and were therefore not included in the prioritised list, unless other of the parametres above showed that the pathway was a of concern.

${ }^{1}$ Percentage of invasive introductions $=$ (invasive introductions by that pathway/all introductions by that pathway) $\mathrm{x} 100$ ). 



\section{Pathway analysis}

The pathway analysis contains the following subanalyses:

- Pathways of introduced species.

- Invasiveness of introduced species.

- Taxonomic groups of introduced species.

- Temporal development of pathways.

- Species origin and the pathway of introduction.

Each subanalysis is divided into the three regions: the Nordic region, the Baltic region and Islands in the North Atlantic Ocean. The total number of introduced species for each of the regions is presented in table 6 .

$\begin{array}{llr}\begin{array}{l}\text { Table 6: Total number of introduced species per country, and total number of introduced species } \\ \text { per region analysed for the pathway analysis }\end{array} & \text { Number of species (N) } \\ \text { Region } & \text { Country } & 2,422 \\ \text { Nordic region } & \text { Denmark } & 407 \\ & \text { Finland } & \text { Norway } \\ & \text { Svalbard } & 2,240 \\ & \text { Sweden } & 89 \\ & \text { Total* } & 2,192 \\ & & 4,796 \\ \text { Baltic region } & \text { Estonia } & 970 \\ & \text { Latvia } & 416 \\ & \text { Lithuania } & 580 \\ \text { Tslands of the North Atlantic Ocean } & \text { Total } & 1,354 \\ & \text { Iceland } & 154 \\ & \text { The Faroe Islands } & 147\end{array}$

*The totals differ from the sum of the numbers above, due to the removal of redundant species. The redundant species are present in more than one country or territory in the same region, and will therefore appear more than once in the data for the regional analyses if not removed. 


\subsection{Pathways of introduced species}

In the following sections the pathway analysis for the regions is presented. The analysis comprises the number of alien species introduced by each pathway. It is important to remember, that species might use more than one pathway of introduction or have different pathways of introduction in the different countries in the region. Species may also be registred in one country or territory as introduced by an unknown pathway, but registred with a known pathway in another country or territory. In this situation the species is assigned with the known pathway for the region in these analyses.

\subsubsection{Nordic region}

A total of 4,796 alien species were analysed for the Nordic region.

A total of 22 taxonomic groups were represented in the data: angiosperms, annelids, arthropods, birds, bryophytes, cnidarians, comb jellies, coniferous plants, ferns, fish, flatworms, fungi, macroalgae, mammals, microorganisms, molluscs, nematodes, other chordates, other invertebrates, phytoplankton, protozoans, and reptiles \& amphibians.

A total of 19 pathways were registered for this region: agriculture, angling/sport, animal husbandry, aquaculture, aquaria, ballast water \& sediments, biological control, escapes, fisheries, forestry, horticulture, hull fouling, landscaping, medicinal, ornamental, reintroduction, secondary introduction and transport.

Some of the species use more than one pathway of introduction, and may be represented more then once in the analysis.

In figure 1 the number of alien species introduced by the different pathways is shown for the Nordic region. In figure 2 the introductions are shown for the Nordic countries separately. 
Figure 1: Pathway of introduction for non-native species in the Nordic region. The graph shows the number of species introduced by each pathway

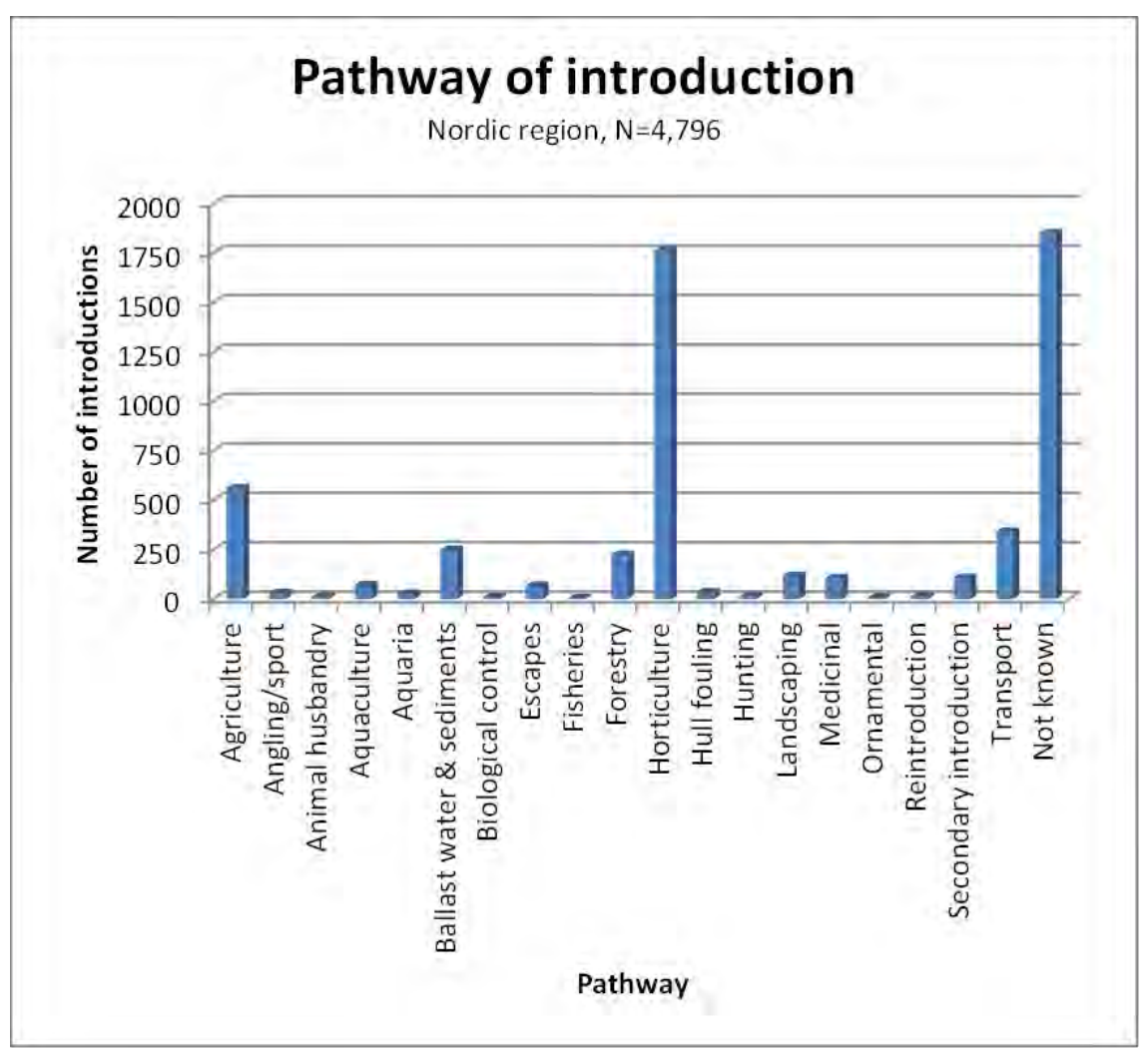


Figure 2: Pathway of introduction for non-native species in the Nordic region. The graph shows the number of species introduced by each pathway

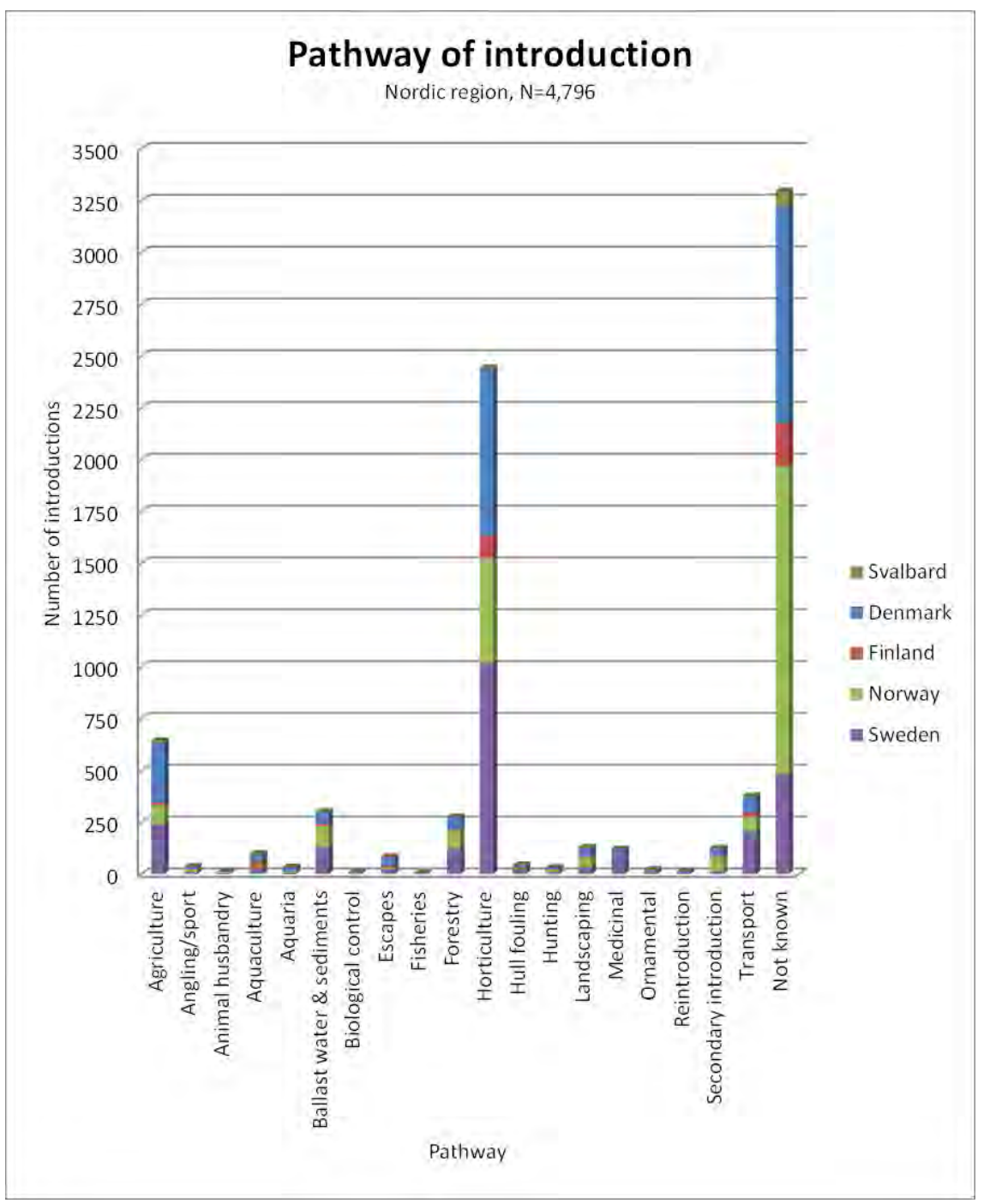

The most common pathway of introduction is horticulture, which is used by 1,763 of the alien species recorded in the region. Also agriculture $(\mathrm{N}=561)$, transport $(\mathrm{N}=342)$, ballast water \& sediments $(\mathrm{N}=250)$ and forestry $(\mathrm{N}=225)$ are registered for several species, while the remaining pathways are registered less in the region. 
For a large number of species registered as alien in the region, no pathway of introduction is currently recorded. Most of the species with unknown pathway were recorded in the Norwegian database $(\mathrm{N}=1,486),{ }^{2}$ and in Denmark $(\mathrm{N}=1,049)$, while Sweden $(\mathrm{N}=483)$, Finland $(\mathrm{N}=206)$ and Svalbard $(\mathrm{N}=73)$ had fewer species with unidentified pathways. For the whole region a total of 1850 alien species were registered without a pathway of introduction, due to the removal of redundant species (see chapter 4 Pathway analysis).

The percentage of species using each pathway is shown in figure 3. The distribution of alien species for each pathway shows a similar pattern to the absolute number in figure 2. Although, the percentage distribution highlights that Sweden has a relatively low percentage of alien species with unknown pathways, while Svalbard (82\%), Norway (66.3\%) and Finland (50.6\%) has a high percentage of alien species with unknown pathways.

2 This may be due to the differences in pathway categorisation between the Norwegian ArtsDatabanken and the NOBANIS database (see Methods for further explanation). 
Figure 3: Percentage distribution of pathway of introduction for non-native species in the Nordic region. The graph shows the percentage of species introduced by each pathway. Each columb shows the cumulated percentages for each pathway, and therefore the percentage may exceed $100 \%$

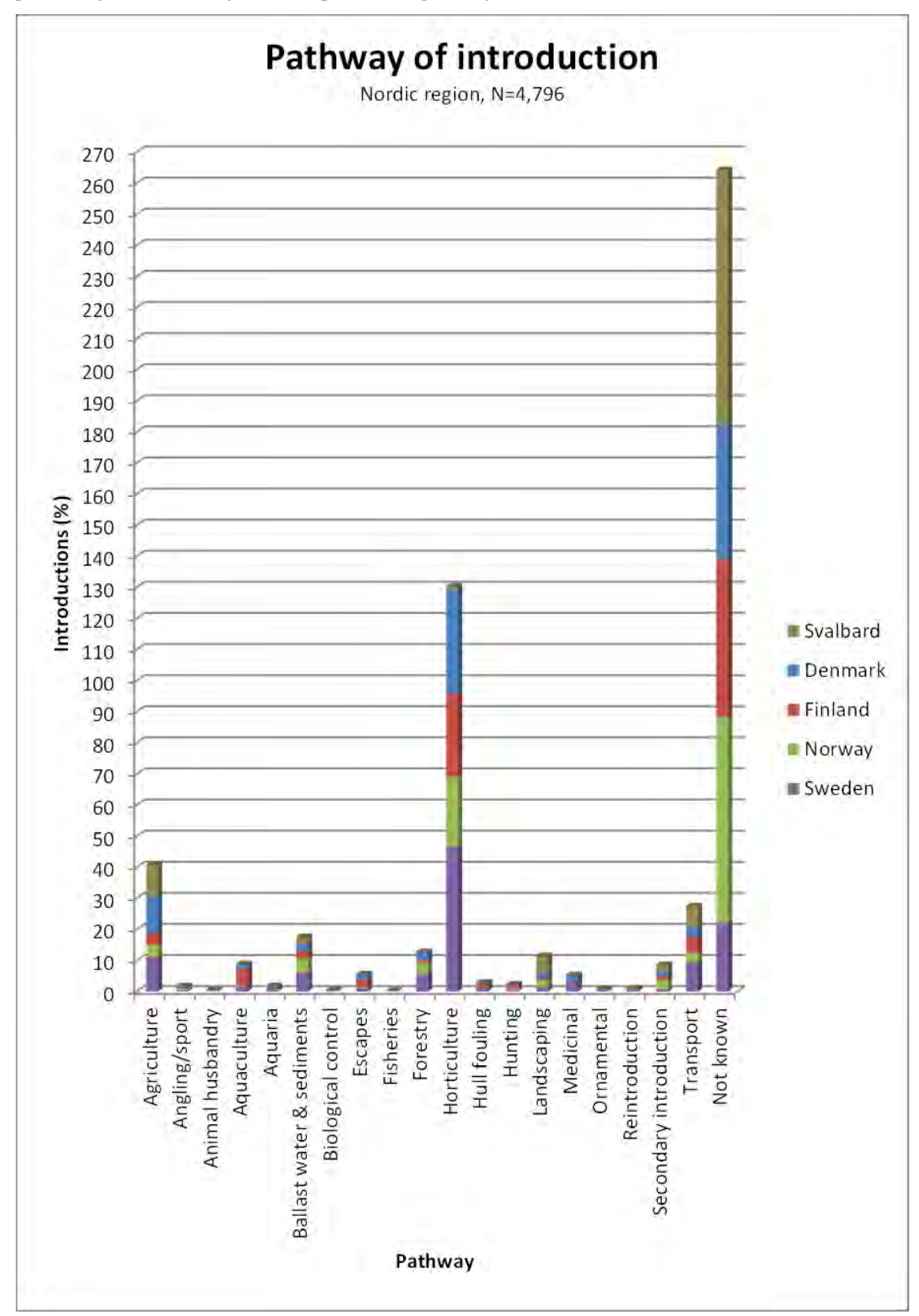




\subsubsection{Baltic region}

A total of 1,354 alien species were analysed for the Baltic region.

A total of 16 taxonomic groups were represented: angiosperms, annelids, arthropods, birds, bryophytes, cnidarians, coniferous plants, fish, flatworms, fungi, mammals, microorganisms, molluscs, nematodes, phytoplankton and reptilia \& amphibia.

A total of 17 pathways were registered for this region: agriculture, animal hunbandry, aquaculture, aquaria, ballast water \& sediments, Biological control, escapes, fisheries, forestry, horticulture, hull fouling, landscaping, medicinal, ornamental, secondary introduction and transport. Some of the species use more than one pathway of introduction and may be represented more than once in the analysis.

In figure 4 the number of alien species introduced by the different pathways is shown for the Baltic region. In figure 5 the introductions are shown for the Baltic countries separately.

Figure 4: Pathway of introduction for non-native species in the Baltic region. The graph shows the number of species introduced by each pathway

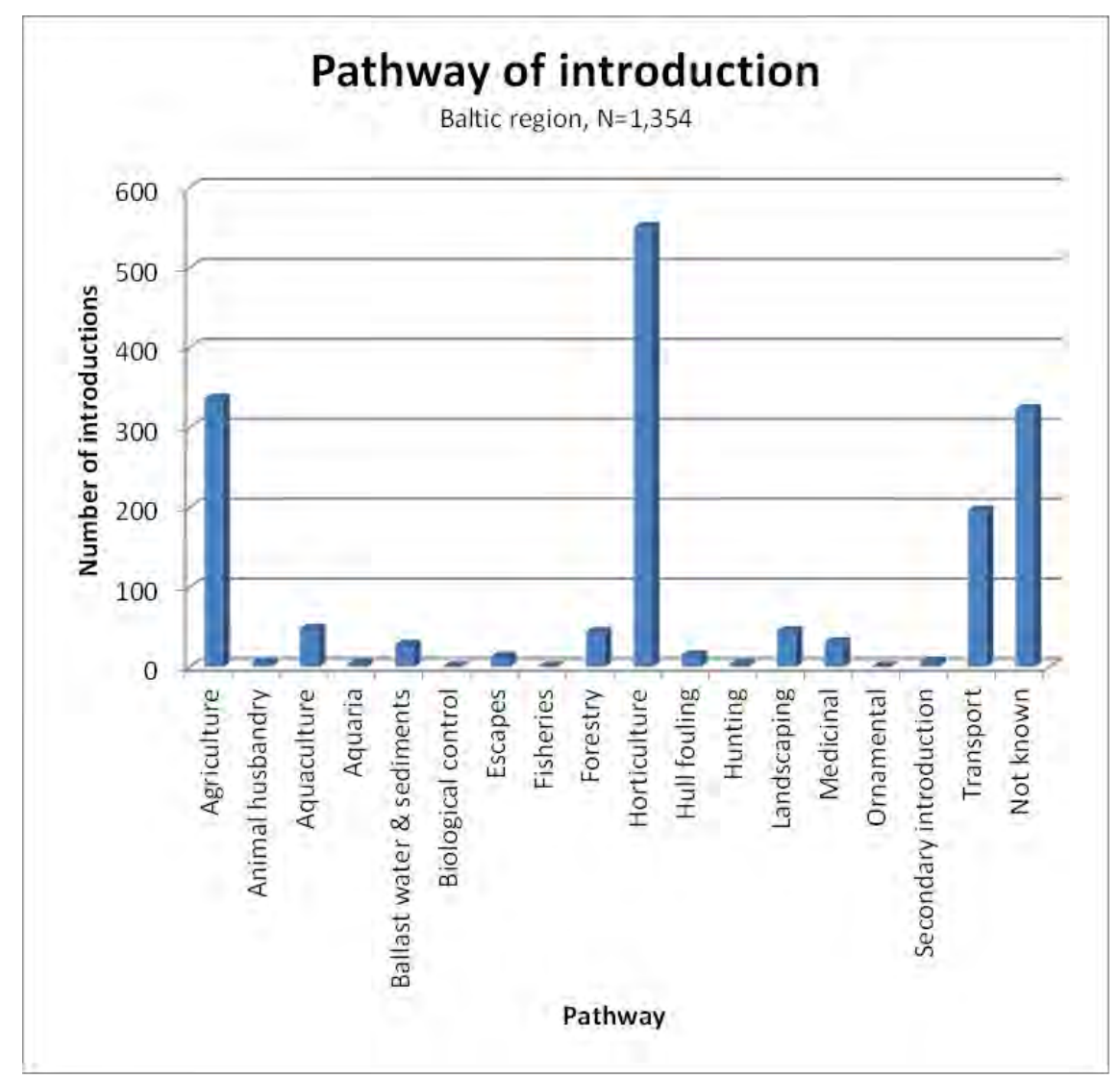


Figure 5: Pathways of introduction for non-native species in the Baltic region. The graph shows the number of species introduced by each pathway

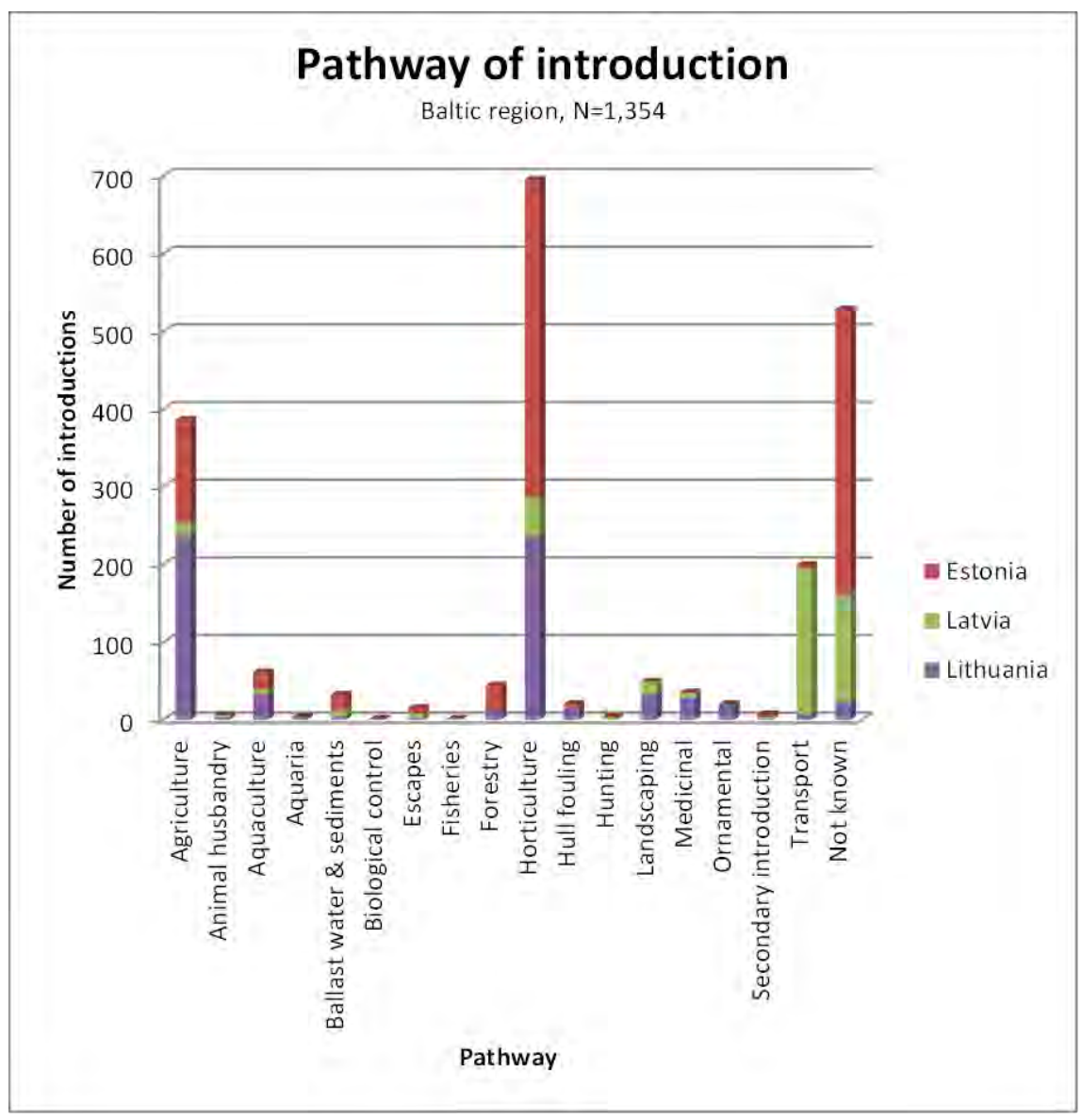

The most common pathway of introduction is horticulture, which by 551 of the alien species recorded in the region. Also agriculture $(\mathrm{N}=336)$ and transport $(\mathrm{N}=196)$ are registered for several species, while the remaining pathways are registered less in the region.

The pathway of introduction and the number of alien species registered in Estonia follows the tendency in the region as a whole, while Latvia stands out with transport as the most used pathway. In Lithuania most alien species are introduced by horticulture and agriculture.

For some species registered as alien in the region, no pathway of introduction is currently recorded. Most of the species with no known pathway is located in Estonia ( $\mathrm{N}=366)$, while Latvia $(\mathrm{N}=140)$ and Lithuania $(\mathrm{N}=22)$ have fewer species with unknown pathways. For the whole region a total of 323 alien species are registered without a pathway of introduction, due to the removal of redundant species in the regional analysis (see chapter 4 Pathway analysis). 
The percentage of species using each pathway is shown figure 6. The distribution of alien species for each pathway shows a similar pattern to the absolute number in figure 5. Although, the percentage distribution highlights that the highest percentage of alien species using the transport pathway is for Latvia. It also highlights that Latvia (33.7\%) like Estonia has $(37.7 \%)$ a high percentage of species with unknown pathways.

Figure 6: Pathways of introduction for non-native species in the Baltic region. The graph shows the cumulated percentage of species using each pathway. Each columb shows the cumulated percentages for each pathway, and therefore the percentage may exceed $100 \%$

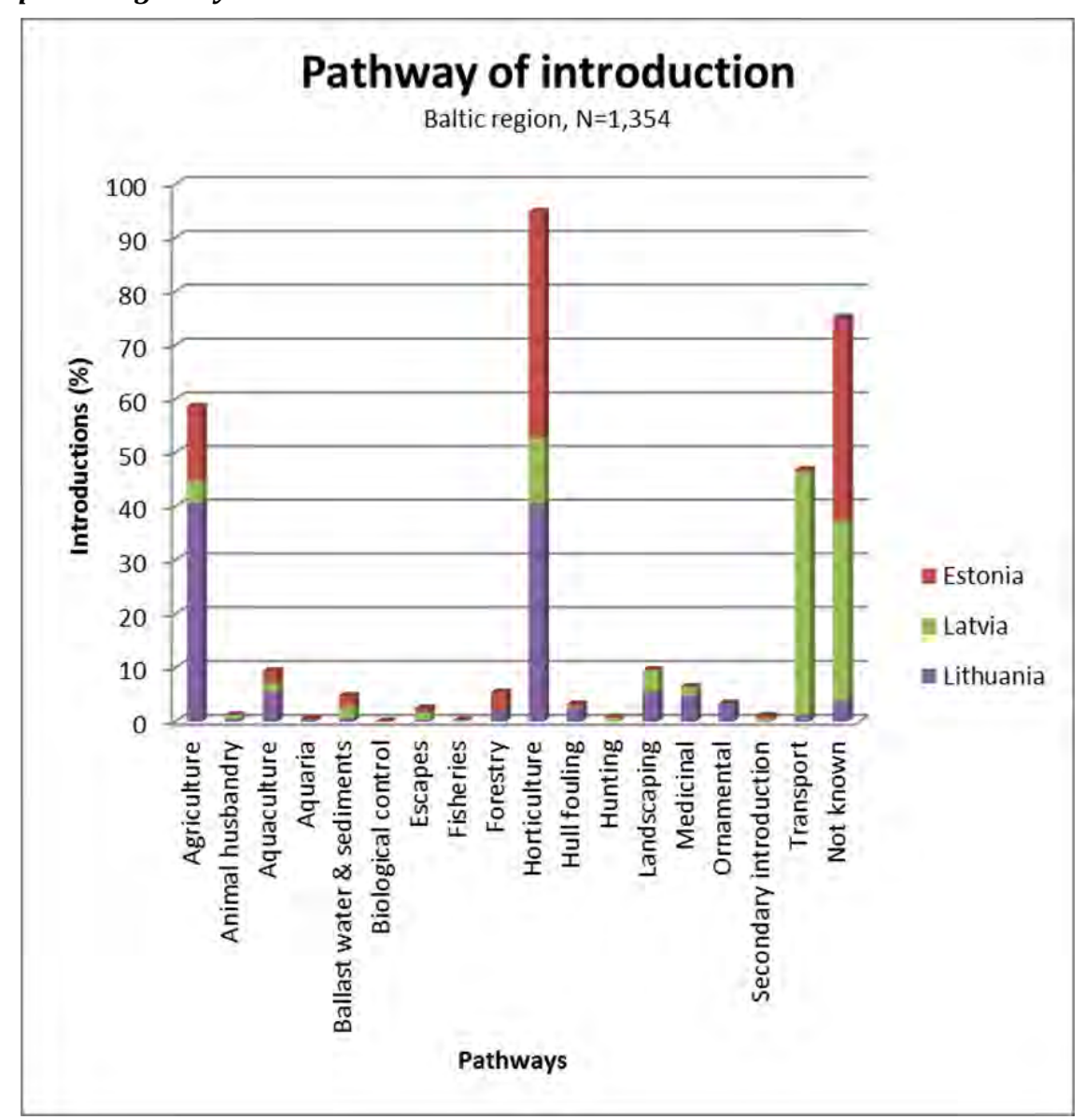

The graph also shows that the number of alien species using horticulture as a pathway of introdution registered for Estonia and Lithuania is very similar, while alien species using horticulture as a pathway of introduction in Latvia is minor. 


\subsubsection{Islands of the North Atlantic Ocean}

A total of 279 alien species is analysed for the Islands of the North Atlantic Ocean.

A total of 13 taxonomic groups are represented: angiosperms, annelids, arthropods, birds, bryophytes, coniferous plants, fish, flatworms, fungi, macroalgae, mammals, microorganisms and molluscs.

A total of 14 pathways are registered for this region: agriculture, animal husbandry, aquaculture, aquaria, ballast water \& sediments, escapes, forestry, horticulture, hunting, landscaping, medicinal, ornamental, secondary introduction and transport. Some of the species use more than one pathway of introduction.

In figure 7 the number of alien species introduced by the different pathways is shown for the region. In figure 8 the introductions are shown for Iceland and the Faroe Islands separately.

Figure 7: Pathways of introduction for non-native species in Islands of the North Atlantic Ocean. The graph shows the number of species introduced by each pathway

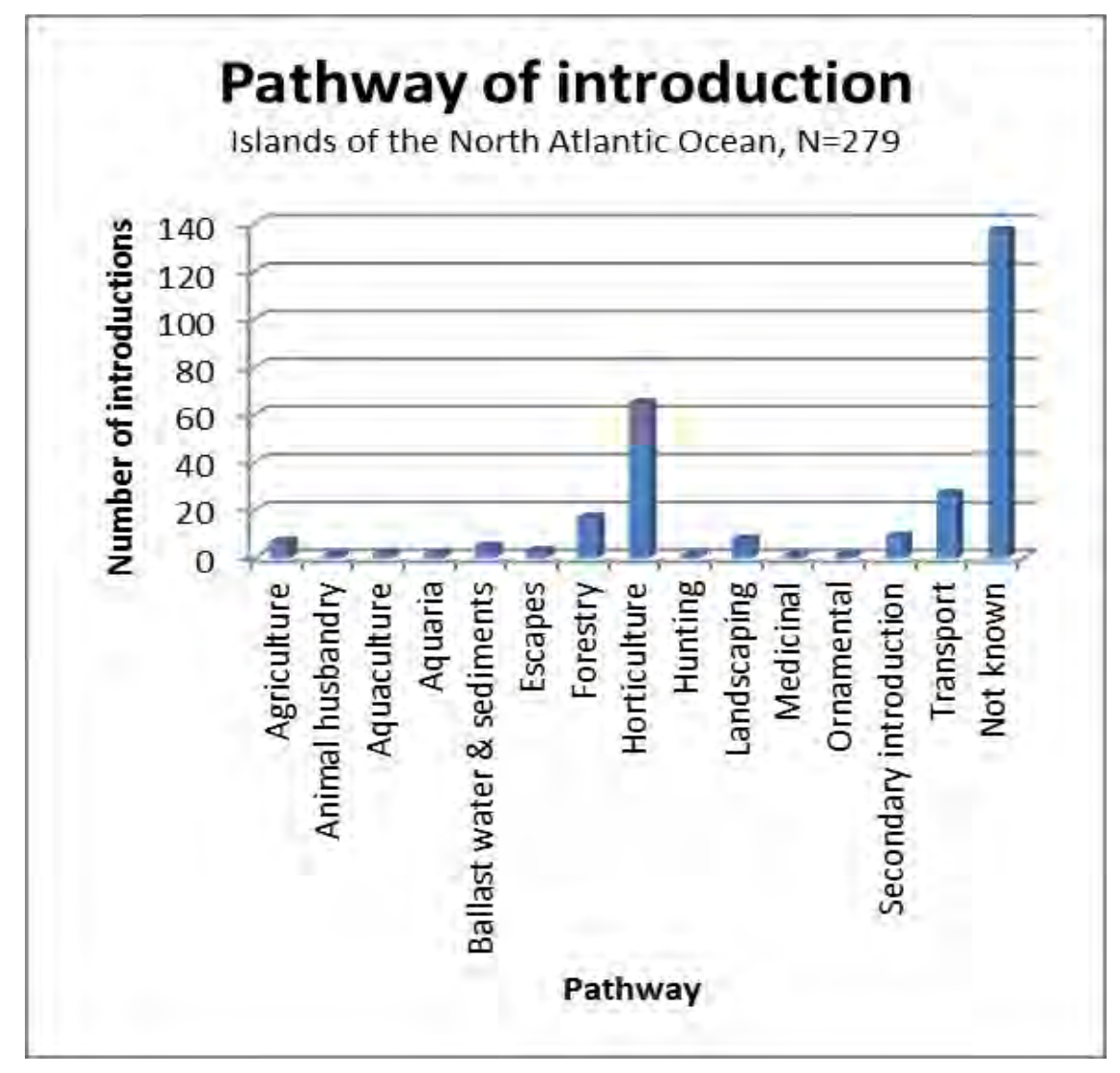


Figure 8: Pathways of introduction for non-native species in Islands of the North Atlantic Ocean. The graph shows the number of species introduced by each pathway

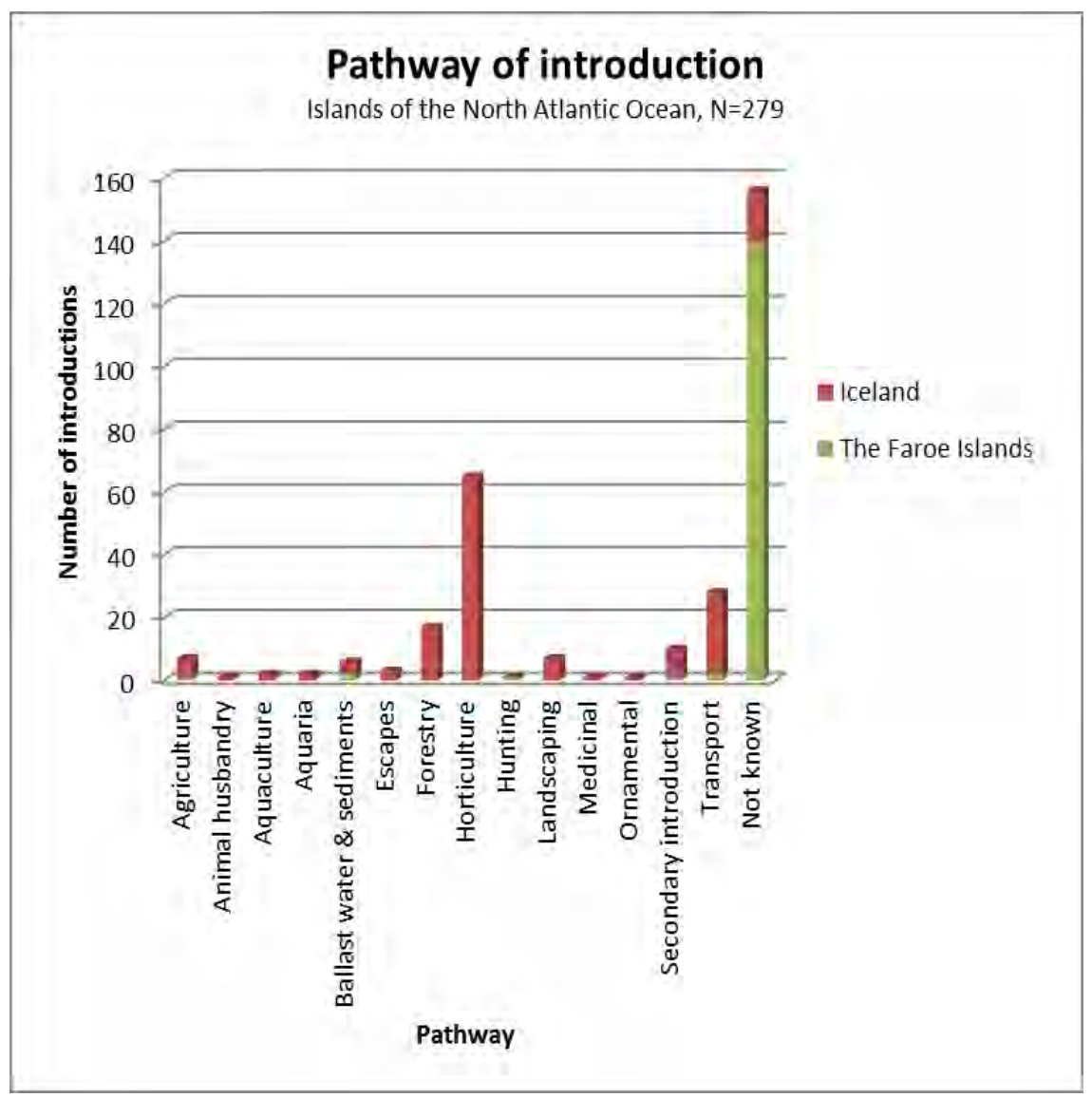

The most common pathway of introduction is horticulture, which is used by 65 of the alien species recorded in the region. Also transport $(\mathrm{N}=27)$ and forestry $(\mathrm{N}=17)$ are registered for several species, while the remaining pathways are registered less in the region. The data for this region is predominantly based on the data from Iceland.

For some species registered as alien in the region, no pathway of introduction is currently recorded. Most of the species with no known pathway are in the Faroe Islands $(\mathrm{N}=140)$. For Iceland there are fewer species $(\mathrm{N}=16)$ with unknown pathways. For the whole region a total of 137 alien species have an unknown pathway, due to the removal of redundant species for this analysis (see chapter 4 Pathway analysis).

In the pathway analysis for the Nordic region and Baltic region the percentage distribution of each pathway is shown for the regions. Although, this is not the case for this region, due to the similarity of the 
number of alien species for Iceland $(\mathrm{N}=154)$ and the Faroe Islands $(\mathrm{N}=147)$. When the numbers are similar the presentation of a percentage distribution will not contribute new information.

\subsubsection{Summary}

The most common pathway of introduction in all three regions is horticulture, while also agriculture, transport, forestry and ballast water \& sediments are registered as being used by several species.

\section{Nordic region}

The most used pathway of introduction is horticulture. Also agriculture, transport, ballast water \& sediments and forestry are registered for several species.

For the whole region a total of 1,850 alien species are registered without a pathway of introduction. The highest numbers are from Norway and Denmark. But if we look at the percentage distribution, Svalbard, Norway and Finland has the highest percentage of alien species with an unknown pathway of introduction.

\section{Baltic region}

The most used pathway of introduction is horticulture. Also agriculture and transport are registered for several species.

The pathway of introduction and the number of alien species registered in Estonia follows the tendency in the region as a whole, while Latvia stands out with transport as the most common pathway. In Lithuania most alien species are introduced by horticulture and agriculture, while in Latvia the percentage of species using horticulture is minor.

For the whole region a total of 323 alien species were registered without a pathway of introduction, where the highest number are from Estonia. Looking at the percentage distribution, Estonia and Latvia has the highest percentage of alien species with an unknown pathway.

\section{Islands of the North Atlantic Ocean}

The most used pathway of introduction is horticulture, but also transport and forestry are registered for several species. The data for this region is predominantly based on data from Iceland.

For the whole region a total of 137 alien species has an unknown pathway. Faroe Islands have the highest number of species reported with unknown pathways of introduction. 


\subsection{Invasiveness of introduced species}

The invasiveness of the species is presented in two ways. Firstly, the invasiveness of the taxonomic groups is shown in both absolute numbers and percentage distribution (\%). The percentage distribution for the taxonomic groups is the number of species in each invasiveness category relative to the total number of species in the taxonomic group (N). The percentage distribution for the pathways is the number of species in each invasiveness category relative to the total number of species using the pathway. Secondly, the invasiveness of species using the different pathways is presented.

The species may have different status of invasiveness in the different countries in the region. Therefore a species can have more than one status of invasiveness, whereby the number of statuses exceeds the number of species $(\mathrm{N})$ and also exceeds $100 \%$.

\section{Nordic region}

The invasiveness status is known for 4,796 alien species registered in the NOBANIS database for the Nordic region. As shown in table 7,646 species are considered invasive, 427 as potentially invasive and 3,216 are not invasive.

\begin{tabular}{|c|c|c|c|c|c|}
\hline & \multicolumn{5}{|c|}{ Status of invasiveness } \\
\hline & Species (N) & Invasive & $\begin{array}{r}\text { Potentially } \\
\text { invasive }\end{array}$ & Not invasive & Not known \\
\hline Angiosperms & 3,272 & 255 & 242 & 2,700 & 334 \\
\hline Annelids & 26 & 3 & 3 & 7 & 15 \\
\hline Arthropods & 928 & 182 & 114 & 254 & 468 \\
\hline Birds & 81 & 7 & 8 & 68 & 7 \\
\hline Bryophytes & 6 & 2 & 0 & 1 & 3 \\
\hline Cnidarians & 8 & 3 & 2 & 3 & 2 \\
\hline Comb jellies & 4 & 1 & 1 & 0 & 3 \\
\hline Coniferous plants & 82 & 15 & 15 & 60 & 9 \\
\hline Ferns & 11 & 0 & 1 & 11 & 0 \\
\hline Fish & 40 & 12 & 10 & 17 & 8 \\
\hline Flatworms & 8 & 5 & 0 & 2 & 1 \\
\hline Fungi & 120 & 68 & 6 & 48 & 3 \\
\hline Macroalgae & 17 & 8 & 2 & 5 & 3 \\
\hline Mammals & 43 & 19 & 4 & 15 & 13 \\
\hline Microorganisms & 35 & 29 & 4 & 3 & 0 \\
\hline Molluscs & 69 & 21 & 4 & 19 & 30 \\
\hline Nematodes & 13 & 5 & 1 & 1 & 7 \\
\hline Other chordates & 1 & 1 & 1 & 0 & 0 \\
\hline Other invertebrates & 2 & 0 & 2 & 0 & 0 \\
\hline Phytoplankton & 17 & 6 & 5 & 0 & 7 \\
\hline Protozoans & 2 & 2 & 0 & 0 & 0 \\
\hline Reptiles \& amphibians & 11 & 2 & 2 & 2 & 5 \\
\hline Total & 4,796 & 646 & 427 & 3,216 & 918 \\
\hline
\end{tabular}


A total of 22 different taxonomic groups are registered for the region. The group with the highest number of invasive species is angiosperms $(\mathrm{N}=255)$, followed by arthropods $(\mathrm{N}=182)$. This tendency is also seen in the categories potentially invasive and not invasive, which reflects that these two groups have the highest number of alien species in the Nordic region.

No species of ferns or other invertebrates are considered invasive in the Nordic region, but a few species in the groups are considered potentially invasive.

In table 8 the percentage distribution of invasive status is shown for each taxonomic group. The groups with the highest percentage of invasive species are microorganisms (83\%), flatworms (63\%), fungus (57\%), macroalgae (47\%) and mammals (44\%). Protozoans (100\%) and other chordates $(100 \%)$ also have a high percentage of species registered as invasive, but the results are based on only two and one registrations in the region. This is also the case when looking at potentially invasive species, where other chordates and other invertebrates have a high percentage of species registered (100\%) but the results are based on only one and two registrations respectively.

\begin{tabular}{|c|c|c|c|c|c|}
\hline & \multicolumn{5}{|c|}{ Status of invasiveness (\% distribution) } \\
\hline & Species (N) & Invasive (\%) & $\begin{array}{r}\text { Potentially } \\
\text { invasive (\%) }\end{array}$ & Not invasive (\%) & Not known (\%) \\
\hline Angiosperms & 3,272 & 8 & 7 & 83 & 10 \\
\hline Annelids & 26 & 12 & 12 & 27 & 58 \\
\hline Arthropods & 928 & 20 & 12 & 27 & 50 \\
\hline Birds & 81 & 9 & 10 & 84 & 9 \\
\hline Bryophytes & 6 & 33 & 0 & 17 & 50 \\
\hline Cnidarians & 8 & 38 & 25 & 38 & 25 \\
\hline Comb jellies & 4 & 25 & 25 & 0 & 75 \\
\hline Coniferous plants & 82 & 18 & 18 & 73 & 11 \\
\hline Ferns & 11 & 0 & 9 & 100 & 0 \\
\hline Fish & 40 & 30 & 25 & 43 & 20 \\
\hline Flatworms & 8 & 63 & 0 & 25 & 13 \\
\hline Fungi & 120 & 57 & 5 & 40 & 3 \\
\hline Macroalgae & 17 & 47 & 12 & 29 & 18 \\
\hline Mammals & 43 & 44 & 9 & 35 & 30 \\
\hline Microorganisms & 35 & 83 & 11 & 9 & 0 \\
\hline Molluscs & 69 & 30 & 6 & 28 & 43 \\
\hline Nematodes & 13 & 38 & 8 & 8 & 54 \\
\hline Other chordates & 1 & 100 & 100 & 0 & 0 \\
\hline Other invertebrates & 2 & 0 & 100 & 0 & 0 \\
\hline Phytoplankton & 17 & 35 & 29 & 0 & 41 \\
\hline Protozoans & 2 & 100 & 0 & 0 & 0 \\
\hline Reptiles \& amphibians & 11 & 18 & 18 & 18 & 45 \\
\hline
\end{tabular}


In table 9 the invasiveness for species using each pathway is shown. Horticulture $(\mathrm{N}=282)$ is the main pathway of introduction of alien species considered to be invasive. Many species considered to be invasive are also introduced by transport $(\mathrm{N}=109)$, agriculture $(\mathrm{N}=86)$ and ballast water \& sediments $(\mathrm{N}=72)$.

Table 9: The invasive status of the species entering through different pathways of introduction to the Nordic region

\begin{tabular}{|c|c|c|c|c|}
\hline & \multicolumn{4}{|c|}{ Status of invasiveness } \\
\hline & Invasive & $\begin{array}{r}\text { Potentially } \\
\text { invasive }\end{array}$ & Not invasive & Not known \\
\hline Agriculture & 86 & 63 & 461 & 57 \\
\hline Angling/sport & 16 & 8 & 16 & 2 \\
\hline Animal husbandry & 4 & 3 & 3 & 2 \\
\hline Aquaculture & 30 & 11 & 21 & 17 \\
\hline Aquaria & 8 & 3 & 11 & 9 \\
\hline Ballast water \& sediments & 72 & 57 & 146 & 36 \\
\hline Biological control & 3 & 1 & 4 & 3 \\
\hline Escapes & 22 & 11 & 34 & 17 \\
\hline Fisheries & 5 & 3 & 2 & 0 \\
\hline Forestry & 48 & 39 & 114 & 79 \\
\hline Horticulture & 282 & 251 & 1,379 & 192 \\
\hline Hull fouling & 19 & 11 & 10 & 4 \\
\hline Hunting & 11 & 3 & 9 & 1 \\
\hline Landscaping & 41 & 27 & 82 & 10 \\
\hline Medicinal & 19 & 12 & 83 & 18 \\
\hline Ornamental & 5 & 0 & 4 & 1 \\
\hline Reintroduction & 4 & 0 & 5 & 6 \\
\hline Secondary introduction & 43 & 23 & 63 & 9 \\
\hline Transport & 109 & 61 & 191 & 73 \\
\hline Not known & 121 & 54 & 1,344 & 445 \\
\hline
\end{tabular}

The main pathway for the majority of species considered to be potentially invasive is also horticulture $(\mathrm{N}=251)$, while agriculture $(\mathrm{N}=63)$, transport $(\mathrm{N}=61)$ and ballast water \& sediments $(\mathrm{N}=57)$ are used by numerous potentially invasive species.

The pathways with the lowest number of invasive and potentially invasive species are animal husbandry, biological control, fisheries, ornamental and reintroduction.

The majority of the species with unknown pathway of introduction is considered not invasive $(\mathrm{N}=1,344)$, but a number of the species with unknown pathway also has an unknown invasiveness status $(\mathrm{N}=445)$. 
In table 10 the percentages of the registered introductions of each invasiveness category are shown. Angling/sport, hull fouling, aquaculture and secondary introduction are the pathways with the highest percentage of invasive species (fisheries, hunting and ornamental have a higher percentage, but this is based on relatively few introductions).

Table 10: Percentages of the registered introductions of each invasiveness category is shown for each pathway in the Nordic region

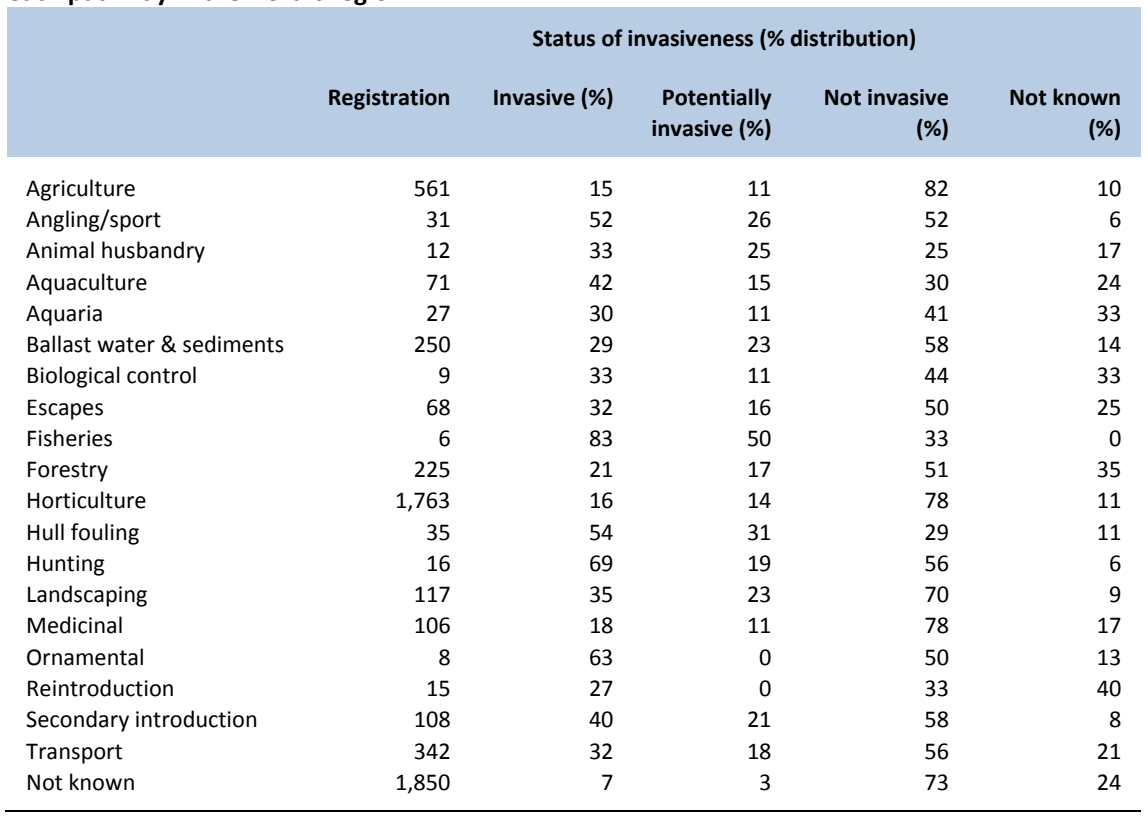

\section{Baltic region}

The invasiveness status for many of the 1,354 alien species registered in the NOBANIS database for the Baltic region is unknown $(\mathrm{N}=819)$. For the alien species where the invasive status is known, the majority are considered to be not invasive $(\mathrm{N}=327)$, while only 130 species are considered to be invasive and 160 species are considered being potentially invasive (see table 11). 


\begin{tabular}{|c|c|c|c|c|c|}
\hline & \multicolumn{5}{|c|}{ Status of invasiveness } \\
\hline & Species (N) & Invasive & $\begin{array}{r}\text { Potentially } \\
\text { invasive }\end{array}$ & Not invasive & Not known \\
\hline Angiosperms & 1,069 & 91 & 113 & 274 & 652 \\
\hline Annelids & 10 & 2 & 7 & 0 & 1 \\
\hline Arthropods & 164 & 24 & 8 & 14 & 124 \\
\hline Birds & 19 & 2 & 2 & 12 & 5 \\
\hline Bryophytes & 1 & 0 & 1 & 0 & 0 \\
\hline Cnidarians & 4 & 1 & 4 & 0 & 0 \\
\hline Coniferous plants & 13 & 0 & 3 & 2 & 8 \\
\hline Ferns & 1 & 0 & 0 & 0 & 1 \\
\hline Fish & 34 & 4 & 14 & 17 & 7 \\
\hline Flatworms & 1 & 0 & 1 & 0 & 0 \\
\hline Fungi & 10 & 0 & 0 & 1 & 9 \\
\hline Macroalgae & 1 & 0 & 0 & 1 & 0 \\
\hline Mammals & 6 & 2 & 2 & 2 & 1 \\
\hline Microorganisms & 1 & 0 & 0 & 0 & 1 \\
\hline Molluscs & 9 & 2 & 2 & 4 & 3 \\
\hline Nematodes & 8 & 1 & 1 & 0 & 7 \\
\hline Phytoplankton & 1 & 1 & 1 & 0 & 0 \\
\hline Reptiles \& amphibians & 2 & 0 & 2 & 0 & 0 \\
\hline Total & 1,354 & 130 & 161 & 327 & 819 \\
\hline
\end{tabular}

A total of 18 different taxonomic groups are registered for the region. The group with the highest number of invasive species is angiosperms $(\mathrm{N}=91)$, and thereafter arthropods $(\mathrm{N}=24)$. The highest numbers of potentially invasive, not invasive and species of unknown invasiveness is also largely represented by angiosperms, which reflects that the group have the highest number of alien species in the Baltic region.

No species of bryophytes, coniferous plants, ferns, flatworms, fungi, macroalgae, microorganisms or reptiles \& amphibians is considered invasive in the Baltic region, although some species in the groups are considered potentially invasive.

In table 12 the percentage distribution of invasive status is shown for each taxonomic group. The groups with the highest percentage of invasive species are cnidarians (25\%) and mammals (33\%). Phytoplankton also has a high percentage of species registered as invasive (100\%), but the result is only based on a single registration in the region. 
Table 12: The percentage distribution of the invasive status for the species in the taxonomic groups in the Baltic region

\begin{tabular}{lrrrrr}
\multicolumn{5}{c}{ Status of invasiveness (\% distribution) } \\
Species (N) & Invasive (\%) & $\begin{array}{r}\text { Potentially } \\
\text { invasive (\%) }\end{array}$ & Not invasive (\%) & Not known (\%) \\
Angiosperms & & & & & \\
Annelids & 1,069 & 9 & 11 & 26 & 61 \\
Arthropods & 10 & 20 & 70 & 0 & 10 \\
Birds & 164 & 15 & 5 & 9 & 76 \\
Bryophytes & 19 & 11 & 11 & 63 & 26 \\
Cnidarians & 1 & 0 & 100 & 0 & 0 \\
Coniferous plants & 4 & 25 & 100 & 0 & 0 \\
Ferns & 13 & 0 & 23 & 15 & 62 \\
Fish & 1 & 0 & 0 & 0 & 100 \\
Flatworms & 34 & 12 & 41 & 50 & 21 \\
Fungi & 1 & 0 & 100 & 0 & 0 \\
Macroalgae & 10 & 0 & 0 & 10 & 0 \\
Mammals & 1 & 0 & 0 & 100 & 17 \\
Microorganisms & 6 & 33 & 33 & 33 & 100 \\
Molluscs & 1 & 0 & 0 & 0 & 33 \\
Nematodes & 9 & 22 & 22 & 44 & 78 \\
Phytoplankton & 8 & 11 & 11 & 0 & 0 \\
Reptiles \& amphibians & 1 & 100 & 100 & 0 & 0 \\
\hline
\end{tabular}

The groups with the highest percentage of species registered as potentially invasive are annelids, bryophytes, cnidarians, flatworms, fish, mammals, phytoplankton and reptiles \& amphibians. However, it should be noted that for some of the groups the results are based on a single registration, namely the bryophytes, flatworms and phytoplankton. Also for the group reptiles \& amphibians there are only two registrations.

In table 13 the status of invasiveness for species using each pathway is shown for the Baltic region. Horticulture $(\mathrm{N}=67)$ is the main pathway of introduction for the majority of alien species considered to be invasive. Many species considered being invasive are also introduced by agriculture $(\mathrm{N}=34)$, forestry $(\mathrm{N}=23)$, landscaping $(\mathrm{N}=21)$ and transport $(\mathrm{N}=21)$. 
Table 13: The invasive status of the species entering through different pathways of introduction for the Baltic region

\begin{tabular}{|c|c|c|c|c|}
\hline & & Status of ir & eness & \\
\hline & Invasive & $\begin{array}{r}\text { Potentially } \\
\text { invasive }\end{array}$ & Not invasive & Not known \\
\hline Agriculture & 34 & 30 & 98 & 202 \\
\hline Angling/sport & 0 & 0 & 0 & 0 \\
\hline Animal husbandry & 1 & 2 & 5 & 1 \\
\hline Aquaculture & 16 & 22 & 27 & 3 \\
\hline Aquaria & 1 & 3 & 0 & 0 \\
\hline Ballast water \& sediments & 7 & 17 & 8 & 4 \\
\hline Biological control & 0 & 0 & 0 & 1 \\
\hline Escapes & 4 & 3 & 6 & 2 \\
\hline Fisheries & 0 & 1 & 0 & 0 \\
\hline Forestry & 23 & 20 & 11 & 7 \\
\hline Horticulture & 67 & 81 & 108 & 333 \\
\hline Hull fouling & 6 & 6 & 9 & 0 \\
\hline Hunting & 3 & 1 & 1 & 0 \\
\hline Landscaping & 21 & 9 & 7 & 15 \\
\hline Medicinal & 5 & 3 & 13 & 15 \\
\hline Ornamental & 1 & 1 & 1 & 0 \\
\hline Reintroduction & 0 & 0 & 0 & 0 \\
\hline Secondary introduction & 3 & 5 & 3 & 0 \\
\hline Transport & 21 & 14 & 99 & 80 \\
\hline Not known & 7 & 4 & 44 & 268 \\
\hline
\end{tabular}

For the majority of species considered to be potentially invasive the main pathway of introduction is by horticulture $(\mathrm{N}=81)$, but also agriculture $(\mathrm{N}=30)$, aquaculture $(\mathrm{N}=22)$ and forestry $(\mathrm{N}=20)$ are important for numerous potentially invasive species.

The pathways with the lowest number of invasive and potentially invasive species are animal husbandry, aquaria, biological control, fisheries, hunting and ornamental. The categories angling/sport and reintroduction have no registrations of invasiveness in the Baltic region.

In table 14 the percentages of the registered introductions of each invasiveness category are shown. Forestry, landscaping, secondary introduction and hull fouling are the pathways with the highest percentage of invasive species (hunting and ornamental have a higher percentage, but this is based on only a few introductions). 


\begin{tabular}{|c|c|c|c|c|c|}
\hline & \multicolumn{5}{|c|}{ Status of invasiveness (\% distribution) } \\
\hline & Registrations & Invasive (\%) & $\begin{array}{r}\text { Potentially } \\
\text { invasive (\%) }\end{array}$ & $\begin{array}{r}\text { Not invasive } \\
\text { (\%) }\end{array}$ & $\begin{array}{r}\text { Not known } \\
\text { (\%) }\end{array}$ \\
\hline Agriculture & 336 & 10 & 9 & 29 & 60 \\
\hline Angling/sport & 0 & 0 & 0 & 0 & 0 \\
\hline Animal husbandry & 6 & 17 & 33 & 83 & 17 \\
\hline Aquaculture & 48 & 33 & 46 & 56 & 6 \\
\hline Aquaria & 4 & 25 & 75 & 0 & 0 \\
\hline Ballast water \& sediments & 28 & 25 & 61 & 29 & 14 \\
\hline Biological control & 1 & 0 & 0 & 0 & 100 \\
\hline Escapes & 13 & 31 & 23 & 46 & 15 \\
\hline Fisheries & 1 & 0 & 100 & 0 & 0 \\
\hline Forestry & 44 & 52 & 45 & 25 & 16 \\
\hline Horticulture & 551 & 12 & 15 & 20 & 60 \\
\hline Hull fouling & 15 & 40 & 40 & 60 & 0 \\
\hline Hunting & 3 & 100 & 33 & 33 & 0 \\
\hline Landscaping & 45 & 47 & 20 & 16 & 33 \\
\hline Medicinal & 31 & 16 & 10 & 42 & 48 \\
\hline Ornamental & 1 & 100 & 100 & 100 & 0 \\
\hline Reintroduction & 0 & 0 & 0 & 0 & 0 \\
\hline Secondary introduction & 7 & 43 & 71 & 43 & 0 \\
\hline Transport & 196 & 11 & 7 & 51 & 41 \\
\hline Not known & 323 & 2 & 1 & 14 & 83 \\
\hline
\end{tabular}

\subsubsection{Islands of the North Atlantic Ocean}

The invasiveness status for many of the 279 alien species registered in the NOBANIS database for the Islands of the North Atlantic Ocean is unknown $(\mathrm{N}=131)$. For the alien species where the invasive status is known, the majority are considered to be not invasive $(\mathrm{N}=116)$, while only 8 species are considered to be invasive and 24 species are considered being potentially invasive (see table 15 ). 
Table 15: The invasive status of the different taxonomic groups on the Islands of the North Atlantic Ocean

\begin{tabular}{|c|c|c|c|c|c|}
\hline & \multicolumn{5}{|c|}{ Status of invasiveness } \\
\hline & Species (N) & Invasive & $\begin{array}{r}\text { Potentially } \\
\text { invasive }\end{array}$ & Not invasive & Not known \\
\hline Angiosperms & 120 & 2 & 10 & 56 & 52 \\
\hline Annelids & 6 & 0 & 1 & 0 & 5 \\
\hline Arthropods & 101 & 1 & 2 & 39 & 59 \\
\hline Birds & 8 & 0 & 5 & 3 & 0 \\
\hline Bryophytes & 3 & 1 & 0 & 1 & 1 \\
\hline Coniferous plants & 3 & 0 & 1 & 2 & 0 \\
\hline Fish & 2 & 0 & 0 & 2 & 0 \\
\hline Flatworms & 1 & 1 & 0 & 0 & 0 \\
\hline Fungi & 10 & 0 & 0 & 10 & 0 \\
\hline Macroalgae & 2 & 0 & 1 & 1 & 0 \\
\hline Mammals & 7 & 1 & 3 & 1 & 2 \\
\hline Microorganisms & 1 & 0 & 1 & 0 & 0 \\
\hline Molluscs & 15 & 2 & 0 & 1 & 12 \\
\hline Total & 279 & 8 & 24 & 116 & 131 \\
\hline
\end{tabular}

A total of 13 different taxonomic groups are registered for the region. None of the groups has markedly more invasive species than others, however when looking at species considered to be potentially invasive, angiosperms $(\mathrm{N}=10)$ and birds $(\mathrm{N}=5)$ stands out together with mammals $(\mathrm{N}=3)$.

The categories not invasive and unknown are largely represented by angiosperms and arthropods, which reflects that these taxonomic groups have the highest number of alien species in the region.

In table 16 the percentage distribution of invasive status is shown for each taxonomic group. The group with the highest percentage of invasive species is bryophytes (33\%) and mammals (14\%). The group flatworms also have a high percentage of species registered as invasive $(100 \%)$, but the result is based on a single registration in the region.

Table 16: The percentage distribution and the invasive status for the species in the taxonomic groups on the Islands of the North Atlantic Ocean

\begin{tabular}{lrrrrr}
\multicolumn{5}{c}{ Status of invasiveness (\% distribution) } \\
Species (N) & Invasive (\%) & $\begin{array}{c}\text { Potentially } \\
\text { invasive (\%) }\end{array}$ & Not invasive (\%) & Not known (\%) \\
Angiosperms & 120 & & & & 43 \\
Annelids & 6 & 0 & 17 & 0 & 83 \\
Arthropods & 101 & 1 & 2 & 39 & 58 \\
Birds & 8 & 0 & 63 & 38 & 0 \\
Bryophytes & 3 & 33 & 0 & 33 & 33 \\
Coniferous plants & 3 & 0 & 33 & 67 & 0 \\
Fish & 2 & 0 & 0 & 100 & 0 \\
Flatworms & 1 & 100 & 0 & 0 & 0 \\
Fungi & 10 & 0 & 0 & 100 & 0 \\
Macroalgae & 2 & 0 & 50 & 14 & 0 \\
Mammals & 7 & 14 & 43 & 0 & 89 \\
Microorganisms & 1 & 0 & 100 & 7 & 0 \\
Molluscs & 15 & 13 & 0 & & 0 \\
\hline
\end{tabular}


The taxonomic groups with the highest percentage of species registered as potentially invasive are birds, macroalgae, mammals and microorganisms. Although for microorganisms the result is based on a single registration.

In table 17 the invasiveness of species using each pathway is shown. Horticulture $(\mathrm{N}=3)$ is the main pathway of introduction where the largest number of alien species that are considered to be invasive are introduced. For the majority of potentially invasive species the main pathway of introduction is horticulture $(\mathrm{N}=8)$, ballast water \& sediments $(\mathrm{N}=3)$ or secondary introduction $(\mathrm{N}=4)$.

Table 17: The invasive status of the species entering through different pathways of introduction to the Islands of the North Atlantic Ocean

\begin{tabular}{|c|c|c|c|c|c|}
\hline & \multicolumn{5}{|c|}{ Status of invasiveness } \\
\hline & Registrations & Invasive & $\begin{array}{r}\text { Potentially } \\
\text { invasive }\end{array}$ & Not invasive & Not known \\
\hline Agriculture & 7 & 1 & 0 & 6 & 0 \\
\hline Animal husbandry & 1 & 0 & 0 & 1 & 0 \\
\hline Aquaculture & 2 & 0 & 1 & 1 & 0 \\
\hline Aquaria & 2 & 1 & 1 & 0 & 0 \\
\hline $\begin{array}{l}\text { Ballast water \& sedi- } \\
\text { ments }\end{array}$ & 5 & 0 & 3 & 0 & 2 \\
\hline Escapes & 3 & 1 & 1 & 1 & 0 \\
\hline Forestry & 17 & 0 & 2 & 15 & 0 \\
\hline Horticulture & 65 & 3 & 8 & 52 & 2 \\
\hline Hunting & 1 & 0 & 0 & 0 & 1 \\
\hline Landscaping & 8 & 1 & 2 & 5 & 0 \\
\hline Medicinal & 1 & 0 & 0 & 1 & 0 \\
\hline Ornamental & 1 & 0 & 1 & 0 & 0 \\
\hline Secondary introduction & 9 & 1 & 4 & 4 & 0 \\
\hline Transport & 27 & 1 & 0 & 25 & 1 \\
\hline Not known & 137 & 0 & 2 & 10 & 125 \\
\hline
\end{tabular}

In the Nordic and Baltic regions the percentages of the registered introductions of each invasiveness category are shown for each pathway, but due to the small amount of data available for this region the calculations will not be shown.

\subsubsection{Summary}

\section{Nordic region}

The analysis shows that of the 4,796 species registered for the Nordic region, 646 species are considered invasive, 427 as potentially invasive, 3,216 not invasive, while 918 have an unknown status of invasiveness.

The highest number of invasive species is registered for the angiosperms and arthropods. This tendency is also seen in the categories potentially invasive and not invasive. But when examining the invasiveness within each 
taxonomic group, the groups with the highest percentage of invasive species are microorganisms, flatworms, fungi, macroalgae and mammals.

The main pathway of introduction for the majority of species considered to be invasive is horticulture, followed by transport, agriculture and ballast water \& sediments. However, looking at the percentage distribution angling/sport, hull fouling, aquaculture and secondary introduction are the pathways with the highest percentage of invasive alien species introduced.

\section{Baltic region}

The analysis shows that of the 1,354 alien species registered for the Baltic region, 819 species have an unknown status of invasiveness. 130 are considered to be invasive, 161 to be potentially invasive and 327 to be not invasive.

The highest number of invasive and potentially invasive species is represented by angiosperms.

When examining the invasiveness within each taxonomic group, the groups with the highest percentage of invasive species are the annelids, bryophytes, cnidarians, flatworms, phytoplankton and reptiles \& amphibians.

For the analysis concerning the invasive status of the taxonomic groups, many results have here been based on single species registration causing some uncertainties in the results. But also the lack of information concerning the invasive status for many of the species registered in the region makes the results for the Baltic region unclear.

The main pathway of introduction for the majority of species considered to be invasive or potentially invasive is horticulture, but also agriculture, forestry and aquaculture are registered several times. However, looking at the percentage distribution forestry, landscaping, secondary introduction and hull fouling are the pathways with the highest percentage of invasive alien species introduced.

\section{Islands of the North Atlantic Ocean}

The analysis shows that of the 279 alien species registered for the region, 131 have an unknown status of invasiveness. 8 are considered to be invasive, 10 to be potentially invasive and 116 to be not invasive.

None of the taxonomic groups has markedly more invasive species than others, however when looking at species considered being potentially invasive, angiosperms and birds stand out. The number of registrations as invasive and potentially invasive is relatively low, and some groups are represented by only one or two species.

The group with the highest percentage of invasive species are bryophytes, mammals and flatworms, while the groups with the highest per- 
centage of species registered as potentially invasive are birds, macroalgae, mammals and microorganisms. However, for flatworms and microorganisms the results are based on a single registration in each group.

The main pathway of introduction for the majority of species considered to be invasive or potentially invasive is horticulture, but also ballast water \& sediments and secondary introduction are registered a number of times. $47 \%$ of the species in the region have an unknown invasiveness status.

\subsection{Taxonomic groups of introduced species}

\subsubsection{Nordic region}

The pathways of introduction are shown for each group of species registered in the Nordic region. The types of introduction - intentional and/or unintentional, as well as unknown - are also presented for each taxonomic group. Introductions of both types - intentional \& unintentional - may be registered with both types in one country, or as unintentional in one country and as intentional in another.

A total of 22 taxonomic groups were represented: angiosperms, annelids, arthropods, birds, bryophytes, cnidarians, comb jellies, coniferous plants, ferns, fish, flatworms, fungi, macroalgae, mammals, microorganisms, molluscs, nematodes, other chordates, other invertebrates, phytoplankton, protozoans and reptiles \& amphibians.

A total of 19 pathways of introduction were represented: agriculture, angling/sport, animal husbandry, aquaculture, aquaria, ballast water \& sediments, biological control, escapes, fisheries, forestry, horticulture, hull fouling, hunting, landscaping, medicinal, ornamental, reintroduction, secondary introduction and transport. Each species may have multiple pathways of introduction.

\section{Angiosperms}

There are 3,272 non-native species of angiosperms currently identified in the NOBANIS database for the Nordic region.

A total of 12 pathways of introduction are currently recorded for the group (see figure 9). The most frequently registered pathway of introduction is horticulture $(\mathrm{N}=1,460)$, followed by agriculture $(\mathrm{N}=477)$ and transport $(\mathrm{N}=186)$. For 1,305 of the non-native angiosperms the pathway of introduction is unknown. 
Figure 9: Pathways of introduction for non-native angiosperms introduced to the Nordic region

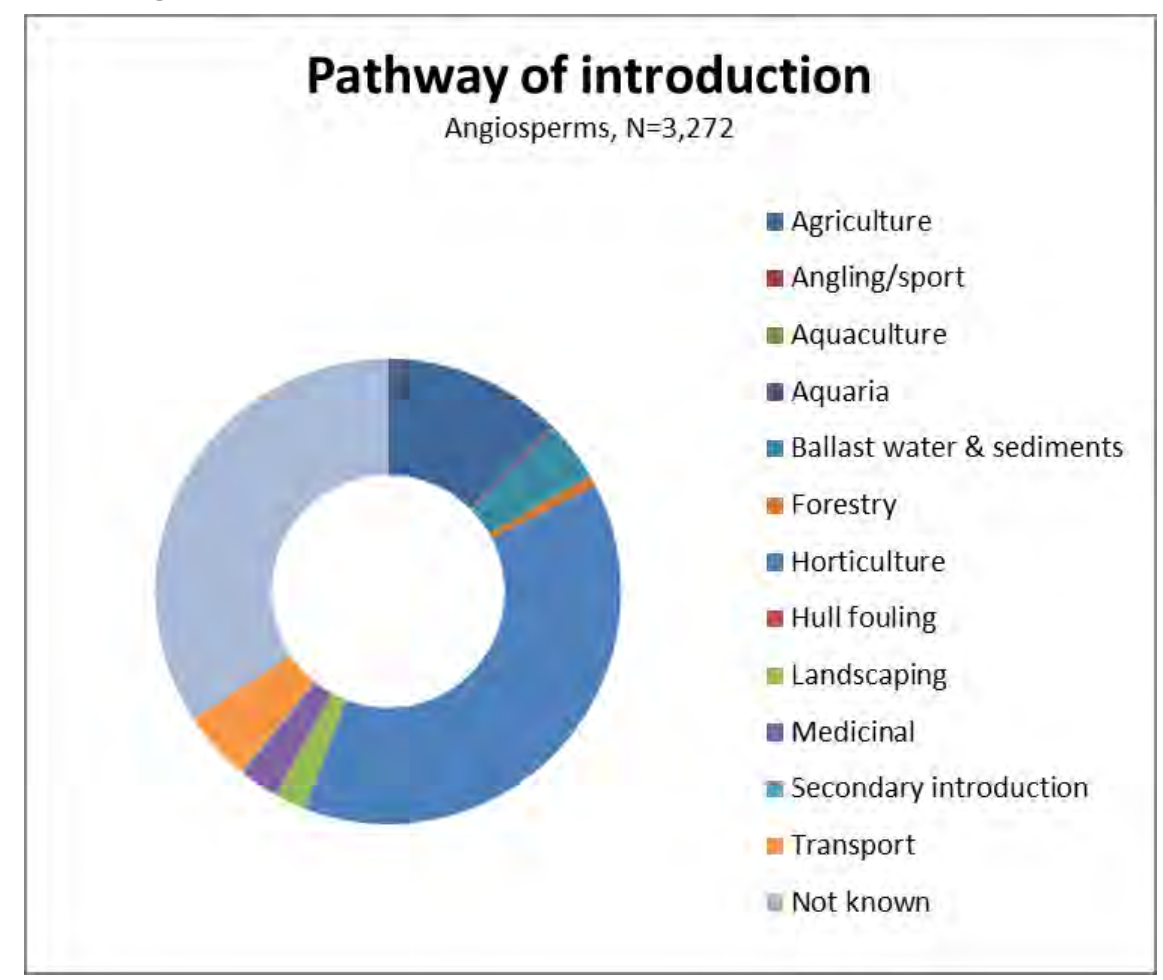

Most introductions of angiosperms are unintentional $(\mathrm{N}=1,763$, see figure 10). The majority of these are introduced by unknown pathways $(\mathrm{N}=953)$, followed by agriculture $(\mathrm{N}=270)$ and horticulture $(\mathrm{N}=265)$. Of the intentional introductions $(\mathrm{N}=675)$, the vast majority are introduced by horticulture $(\mathrm{N}=480)$. 
Figure 10: Types of introduction (intentional, unintentional, both or unknown) for non-native angiosperms in the Nordic region

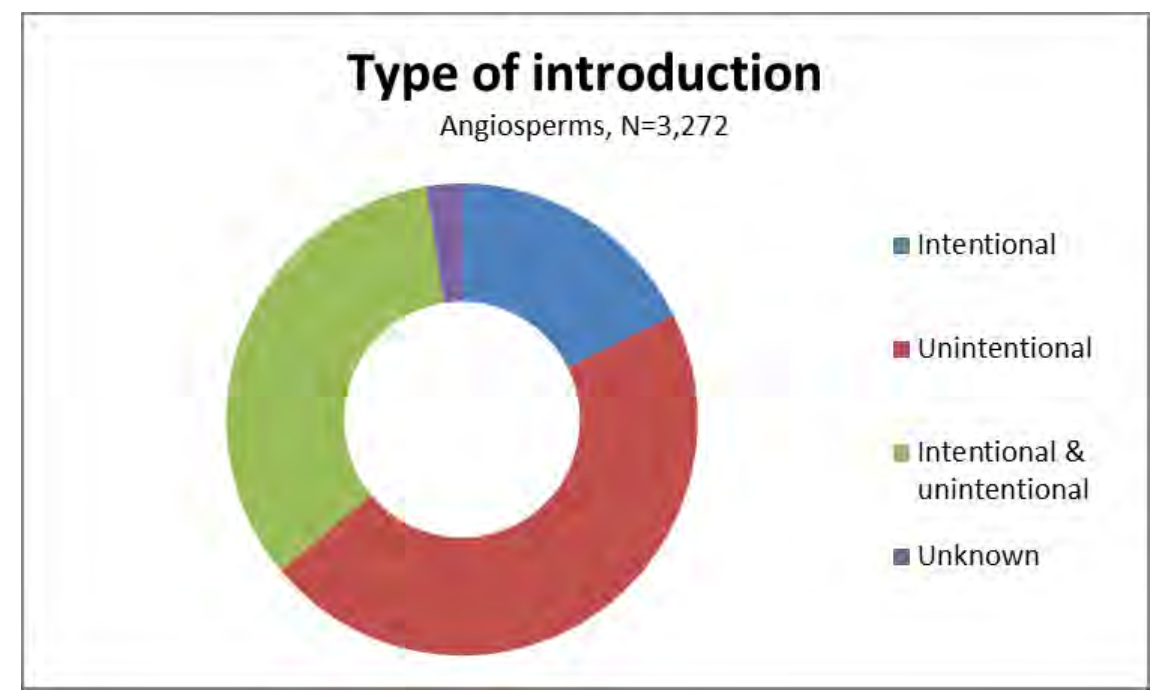

Some of the introductions are registered as both unintentional and intentional $(\mathrm{N}=1,280)$, where these primarily are introduced by horticulture $(\mathrm{N}=710)$ as well.

A number of introductions are registered with unknown type ( $N=93)$, where the vast majority of these also lacks information on the pathway of introduction.

\section{Annelids}

There are presently identified 26 non-native species of annelids in the NOBANIS database for the Nordic region.

A total of 6 pathways of introduction are currently recorded for the group (see figure 11). The most registered pathway of introduction is ballast water \& sediments $(\mathrm{N}=8)$, while for 8 species the pathway of introduction is unknown. 
Figure 11: Pathways of introduction for non-native annelids introduced to the Nordic region

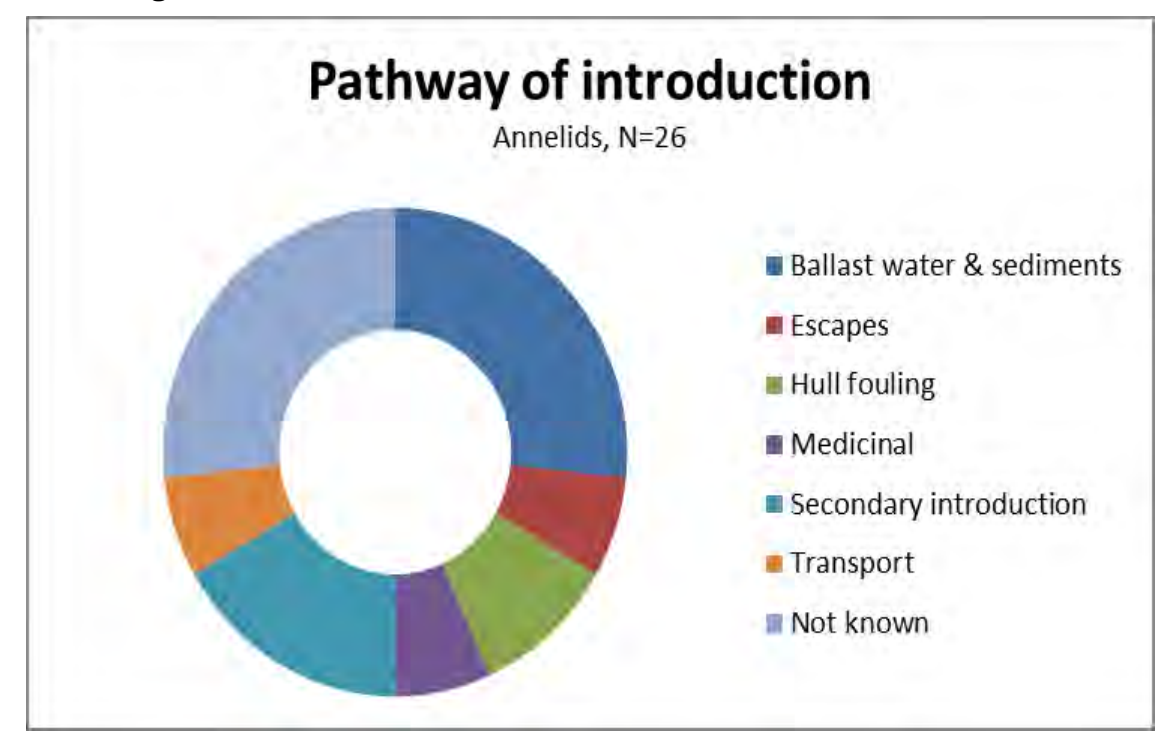

Most types of introductions are unintentional ( $\mathrm{N}=19$, see figure 12$)$, and the majority of the unintentional introductions are by ballast water \& sediments $(\mathrm{N}=7)$

Figure 12: Types of introduction (unintentional, intentional or unknown) for non-native annelids in the Nordic region

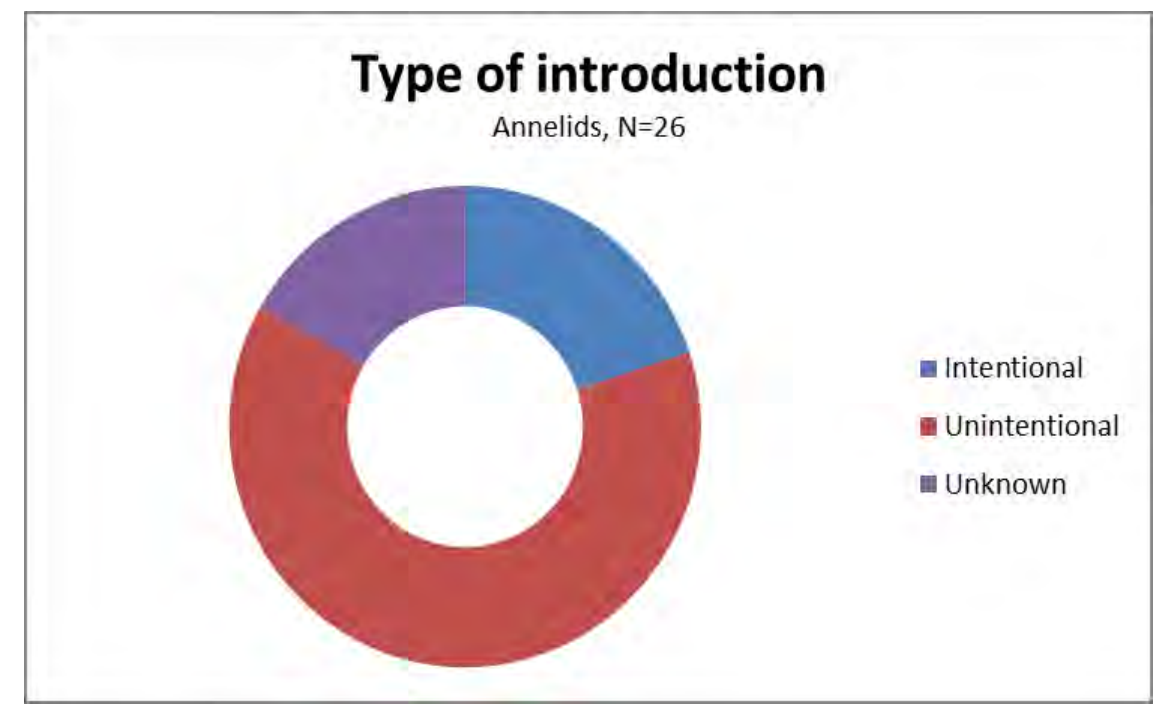


The introductions that are intentional $(\mathrm{N}=6)$, are introduced by escapes $(\mathrm{N}=2)$, medicinal $(\mathrm{N}=2)$ and by unknown pathways $(\mathrm{N}=2)$.

A number of species are registered with unknown types of introduction $(\mathrm{N}=5)$, where the majority is introduced by from secondary introduction $(\mathrm{N}=3)$.

\section{Arthropods}

There are currently identified 928 non-native species of arthropods in the NOBANIS database for the Nordic region.

A total of 17 pathways of introduction are currently recorded for the group (see figure 13). The most frequently registered pathways of introduction are horticulture $(\mathrm{N}=228)$, forestry $(\mathrm{N}=225)$ and transport $(\mathrm{N}=134)$. For 408 species the pathway of introduction is still not identified.

Figure 13: Pathways of introduction for non-native arthropods introduced to the Nordic region

\begin{tabular}{|c|c|}
\hline $\begin{array}{l}\text { Pathway of introd } \\
\qquad \text { Arthropods, } \mathrm{N}=928\end{array}$ & 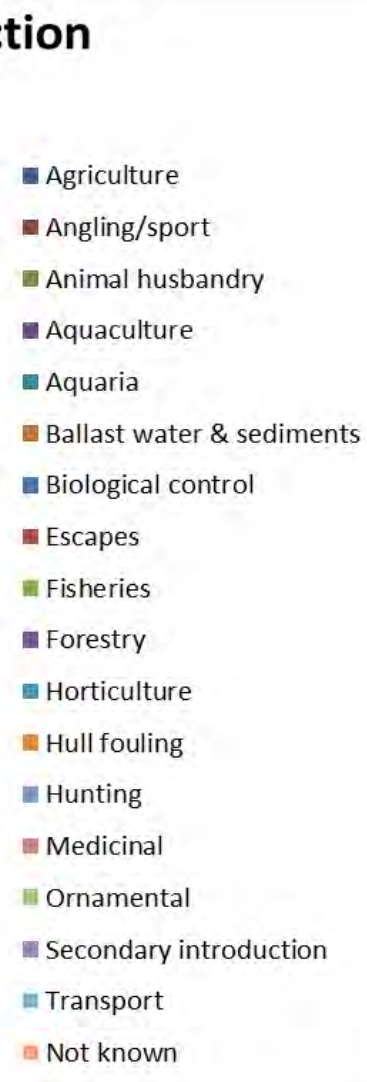 \\
\hline
\end{tabular}


Most introductions of arthropods are unintentional $(\mathrm{N}=773$, see figure 14). The majority of these are introduced by unknown pathways $(\mathrm{N}=290)$, but a large number of unintentional introductions are by horticulture $(\mathrm{N}=142)$ and transport $(\mathrm{N}=122)$. The arthropods that are intentionally introduced $(\mathrm{N}=41)$ is primarily by unknown pathways $(\mathrm{N}=15)$.

Figure 14: Types of introduction (intentional, unintentional, both or unknown) for non-native arthropods in the Nordic region

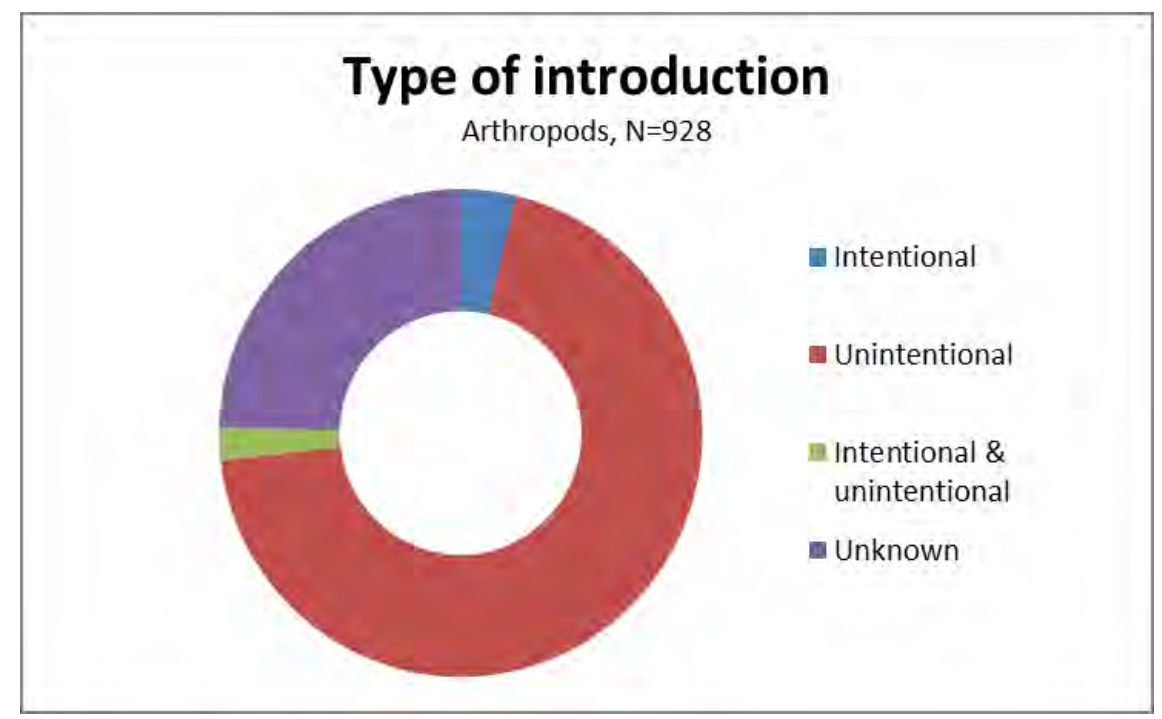

Some of the introductions are registered as both unintentional and intentional $(\mathrm{N}=24)$, and these are dispersed by several pathways, but primarily by horticulture $(\mathrm{N}=5)$ and biological control $(\mathrm{N}=4)$.

A number of introductions are registered with unknown types of introduction $(\mathrm{N}=274)$, and the most commonly registered pathway of introduction for these species is "unknown" $(\mathrm{N}=102)$.

The analysis also shows that alien species of arthropods are registered with 17 different pathways of introduction, but many of the pathways are used by only a few species.

\section{Birds}

There are currently identified 81 non-native species of birds in the NOBANIS database for the Nordic region.

A total of 6 pathways of introduction are currently recorded for the group (see figure 15). The most frequently registered pathway of introduction are secondary introduction $(\mathrm{N}=34)$, followed by escapes $(\mathrm{N}=24)$. For 24 species of birds the pathway of introduction is unknown. 
Figure 15: Pathways of introduction for non-native birds introduced to the Nordic region

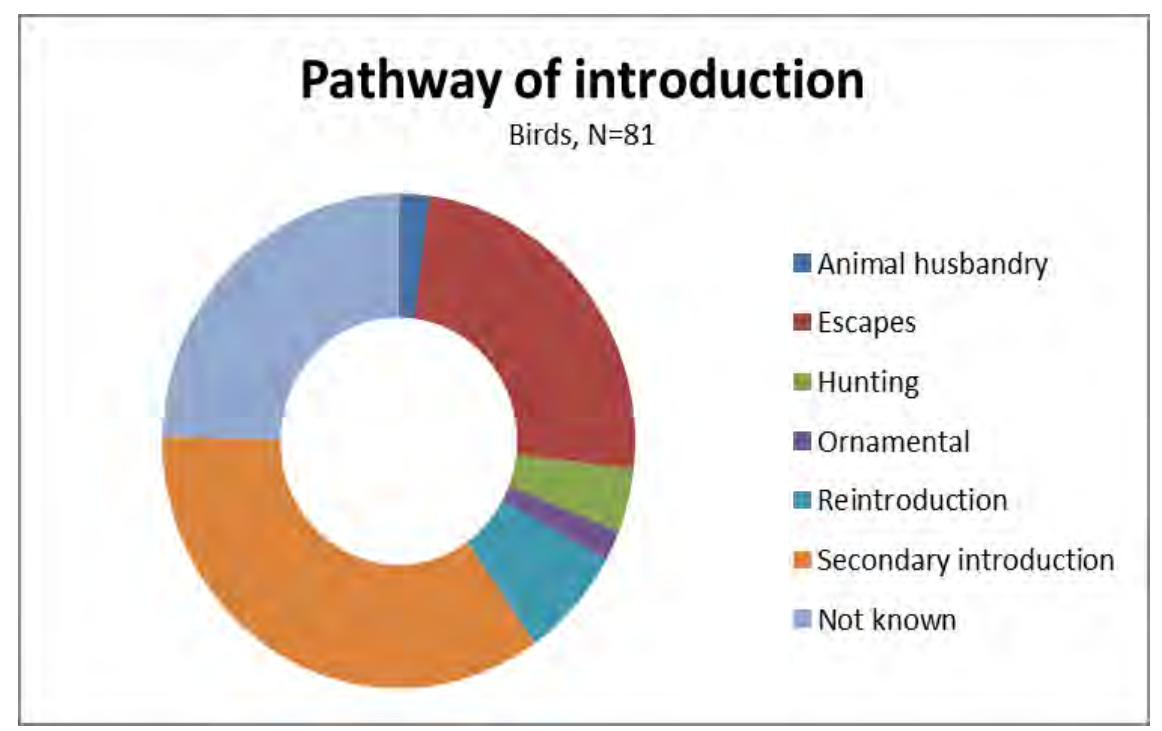

Most types of introductions are unintentional $(\mathrm{N}=40$, see figure 16), and most of these are secondary introductions $(\mathrm{N}=17)$. The intentional introductions $(\mathrm{N}=25)$ are primarily escapes $(\mathrm{N}=8)$ or reintroductions $(\mathrm{N}=6)$.

Figure 16: Types of introduction (intentional, unintentional, both or unknown) for non-native birds in the Nordic region

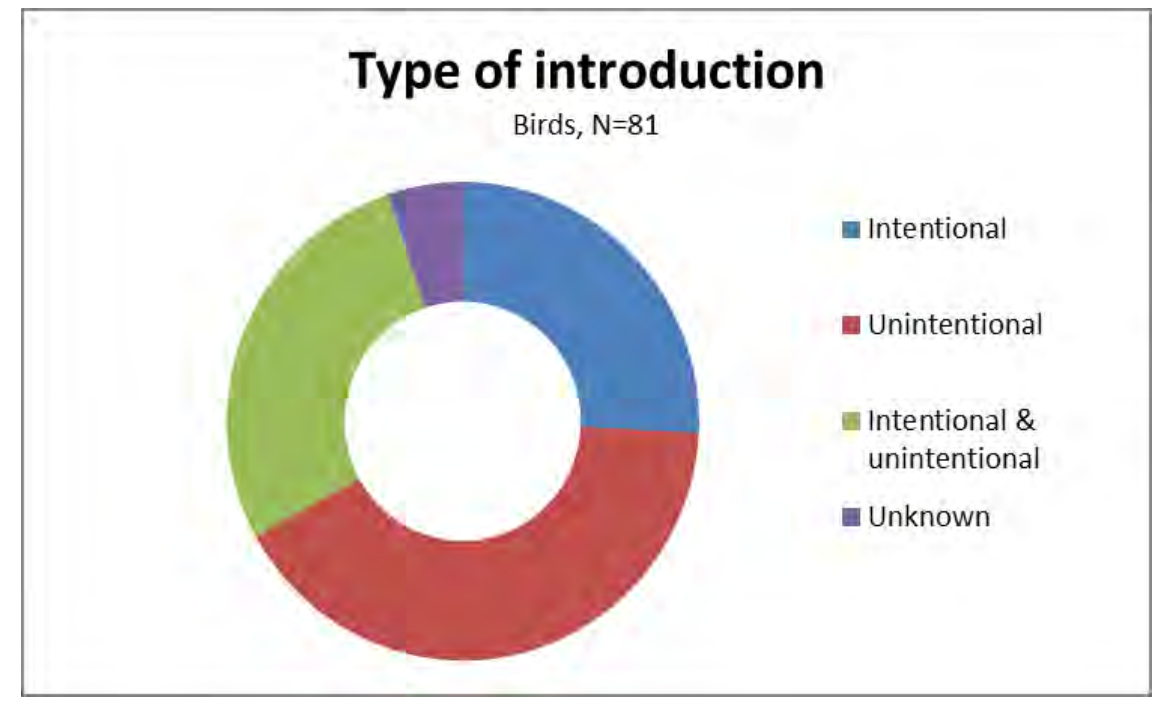


Some of the introductions are registered as both unintentional and intentional $(\mathrm{N}=27)$, and these are primarily escapes $(\mathrm{N}=12)$ and secondary introductions $(\mathrm{N}=11)$.

A number of introductions are registered with unknown types of introduction $(\mathrm{N}=5)$.

\section{Bryophytes}

There are currently identified 6 non-native species of bryophytes in the NOBANIS database for the Nordic region.

Three pathways of introduction are currently recorded for the group (see figure 17). The most registered pathway of introduction are transport $(\mathrm{N}=6)$, followed by secondary introduction $(\mathrm{N}=3)$ and forestry $(\mathrm{N}=1)$.

Figure 17: Pathways of introduction for non-native bryophytes introduced to the Nordic region

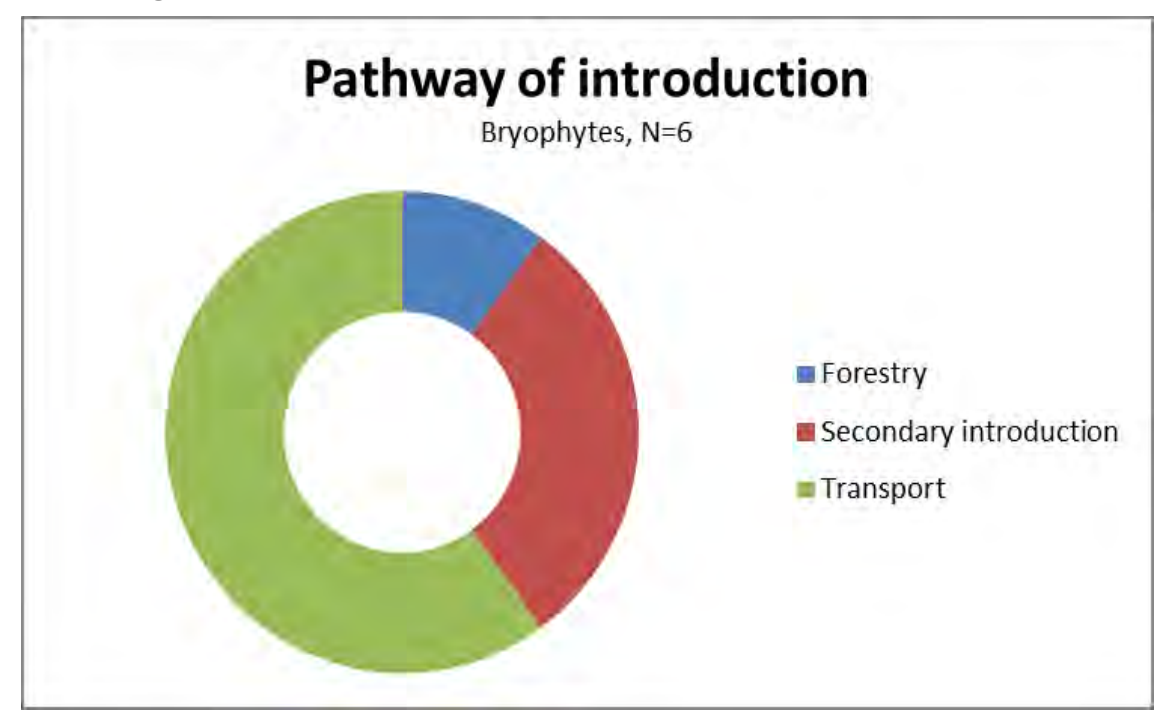

All alien introductions of bryophytes in the Nordic region are recorded as unintentional.

\section{Cnidarians}

There are currently identified 8 non-native species of cnidarians in the NOBANIS database for the Nordic region.

A total of three pathways of introduction are currently recorded for the group (see figure 18). The most frequently registered pathways of introduction are ballast water \& sediments $(\mathrm{N}=6)$, followed by hull fouling $(\mathrm{N}=5)$ and angling/sport $(\mathrm{N}=1)$. 


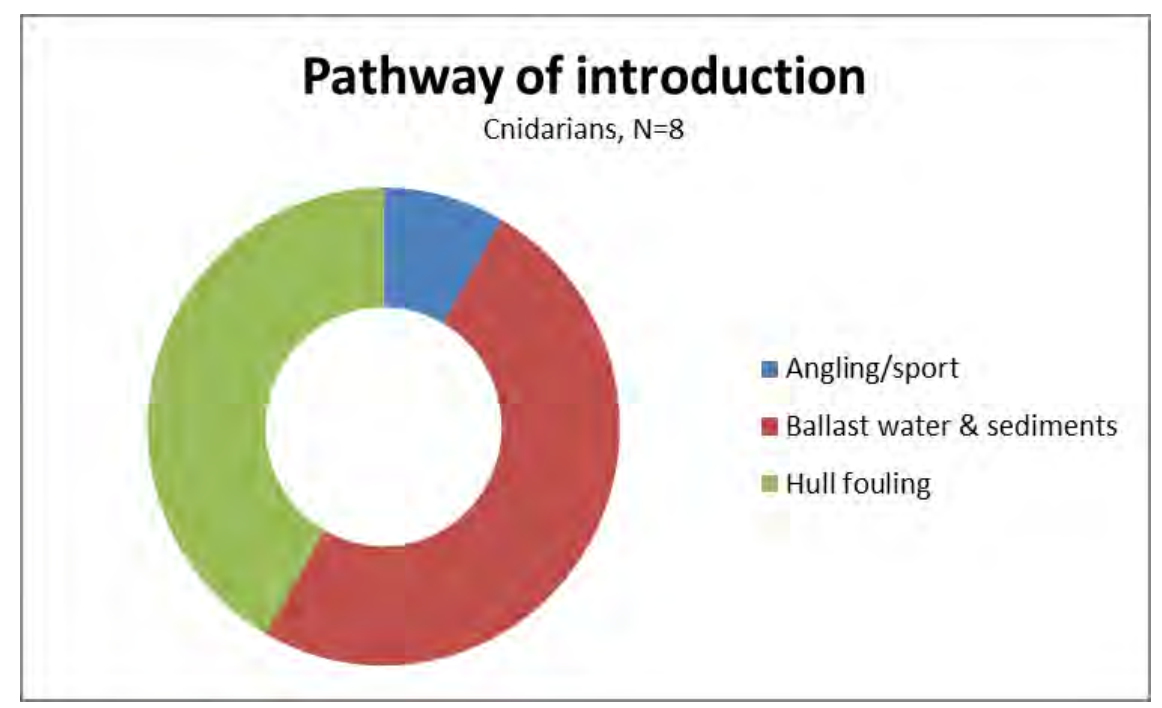

Most introductions are unintentional $(\mathrm{N}=10)$, and by ballast water \& sediments $(\mathrm{N}=5)$ or hull fouling $(\mathrm{N}=4)$.

\section{Comb jellies}

There are currently identified four non-native species of comb jellies in the NOBANIS database for the Nordic region.

Two pathways of introduction are currently recorded for the group. The most frequently registered pathway of introduction is ballast water \& sediments $(\mathrm{N}=4)$, but also secondary introduction $(\mathrm{N}=1)$ is registered.

Three of the introductions by ballast water \& sediments are unintentional. Of the two introductions registered in the category intentional \& unintentional, one is by ballast water \& sediments and one is by hull fouling.

\section{Coniferous plants}

There are currently identified 82 non-native species of coniferous plants in the NOBANIS database for the Nordic region.

Three pathways of introduction are currently recorded for the group (see figure 19). The most frequently registered pathways of introduction are horticulture $(\mathrm{N}=62)$ and forestry $(\mathrm{N}=61)$, but also landscaping $(\mathrm{N}=28)$ is registered. For two species the pathways of introduction are unknown. 
Figure 19: Pathways of introduction for non-native coniferous plants introduced to the Nordic region

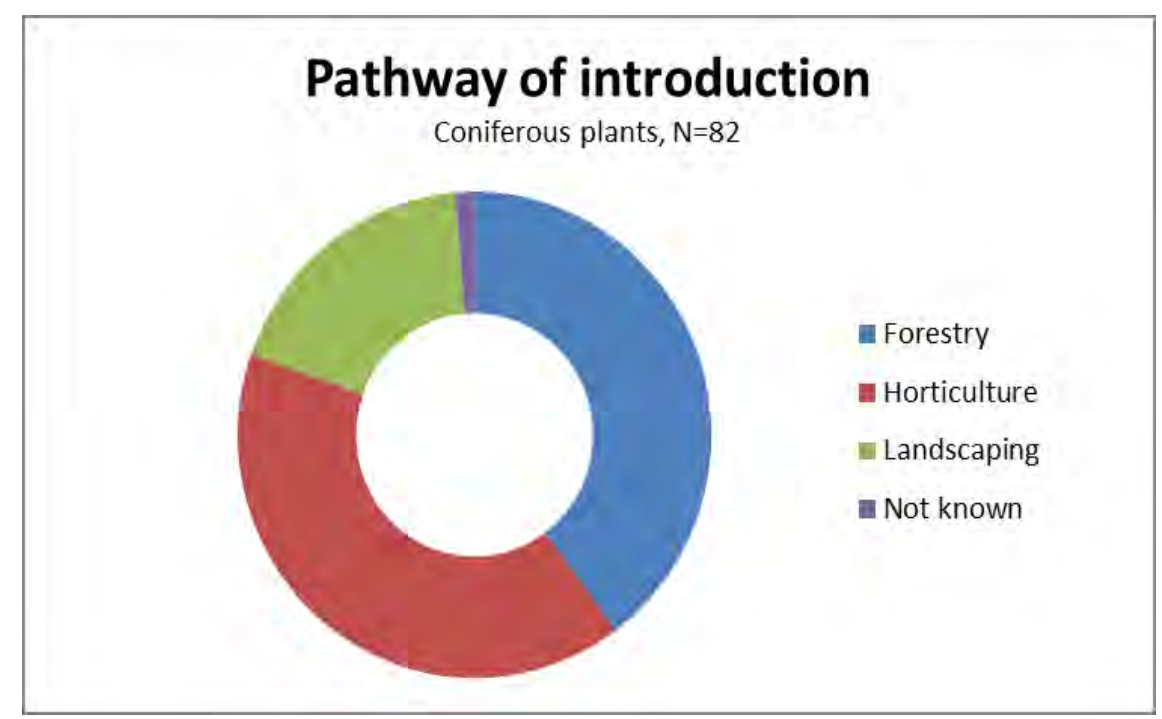

Most introductions are intentional $(\mathrm{N}=81$, see figure 20$)$, and these are primarily by horticulture $(\mathrm{N}=34)$ or forestry $(\mathrm{N}=33)$.

A number of the introductions are registered as both unintentional and intentional $(\mathrm{N}=70)$, and these are primarily by horticulture $(\mathrm{N}=28)$ and forestry $(\mathrm{N}=28)$.

Figure 20: Types of introduction (intentional, unintentional or both) for nonnative coniferous plants in the Nordic region

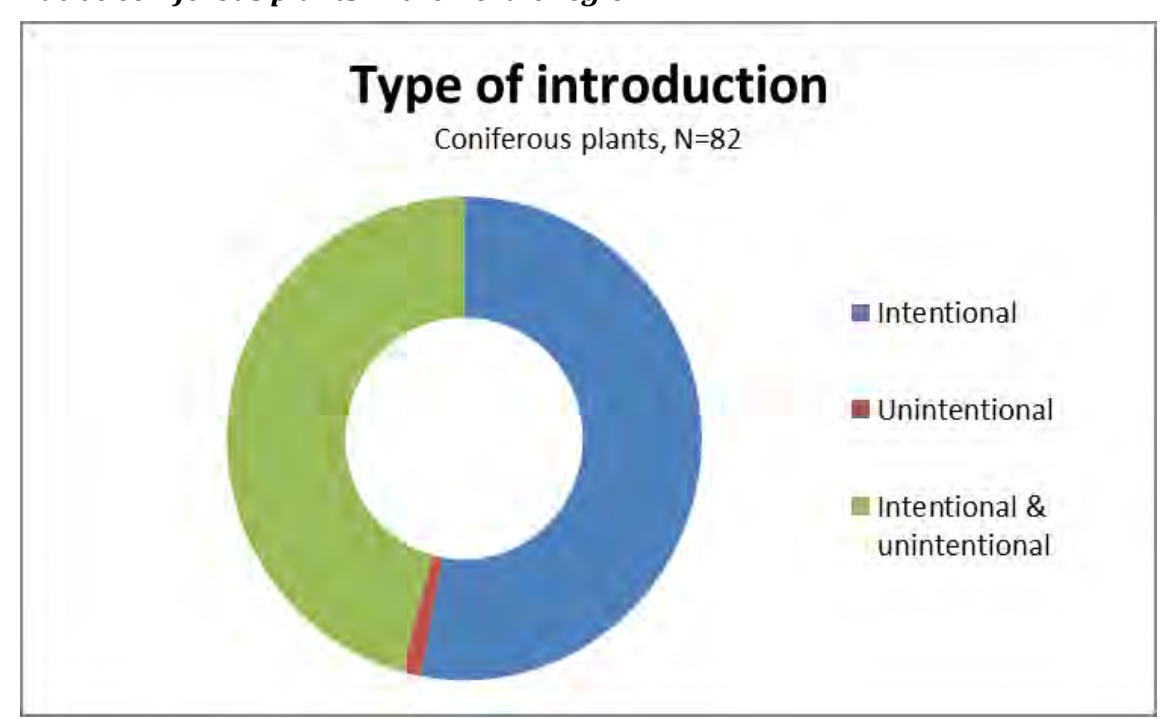




\section{Ferns}

There are currently identified 11 non-native species of ferns in the NOBANIS database for the Nordic region.

A total of four pathways of introduction are currently recorded for the group (see figure 21). The most frequently registered pathways of introduction are horticulture $(\mathrm{N}=5)$ and agriculture $(\mathrm{N}=3)$. For three species the pathway of introduction is unknown.

Figure 21: Pathways of introduction for non-native ferns introduced to the Nordic region

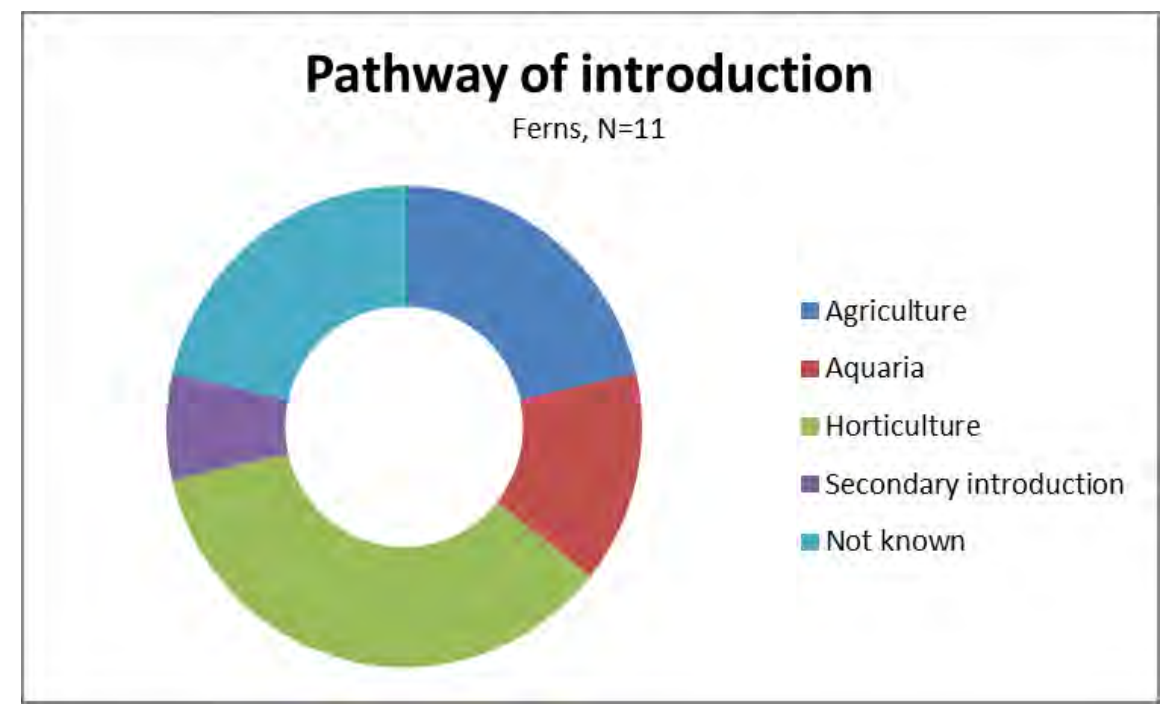

Of the introduced ferns, half of the introductions are categorised as intentional \& unintentional ( $N=7$, see figure 22$)$, and most of these are by horticulture $(\mathrm{N}=4)$.

For the introductions that are categorised as unintentional $(\mathrm{N}=6)$ most of the pathways were unknown $(\mathrm{N}=3)$, and for the one intentionally introduced species the cause of introduction is horticulture. 
Figure 22: Types of introduction (intentional, unintentional or both) for nonnative ferns in the Nordic region

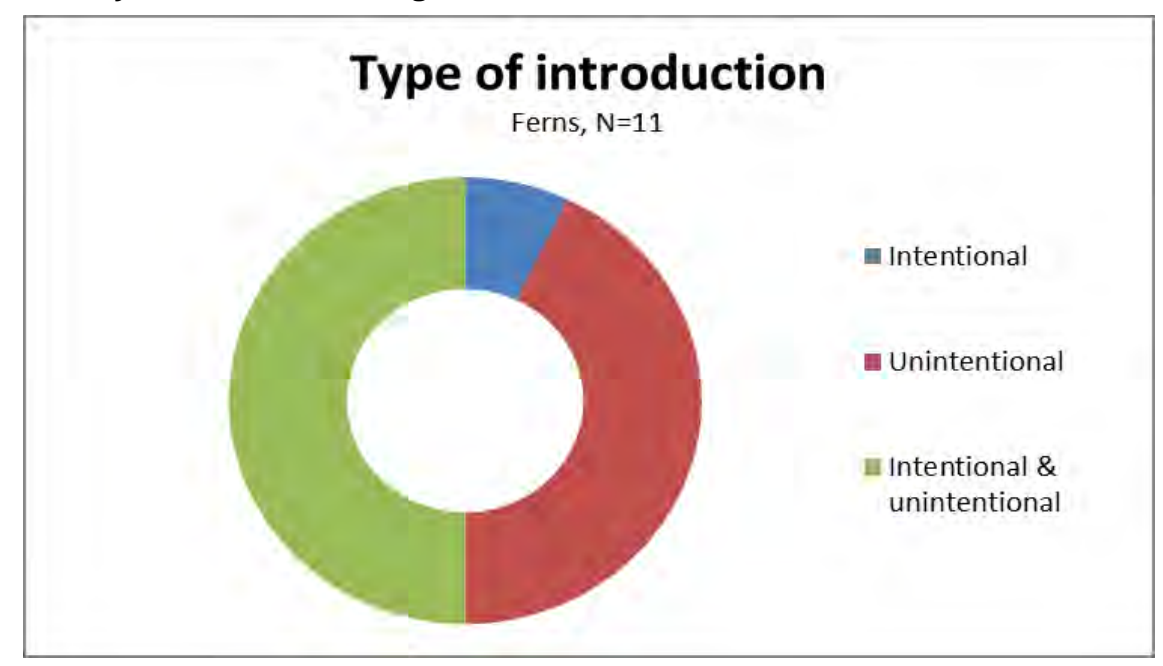

Fish

There are currently identified 40 non-native species of fish in the NOBANIS database for the Nordic region.

A total of 8 pathways of introduction are currently recorded for the group (see figure 23). The most frequently registered pathways of introduction are aquaculture $(\mathrm{N}=29)$ and angling/sport $(\mathrm{N}=24)$. Only one species is registered with an unknown pathway of introduction.

Figure 23: Pathways of introduction for non-native fish introduced to the Nordic region

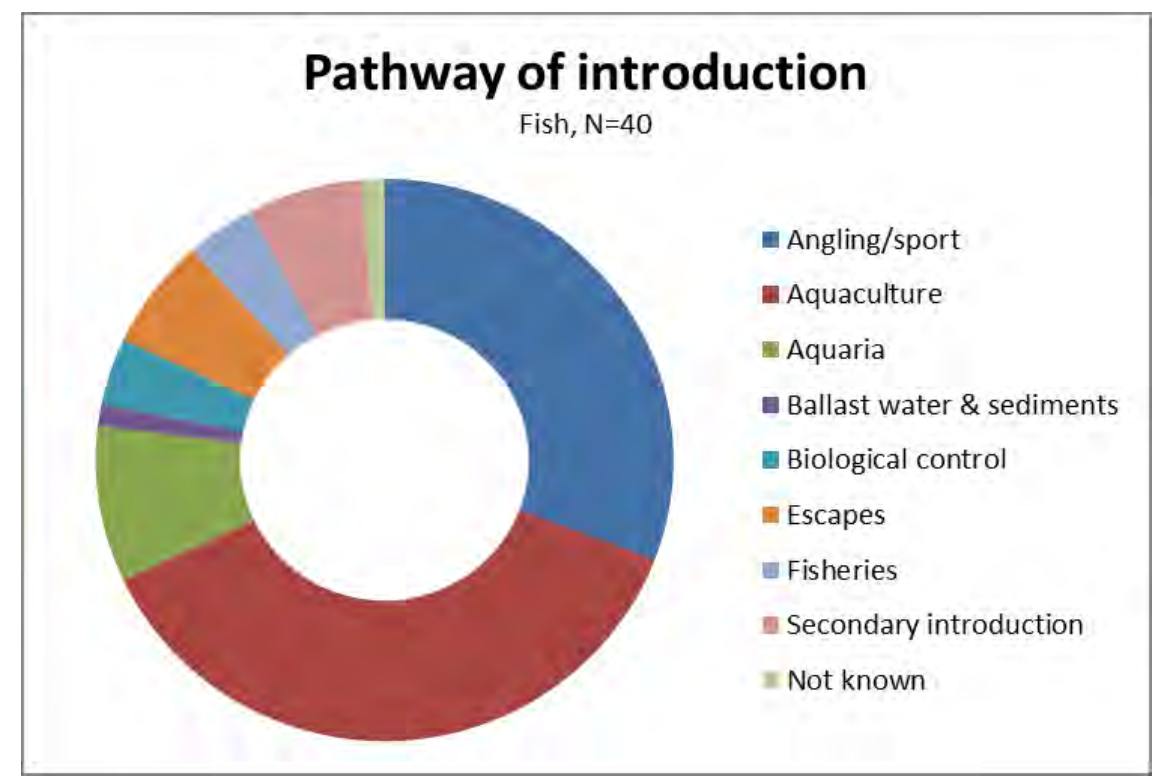


Most introductions are intentional $(\mathrm{N}=68$, see figure 24). The most registered pathways of these are aquaculture $(\mathrm{N}=26)$ and angling/sport $(\mathrm{N}=21)$. The introductions that are unintentional $(\mathrm{N}=4)$ are mostly by aquaculture $(\mathrm{N}=2)$.

A number of the introductions are registered with both unintentional and intentional introductions $(\mathrm{N}=3)$, and these are primarily by angling/sport ( $\mathrm{N}=3)$.

Figure 24: Types of introduction (intentional, unintentional or both) for nonnative fish in the Nordic region

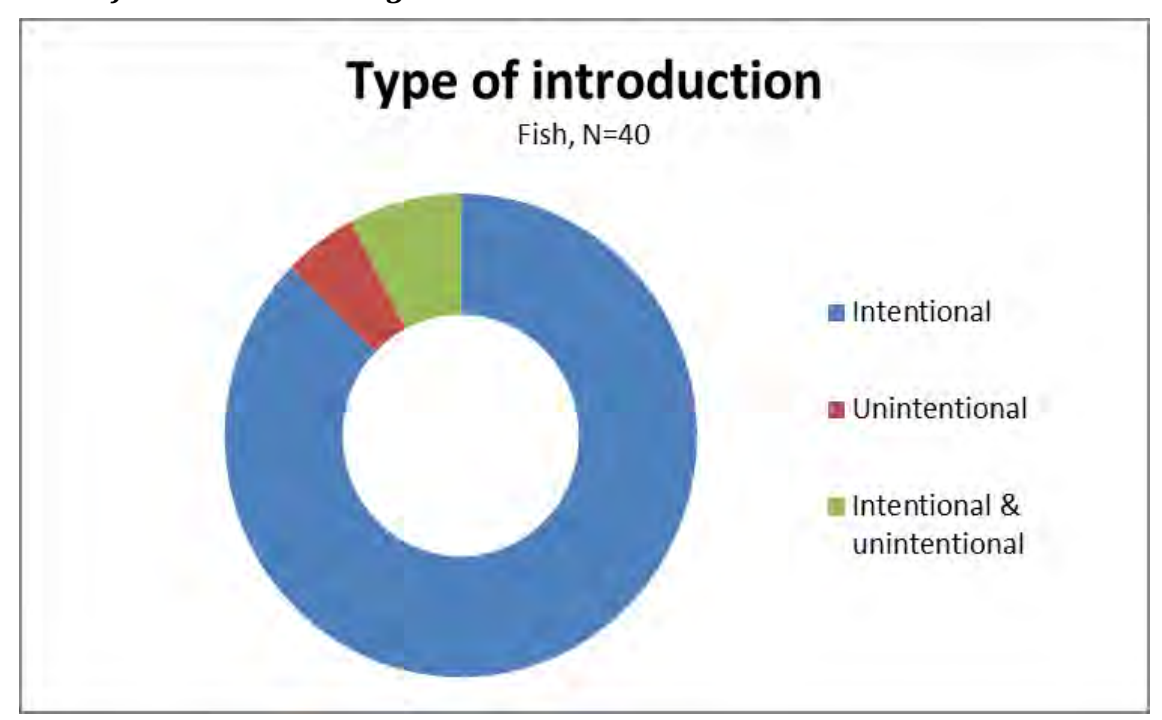

\section{Flatworms}

There are currently identified 8 non-native species of flatworms in the NOBANIS database for the Nordic region.

A total of 5 pathways of introduction are currently recorded for the group (see figure 25). The most frequently registered pathways of introduction are aquaculture $(\mathrm{N}=4)$ and ballast water \& sediments $(\mathrm{N}=2)$. All of the introductions are unintentional. 
Figure 25: Pathways of introduction for non-native flatworms introduced to the Nordic region

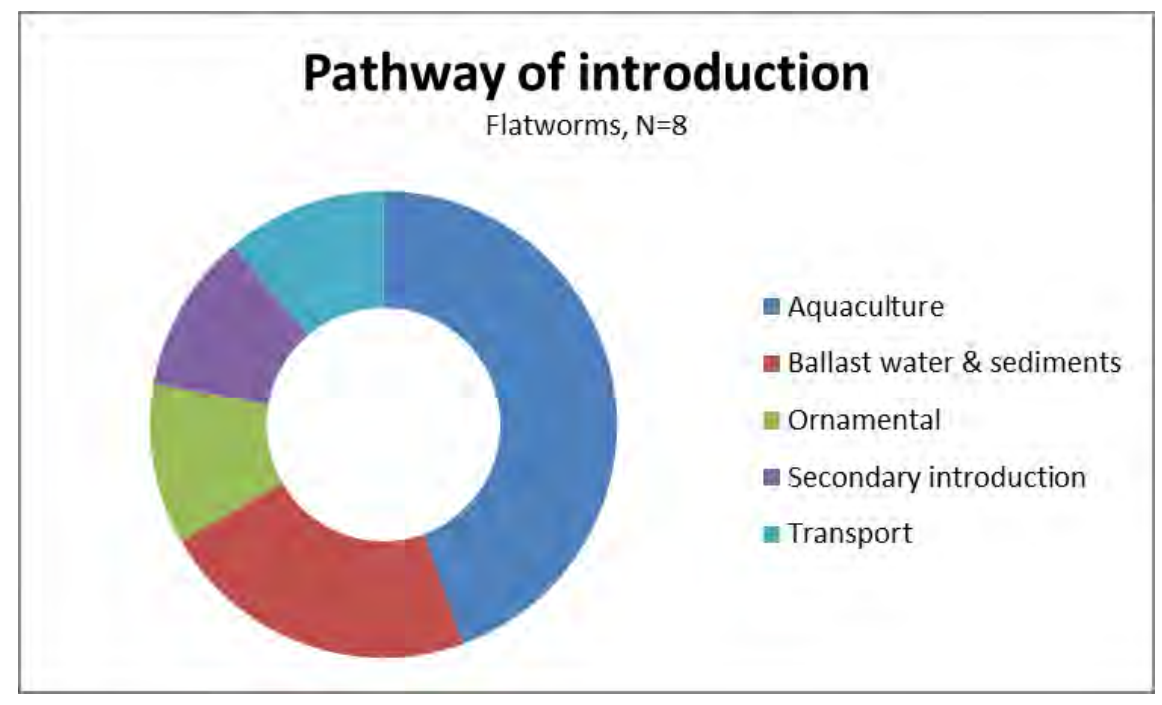

Fungi

There are currently identified 120 non-native species of fungi in the NOBANIS database for the Nordic region.

A total of 8 pathways of introduction are currently recorded for the group (see figure 26). The most frequently registered pathways of introduction are horticulture $(\mathrm{N}=27)$ and forestry $(\mathrm{N}=18)$, but for 69 species the pathway of introduction is unknown.

Figure 26: Pathways of introduction for non-native fungi introduced to the Nordic region

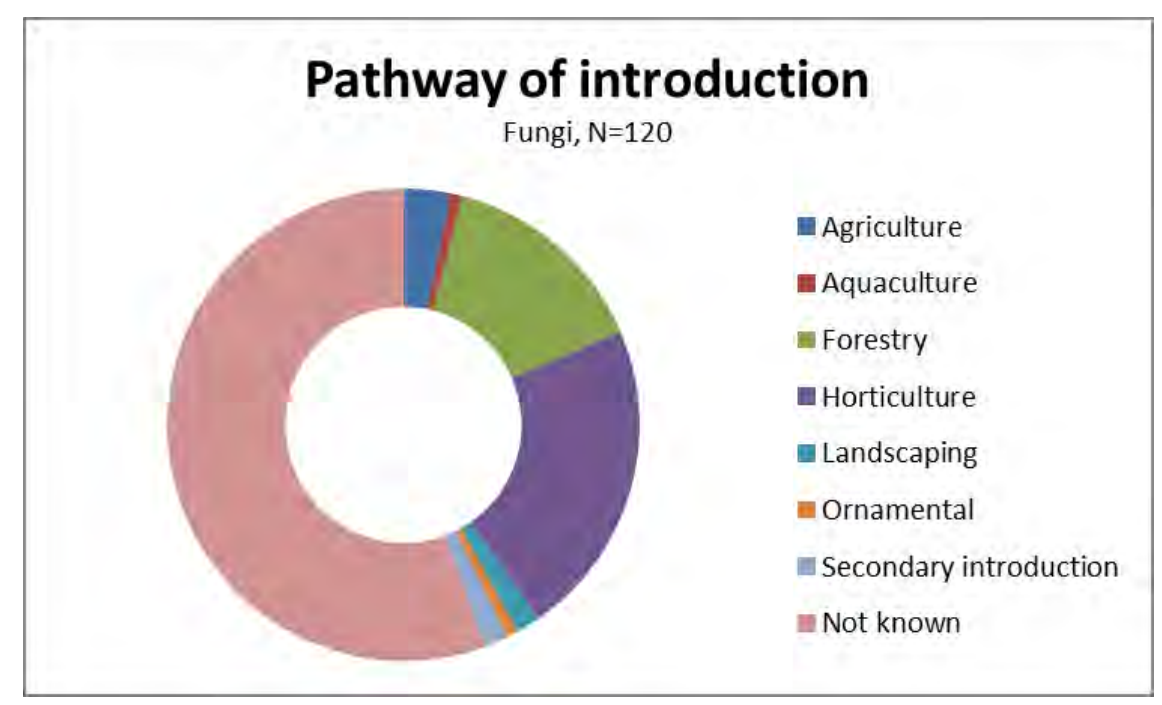


Most types of introductions are unknown ( $\mathrm{N}=92$, see figure 27). A number of introductions are unintentional $(\mathrm{N}=24)$, where most are by forestry $(\mathrm{N}=10)$ or horticulture $(\mathrm{N}=9)$. A few introductions are registered as intentional \& unintentional $(\mathrm{N}=3)$.

Figure 27: Types of introduction (intentional, unintentional, both or unknown) for non-native fungi in the Nordic region

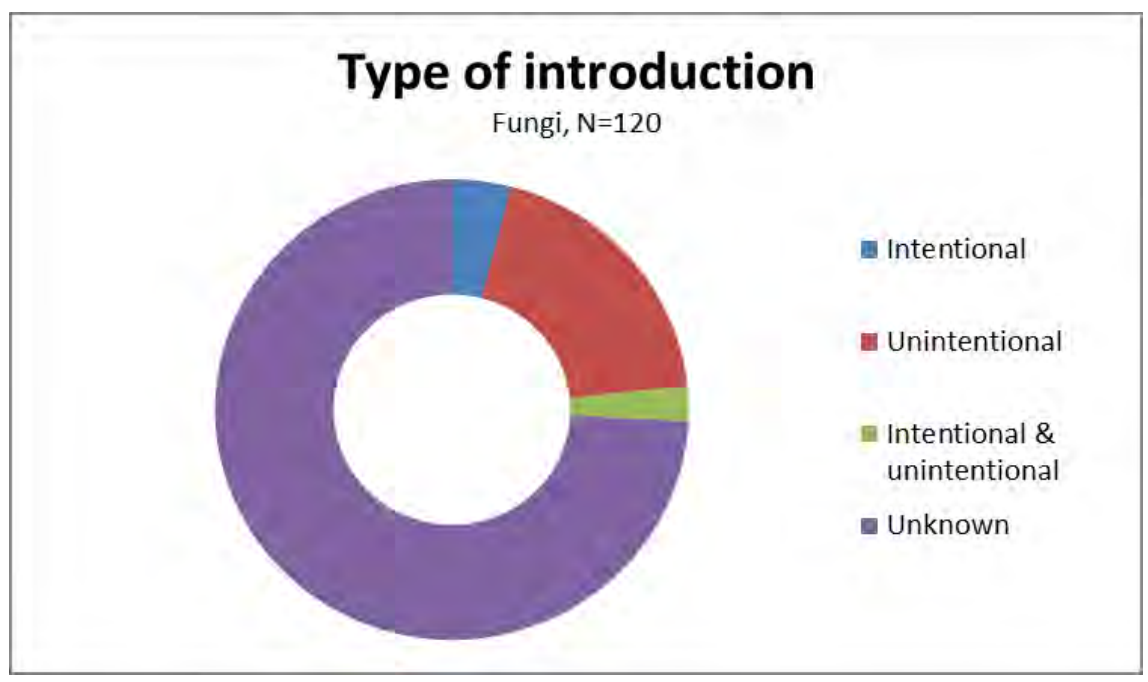

\section{Macroalgae}

There are currently identified 17 non-native species of macroalgae in the NOBANIS database for the Nordic region.

A total of 6 pathways of introduction are currently recorded for the group (see figure 28). The most frequently registered pathway of introduction is ballast water \& sediments ( $\mathrm{N}=11)$, followed by aquaculture $(\mathrm{N}=9)$ and hull fouling $(\mathrm{N}=9)$. For one species the pathway of introduction is unknown. 
Figure 28: Pathways of introduction for non-native macroalgae introduced to the Nordic region

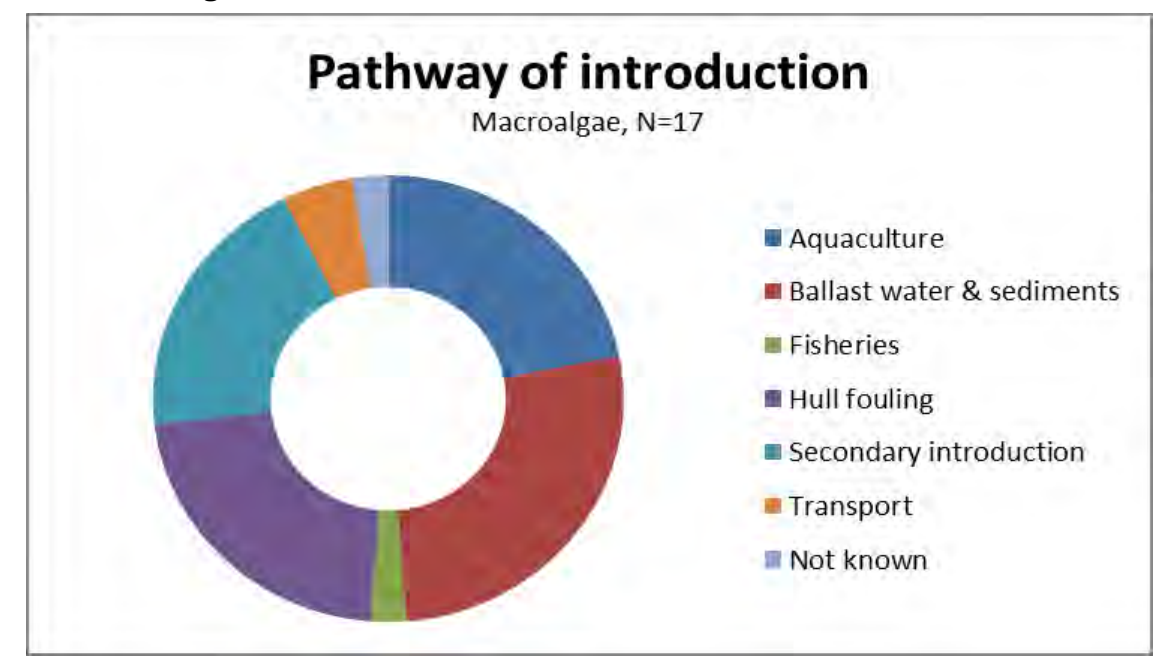

The vast majority of the introductions are unintentional $(\mathrm{N}=38)$, and for a few the type of introduction is unknown $(\mathrm{N}=3)$.

\section{Mammals}

There are currently identified 43 non-native species of mammals in the NOBANIS database for the Nordic region.

A total of 7 pathways of introduction are currently recorded for the group (see figure 29). The most frequently registered pathway of introduction is escapes $(\mathrm{N}=22)$, followed by secondary introduction $(\mathrm{N}=10)$. For four species the pathway of introduction is unknown.

Figure 29: Pathways of introduction for non-native mammals introduced to the Nordic region

\begin{tabular}{|l|l|}
\hline Pathway of introduction \\
& \\
& $=$ Animal husbandry \\
& $=$ Ballast water \& sediments \\
& $=$ Escapes \\
& $=$ Hunting \\
& $=$ Reintroduction \\
& $=$ Secondary introduction \\
& $=$ Transport \\
& $=$ Not known
\end{tabular}


Most introductions are intentional $(\mathrm{N}=39$, see figure 30$)$ and by escapes $(\mathrm{N}=14)$ or secondary introductions $(\mathrm{N}=7)$.

Figure 30: Types of introduction (intentional, unintentional or both) for nonnative mammals in the Nordic region

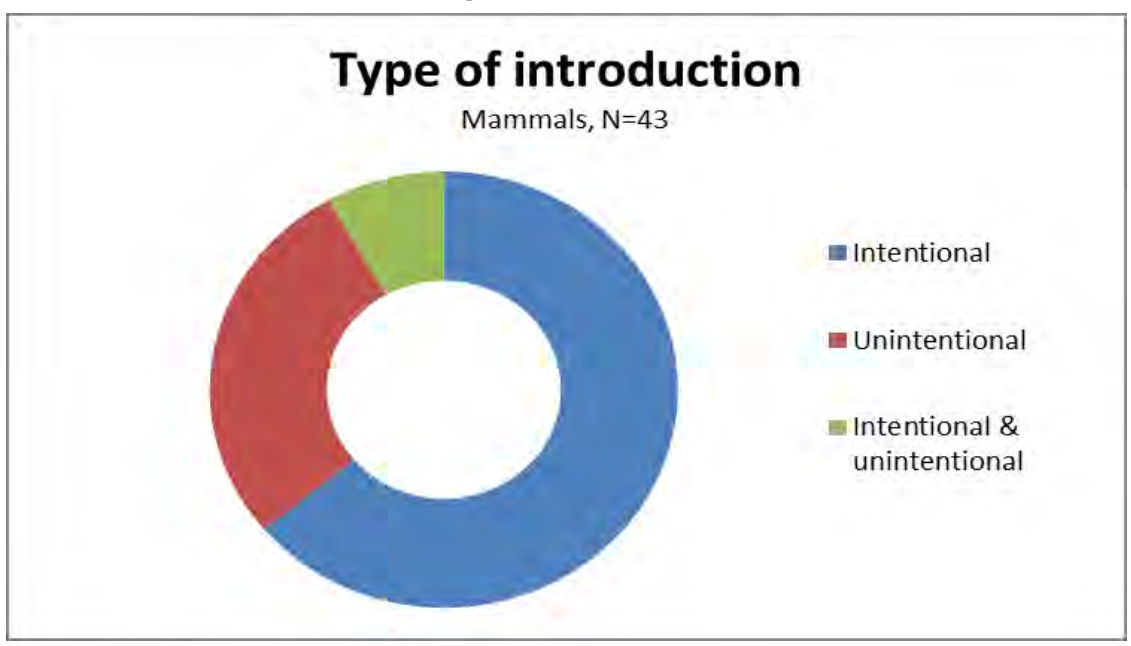

\section{Microorganisms}

There are currently identified 35 non-native species of microorganisms in the NOBANIS database for the Nordic region.

Two pathways of introduction are currently recorded for the group (see figure 31). The most common pathway of introduction is horticulture $(\mathrm{N}=8)$, but for the majority of the species the pathway of introduction is unknown $(\mathrm{N}=26)$.

Figure 31: Pathways of introduction for non-native microorganisms introduced to the Nordic region

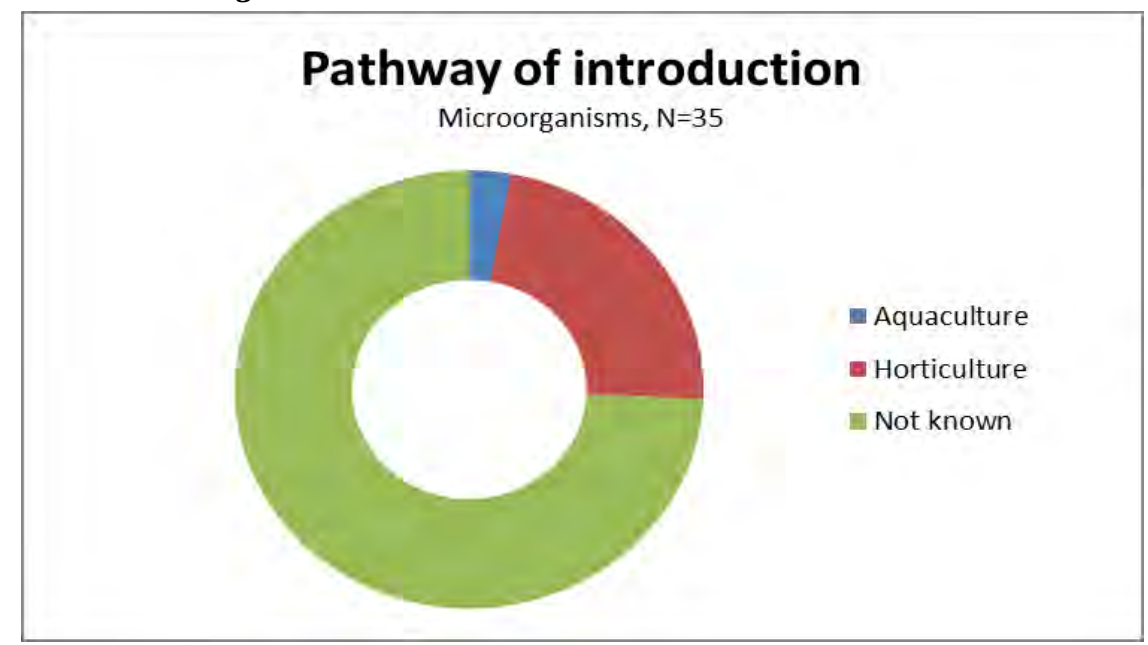


Two of the introductions are registered as unintentional, but for the majority of the non-native species the type of introduction is unknown $(\mathrm{N}=33)$.

\section{Molluscs}

There are currently identified 69 non-native species of molluscs in the NOBANIS database for the Nordic region.

A total of 13 pathways of introduction are currently recorded for the group (see figure 32 ). The most frequently registered pathway of introduction is horticulture $(\mathrm{N}=13)$, followed by ballast water \& sediments $(\mathrm{N}=10)$. For 13 species the pathway of introduction is unknown.

Figure 32: Pathways of introduction for non-native molluscs introduced to the Nordic region

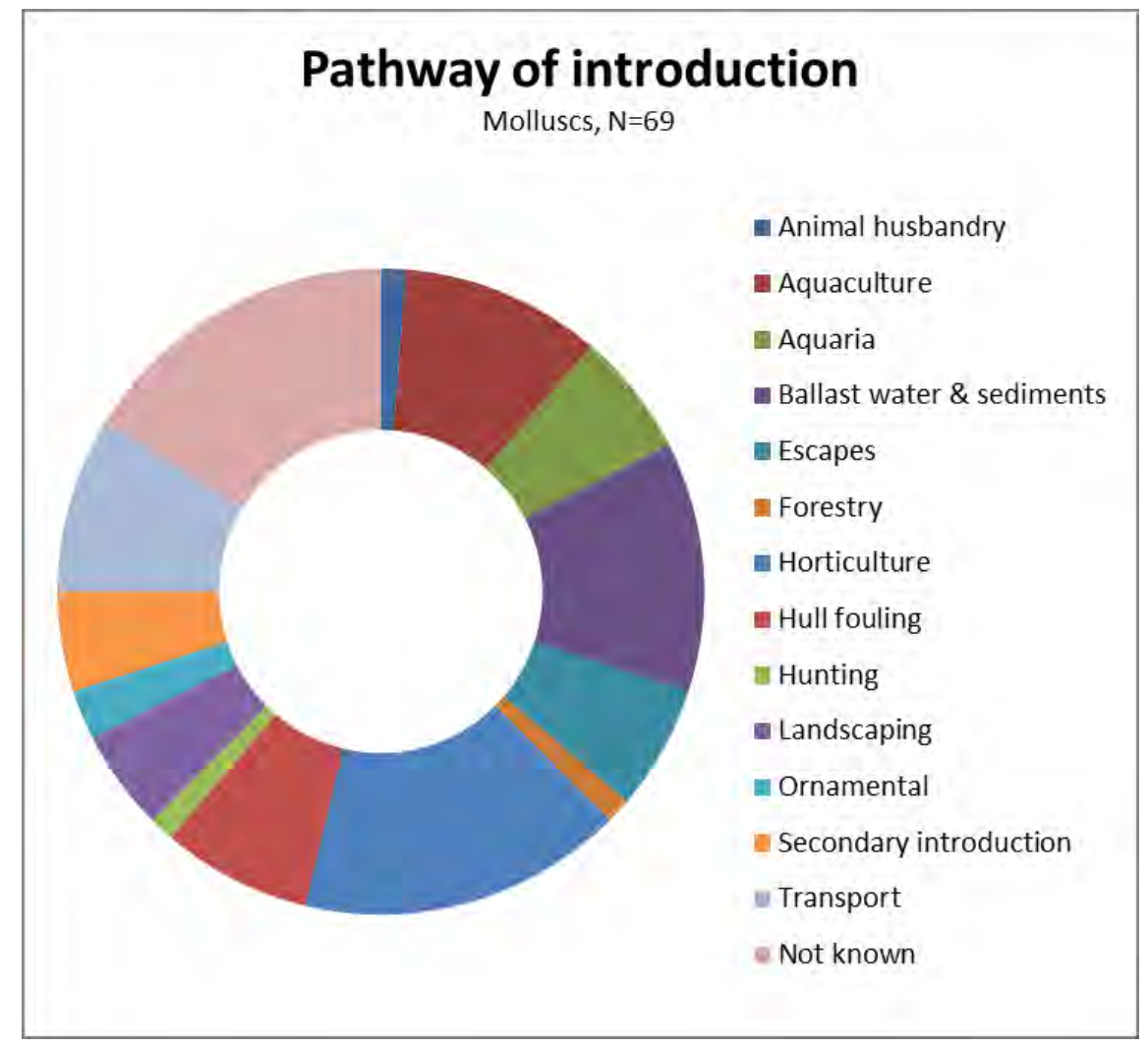

Most introductions are unintentional ( $\mathrm{N}=59$, see figure 33), while 8 are intentional and 11 are registered as intentional \& unintentional. 
Figure 33: Types of introduction (intentional, unintentional, both or unknown) for non-native molluscs in the Nordic region

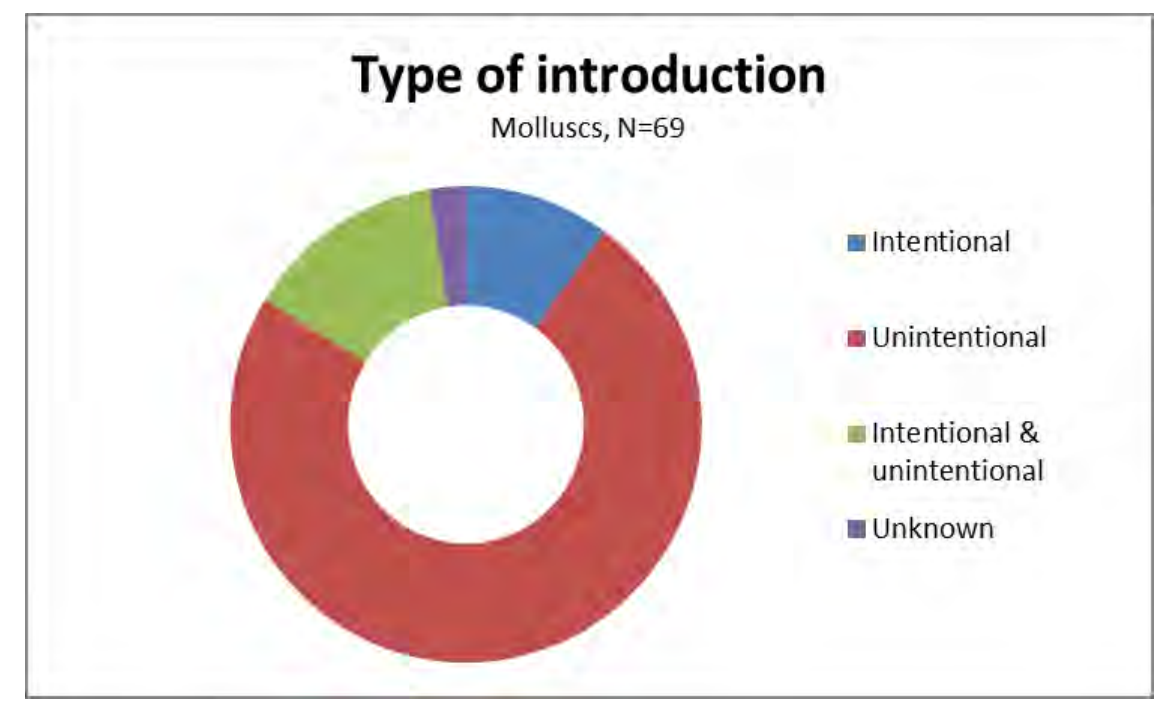

\section{Nematodes}

There are currently identified 13 non-native species of nematodes in the NOBANIS database for the Nordic region.

A total of four pathways of introduction are currently recorded for the group (see figure 34). The main pathway of introduction is horticulture $(\mathrm{N}=2)$, but for most introductions the pathway is unknown $(\mathrm{N}=10)$.

Figure 34: Pathways of introduction for non-native nematodes introduced to the Nordic region

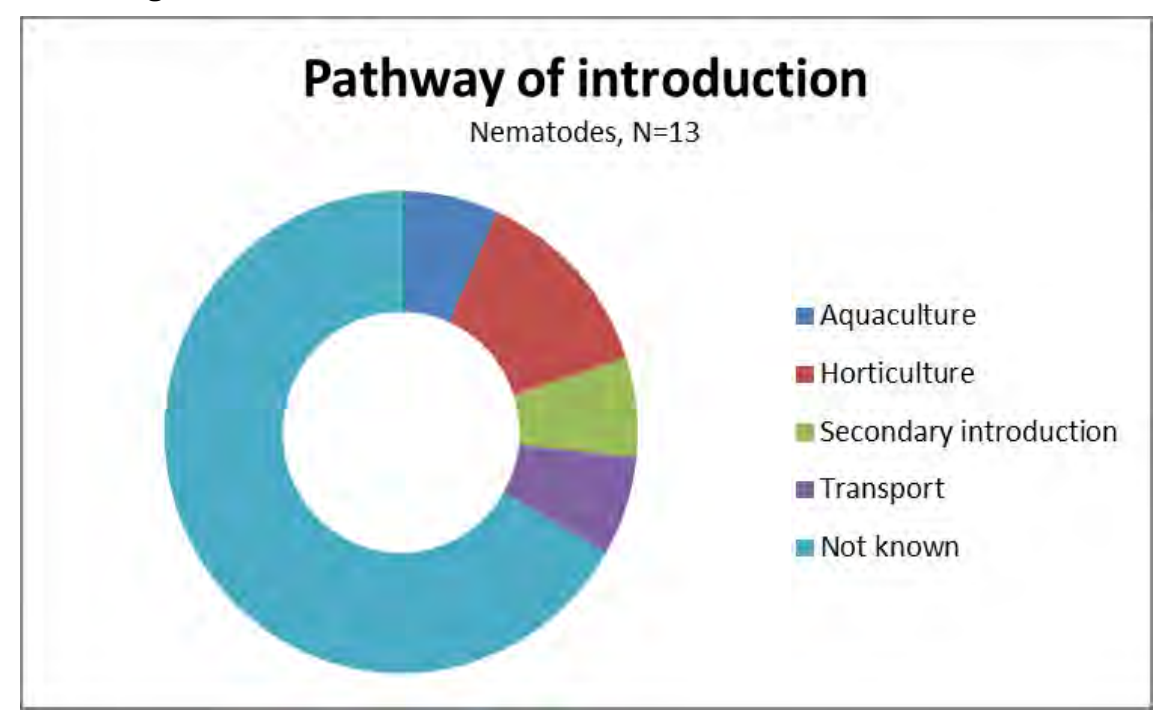


Most introductions are unintentional $(\mathrm{N}=13)$, while a few are unknown $(\mathrm{N}=2)$ and 11 are in the intentional \& unintentional category.

\section{Other chordates}

There are currently identified only one non-native species of other chordates in the NOBANIS database for the Nordic region. The species is Styela clava (Subphylum: Tunicata).

A total of four pathways of introduction are currently recorded for the species (see figure 35). The four pathways are registered once each and all types of introductions are registered as being unintentional.

Figure 35: Pathways of introduction for non-native species of other chordates introduced to the Nordic region

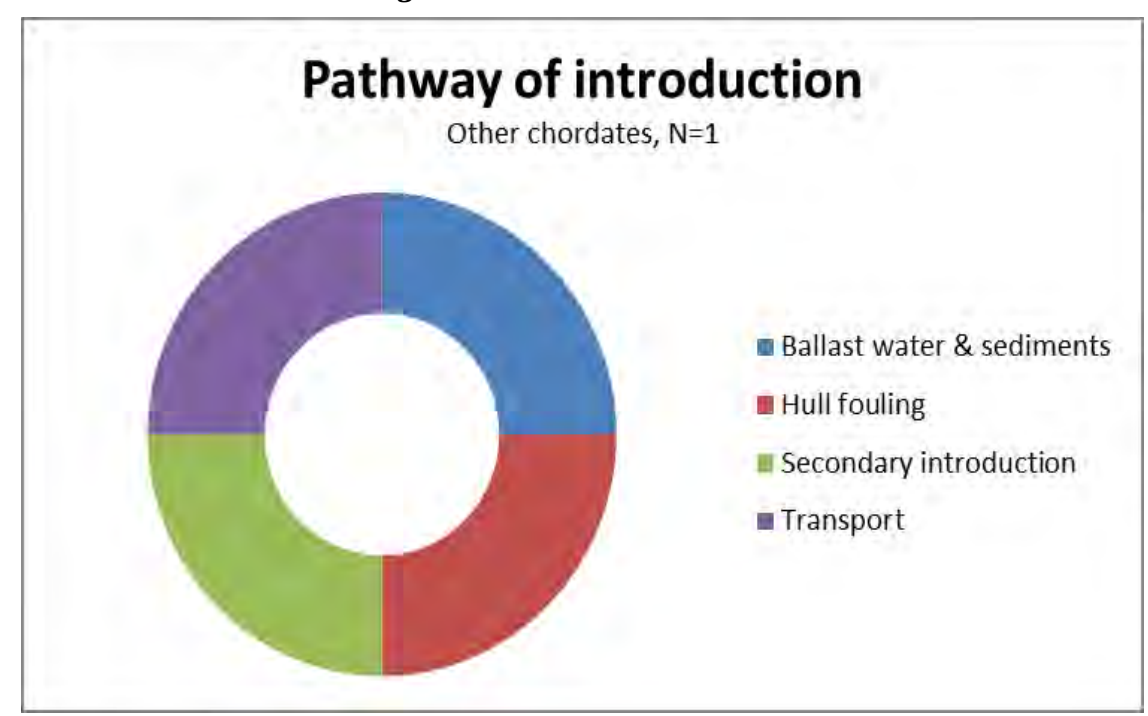

Other invertebrates

There are currently identified two non-native species of other invertebrates in the NOBANIS database for the Nordic region. The species are the bryozoans Bugula neritina and Victorella pavida (Phylum: Bryozoa).

Three pathways of introduction are currently recorded for the species in the Nordic region (see figure 36 ). The registered pathways are ballast water \& sediments $(\mathrm{N}=2)$ and hull fouling $(\mathrm{N}=2)$, and all types of introductions are registered as unintentional. 
Figure 36: Pathways of introduction for non-native species of other invertebrates introduced to the Nordic region

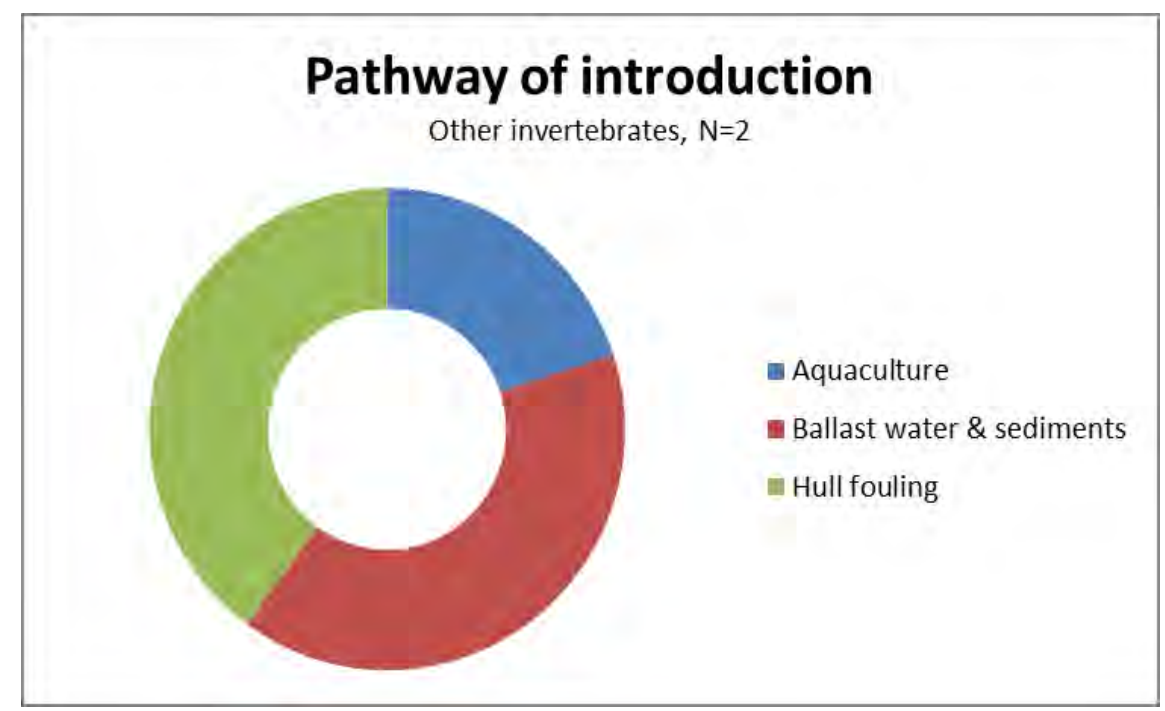

\section{Phytoplankton}

There are currently identified 17 non-native species of phytoplankton in the NOBANIS database for the Nordic region.

A total of three pathways of introduction are currently recorded for the group (see figure 37). The most frequently registered pathway of introduction is ballast water \& sediments $(\mathrm{N}=13)$.

Figure 37: Pathways of introduction for non-native phytoplankton introduced to the Nordic region

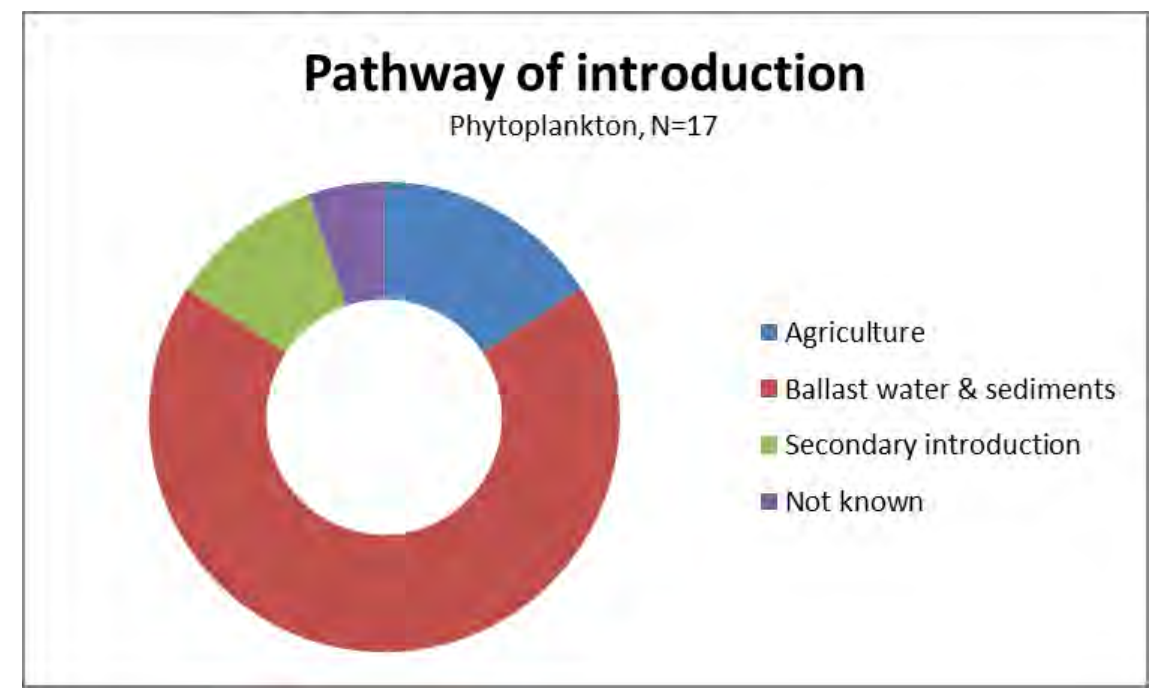


The majority of the introductions are registered as being unintentional $(\mathrm{N}=19)$, while a few are registered as being of unknown type $(\mathrm{N}=3)$.

\section{Protozoans}

There are currently identified two non-native species of protozoans in the NOBANIS database for the Nordic region. The species are the rhizaria Marteilia refringens and Plasmodiophora brassicae.

One pathway of introduction is currently recorded for these species in the Nordic region. For Marteilia refringens the pathway of introduction is aquaculture and is unintentional, while the pathway of introduction for Plasmodiophora brassicae is unidentified.

\section{Reptiles \& amphibians}

There are currently identified 11 non-native species of reptiles \& amphibians in the NOBANIS database for the Nordic region.

A total of 6 pathways of introduction are currently recorded for the group (see figure 38). The most frequently registered pathway of introduction is escape $(\mathrm{N}=6)$. For three species the path way of introduction is unknown.

Figure 38: Pathways of introduction for non-native reptilian \& amphibians introduced to the Nordic region

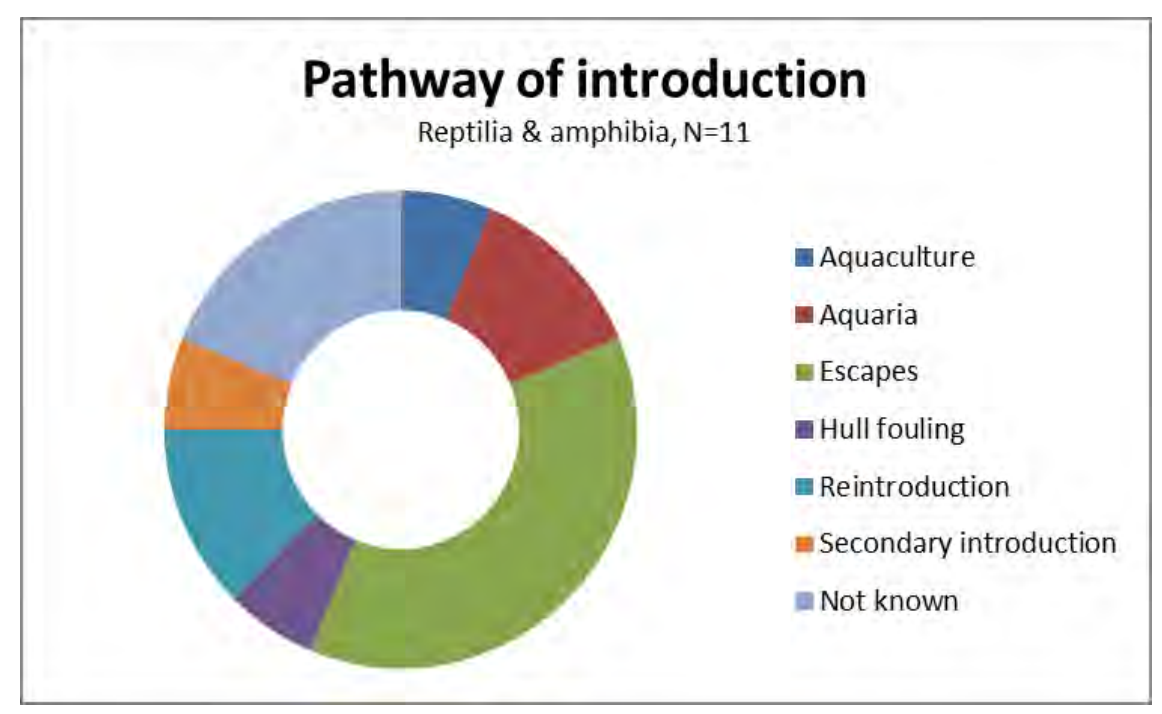

Most types of introductions are intentional ( $\mathrm{N}=8$, see figure 39) or intentional \& unintentional $(\mathrm{N}=7)$. The intentional introductions are mostly escapes $(\mathrm{N}=4)$ or reintroductions $(\mathrm{N}=2)$. 
Figure 39: Types of introduction (intentional, intentional \& unintentional or unknown) for non-native reptiles \& amphibians in the Nordic region

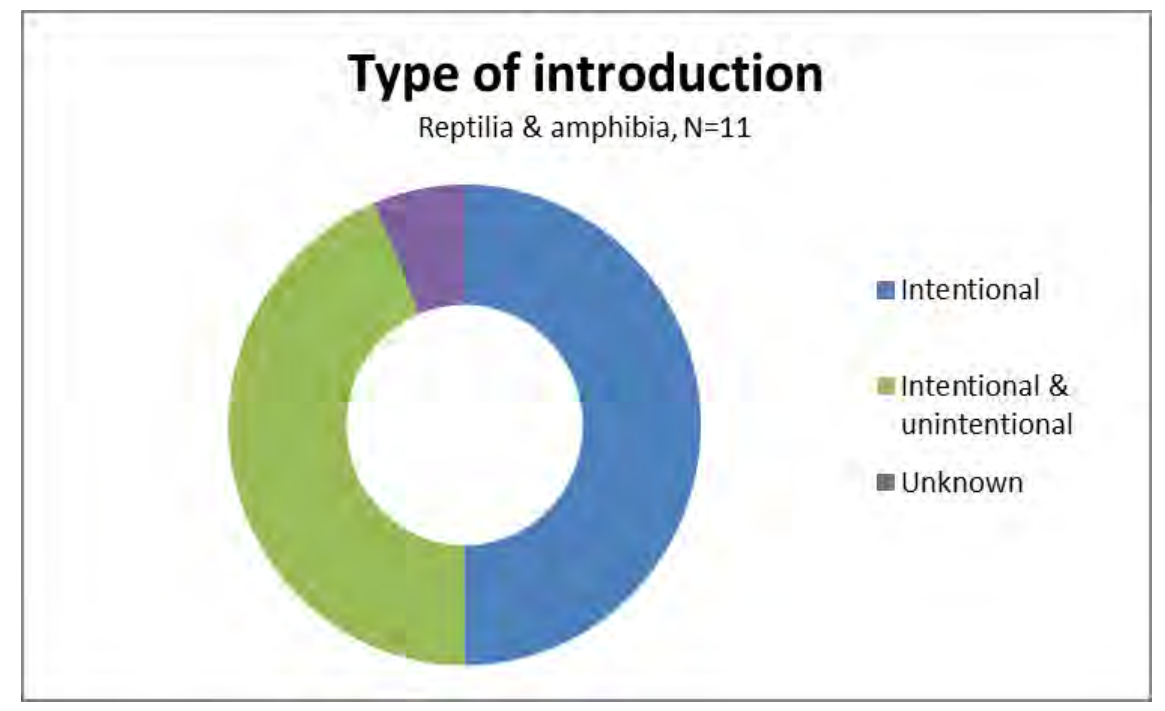

\subsubsection{Baltic region}

The pathways of introduction are shown for each group of species registered in the Baltic region. The type of introduction - intentional and/or unintentional, as well as unknown - is also presented for each taxonomic group. The introductions of both types - intentional \& unintentional may be registered with both types in one country, or as unintentional in one country and as intentional in another.

A total of 18 taxonomic groups are represented: angiosperms, annelids, arthropods, birds, bryophytes, cnidarians, coniferous plants, ferns, fish, flatworms, fungi, macroalgae, mammals, microorganisms, molluscs, nematodes, phytoplankton, and reptiles \& amphibians.

A total of 17 pathways of introduction are represented: agriculture, animal husbandry, aquaculture, aquaria, ballast water \& sediments, biological control, escapes, fisheries, forestry, horticulture, hull fouling, hunting, landscaping, medicinal, ornamental, secondary introduction and transport. Each species may have more than one pathway of introduction.

\section{Angiosperms}

There are currently identified 1,069 non-native species of angiosperms in the NOBANIS database for the Baltic region.

A total of 11 pathways of introduction are currently recorded for the group (see figure 40 ). The most frequently registered pathway is horticulture $(\mathrm{N}=535)$, followed by agriculture $(\mathrm{N}=326)$ and transport $(\mathrm{N}=189)$. For 158 species the pathway of introduction is unidentified. 
Figure 40: Pathways of introduction for non-native angiosperms introduced to the Baltic region

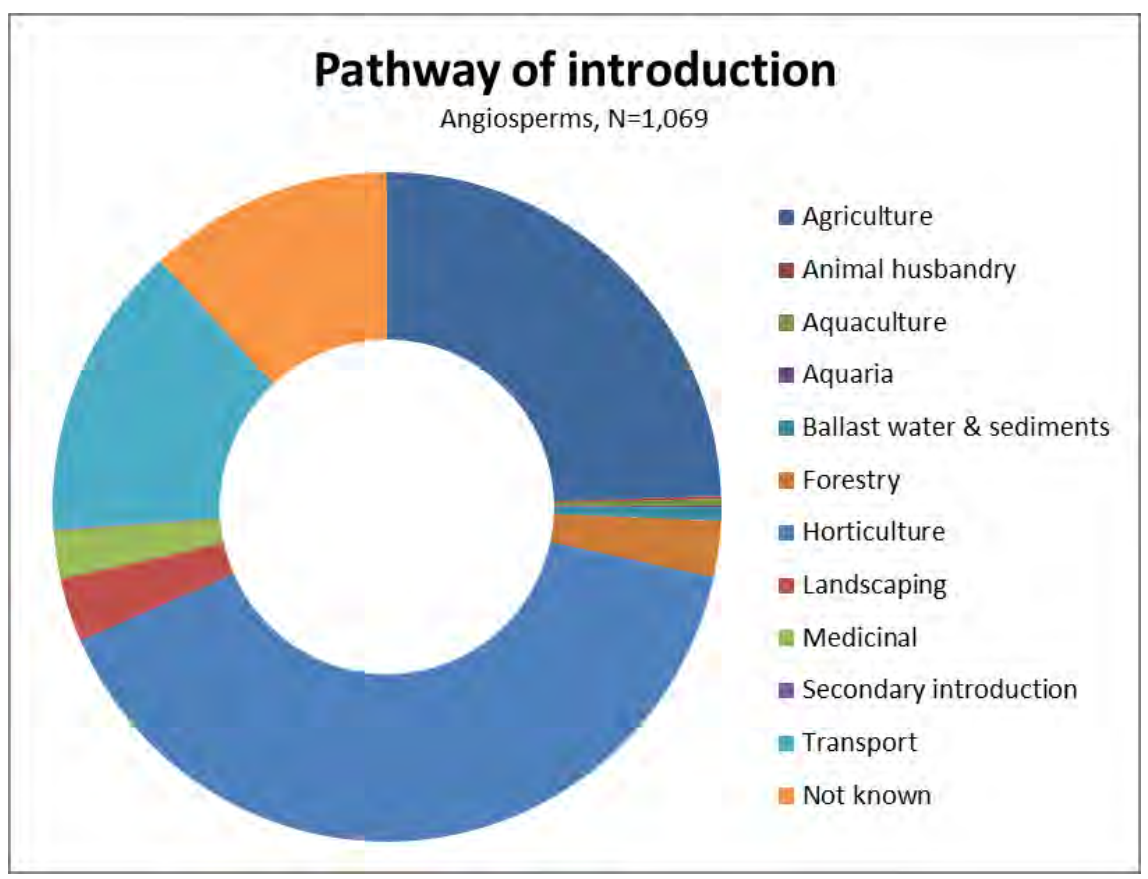

For the majority of species introduced by horticulture, the introduction is intentional, while species introduced by agriculture and transport mostly are unintentionally introduced. An overview of the distribution of introductions is shown in figure 41.

Figure 41: Types of introduction (intentional, unintentional, both or unknown) for alien species of angiosperms in the Baltic region

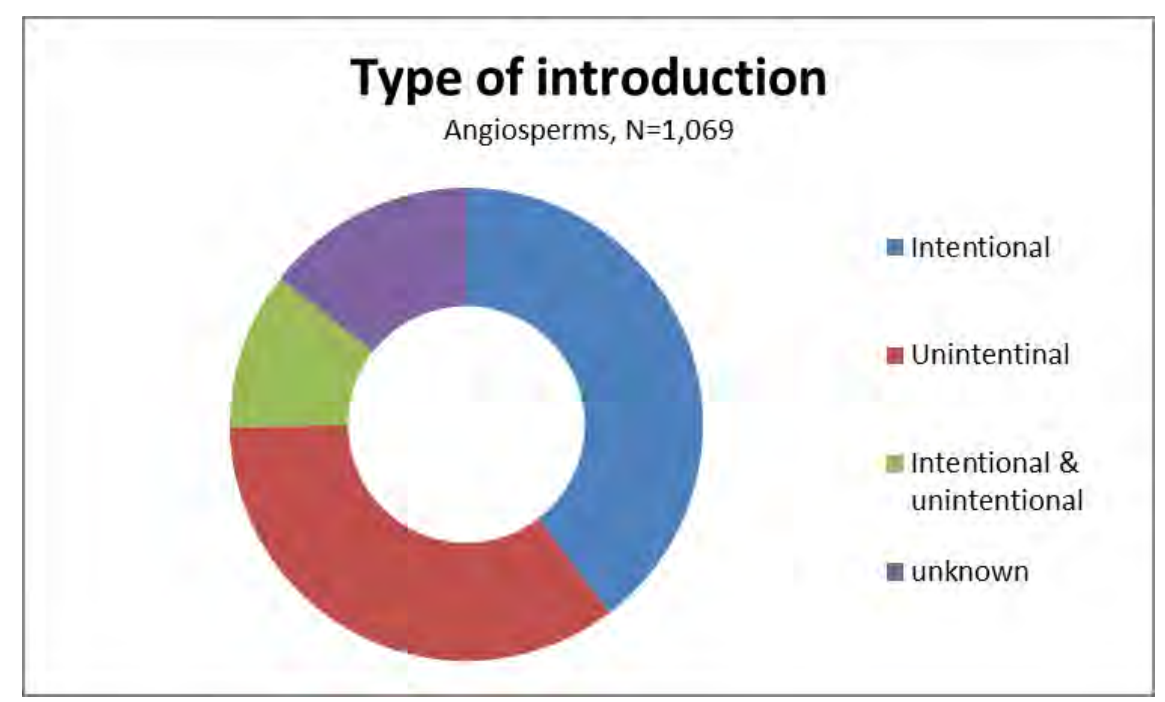




\section{Annelids}

There are currently identified 10 non-native species of annelids in the NOBANIS database for the Baltic region.

Two pathways of introduction are currently recorded for the group (see figure 42), and the most frequently registered pathway of introduction is ballast water \& sediments $(\mathrm{N}=8)$. All types of introductions are registered as being unintentional. For only one species the pathway of introduction is unidentified.

Figur 42: Pathways of introduction for non-native annelids introduced to the Baltic region

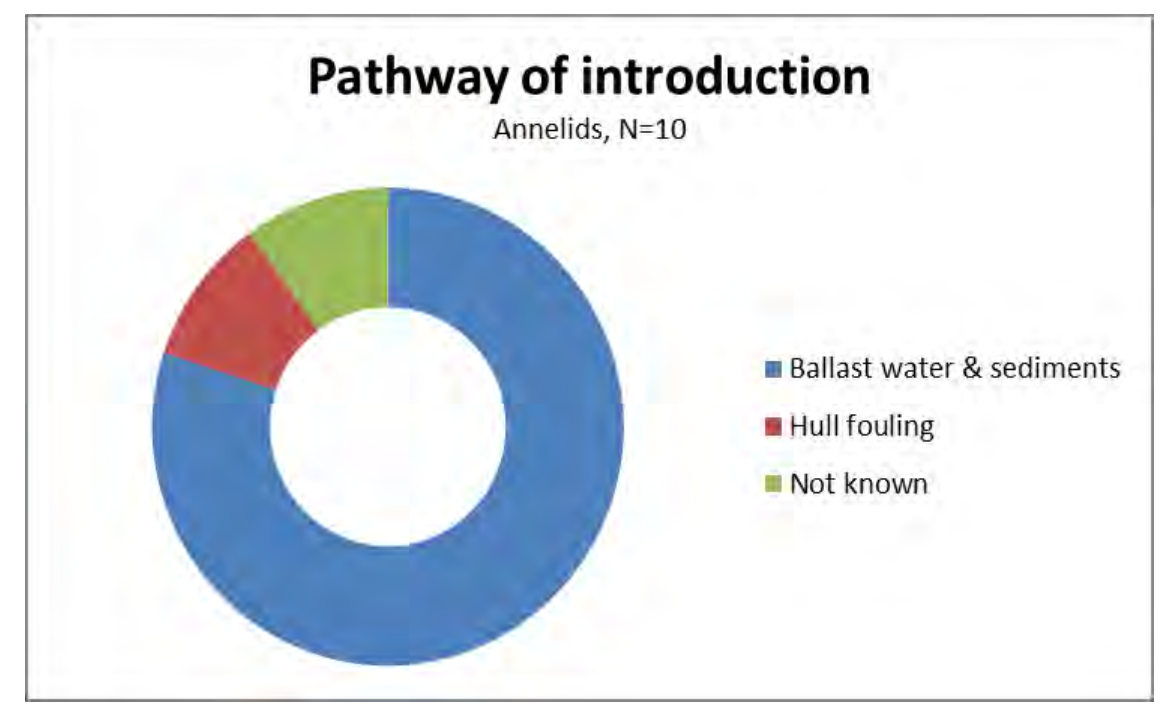

\section{Arthropods}

There are presently identified 164 non-native species of arthropods in the NOBANIS database for the Baltic region.

A total of 10 pathways of introduction are currently recorded for the group (See figure 43). The main pathway of introduction is aquaculture $(\mathrm{N}=13)$, but for the majority of the species $(76 \%)$ the pathway of introduction is unidentified $(\mathrm{N}=125)$. 
Figure 43: Pathways of introduction for non-native arthropods introduced to the Baltic region

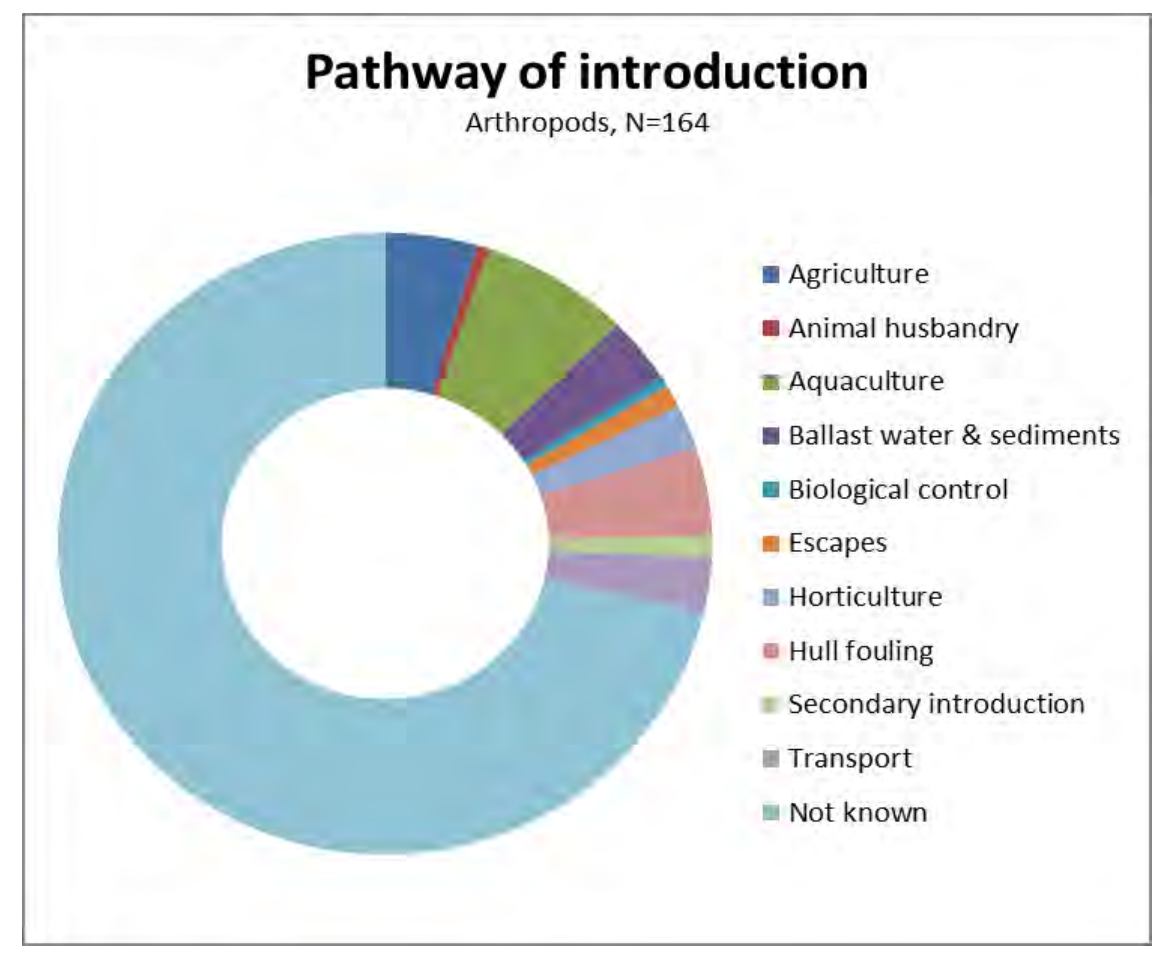

60 of the introductions are intentional, 54 are unintentional and for 56 species the type of introduction is unknown (see figure 44).

Figure 44: Types of introduction (intentional, unintentional, both or unknown) for alien species of arthropods in the Baltic region

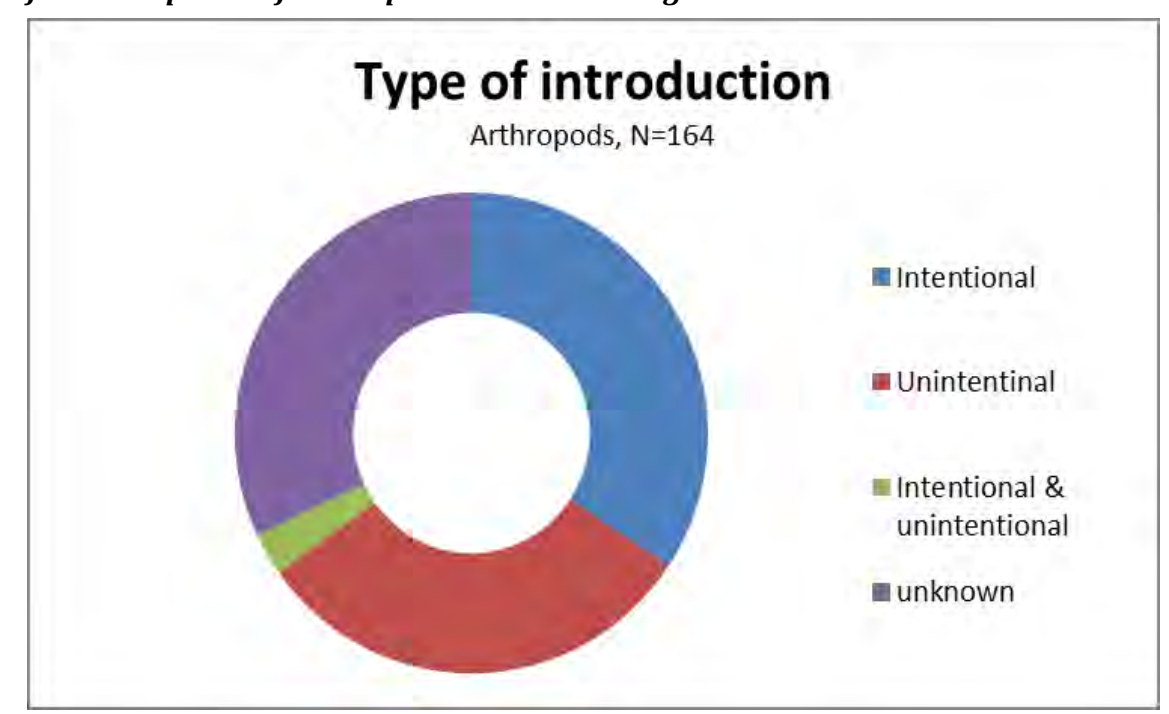




\section{Birds}

There are presently identified 19 non-native species of birds in the NOBANIS database for the Baltic region.

A total of four pathways of introduction are currently recorded for the group (see figure 45), and the main pathway of introduction is escapes $(\mathrm{N}=7)$. For 11 species the pathway of introduction is unidentified.

Figure 45: Pathways of introduction for non-native birds introduced to the Baltic region

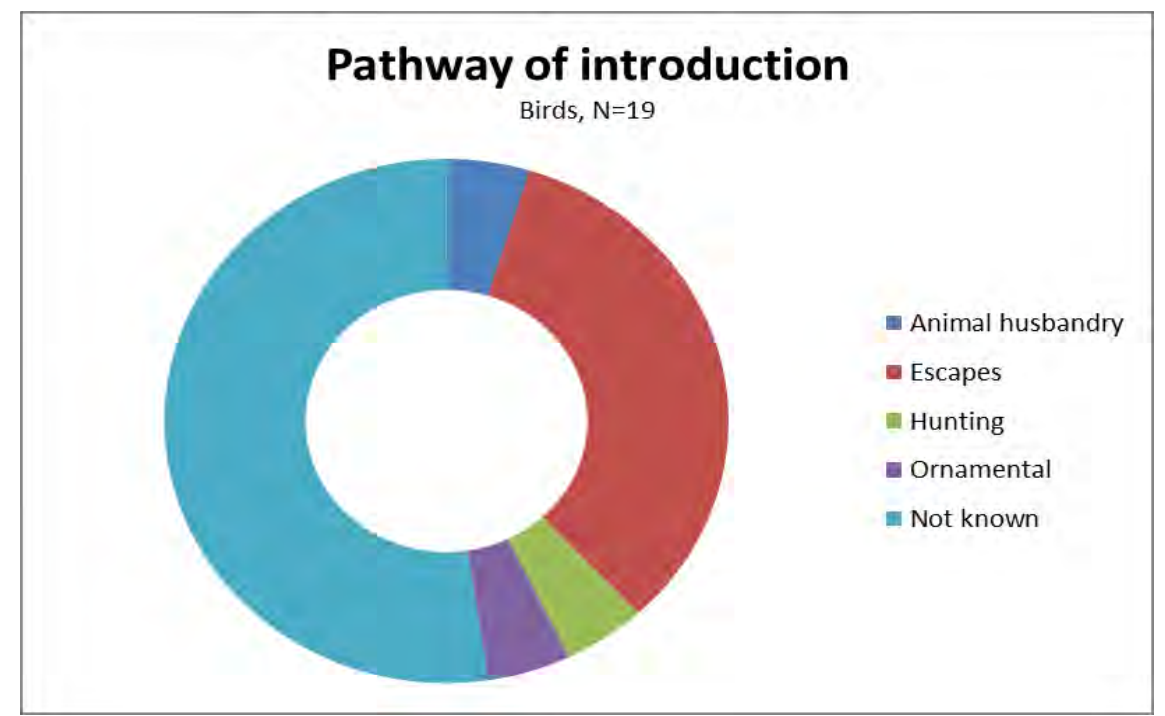

The majority of the introduction occured unintentionally $(\mathrm{N}=9$, see figure 46). 
Figure 46: Types of introduction (intentional, unintentional, both or unknown) for alien species birds in the Baltic region

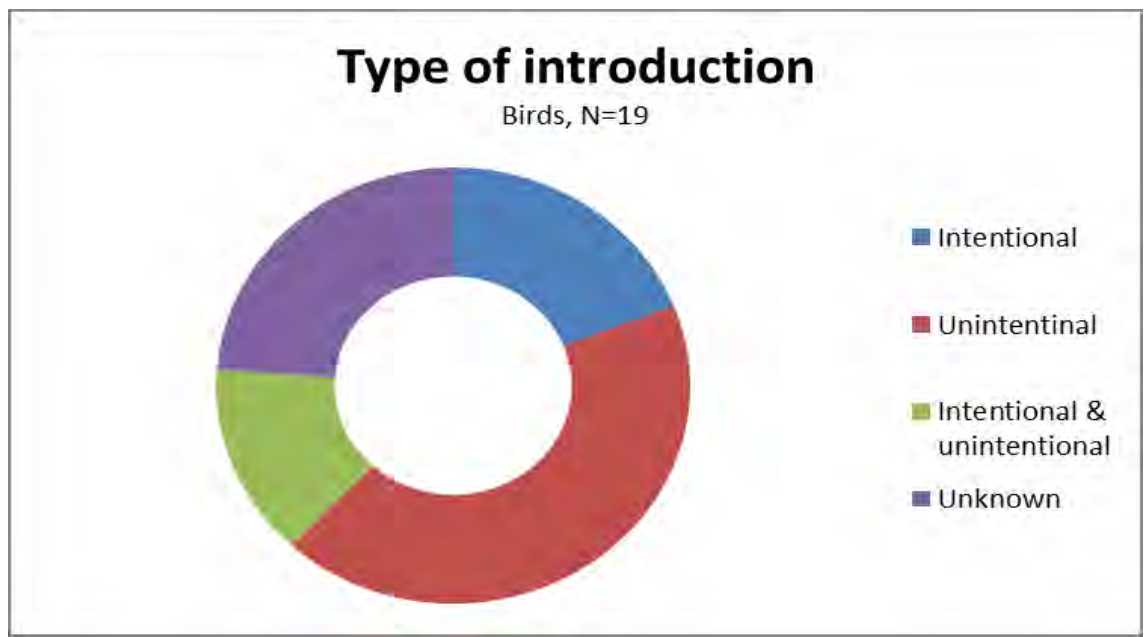

\section{Bryophytes}

There are presently identified only one non-native species of bryophytes in the NOBANIS database for the Baltic region. The species Campylopus introflexus is registered as alien in Estonia.

The introduction is categorised as unintentional but the pathway of introduction is unknown.

\section{Cnidarians}

There are presently identified four non-native species of cnidarians in the NOBANIS database for the Baltic region.

A total of four pathways of introduction are currently recorded for the group (see figure 47), and all introductions are registered as being unintentional. 
Figure 47: Pathways of introduction for non-native cnidarians introduced to the Baltic region

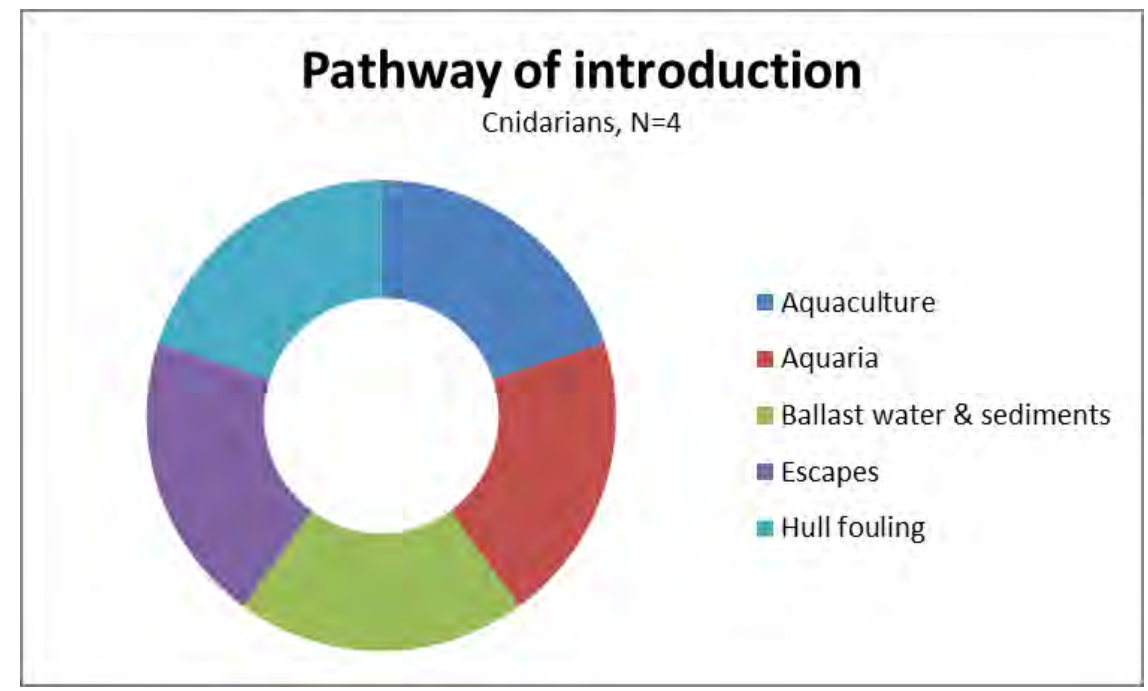

The analysis have not shown any main pathways of introduction, but that the introductions are unintentional and by many different pathways.

\section{Coniferous plants}

There are presently identified 13 non-native species of coniferous plants in the NOBANIS database for the Baltic region.

A total of three pathways of introduction are currently recorded for the group (see figure 48). The main pathway of introduction is horticulture $(\mathrm{N}=11)$ and all introduction are categorised as intentional. 
Figure 48: Pathways of introduction for non-native species of coniferous plants introduced to the Baltic region

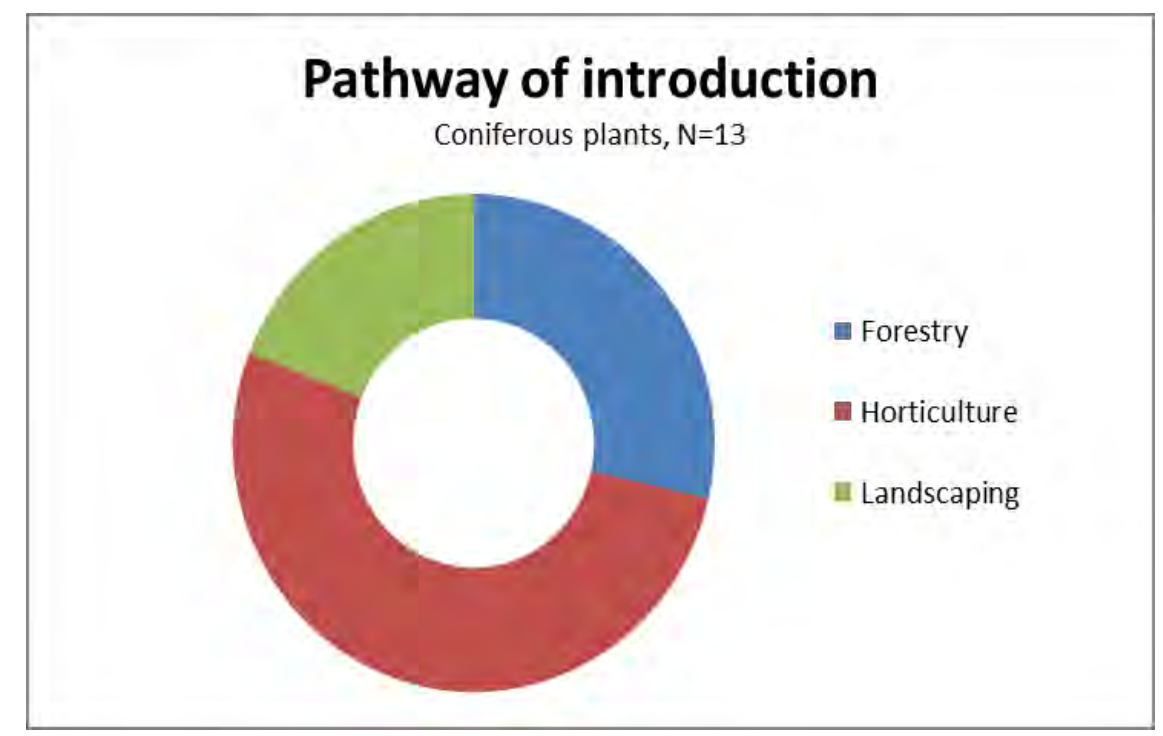

Ferns

There are presently identified one non-native species of ferns in the NOBANIS database for the Baltic region. The species Azolla filiculoides is registered as alien in Lithuania, and has been introduced intentional by horticulture.

\section{Fish}

There are presently identified 34 non-native species of fish in the NOBANIS database for the Baltic region.

A total of four pathways of introduction are currently recorded for the group (see figure 49), and the main pathway of introduction is aquaculture $(\mathrm{N}=28)$. For 6 species the pathway of introduction is unidentified. 
Figure 49: Pathways of introduction for non-native species of fish introduced to the Baltic region

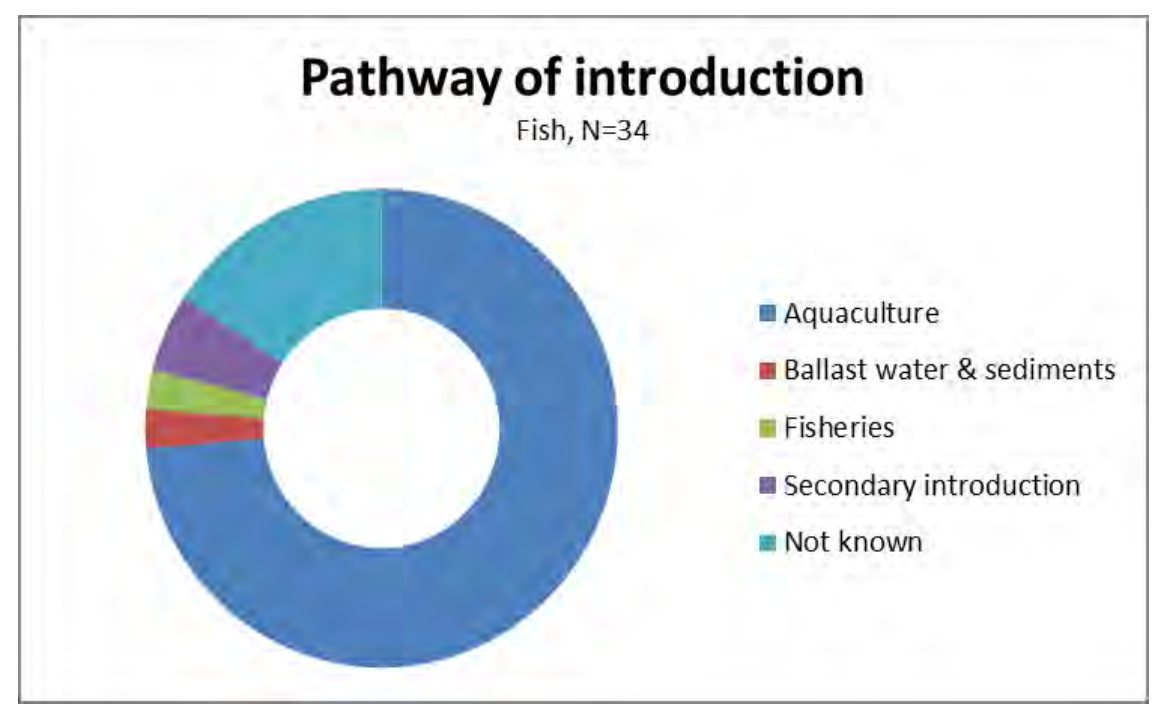

The majority of the introductions of alien species of fish in the region are intentional (see figure 50).

Figure 50: Types of introduction (intentional, unintentional or both) for alien species of fish in the Baltic region

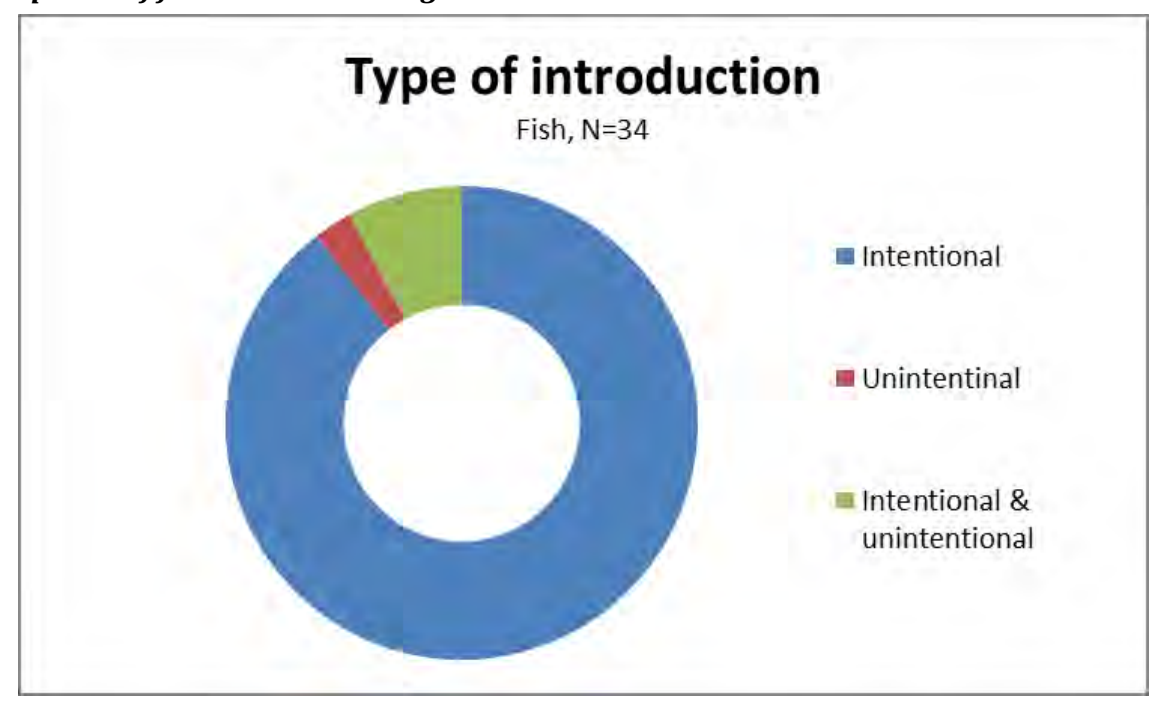

\section{Flatworms}

There are presently identified one non-native species of flatworm in the NOBANIS database for the Baltic region. The species is Valipora campylancristrota, which is registered as alien in Estonia and is introduced unintentionally by aquaculture. 


\section{Fungi}

There are presently identified 10 non-native species of fungi in the NOBANIS database for the Baltic region.

A total of three pathways of introduction are currently recorded for the group (see figure 51) and all types of introductions are registered as unintentional. For 6 species the pathway of introduction is unidentified.

Figure 51: Pathways of introduction for non-native fungi introduced to the Baltic region

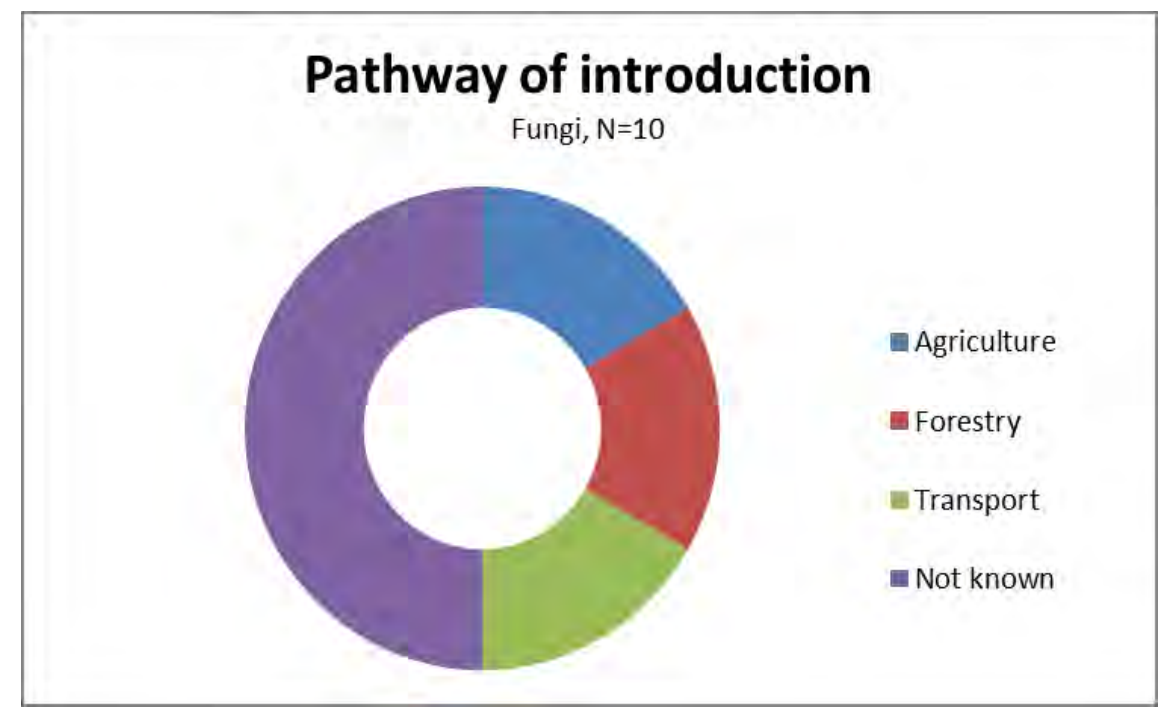

The analysis shows that the pathways of introduction for half of the introductions are unknown $(\mathrm{N}=6)$.

The introductions with known pathways are unintentional $(\mathrm{N}=6)$, while the introductions with unknown pathway have an unknown type of introduction $(\mathrm{N}=6)$.

\section{Macroalgae}

There are presently identified one non-native species of macroalgae in the NOBANIS database for the Baltic region. Chara connivens is registered as an alien species in Lithuania, and is introduced unintentionally by hull fouling.

\section{Mammals}

There are presently identified 6 non-native species of mammals in the NOBANIS database for the Baltic region

A total of four pathways of introduction are currently recorded for the group (see figure 52) and the most frequently registered pathway of introduction is escapes $(\mathrm{N}=3)$. For two species the pathway of introduction is unidentified. 
Figure 52: Pathways of introduction for non-native species of mammals introduced to the Baltic region

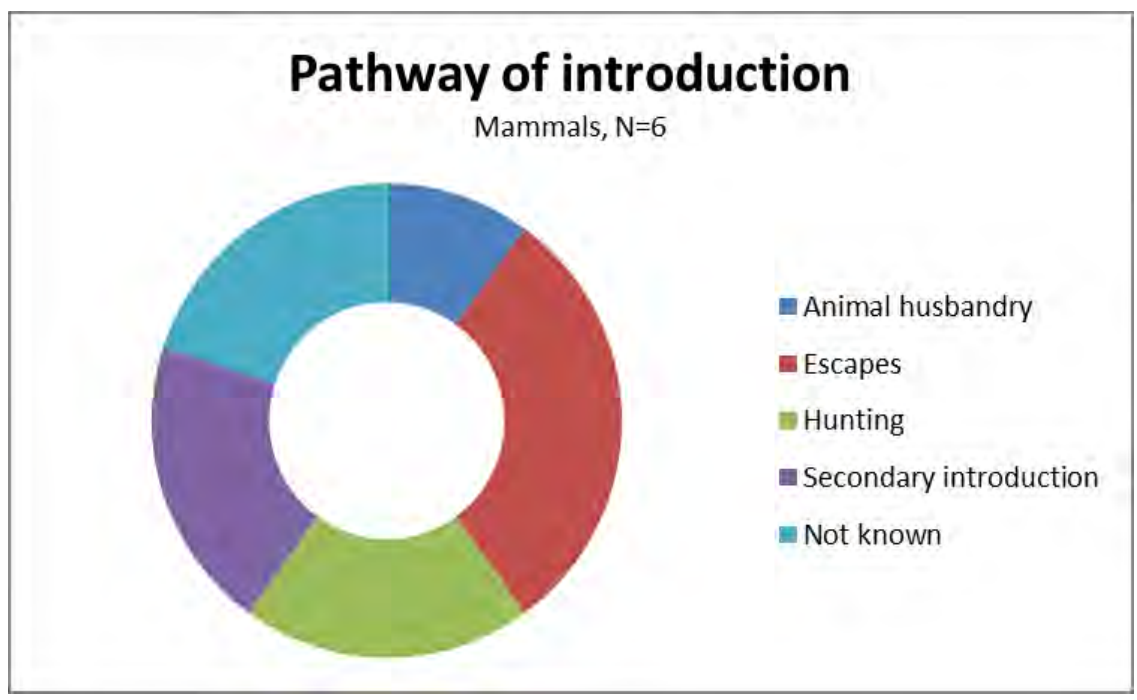

All introductions of alien species of mammals in the region are either intentional $(\mathrm{N}=1)$ or registered as intentional \& unintentional $(\mathrm{N}=9$, see figure 53).

Figure 53: Types of introduction (intentional or intentional \& unintentional) for alien species of mammals in the Baltic region

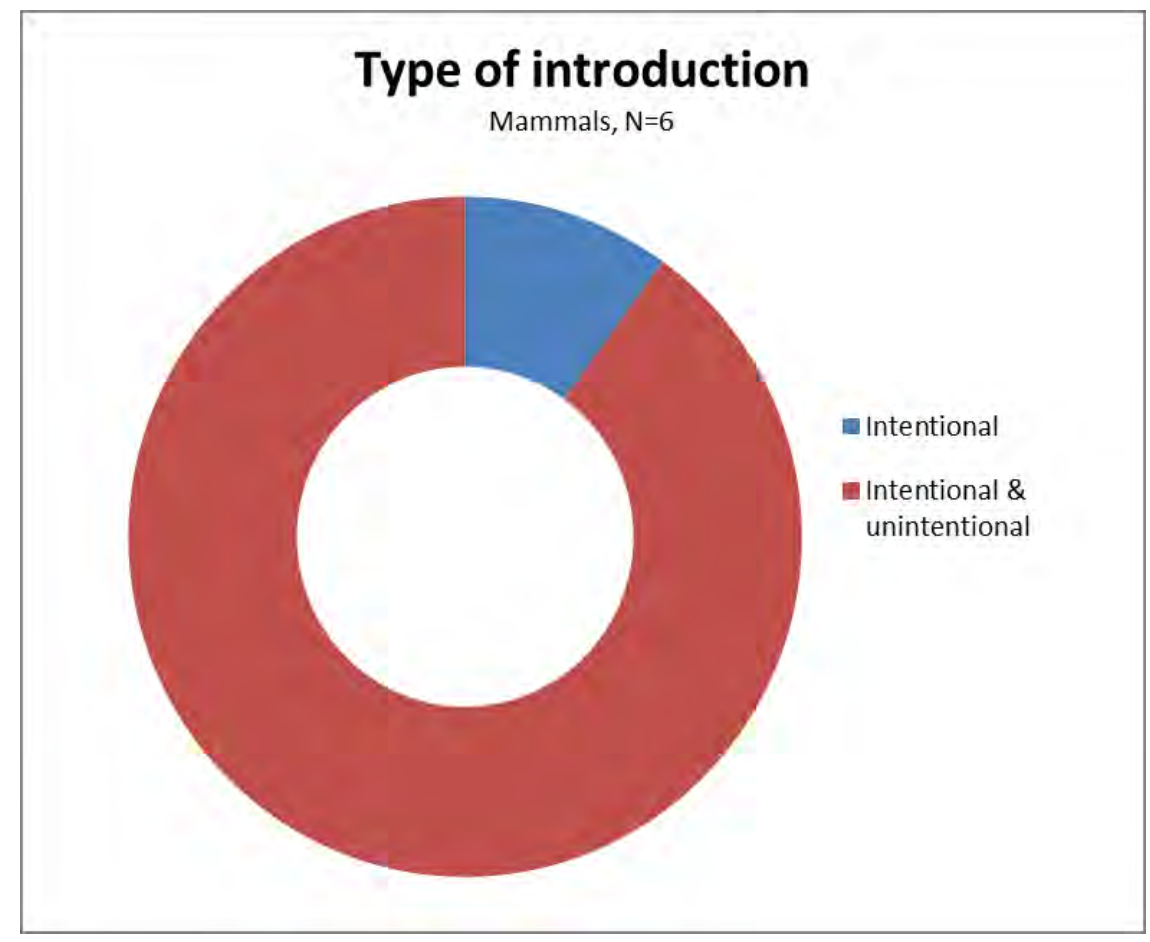




\section{Microorganisms}

There are presently identified one non-native species of microorganisms in the NOBANIS database for the Baltic region. Phytophthora ramorum is registered as an alien species in Estonia. The pathway of introduction is unknown and the introduction is registered as unintentional.

\section{Molluscs}

There are presently identified 9 non-native species of molluscs in the NOBANIS database for the Baltic region.

A total of four pathways of introduction are currently recorded for the group (see figure 54) and the most frequently registered pathway of introduction is hull fouling $(\mathrm{N}=3)$. For three species the pathway of introduction is unidentified.

Figure 54: Pathways of introduction for non-native species of molluscs introduced to the Baltic region

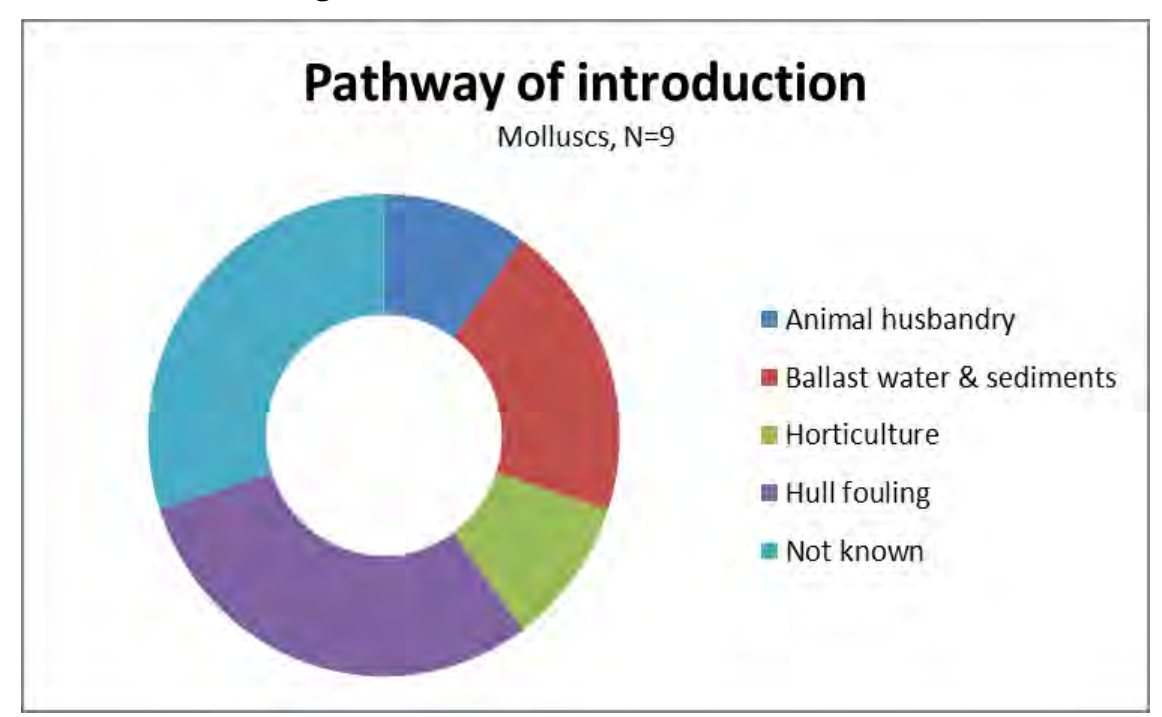

The majority of the introductions of alien species of molluscs in the region are unintentional $(\mathrm{N}=9$, see figure 55$)$, and for a few species the type of introduction is unknown $(\mathrm{N}=3)$. 
Figure 55: Types of introduction (intentional, unintentional or both) for alien species of molluscs in the Baltic region

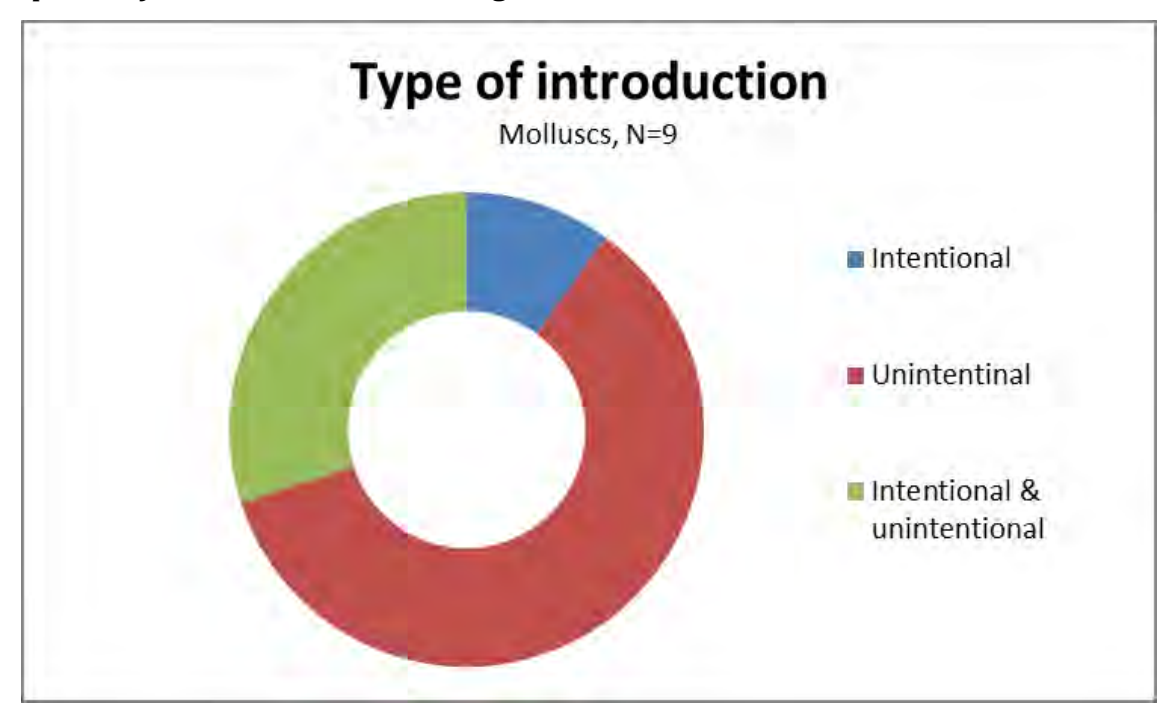

\section{Nematodes}

There are presently identified 8 non-native species of nematodes in the NOBANIS database for the Baltic region.

Aquaculture is the only pathway of introduction recorded for the group ( $\mathrm{N}=1$, see figure 56 ), but for the majority of the species the pathway of introduction is unknown $(\mathrm{N}=7)$. All of the introductions are registered as unintentional.

Figure 56: Pathways of introduction for non-native species of nematodes introduced to the Baltic region

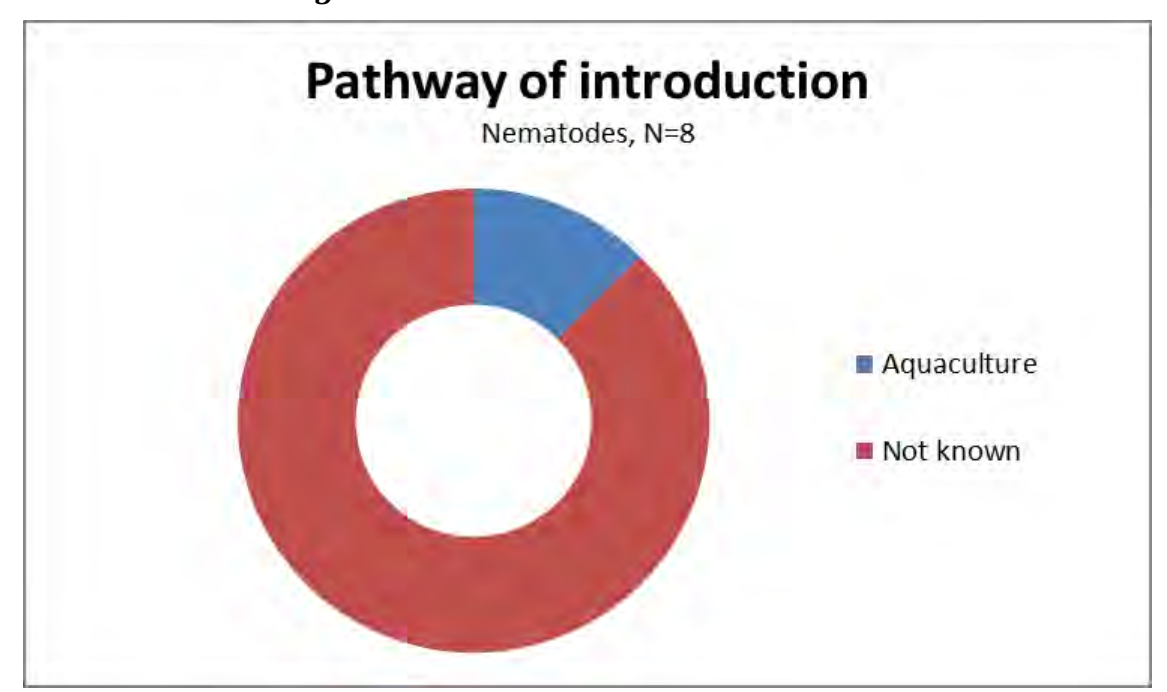




\section{Phytoplankton}

There are presently identified one non-native species of phytoplankton in the NOBANIS database for the Baltic region. Prorocentrum minimum is registered as an alien species in Estonia and Lithuania, and the introductions are registered as unintentional by ballast water \& sediments $(\mathrm{N}=1)$ and hull fouling $(\mathrm{N}=1)$.

\section{Reptiles and amphibians}

There are presently identified two non-native species of reptiles and amphibians in the NOBANIS database for the Baltic region. The species Rana ridibunda and Trachemys scripta are both registered as alien species in Estonia, and are introduced intentionally \& unintentionally by aquaria $(\mathrm{N}=2)$.

\subsubsection{Islands of the North Atlantic Ocean}

The pathways of introduction are shown for each group of species registered in the islands of the North Atlantic Ocean. The type of introduction - intentional and/or unintentional, as well as unknown - is also presented for each taxonomic group. The introductions of both types - intentional \& unintentional - may be registered with both types in one country, or as unintentional in one country and as intentional in another.

A total of 13 taxonomic groups are represented: angiosperms, annelids, arthropods, birds, bryophytes, coniferous plants, fish, flatworms, fungi, macroalgae, mammals, microorganism and molluscs.

A total of 14 pathways of introduction are represented: agriculture, animal husbandry, aquaculture, aquaria, ballast water \& sediments, escapes, fisheries, forestry, horticulture, hull fouling, medicinal, ornamental, secondary introduction and transport. Each species may have multiple pathways of introductions.

\section{Angiosperms}

There are presently identified 120 non-native species of angiosperms in the NOBANIS database for the islands of the North Atlantic Ocean.

A total of 7 pathways of introduction are currently recorded for the group (see figure 57) and the most frequently registered pathway of introduction is horticulture $(\mathrm{N}=36)$, followed by transport $(\mathrm{N}=17)$. For 54 introductions the pathway of introduction is unidentified. 
Figure 57: Pathways of introduction for non-native angiosperms introduced to the islands of the North Atlantic Ocean

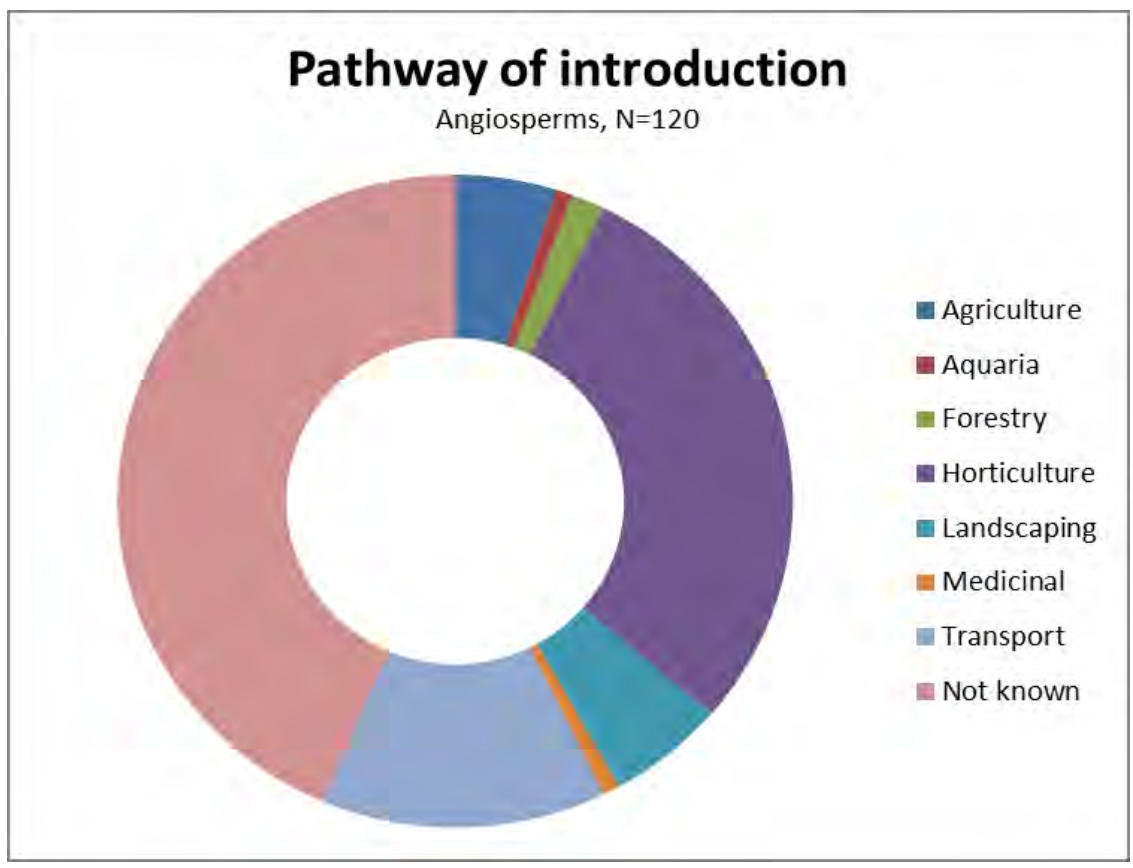

48 of the introductions are intentional (see figure 58) while 58 are unintentional. For only a few introductions $(\mathrm{N}=5)$ the type of introduction is unknown.

Figure 58: Types of introduction (intentional, unintentional, both or unknown) for alien species of angiosperms in the islands of the North Atlantic Ocean

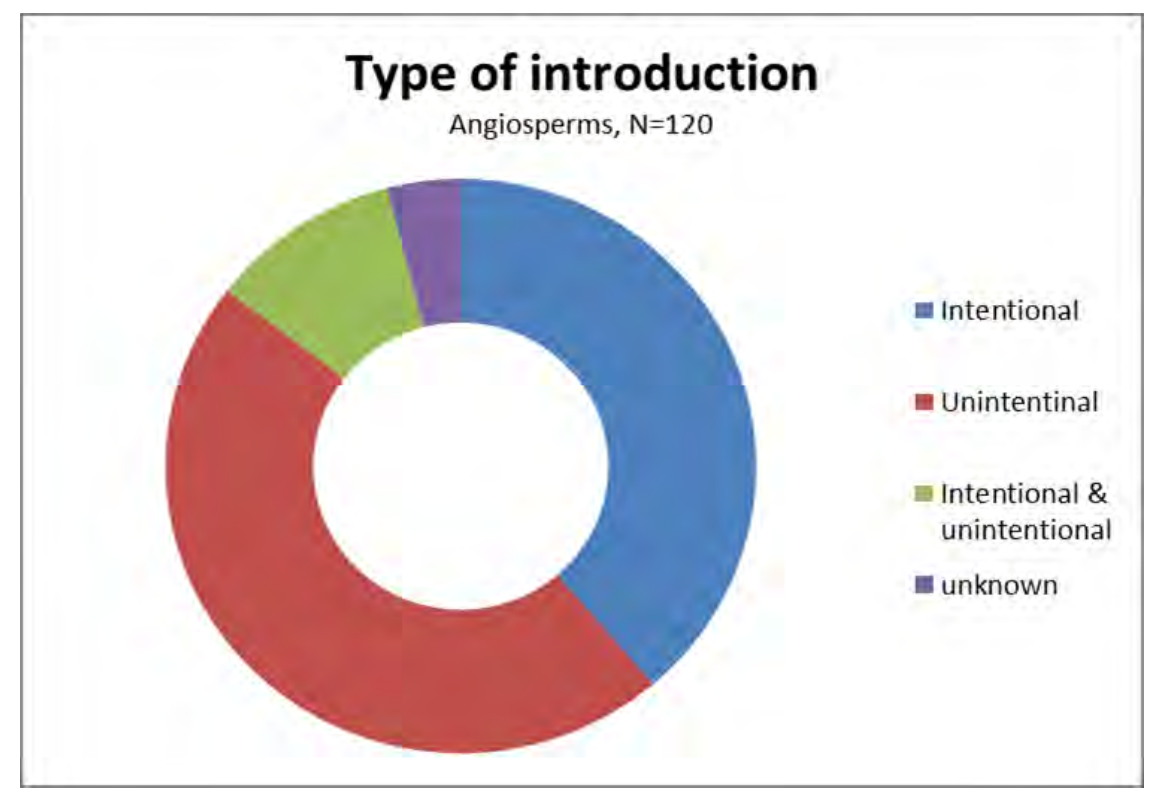




\section{Annelids}

There are presently identified 6 non-native species of annelids in the NOBANIS database for the islands of the North Atlantic Ocean.

The only pathway of introduction registered for the group is aquaculture (see figure 59), which is used in only one introduction. For the remaining introductions of annelids both the pathway and type of introduction are unknown.

Figure 59: Pathways of introduction for non-native annelids introduced to the islands of the North Atlantic Ocean

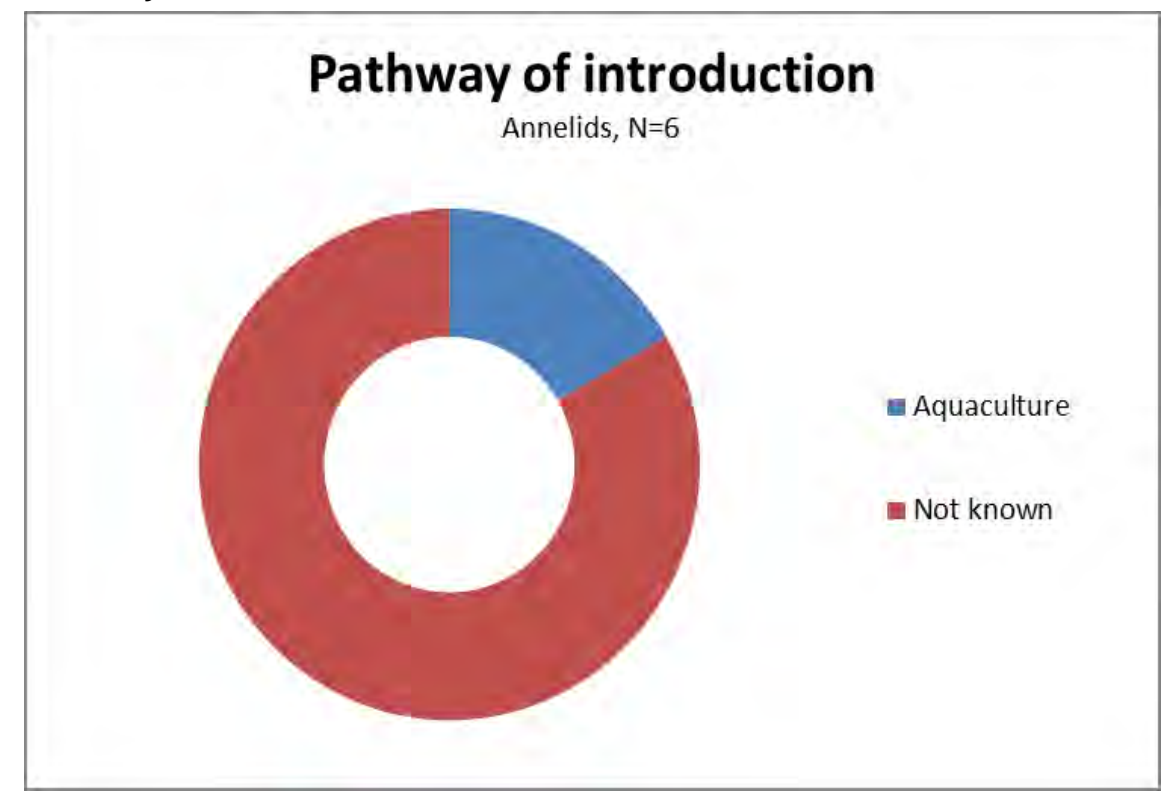




\section{Arthropods}

There are presently identified 101 non-native species of arthropods in the NOBANIS database for the islands of the North Atlantic Ocean.

A total of 5 pathways of introduction are currently recorded for the group, but for many introductions the pathways are unknown $(\mathrm{N}=64$, see figure 60). Of the 5 pathways currently recorded for the group the main pathway of introduction is horticulture $(\mathrm{N}=27)$.

Figure 60: Pathways of introduction for non-native arthropods introduced to the islands of the North Atlantic Ocean

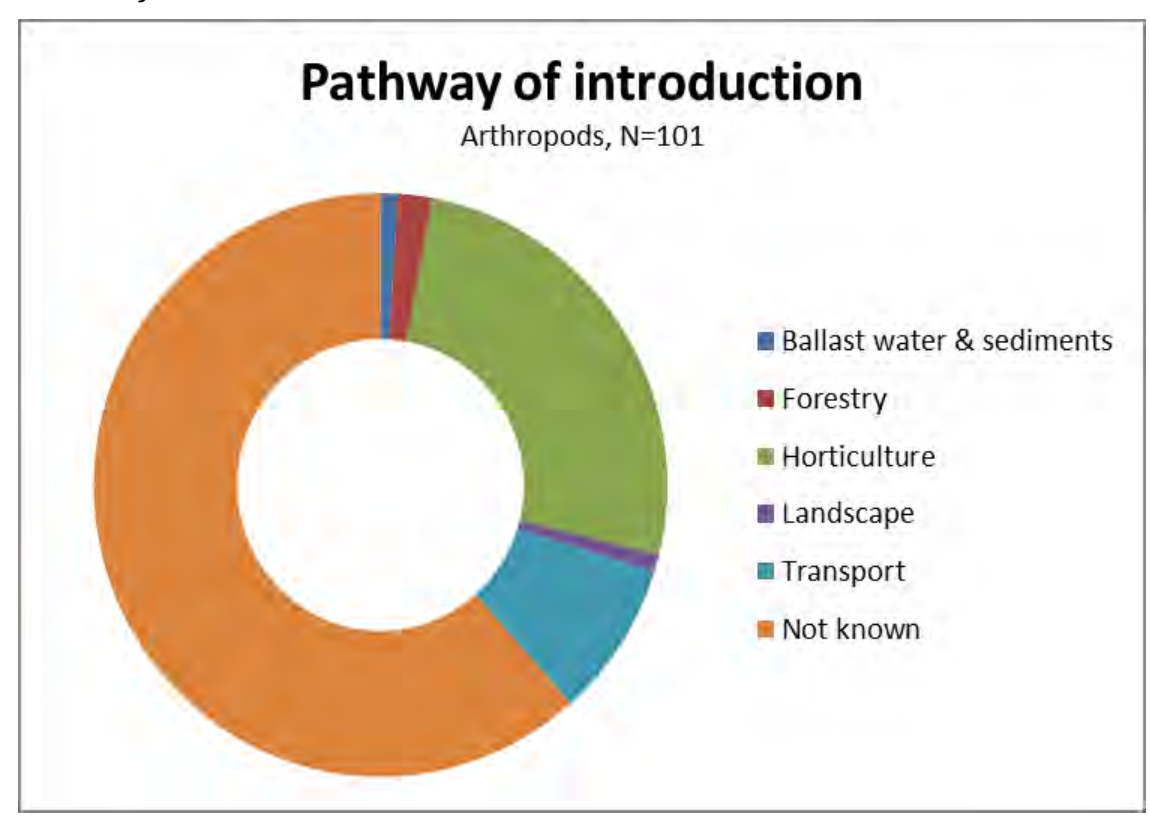

For species of arthropods registered with a pathway of introduction, the main type of introduction is unintentional, while for most introductions with no pathway registered the main type of introduction is also unknown (see figure 61). 
Figure 61: Types of introduction (unintentional or unknown) for alien species of arthropods in the islands of the North Atlantic Ocean

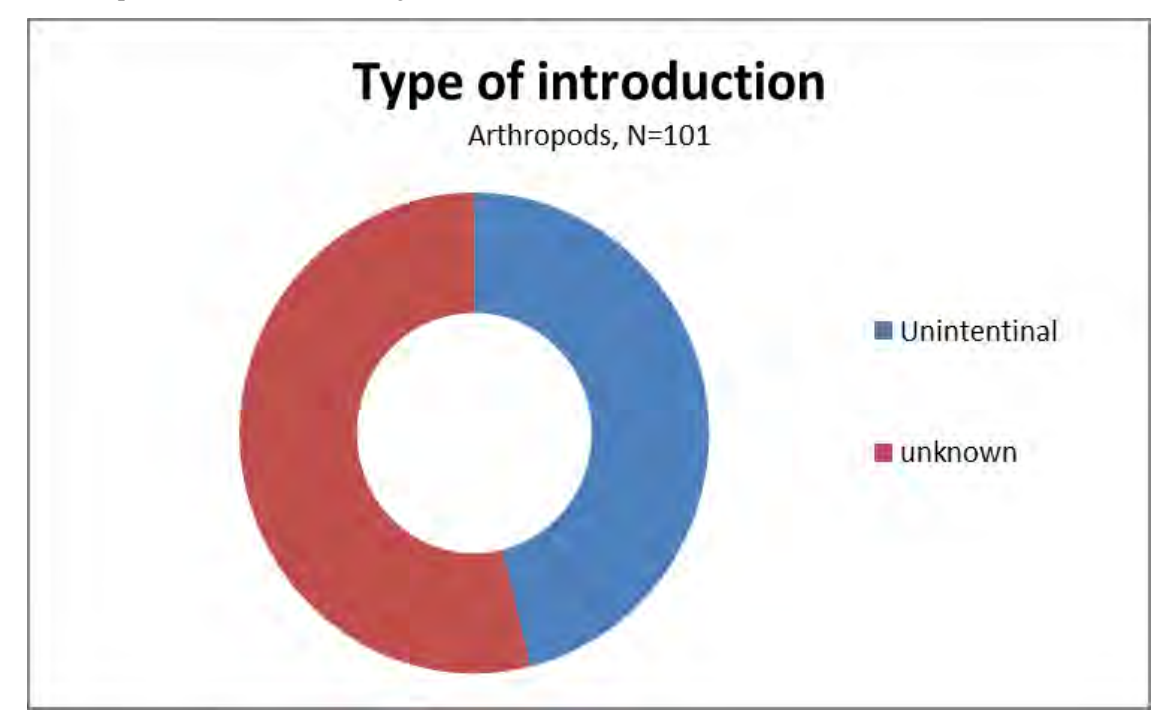

Birds

There are presently identified 8 non-native species of birds in the NOBANIS database for the islands of the North Atlantic Ocean.

A total of three pathways of introduction are currently recorded for group (see figure 62) and the main pathway of introduction is secondary introduction $(\mathrm{N}=6)$.

Figure 62: Pathways of introduction for non-native birds introduced to the islands of the North Atlantic Ocean

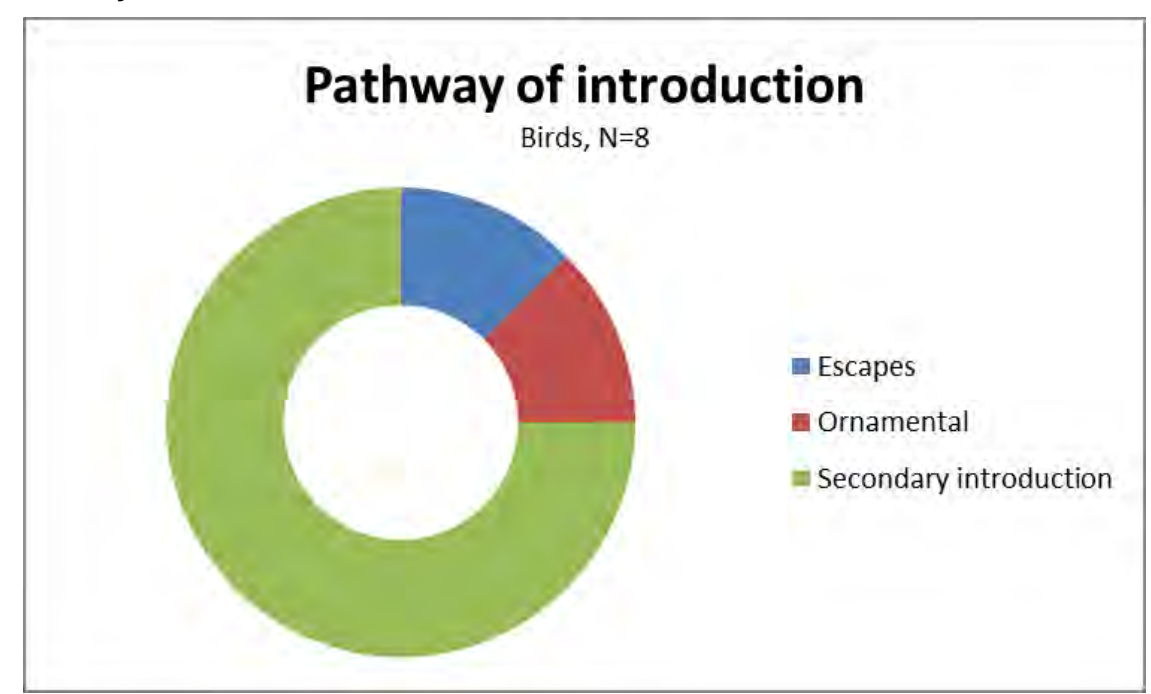


The main type of introduction is unintentional $(\mathrm{N}=6)$, and only a few introductions are registered as intentional $(\mathrm{N}=2$, see figure 63).

Figure 63: Types of introduction (intentional or unintentional) for alien species of birds in the islands of the North Atlantic Ocean

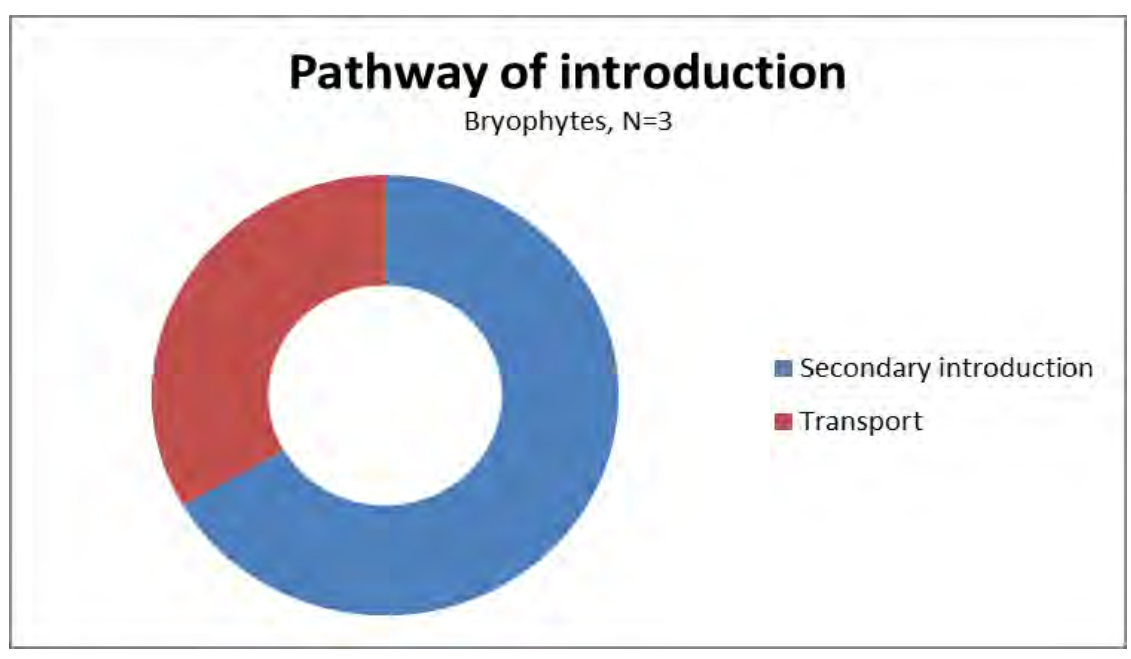

\section{Bryophytes}

There are presently identified three non-native species of bryophytes in the NOBANIS database for the islands of the North Atlantic Ocean.

Two pathways of introduction are currently recorded for the group (see figure 64), where most are introduced by secondary introduction $(\mathrm{N}=2)$. All introductions are registered as unintentional.

Figure 64: Pathways of introduction for non-native bryophytes introduced to the islands of the North Atlantic Ocean

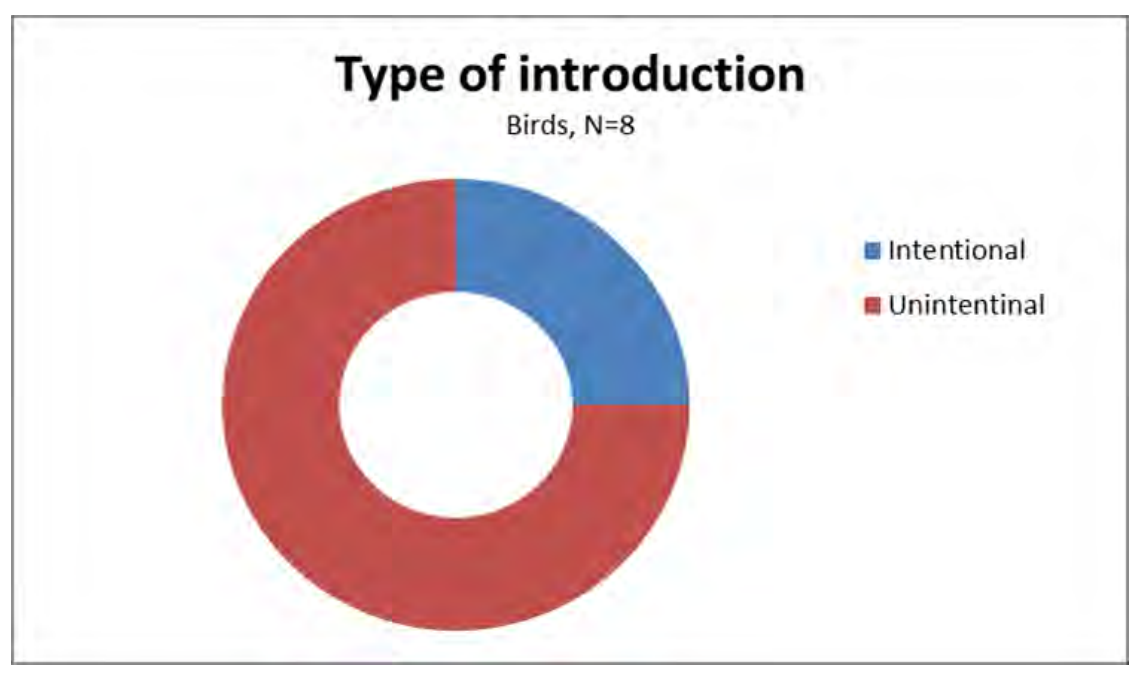




\section{Coniferous plants}

There are presently identified three non-native species of coniferous plants in the NOBANIS database for the islands of the North Atlantic Ocean.

Forestry is the only pathway of introduction currently recorded for the group, and all introductions are considered to be intentional.

\section{Fish}

There are presently identified two non-native species of fish in the NOBANIS database for the islands of the North Atlantic Ocean. Oncorhynchus mykiss was introduced intentionally by aquaculture and Oncorhynchus gorbuscha was introduced unintentionally by secondary introduction.

\section{Flatworms}

There are presently identified one non-native species of flatworm in the NOBANIS database for the islands of the North Atlantic Ocean. The species Arthurdendyus triangulates is registered as unintentionally introduced by agriculture.

\section{Fungi}

There are presently identified 10 non-native species of fungi in the NOBANIS database for the islands of the North Atlantic Ocean.

Forestry is the only pathway of introduction currently recorded for the group, and all introductions are considered to be unintentional.

\section{Macroalgae}

There are presently identified two non-native species of macroalgae (Bonnemaisonia hemifera \& Codium fragile) in the database for the islands of the North Atlantic Ocean.

The pathways of introduction are currently unknown $(\mathrm{N}=2)$, and the type of introduction is considered to be unintentional $(\mathrm{N}=2)$. 


\section{Mammals}

There are presently identified 7 non-native species of mammals in the NOBANIS database for the islands of the North Atlantic Ocean.

Four pathways of introduction are recorded for the group (see figure $65)$, and ballast water \& sediment $(\mathrm{N}=3)$ is the most frequently registered pathway, followed by escapes $(\mathrm{N}=2)$.

Figure 65: Pathways of introduction for non-native mammals introduced to the islands of the North Atlantic Ocean

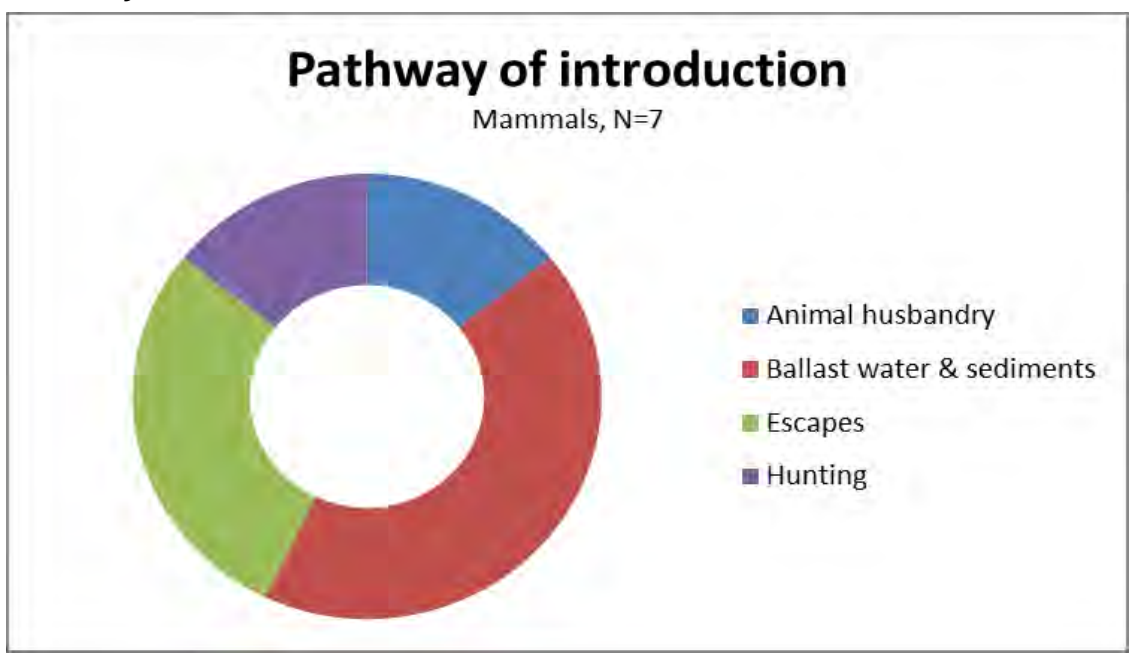

The type of introduction is either intentional $(\mathrm{N}=3)$ or unintentional $(\mathrm{N}=4$, see figure 66$)$.

Figure 66: Types of introduction (intentional or unintentional) for alien species of mammals in the islands of the North Atlantic Ocean

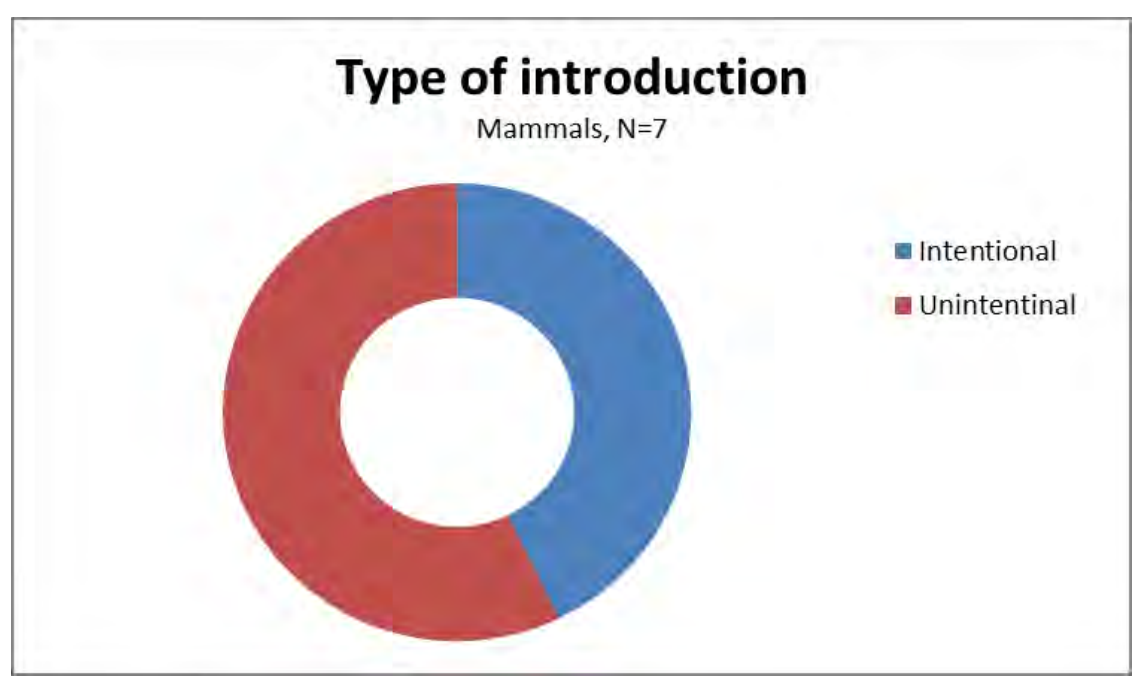




\section{Microorganisms}

There is presently identified one non-native species of microorganisms in the NOBANIS database for the islands of the North Atlantic Ocean. The species Aeromonas salmonicida is registered as being unintentionally introduced, but the pathway of introduction is unknown.

\section{Molluscs}

There are 15 non-native species of molluscs presently identified in the NOBANIS database for the islands of the North Atlantic Ocean.

A total of three pathways of introduction are currently registered for the group, but for the majority of species the pathway of introduction is unknown ( $\mathrm{N}=11$, see figure 67). Horticulture is the most frequently used pathway $(\mathrm{N}=2)$.

Figure 67: Pathways of introduction for non-native molluscs introduced to the islands of the North Atlantic Ocean

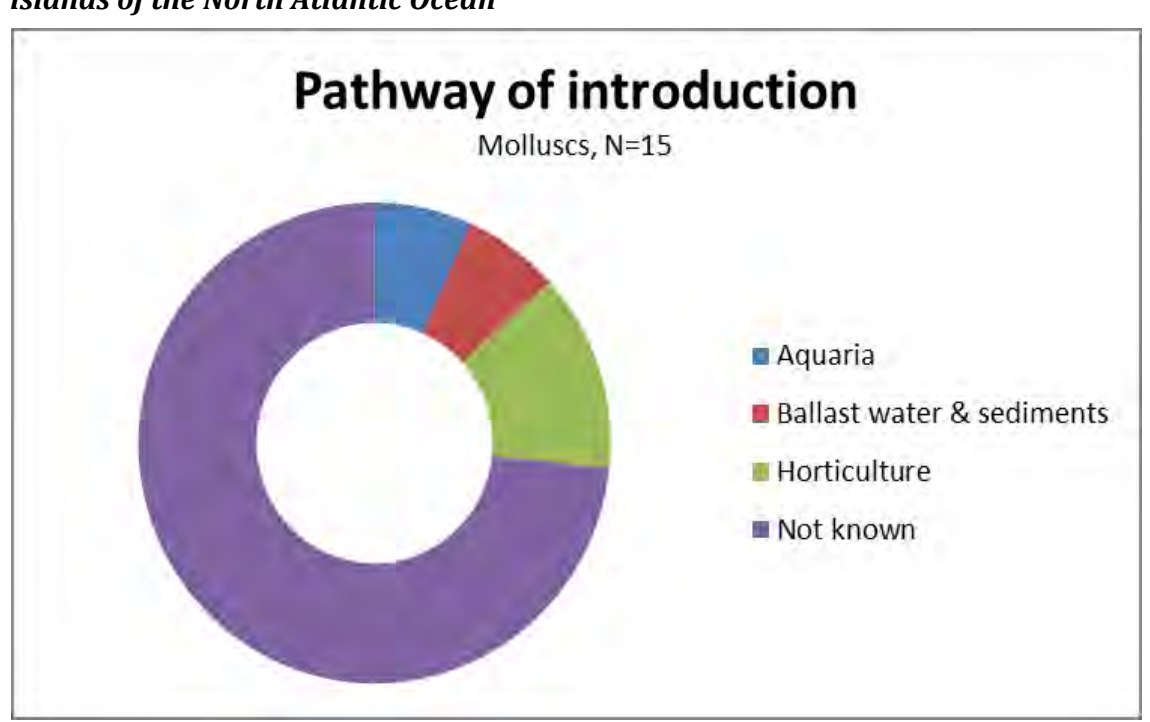


The type of introduction is unintentional $(\mathrm{N}=6)$ or unknown $(\mathrm{N}=9$, see figure 68). Especially for species with unidentified pathway of introduction the type of introduction is rarely known.

Figure 68: Types of introduction (unintentional or unknown) for alien species of molluscs in the islands of the North Atlantic Ocean

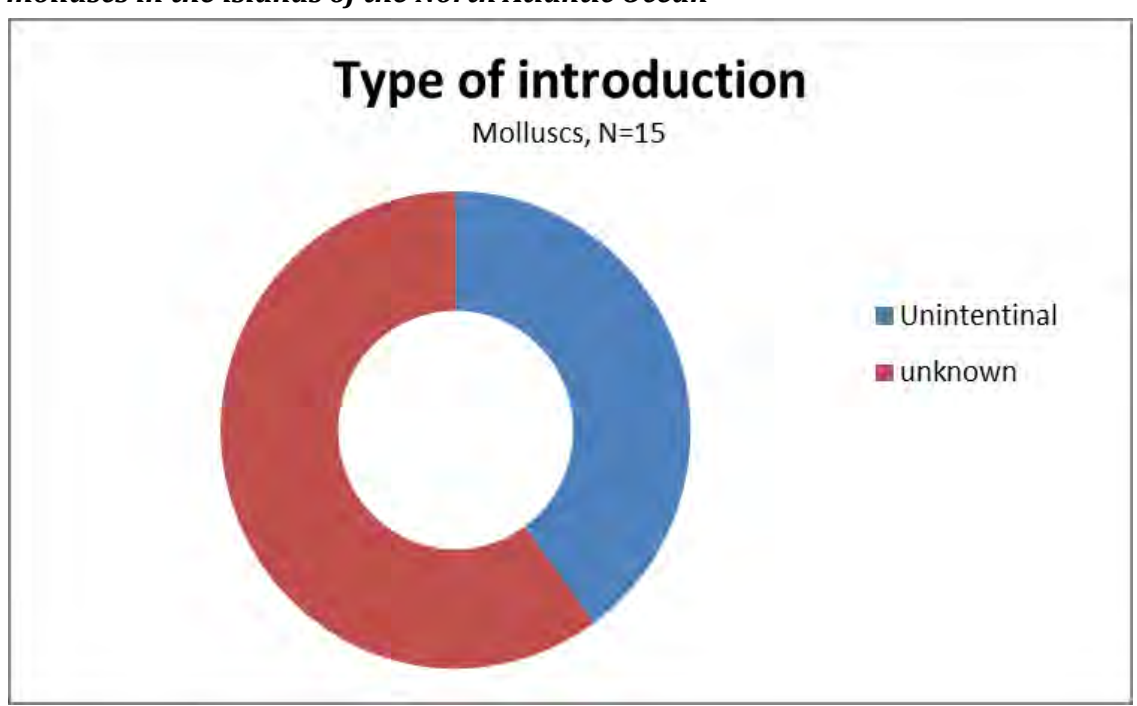

\subsubsection{Summary}

\section{Nordic region}

Based on the data from the NOBANIS database for the Nordic region, the pathway analysis shows that the main pathways of introduction vary between the different taxonomic groups.

The group with the largest number of alien species is the angiosperms, with a total of 3,272 alien species registered for the Nordic region. The most common pathway for the angiosperms is horticulture, followed by agriculture and transport.

The second largest group is the arthropods with 928 alien species registered. The main pathways of introductions for the arthropods are horticulture, transport and forestry, followed by a wide range of other pathways. The wide range of pathways reflects the diversity within the arthropods, covering both terrestrial and marine species.

The two groups, angiosperms and arthropods share horticulture as their main pathway of introduction. Horticulture is also a main pathway of introduction for other groups: coniferous plants, ferns, fungus, microorganisms and molluscs. 
For marine species, aquaculture and ballast water \& sediments are the main pathways of introduction for: annelids, cnidarians, comb jellies, fish, flatworms, macroalgae and phytoplankton. Other chordates, other invertebrates and protozoans are also registered with aquaculture and/or ballast water \& sediments as their main pathways. However there are only a few of these alien species registered.

Molluscs also have aquaculture, ballast water \& sediments and horticulture as main pathways. This reflects the high diversity within the group, covering both terrestrial and marine \& freshwater habitats.

For birds, mammals and reptiles \& amphibians the analysis shows that their main pathway of introduction is escape and/or secondary introduction. Furthermore, a high proportion of introductions by escape is intentional.

Some taxonomic groups have a large percentage of registrations with unknown pathway: angiosperms, annelids, arthropods, birds, fungi, microorganisms and nematodes. Some of these groups - fungi, microorganisms and nematodes - are registered with over $50 \%$ unknown pathways. Overall, $39 \%$ of the alien species in the Nordic region is registered with unknown pathways.

The types of introduction also vary between the different groups. Unintentional introductions are dominant in the groups: angiosperms, annelids, arthropods, birds and molluscs. In other groups most introductions are intentional: coniferous plants, fish, mammals and reptiles \& amphibians.

Two groups have a high degree of unknown types of introduction: fungi and microorganisms. For these types of introductions, little is known about the pathways of introductions as well.

\section{Baltic region}

Based on the data from the NOBANIS database for the Baltic region, the pathway analysis shows that the main pathway of introduction varies between the different taxonomic groups.

The group with the highest number of alien species represented is the angiosperms. A total of 1,069 alien species of angiosperms are recorded for the Baltic region. The main pathway for the group is horticulture, followed by agriculture and transport.

The second largest group is the arthropods with 164 alien species registered. Both the angiosperms and the arthropods have a diverse composition of pathways registered. The analysis also showed that the pathway of introduction for many arthropods still is unidentified $(\mathrm{N}=125)$.

For alien species of coniferous plants the analysis shows that three pathways are responsible for the introductions (forestry, horticulture 
and landscaping), but with horticulture as the main pathway. All introductions of coniferous plants are registered as being intentional.

For alien species of fish registered in the region, the main pathway of introduction is aquaculture and almost all of the introductions are intentional.

For the alien species of birds registered in the region the main pathway is escapes.

For species of molluscs the introductions are unintentional and by hull fouling.

For some taxonomic groups (cnidarians, bryophytes, ferns, flatworms, mammals, microorganisms, nematodes, phytoplankton and reptiles \& amphibians) identifying the main pathway of introduction has proven to be a challenge, due to the small amount of data available.

The analysis also shows that for $23 \%$ of the species registered in the NOBANIS database for the Baltic region no pathway of introduction is registered.

\section{Islands of the North Atlantic Ocean}

Based on the data available in the NOBANIS database for islands of the North Atlantic Ocean the analysis shows that the main pathway of introduction varies between the different taxonomic groups. The group with the highest number of alien species represented is the angiosperms. A total of 120 alien species of angiosperms are recorded for the region, and the main pathways for the angiosperms are horticulture and transport.

The second largest taxonomic group in the region is arthropods with 101 alien species registered. The primary pathway of introductions for the arthropods is horticulture.

Birds are mainly introduced to the region by secondary introduction.

For some taxonomic groups (bryophytes, fish, flatworms, macroalgae, microorganisms and molluscs) no main pathway of introduction is identified.

The analysis shows that the pathway of introduction for many angiosperms, arthropods and molluscs is unknown. For $48 \%$ of all species registered in the NOBANIS database for the region, no pathway of introduction is registered.

The type of introduction also varies between the different groups. The unintentional introductions are dominant in the groups: angiosperms, birds, bryophytes, fish, flatworms, fungi, macroalgae, mammals and microorganisms, while all coniferous plants are introduced intentional.

Two groups have a high degree of unknown type of introduction: arthropods and molluscs. For these introductions, little is known about the pathways as well. 


\subsection{Temporal development of pathways}

For many of the alien species in the NOBANIS database, year of first arrival and pathway of introduction are known, which can give an indication of the development of pathways over time.

\section{Nordic region}

In the Nordic region the number of registered introductions are increasing over time (see figure 69 and table in appendix 4). The increase in introductions is especially seen in the pathways: angling/sport, aquaculture, escapes, forestry, horticulture and secondary introduction. Furthermore, the number of species with unknown pathways increases over time. 
Figure 69: Temporal development of registrations of pathways of alien species in the Nordic region. Note that data from 2000-2014 is not included here

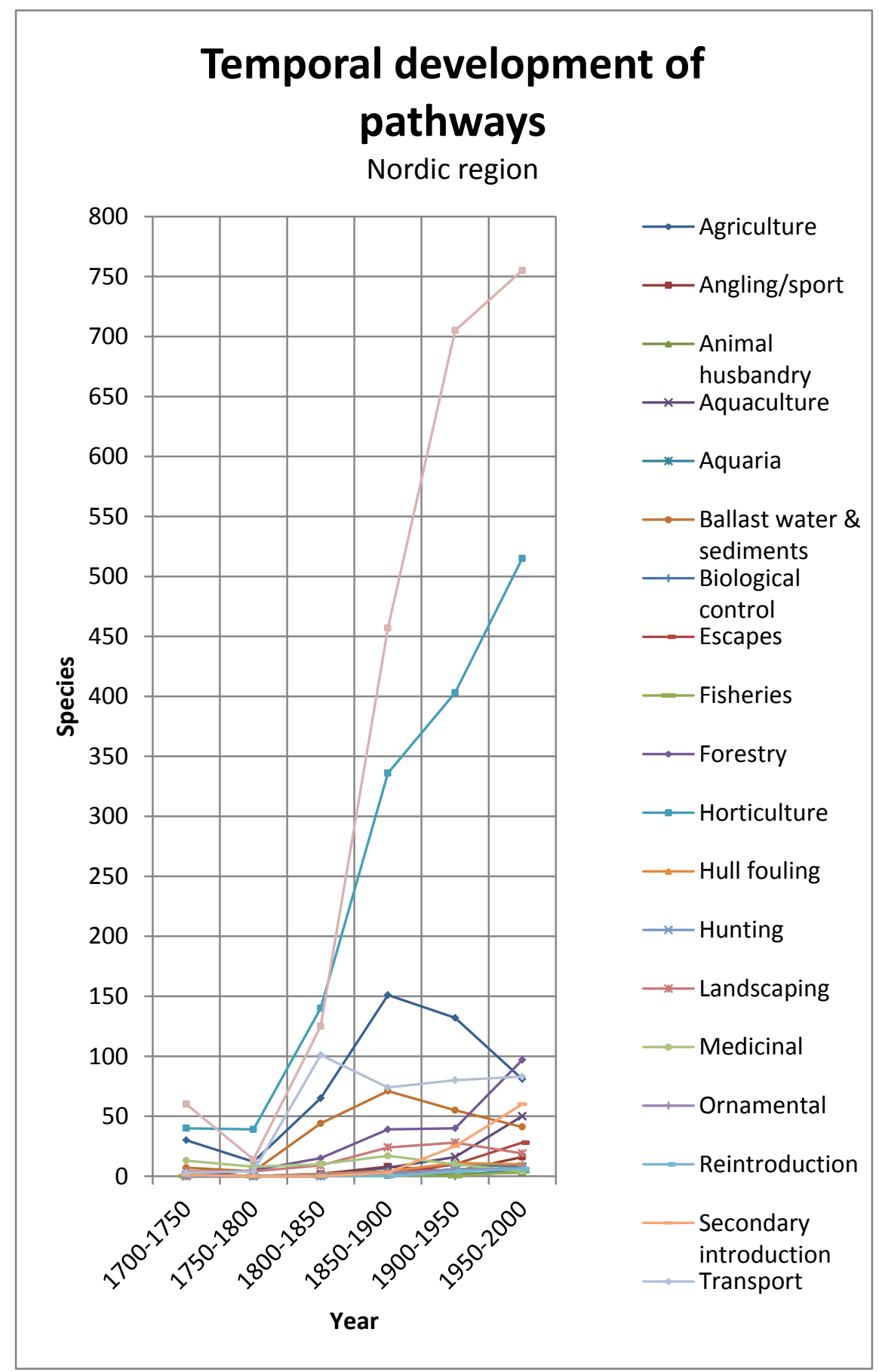


Landscaping has been registered since the beginning of this time frame (1700's) and has increased over the years, but the number of registrations from 2000 and until now (see table in appendix 4) is already higher than the numbers from the earlier fifty year periods.

Agriculture, medicinal and ballast water \& sediments are the main pathways where the number of registered introductions has decreased since 1900.

\section{Baltic region}

In the Baltic region the number of registered introductions is increasing over time (see figure 70 and table in appendix 5). The increase in introductions is especially seen in the pathways: agriculture, aquaculture, ballast water \& sediments, forestry, horticulture and transport. Furthermore, the number of species with unknown pathways has increases over time. 
Figure 70: Temporal development of registrations of pathways of alien species in the Baltic region. Note that data from 2000-2014 is not included here

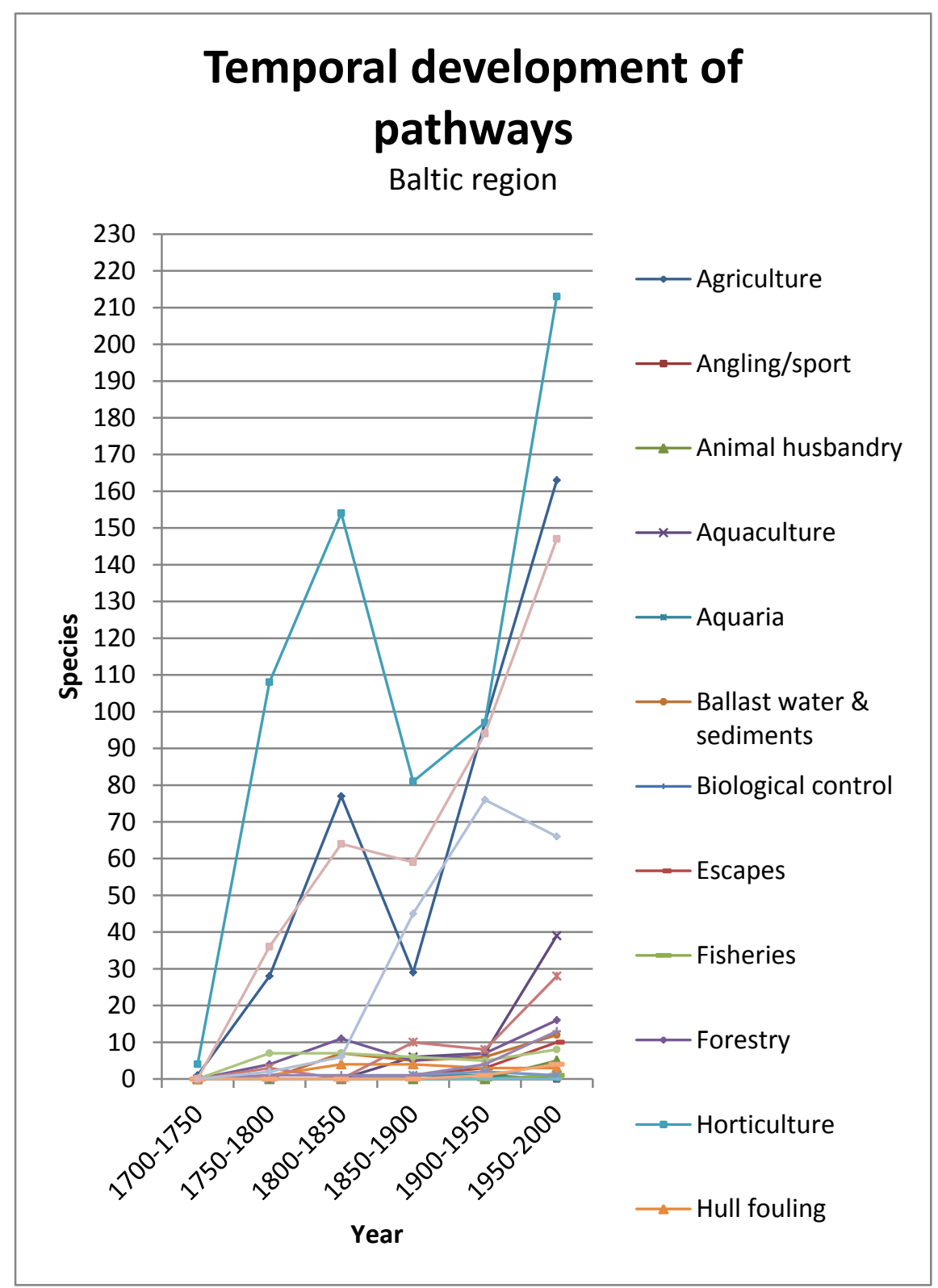


Agriculture, forestry and horticulture are increasing over the time frame, but have decreased briefly between 1850 and 1900 .

Some pathways have first been registered after 1900: animal husbandry, biological control, fisheries and secondary introduction.

No pathways have markedly fewer introductions of alien species over time in the Baltic region.

\section{Islands of the North Atlantic Ocean}

As mentioned in chapter 3.2 only data from Iceland is used in the temporal analysis, since no data regarding "year of introduction" is registered for the Faroe Islands in the NOBANIS database.

In Iceland the overall number of registered introductions is increasing over time (see figure 71). The largest increase is seen for horticulture and transport. 
Figure 71: Temporal development of registrations of pathways of alien species in the Islands of the North Atlantic Ocean. Note that data from 2000-2014 is not included here

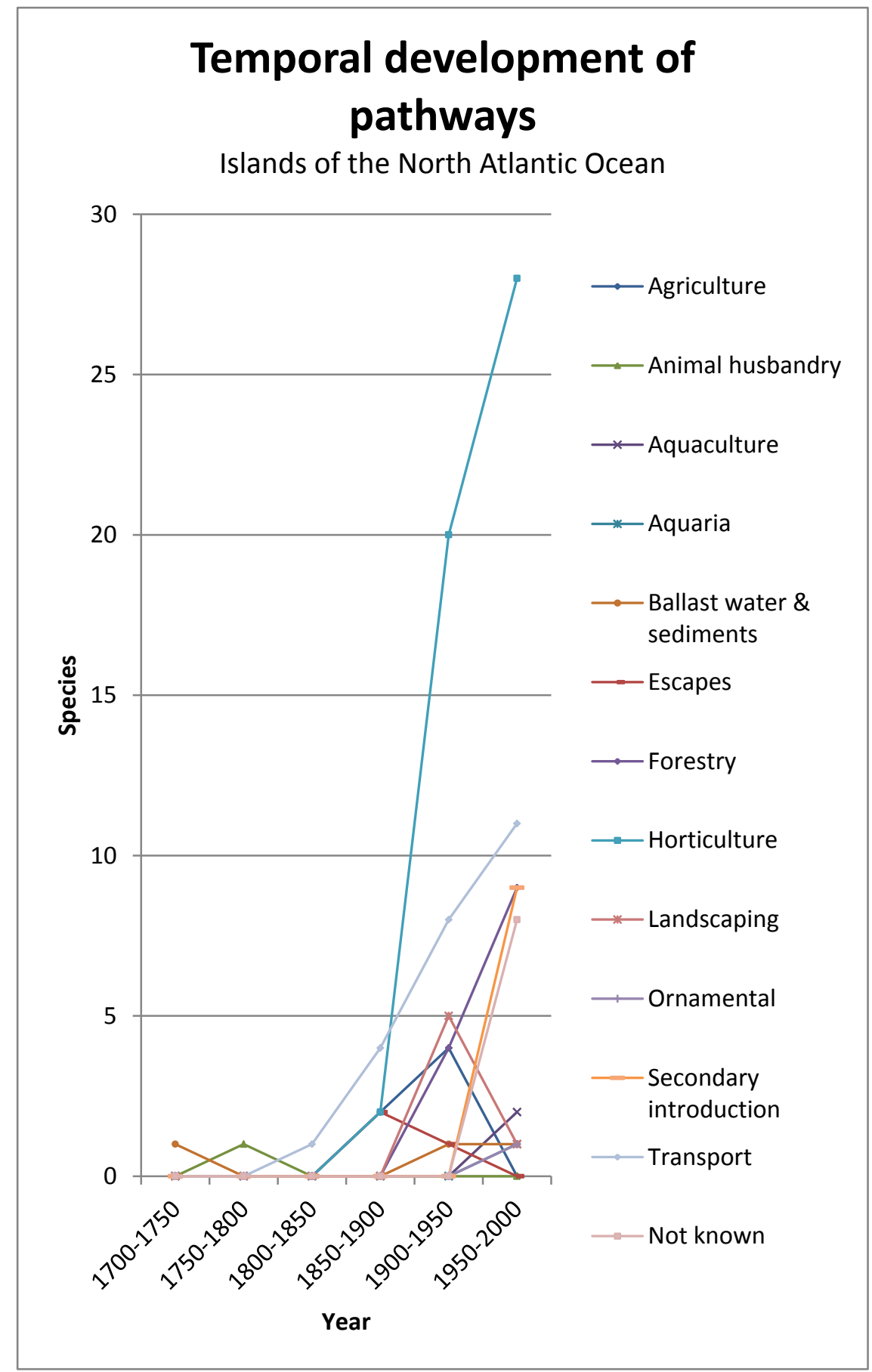


The use of agriculture, escapes and landscaping as pathways of introducetion has increased up to 1950 and then decreased afterwards.

Some pathways have first been registered after 1900: aquaculture, aquaria, forestry, landscaping, ornamental and secondary introduction.

\subsubsection{Summary}

\section{Nordic region}

The analysis shows that the number of introductions and the importance of different pathways vary over time. The importance of angling/sport, aquaculture, escapes, forestry, horticulture, secondary introduction and unknown pathway has increased in time. Furthermore, the number of registrations for landscaping from 2000 and until now (see table in appendix 4) is already higher than the numbers from the earlier fifty year periods.

The use of the pathways agriculture, medicinal and ballast water \& sediments has decreased.

\section{Baltic region}

In the Baltic region the number of registered introductions is increasing over time. The increasingly registered pathways are agriculture, aquaculture, ballast water \& sediments, forestry, horticulture and transport. Furthermore, the number of species with unknown pathways increases over time.

The importance of the different pathways varies over time, hence some pathways have not been important in the beginning of this time frame, but have become important after 1900: animal husbandry, biological control, fisheries and secondary introduction.

No pathways have markedly fewer introductions of alien species over time in the Baltic region.

\section{Islands of the North Atlantic Ocean}

In Iceland the overall number of registered introductions is increasing over time. The largest increase is seen for horticulture and transport, while the use of agriculture, escapes and landscaping has increased up to 1950 and then decreased afterwards.

Like in the Baltic region some pathways have not been important in the beginning of this time frame, but have become important after 1900: aquaculture, aquaria, forestry, landscaping, ornamental and secondaryintroduction. 


\subsection{Species origin and the pathway of introduction}

In this subanalysis the area of origin for the introduced species and their pathway of introductions are examined. The analysis is made both for all the species combined and for each taxonomic group. The results are presented for the three regions combined.

In the NOBANIS terminology 14 natural distribution areas are described. The natural distribution areas are seven continents (Africa, Antarctica, Asia, Europe, N. America, Oceania and S. America) and seven oceans (Arctic Ocean, Indian Ocean, N. Atlantic Ocean, S. Atlantic Ocean, N. Pacific Ocean, S. Pacific Ocean and Southern Ocean). See chapter 3.2 for further details on the delimitations of the natural distribution areas.

As shown in figure 72, most non-native species registered in the participating countries and territories originates from Europe, Asia or North America, and the main pathway of introduction is horticulture.

Species originating from Europe are mainly introduced by horticulture and agriculture, but also ballast water $\&$ sediments and forestry are widely used pathways of introduction. The same pathways apply to species native to Asia, except that transport also is a widely used pathway of introduction. For species native to North America the main pathway of introduction is horticulture. 
Figure 72: The area of origin for introduced species in the NOBANIS database and their pathways of introduction

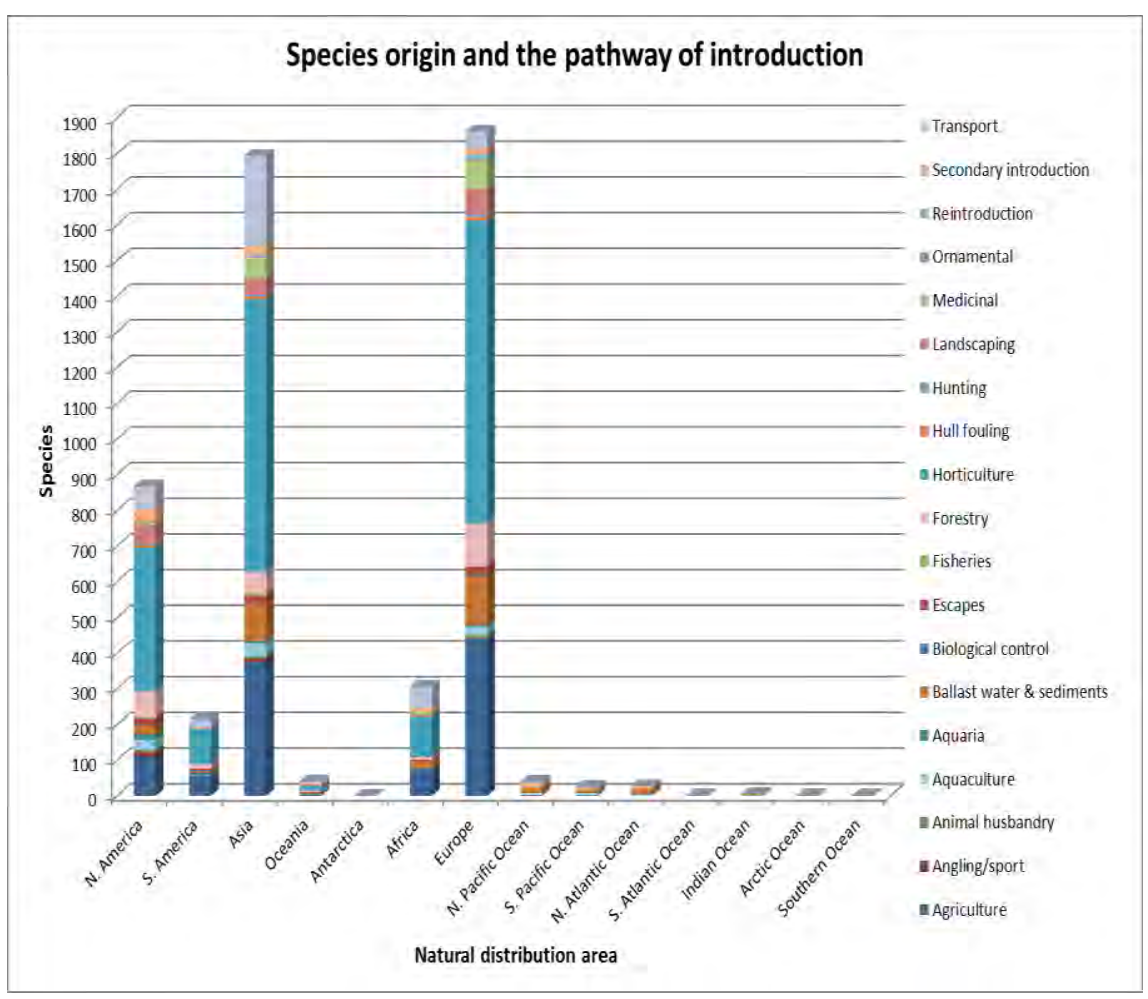

Species that originated from Africa or South America are mainly introduced by horticulture and agriculture and for species native to Africa also by transport. Only a few non-native species originate from Oceania, Antarctica, North Pacific Ocean, South Pacific Ocean, North Atlantic Ocean, South Atlantic Ocean, Indian Ocean, Arctic Ocean and the Southern Ocean.

Note that one species may have multiple pathways of introduction into the various countries and territories participating in the project, as well as having more than one area of origin.

For Protozoans registered for the participating countries and territories no information was available on pathway of introduction or place of origin. 


\section{Angiosperms}

For the species of angiosperms seven natural distribution areas are registered for the group and 13 pathways of introduction (see figure 73).

Figure 73: The area of origin for introduced angiosperms and their pathways of introduction

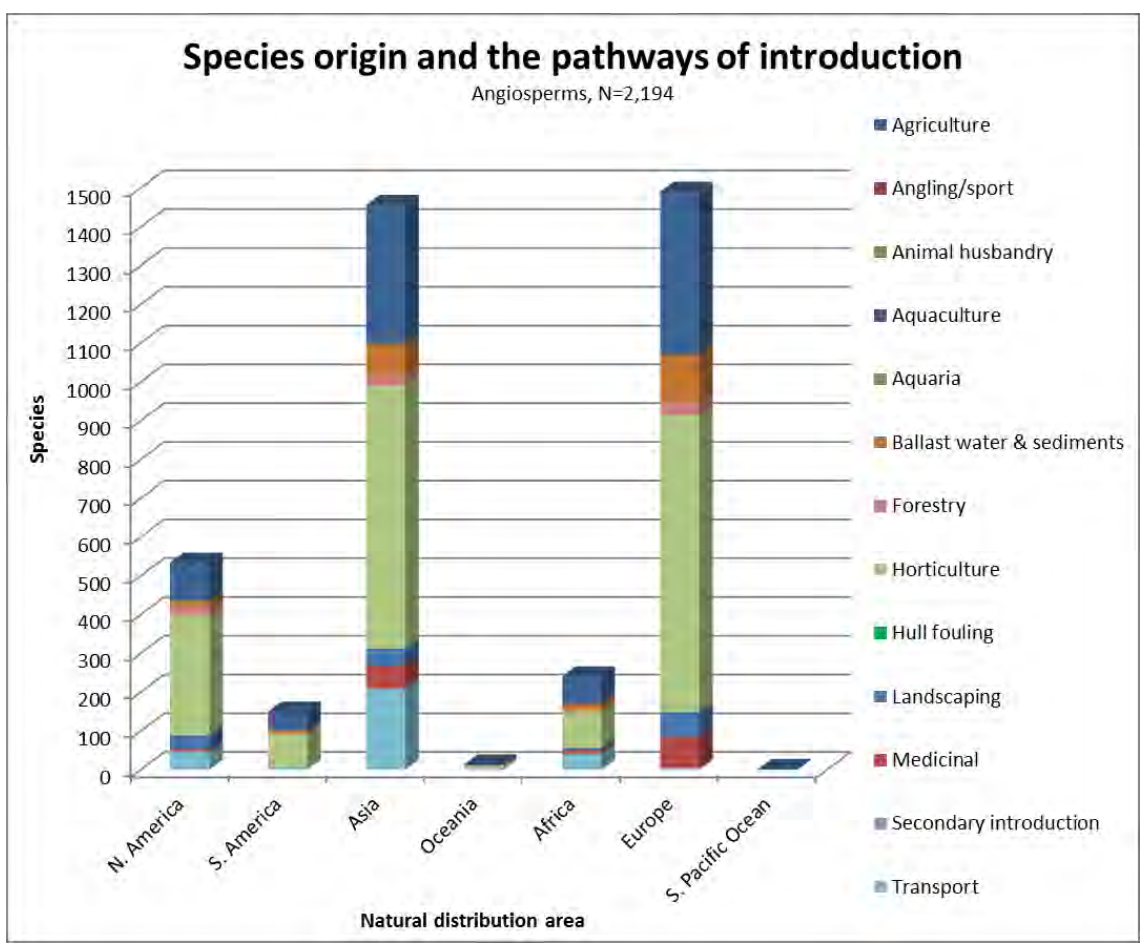

For the majority of the non-native species of angiosperms the natural distribution area is registered as Europe or Asia, and the main pathway of introduction is horticulture, followed by agriculture. For species originating from North America, South America and Africa, horticulture is the main pathway of introduction. 


\section{Annelids}

For the species of annelids, 7 natural distribution areas are registered for the group and 7 pathways of introduction (see figure 74).

The majority of the non-native species of annelids originates from Europe and is introduced by ballast water \& sediments. Species registered as originating from Asia are only introduced by ballast water \& sediments, while species originating from North America are introduced by transport and secondary introduction. For species with a natural distribution in the North Atlantic Ocean, ballast water \& sediment and secondary introduction are the main pathways of introduction.

Figure 74: The area of origin for introduced annelids and their pathways of introduction

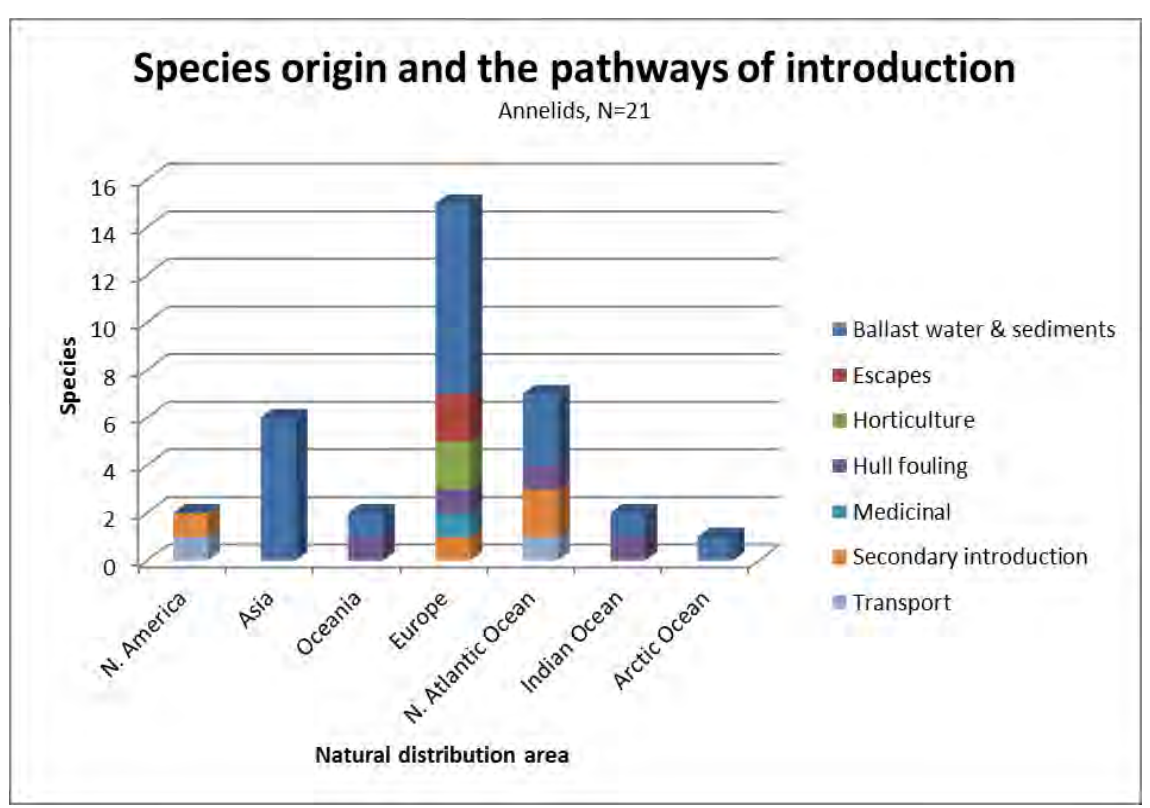




\section{Arthropods}

For the species of arthropods 10 natural distribution areas are registered for the group and 18 pathways of introduction (see figure 75).

For the majority of the non-native species of arthropods the natural distribution area is registered as Europe or Asia, but also North America is well represented. The main pathway of introduction for species originating from Europe is forestry, but also horticulture is registered for many species. For species originating from Asia and North America horticulture is the main pathway, followed by forestry and transport.

For species originating from South America and Africa horticulture, forestry and transport are the most registered pathways of introduction.

Figure 75: The area of origin for introduced arthropods and their pathways of introduction

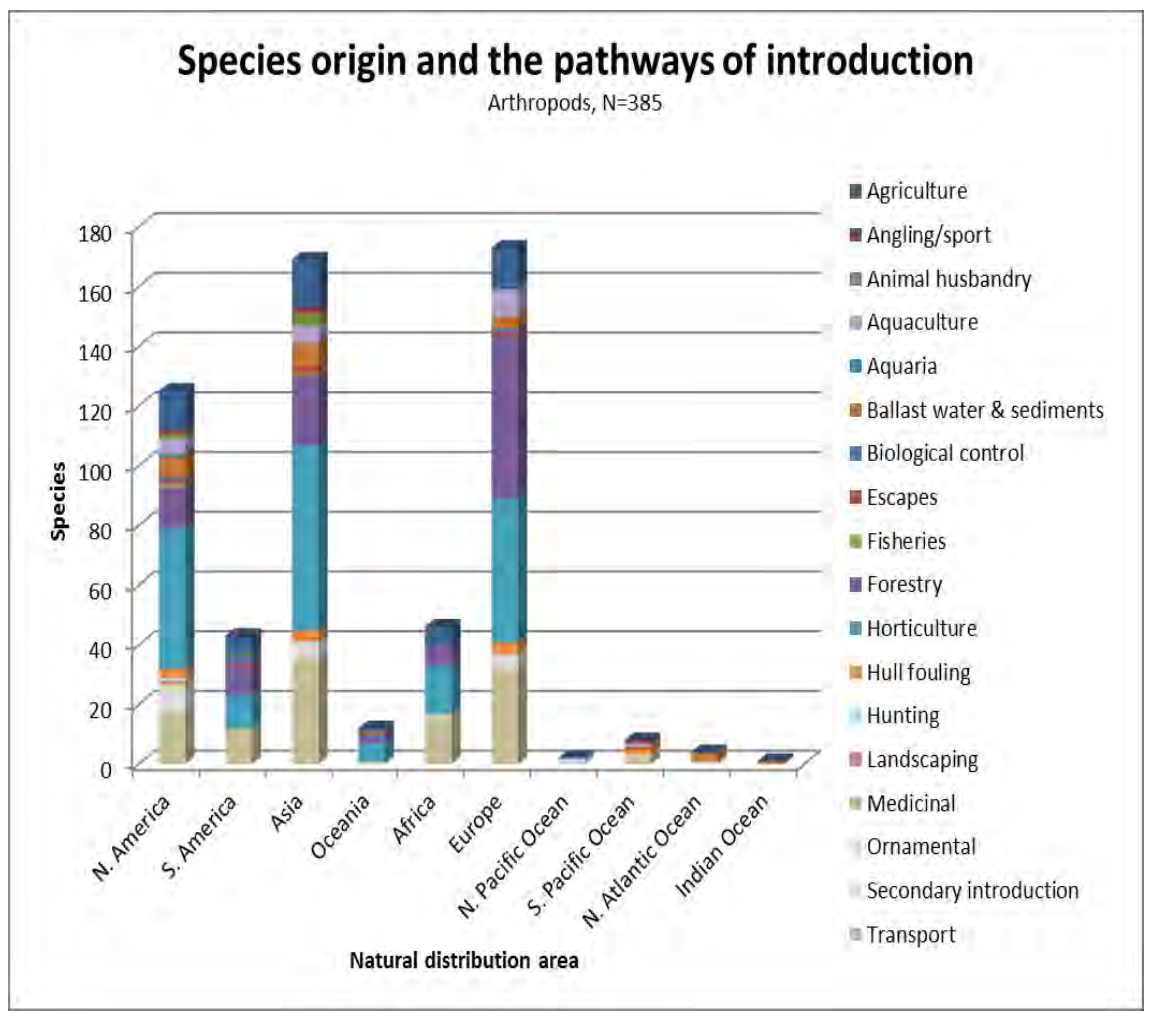




\section{Birds}

For the species of birds, 7 natural distribution areas are registered for the group and 6 pathways of introduction (see figure 76).

The majority of the non-native species of birds originates from Asia, North America and Europe. Species originating from Asia or North America are mainly introduced by secondary introduction and escape, while species originating from Europe are mainly introduced by reintroduction and escape.

Figure 76: The area of origin for introduced birds and their pathways of introduction

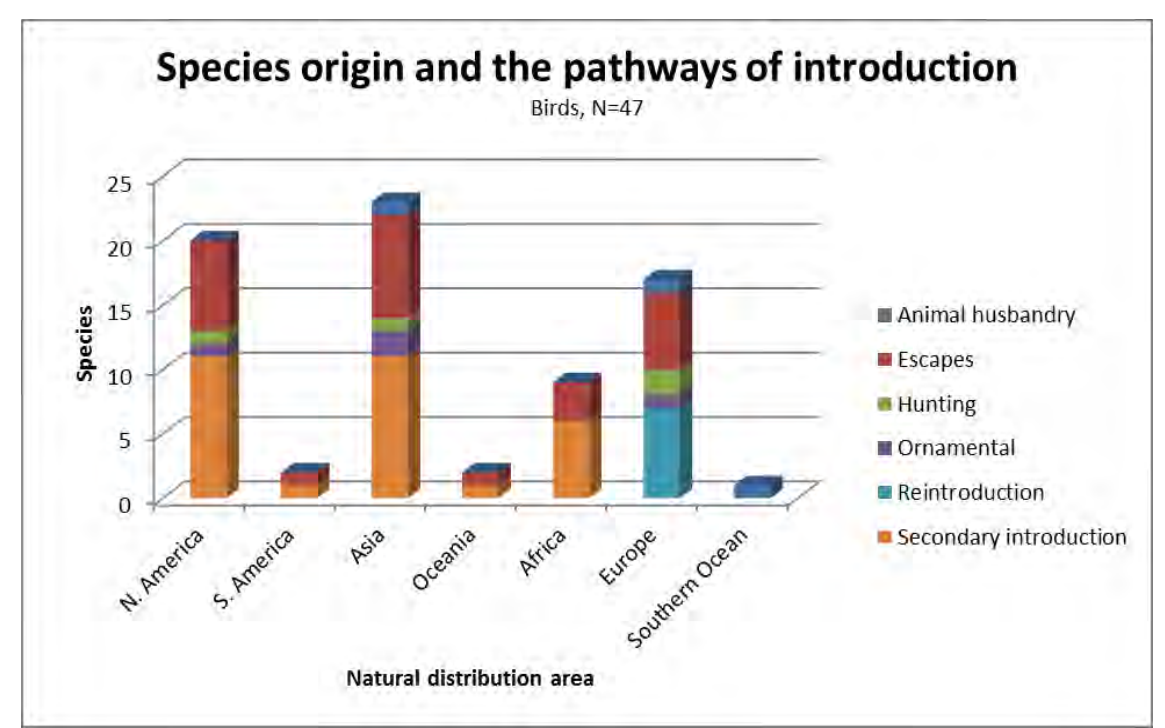




\section{Bryophytes}

For the species of bryophytes, four natural distribution areas are registered for the group and three pathways of introduction (see figure 77).

Species originating from South America, Oceania, or Africa are mainly introduced by secondary introduction, while species originating from Europe are mainly introduced by transport.

Figure 77: The area of origin for introduced bryophytes and their pathways of introduction

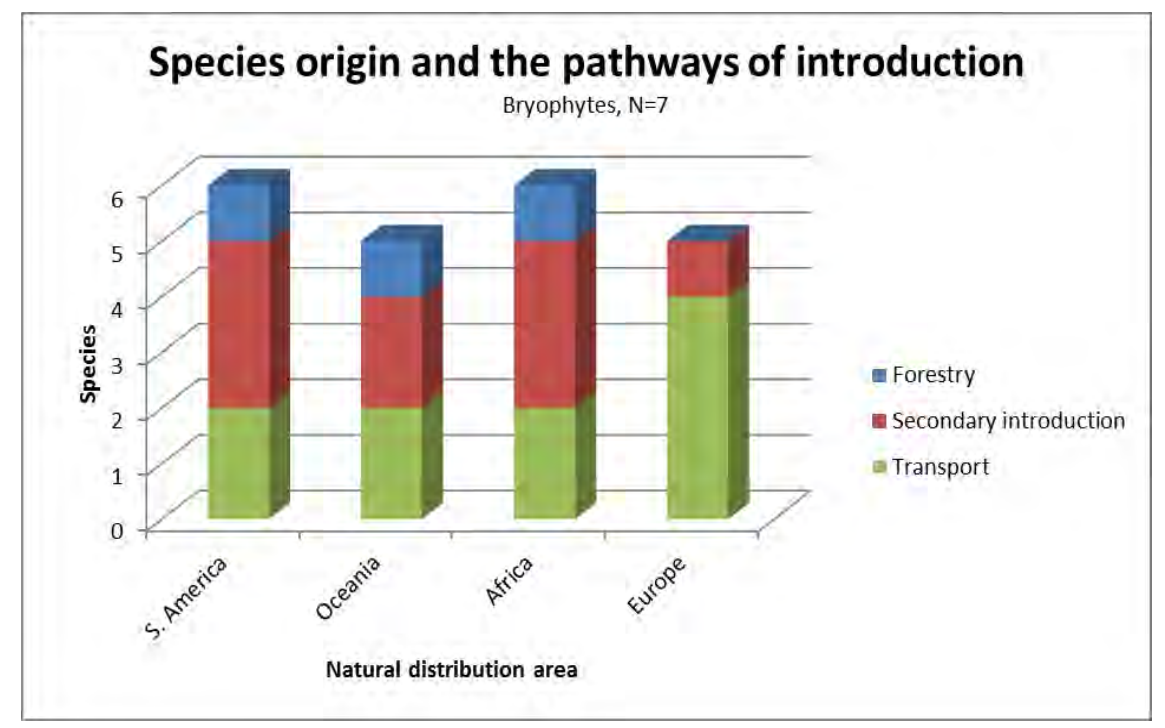




\section{Cnidarians}

For the species of cnidarians, three natural distribution areas were registered for the group and seven pathways of introduction (see figure 78).

The majority of the non-native species of cnidarians originates from the North Pacific Ocean, where the main pathway of introduction is by hull fouling and ballast water \& sediments.

Figure 78: The area of origin for introduced cnidarians and their pathways of introduction

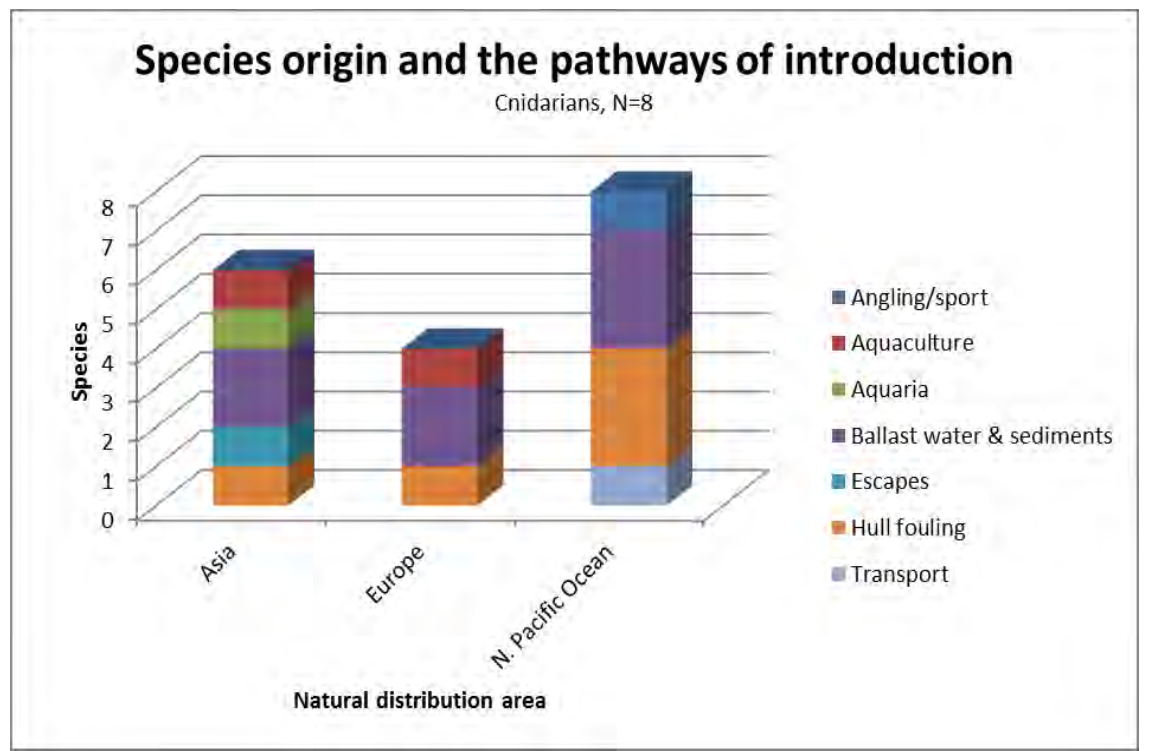




\section{Comb jellies}

For the species of comb jellies, five natural distribution areas are registered for the group and two pathways of introduction (see figure 79).

Figure 79: The area of origin for introduced comb jellies and their pathways of introduction

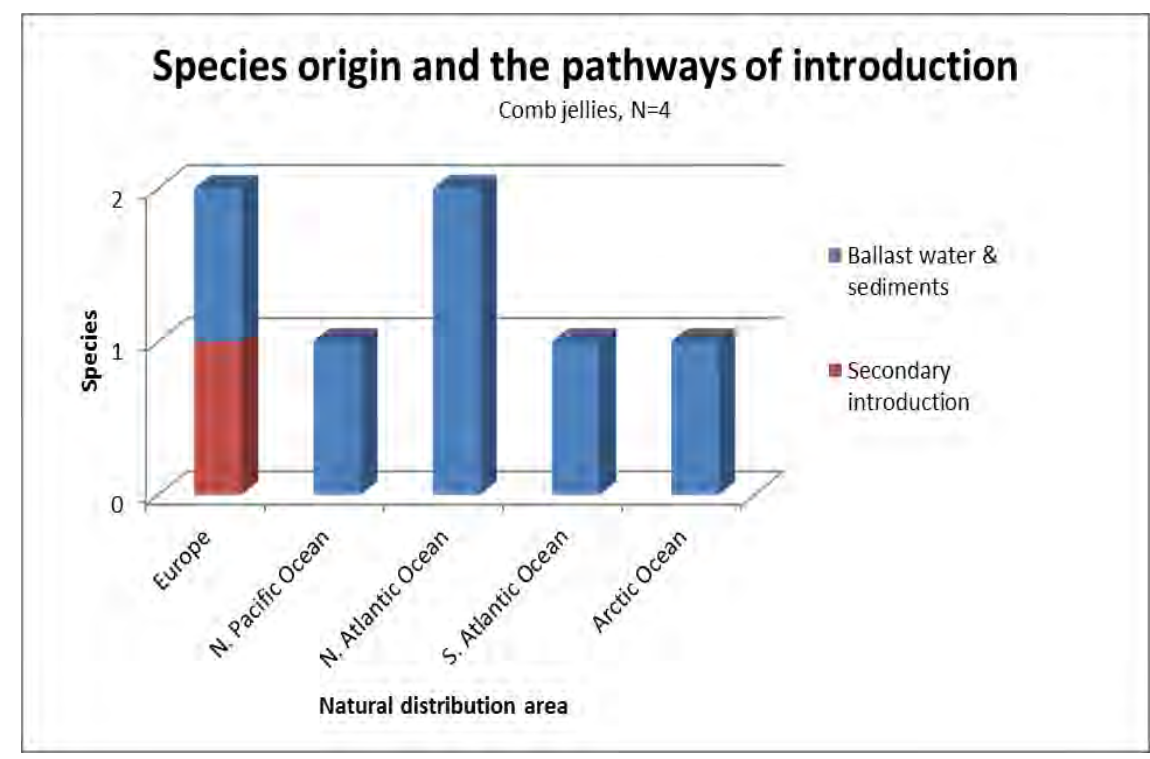

The majority of the non-native species of comb jellies originates from the North Atlantic Ocean and Europe, where the main pathways of introduction are by ballast water \& sediments and secondary introduction.

Of species originating from the North Pacific Ocean, South Atlantic Ocean and Arctic Ocean the majority are introduced by ballast water \& sediments. 


\section{Coniferous plants}

For the species of coniferous plants, three natural distribution areas are registered for the group and three pathways of introduction (see figure 80).

The majority of the non-native species of coniferous plants originates from North America, where the main pathways of introduction are by horticulture and forestry. For species originating from Europe and Asia the main pathways of introduction are also horticulture and forestry.

Figure 80: The area of origin for introduced coniferous plants and their pathways of introduction

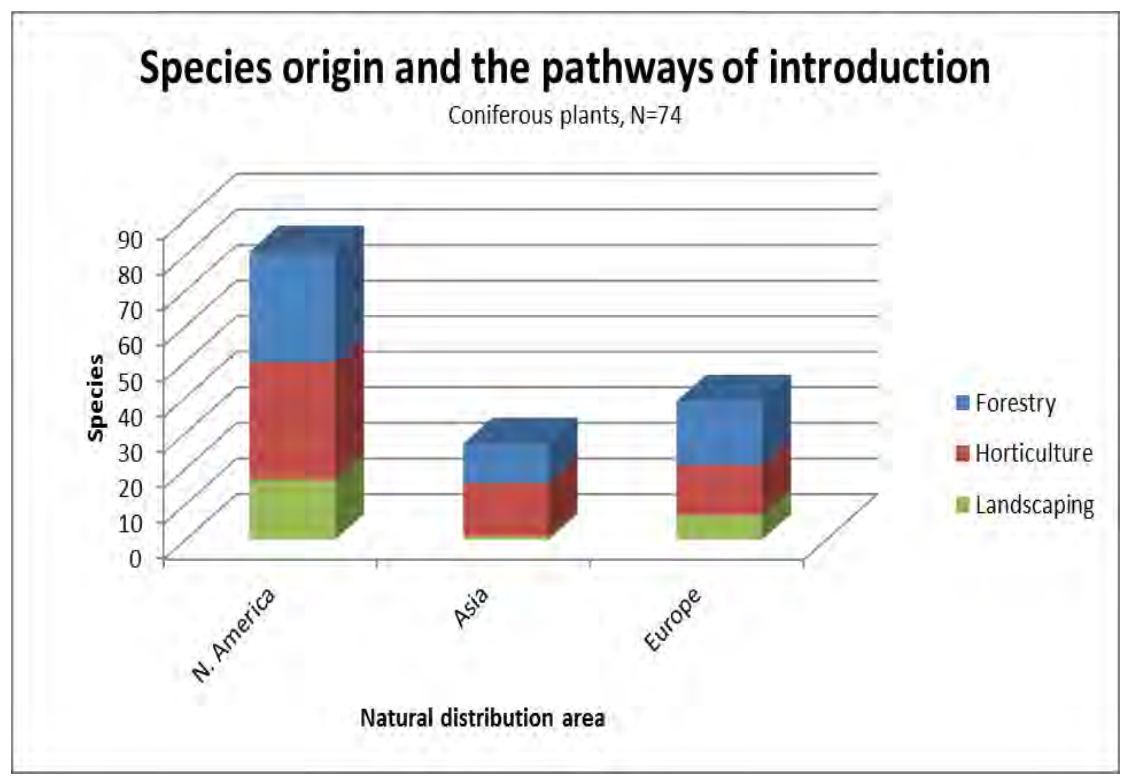




\section{Ferns}

For the species of ferns, four natural distribution areas are registered for the group and four pathways of introduction (see figure 81).

The majority of the non-native species of ferns originates from North America and Europe. The main pathway of introduction for species originating from North America is horticulture, while for species originating from Europe it is mainly agriculture. For species originating from South America the pathway is mainly aquaria.

Figure 81: The area of origin for introduced ferns and their pathways of introduction

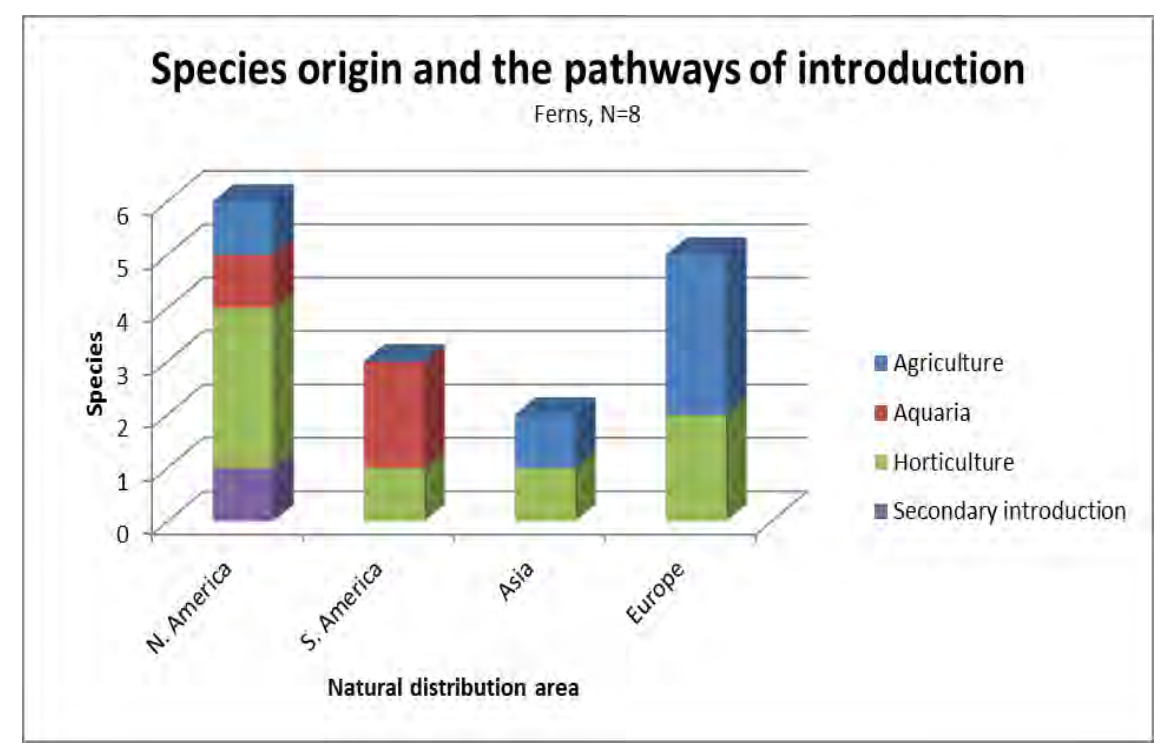


Fish

For the species of fish, four natural distribution areas are registered for the group and 9 pathways of introduction (see figure 82).

The majority of the non-native species of fish originates from Asia and North America, where the main pathway of introduction is aquaculture. For the species originating from Europe the main pathway of introduction is also aquaculture, while species originating from the North Pacific Ocean are introduced by secondary introduction and angling/sport.

Figure 82: The area of origin for introduced fish and their pathways of introduction

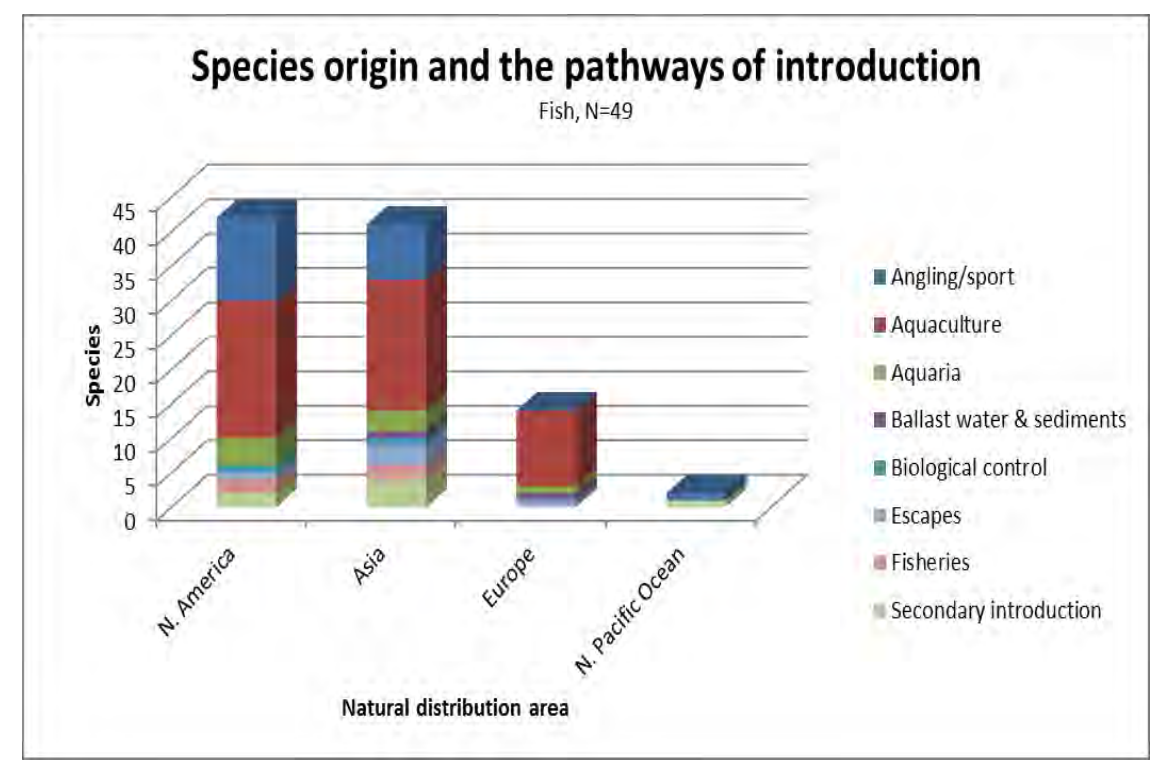




\section{Flatworms}

For the species of flatworms, four natural distribution areas are registered for the group and five pathways of introduction (see figure 83).

The majority of the non-native species of flatworms originates from Asia, where the main pathway of introduction is aquaculture. For the species originating from Europe and North America, no main pathway of introduction is identified, and for species originating from Oceania only agriculture is identified as a pathway of introduction.

Figure 83: The area of origin for introduced flatworms and their pathways of introduction

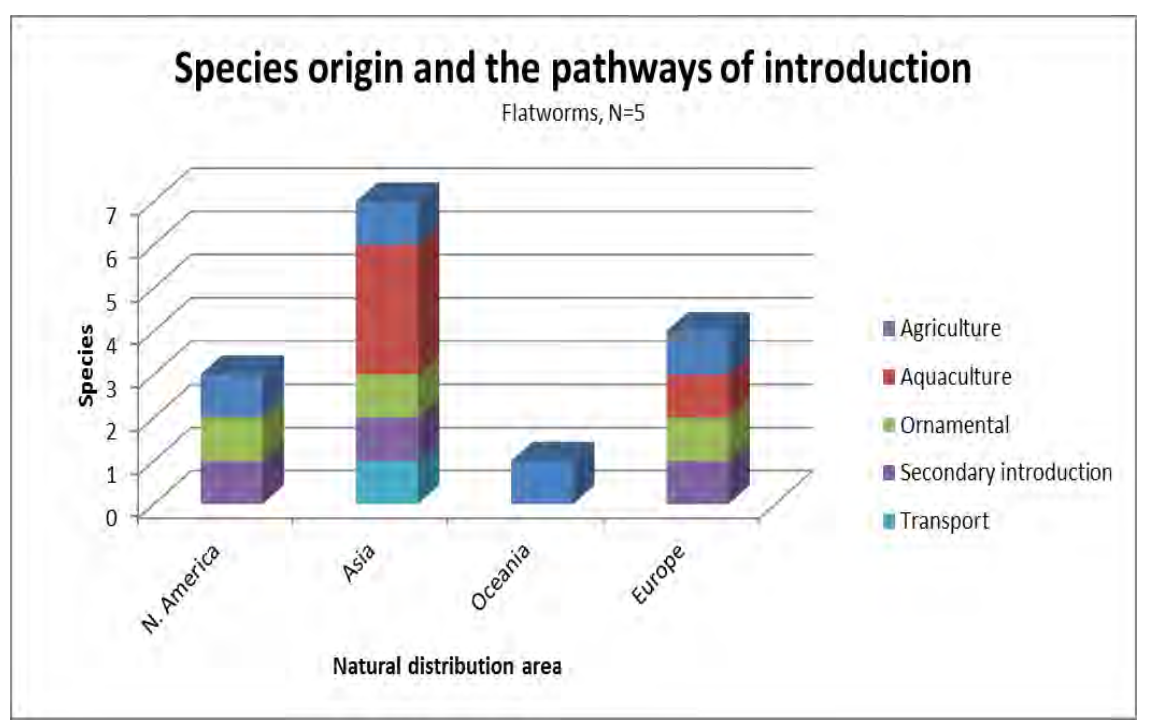




\section{Fungi}

For the species of fungi, four natural distribution areas are registered for the group and five pathways of introduction (see figure 84).

The majority of the non-native species of fungi originates from $\mathrm{Eu}-$ rope and North America, where the main pathway of introduction is forestry. Species originating from Asia are introduced mainly by horticulture and forestry, while species from South America are introduced by transport and agriculture.

Figure 84: The area of origin for introduced fungi and their pathways of introduction

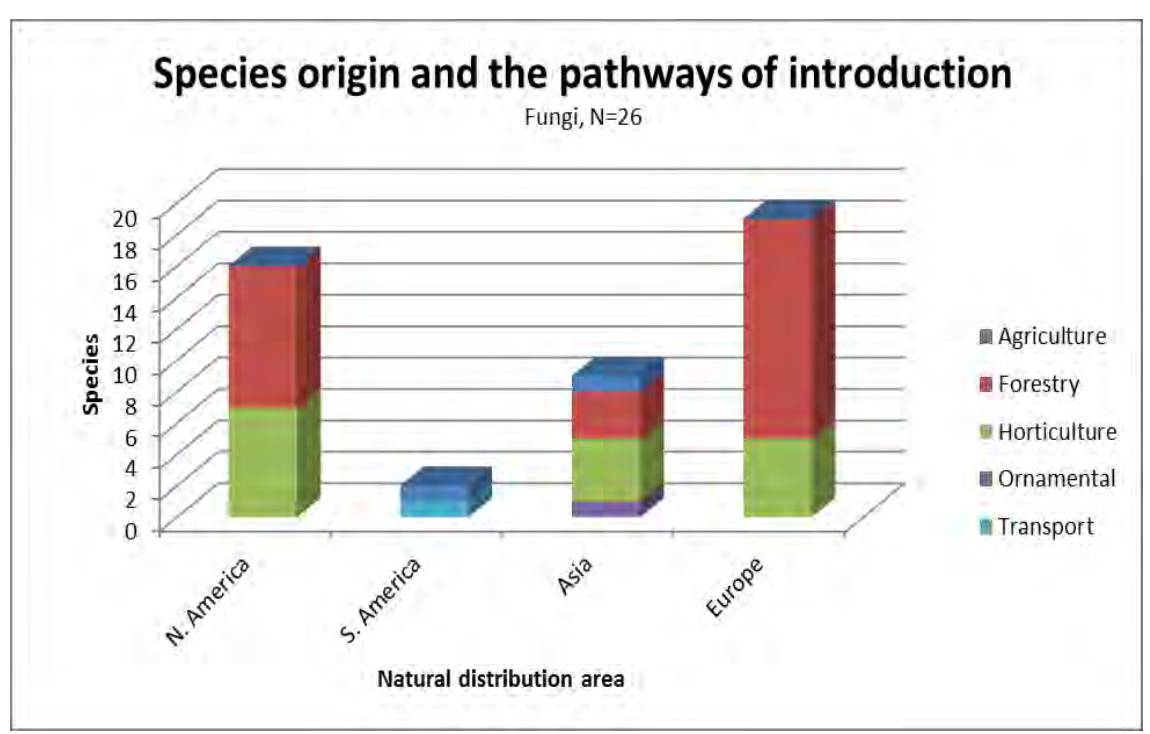




\section{Macroalgae}

For the species of macroalgae, five natural distribution areas are registered for the group and five pathways of introduction (see figure 85).

The majority of the non-native species of macroalgae originates from the North Pacific Ocean, where the most registered pathways of introduction are aquaculture, hull fouling and secondary introduction.

For species originating from the South Pacific Ocean the majority is introduced by ballast water \& sediments and aquaculture, while species originating from the $\mathrm{N}$. Atlantic Ocean are introduced by ballast water \& sediments and hull fouling.

Figure 85: The area of origin for introduced macroalgae and their pathways of introduction

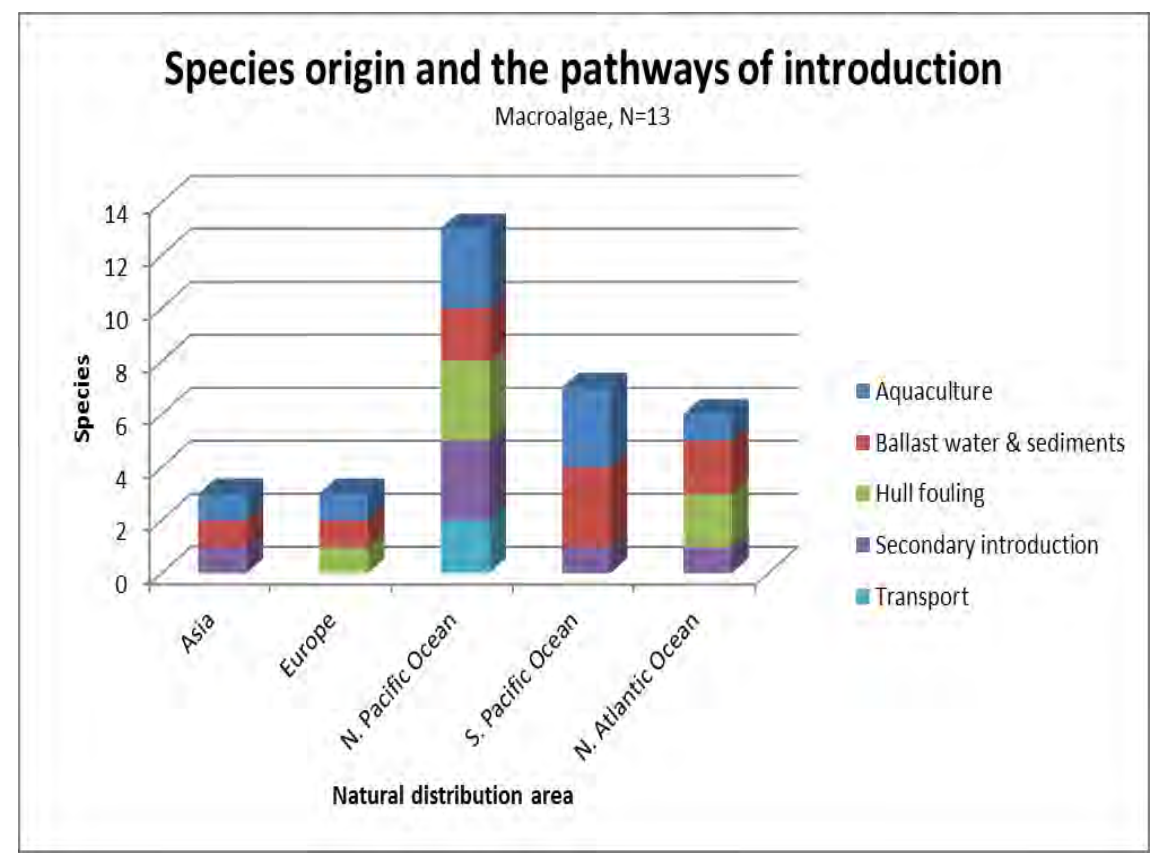




\section{Mammals}

For the species of mammals, five natural distribution areas are registered for the group and 7 pathways of introduction (see figure 86).

The majority of the non-native species of mammals originates from Europe, where the most registered pathways of introduction are escape, hunting and secondary introduction. Also reintroduction is registered for a number of the species of mammals originating from Europe. Species originating from Asia are mainly introduced by escape which is also the case for species originating from North America.

Figure 86: The area of origin for introduced mammals and their pathways of introduction

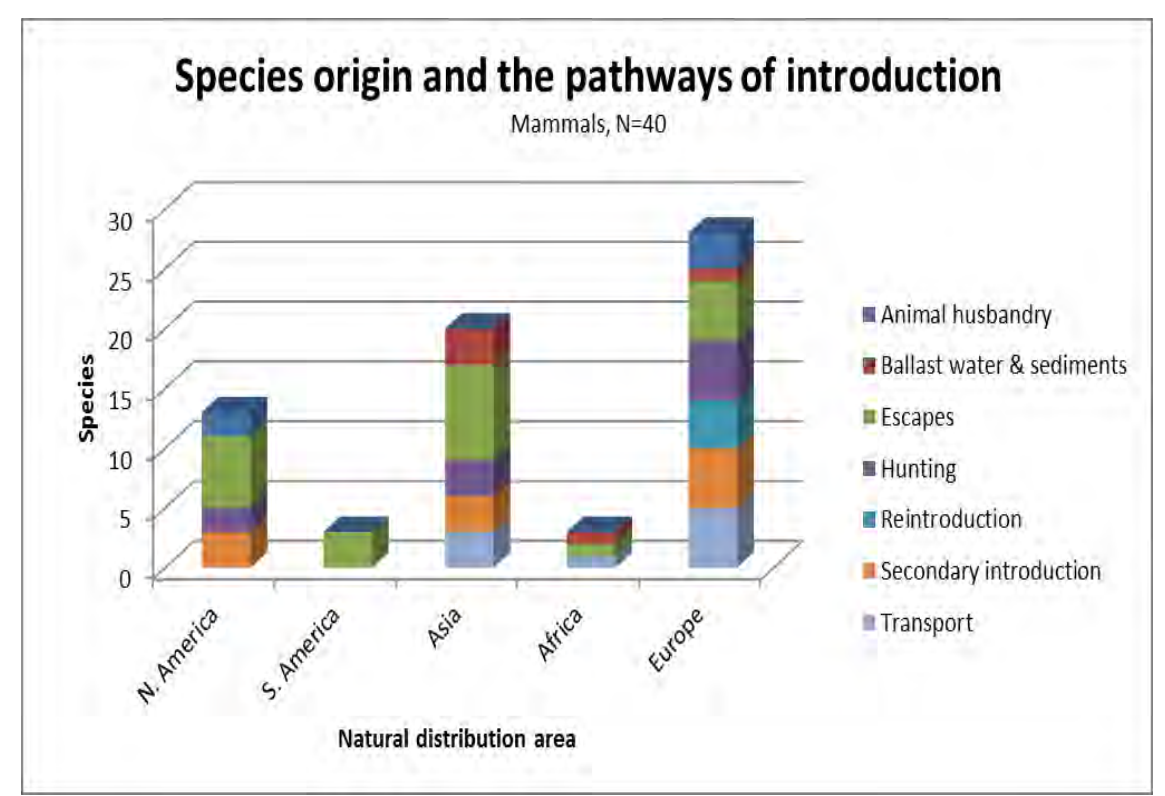




\section{Molluscs}

For the species of molluscs, 8 natural distribution areas are registered for the group and 12 pathways of introduction (see figure 87).

The majority of the non-native species of molluscs originates from Europe, where the main pathway of introduction is horticulture. Species originating from Asia are mostly introduced by aquaculture, ballast water \& sediments and hull fouling, while species from North America are mainly introduced by aquaria and secondary introduction.

Figure 87: The area of origin for introduced Molluscs and their pathways of introduction

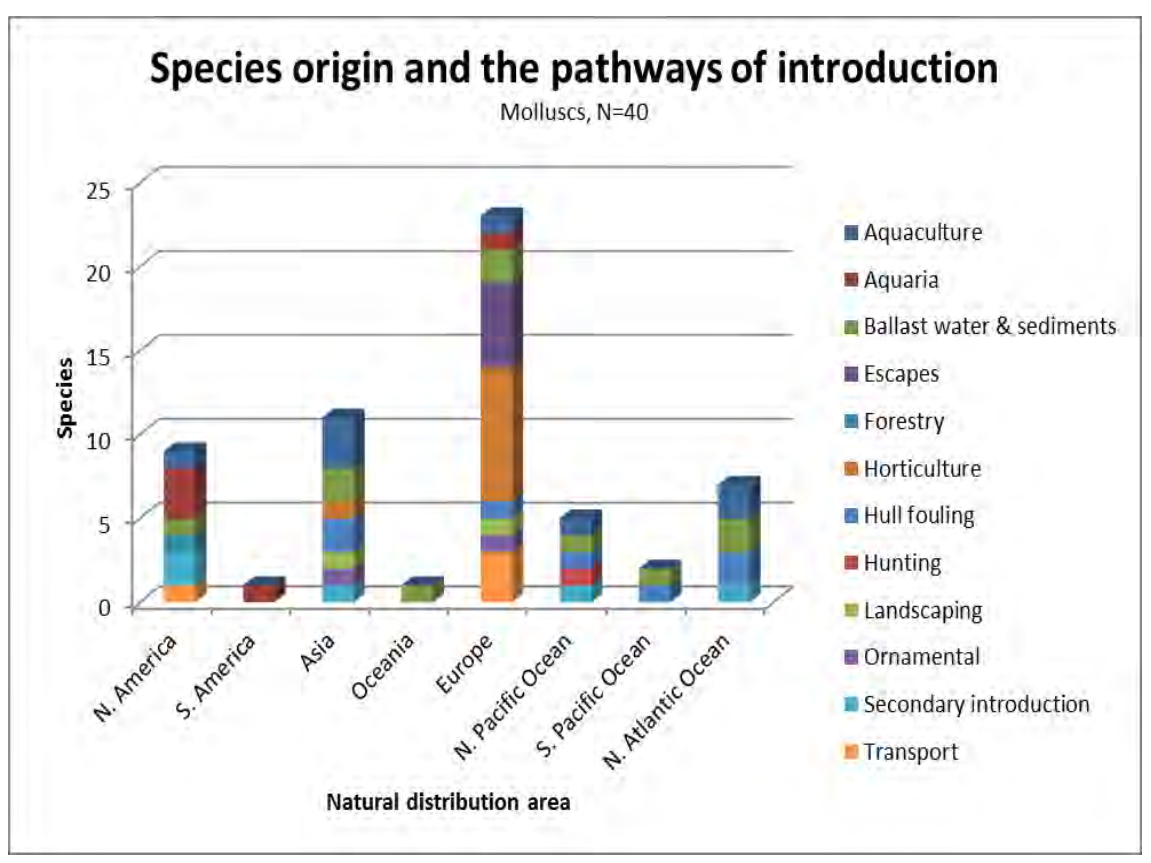

\section{Microorganisms}

Only one species of microorganisms is registered with the relevant information concerning natural distribution area and a pathway of introduction. Aeromonas salmonicida originates from North America and the pathway of introduction is registered as aquaculture.

\section{Nematodes}

For the species of nematodes, 6 natural distribution areas are registered for the group and five pathways of introduction (see figure 88).

The majority of the non-native species of nematodes originates from Asia, Oceania, the North Pacific Ocean and the South Pacific Ocean. Aquaculture, secondary introduction and transport are the pathways of 
introduction for the species of non-native nematodes when introduced to the participating countries and territories. For species originating from North America the majority of introductions occur through horticulture, and for species originating from South America, agriculture is the pathway of introduction.

Figure 88: The area of origin for introduced nematodes and their pathways of introduction

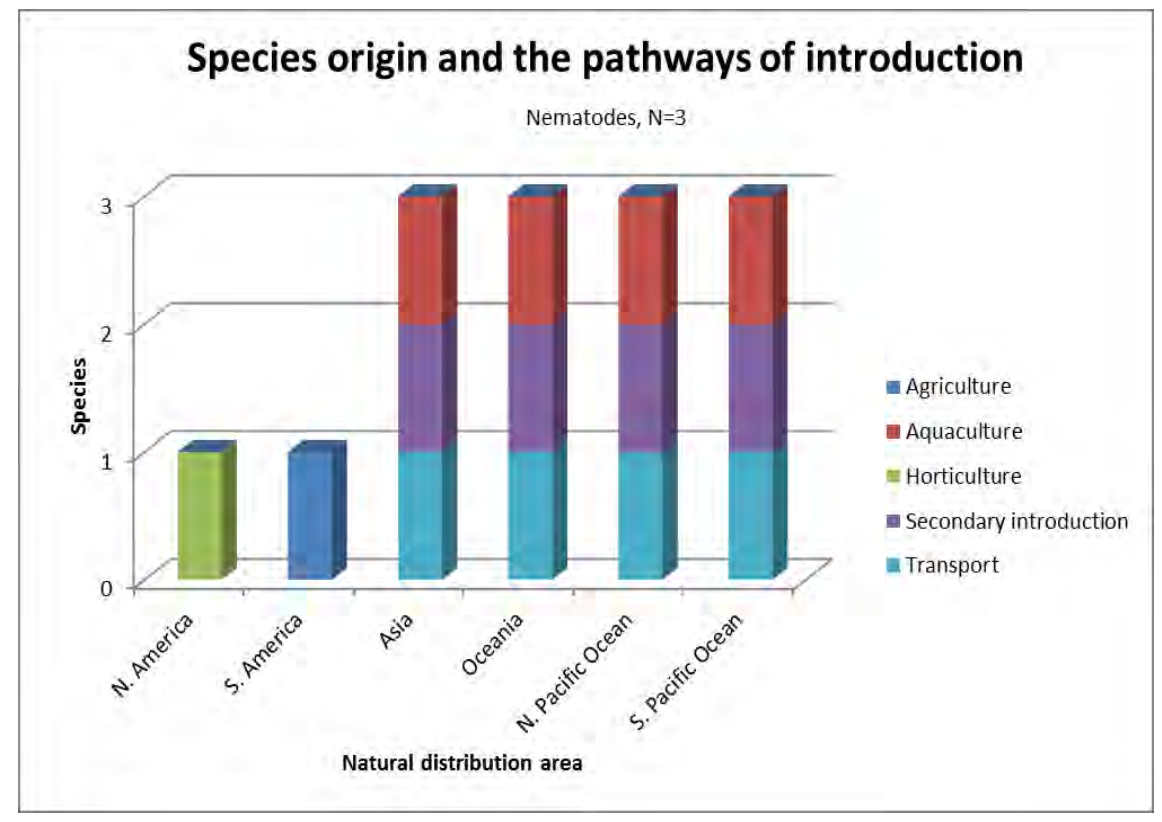

\section{Other chordates}

Only two species of other chordates are registered with the relevant information concerning natural distribution area and a pathway of introduction. Molgula manhattensis originates from North America by ballast water \& sediments and hull fouling, while Styela clava originates from Asia and is introduced by four different pathways of introductions: ballast water \& sediments, hull fouling, secondary introduction and transport.

\section{Other invertebrates}

Only two species of other invertebrates have the relevant information concerning natural distribution area and a pathway of introduction. Bugula neritina and Victorella pavida both originate from Europe and the pathways of introductions are aquaculture, biological control and hull fouling. 


\section{Phytoplankton}

For the species of phytoplankton, five natural distribution areas are registered for the group and three pathways of introduction (see figure 89).

The majority of the non-native species of phytoplankton originates from the North Pacific Ocean, and ballast water \& sediments is the main pathway of introduction. Ballast water \& sediments is also used as a pathway of introduction for species originating from North America, Asia, the South Pacific Ocean and the Indian Ocean.

Figure 89: The area of origin for introduced phytoplankton and their pathways of introduction

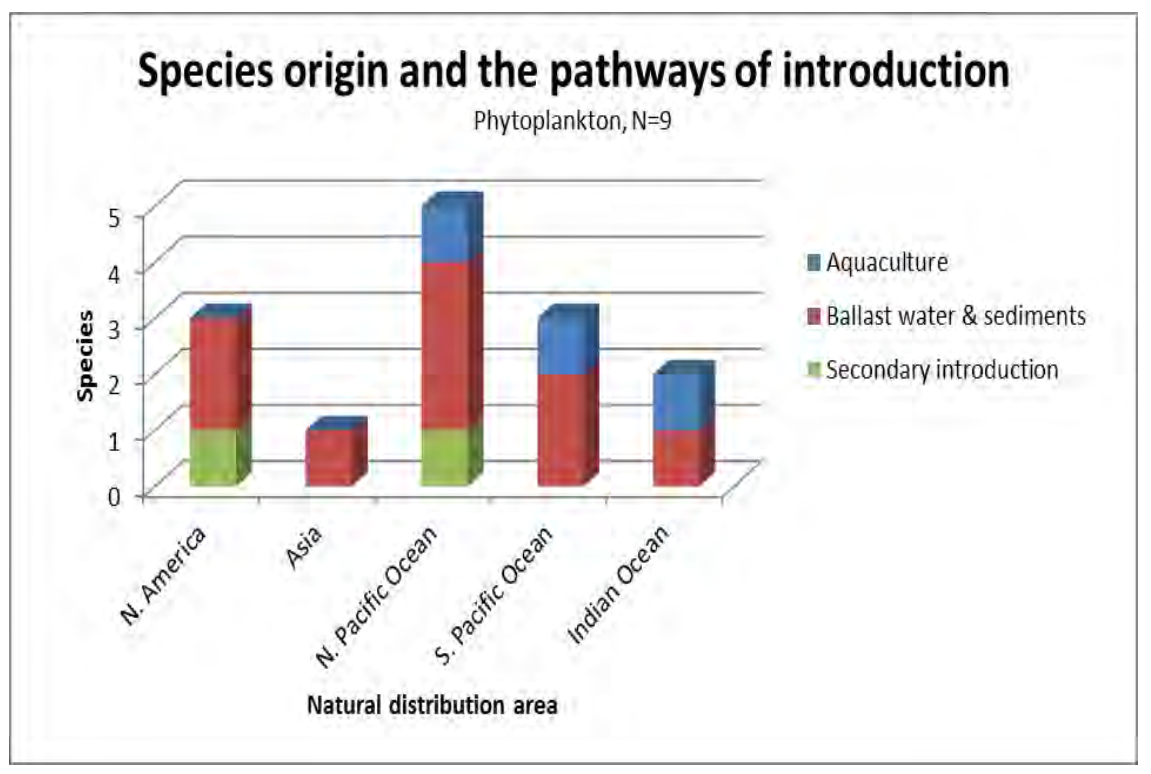




\section{Reptiles and Amphibians}

For the species of reptiles and amphibians, four natural distribution areas are registered for the group and 6 pathways of introduction (see figure 90).

The majority of the non-native species of reptiles and amphibians originates from Europe, and aquaria, escapes and reintroduction are the main pathways. For the species that originate from North America, the pathway of introduction is escape, followed by hull fouling, aquaria and aquaculture.

Figure 90: The area of origin for introduced reptiles and amphibians and their pathways of introduction

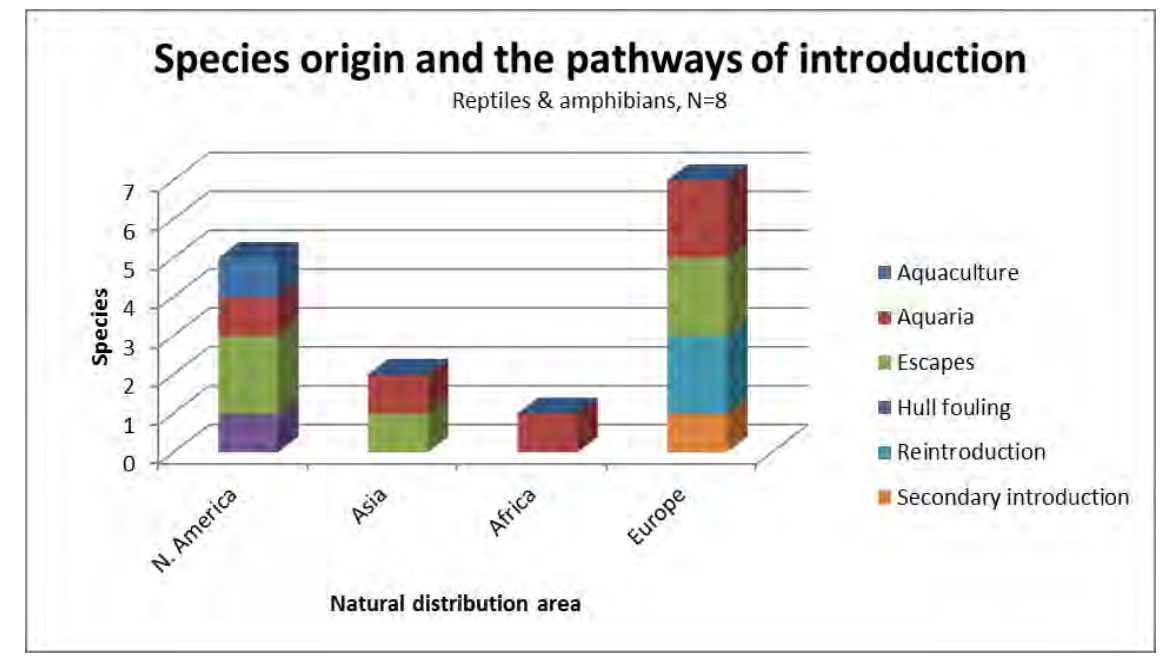

\section{Summary}

Most of the non-native species registered in the participating countries and territories originate from Europe and Asia, followed by North America.

Species originating from Europe are mainly introduced by horticulture and agriculture, but also ballast water \& sediments and forestry are widely used pathways of introduction. For a large proportion of the taxonomic groups Europe is the main area of origin for the non-native species. These groups are angiosperms, annelids, arthropods, fungi, mammals, molluscs, other invertebrates and reptiles \& amphibians.

The same pathways (horticulture, agriculture, ballast water \& sediments and forestry) apply to species native to Asia, except that transport is also a widely used pathway of introduction. The groups with species primarily from Asia are birds and flatworms.

For species native to North America the main pathway of introduction is horticulture. The groups with species primarily from North America are coniferous plants, ferns and fish. 
Species that originated from Africa or South America are mainly introduced by horticulture and agriculture and for species native to Africa also by transport. Only one group of non-native species originates primarily from Africa and South America, namely bryophytes where an equal number of species is from Africa and South America.

Only a few non-native species originate from Oceania, Antarctica, North Pacific Ocean, South Pacific Ocean, North Atlantic Ocean, South Atlantic Ocean, Indian Ocean, Arctic Ocean and the Southern Ocean. However, some groups largely originate from the North Pacific Ocean, these being: cnidarians, macroalgae and phytoplankton. 


\section{Horizon scanning}

In the horizon scanning 414 potentially invasive species (door knocker species) from 22 taxonomic groups were assessed by experts. The assessments were made to establish the species risk of arriving, establishing and having a negative impact. These assessments are the basis for the calculations that subsequently categorise the species as high, medium or low risk species (see the risk categorisations in the box and in chapter 3.3).

\section{Risk categories}

High risk species (A) are species that were assessed to having one of these two scenarios:

- A high risk of arrival in the region of concern, and a medium risk of establishing and having an impact.

- A medium or high risk of arrival in the region of concern, and a high risk of establishing and having a negative impact.

Medium risk species (B) are species that were assessed to having one of three scenarios:

- A high risk of arrival in the region of concern, but a low risk of establishing and having an impact.

- A medium risk of arrival in the region of concern, and a medium risk of establishing and having an impact.

- A low risk of arrival in the region of concern, but a high risk of establishing and having an impact.

Low risk species (C) are species that were assessed to having one of these two scenarios:

- A low risk of establishing and having an impact, and a low or medium risk of arrival in the region of concern.

- A medium risk of establishing and having an impact, but a low risk of arrival in the region of concern. 
This horizon scanning contains lists and figures of the species assessed as high risk and medium risk species. The analysis is conducted for each region.

The lists of experts are available in appendix 2 , and the complete list of assessed species is available in appendix 18. For the full expert assessments please contact the NOBANIS secretariate.

The number of high risk species (A) for the three regions combined is 43 (see table 18 and species list in appendix 6), while the number of medium risk species (B) is 78 (see table 19 and species list in appendix 7).

Some species were not possible for experts to assess ( $N=58$ for the regions combined, see appendix 8), and is therefore not present in the further analysis. Not assessed means that it has not been possible for the expert to asses all the criterias and these species are therefore taken out of the further analysis.

The species categorised as low risk species (C) are not further discussed in this report, but are listed in appendices 15-17.

Table 18: Number of high risk species $(A)$ in each taxonomic group for the regions combined

\begin{tabular}{lr} 
Group & Number \\
Amphibians & 1 \\
Angiosperms & 3 \\
Arthropods & 20 \\
Birds & 1 \\
Fish & 1 \\
Mammals & 3 \\
Molluscs & 1 \\
Plant-parasitic nematodes & 2 \\
Parasitic nematodes & 2 \\
Pathogenic fungi & 5 \\
Reptiles & 4 \\
Total & 43 \\
\hline
\end{tabular}

Table 19: Number of medium risk species (B) in each taxonomic group for the regions combined

Group Number

Amphibians

Angiosperms

Arthropods

Birds

Fish

Mammals

Molluscs

Plant-parasitic nematode

Non-pathogenic fungi

Parasitic nematode

Pathogenic fungi

Reptiles

Total

Number 
Note that the pathways that are assigned to each species in the horizon scanning are either from the expert assessments, or from NOBANIS data from countries in the NOBANIS network that are not participating in this project.

The assigned pathways are either a known pathway for the species, a known pathway for closely related species or the best estimate of a potential pathway. It is important to remember that one species can have several pathways assigned.

\subsection{Nordic region}

\subsubsection{High risk species (A)}

41 species are categorised as high risk (A) of having a negative impact in the Nordic region (see list in appendix 9). The species originate from 10 different taxonomic groups (see figure 91).

Figure 91: Taxonomic groups of species that are of high risk (A) of having a negative impact in the Nordic region

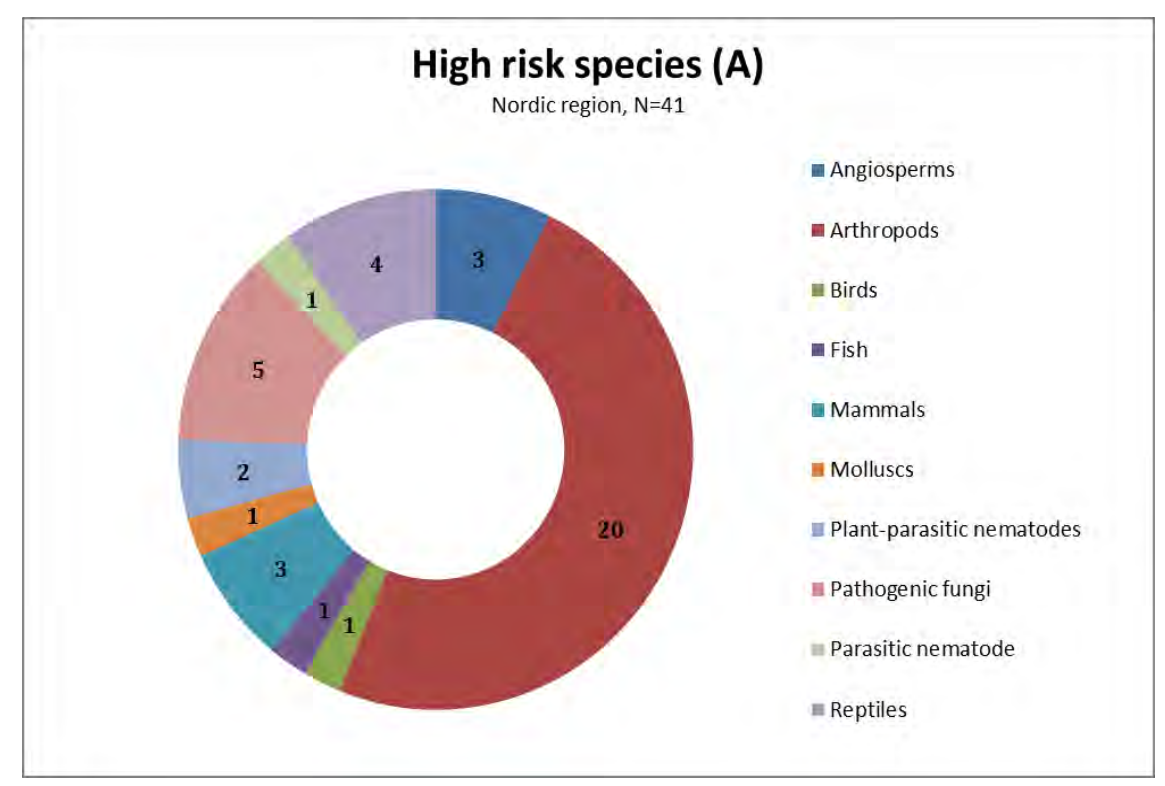


The majority of the high risk species are arthropods, where most are coleoptera $(\mathrm{N}=6)$, pathogenic fungi $(\mathrm{N}=5)$ and reptiles $(\mathrm{N}=4)$. The pathway $^{3}$ of most of the coleopteran is horticulture, while it for pathogenic fungi is horticulture and forestry. The reptiles have escape as their pathway of introduction.

The second largest groups is marine crabs $^{4}(\mathrm{~N}=3)$ and diptera $(\mathrm{N}=3)$ combined where the probable pathways of introductions for marine crabs are by ballast water \& sediments and hull fouling and for the species of diptera it is transport.

The high risk species for the Nordic region have 14 different pathways. Horticulture is the most likely pathway for high risk species $(\mathrm{N}=16$, see figure 92), and is a pathway for angiosperms, arthropods, fungi, molluscs and plant-parasitic nematodes.

Figure 92: Pathways of introduction of species that are of high risk (A) of having a negative impact in the Nordic region

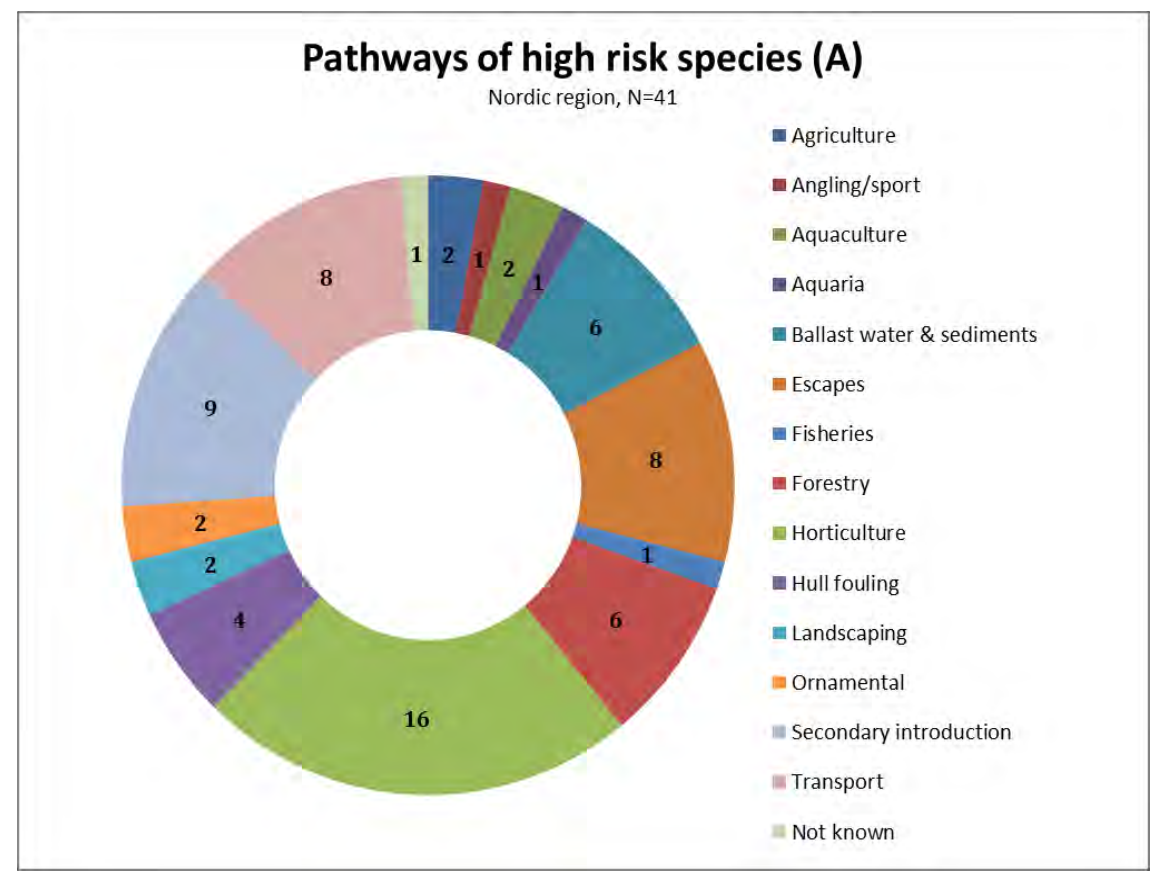

3 The pathways that are assigned to each species in the horizon scanning are from expert assessments or from the NOBANIS database. The assigned pathways are either a known pathway for the species, a known pathway for closely related species or the best estimate for potential pathway.

${ }^{4}$ One species of marine crab Hemigrapsus penicillatus is assessed as a high risk species (A) due to high risk of arrival and establishment, but has a low risk in the assessment of impact. 
Secondary introduction is a probable pathway for 8 high risk species of arthropods and one species of mammal, while transport is a pathway of introduction for 5 species of arthropods and for one species of angiosperm, one parasitic nematode and one mollusc.

Escapes is a pathway for 8 of the species here which are reptiles $(\mathrm{N}=4)$, mammals $(\mathrm{N}=3)$ and one species of bird 5 .

Another likely used pathway by the high risk species is ballast water \& sediments $(\mathrm{N}=6)$ which is a probable pathway for arthropods (amphipods, marine crabs, tanaidacea and prawn).

\subsubsection{Medium risk species (B)}

65 species are categorised as medium risk (B) of having a negative impact in the Nordic region (see list in appendix 10). The species are from 10 taxonomic groups (see figure 93).

Figure 93: Taxonomic groups of species that are of medium risk (B) of having an impact in the Nordic region

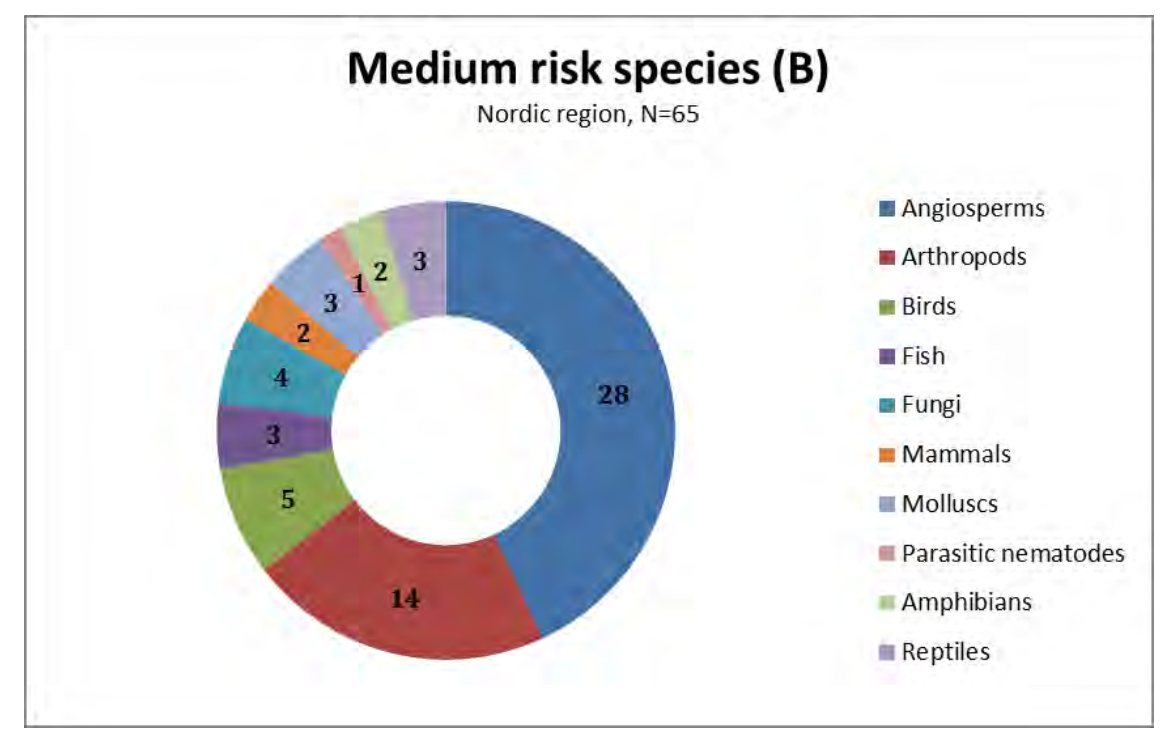

5 This species of birds Myiopsitta monachus is assessed as a high risk species (A) due to high risk of arrival and establishment, but has a low risk in the assessment of impact. 
The largest group of the medium risk species is angiosperms $(\mathrm{N}=28)$. Most of the angiosperms are likely to disperse by horticulture $(\mathrm{N}=20)$, and also by aquaria $(\mathrm{N}=8)$, landscaping $(\mathrm{N}=2)$ and agriculture $(\mathrm{N}=1)$.

The second largest group is arthropods $(\mathrm{N}=14)$ of several types with several probable pathways. The freshwater crayfish $(\mathrm{N}=3)$ are most likely to use aquaria, and for species of lepidoptera $(\mathrm{N}=3)$ it is horticulture.

The medium risk species for the Nordic region are using 15 different pathways. Horticulture is the most likely pathway ( $N=26$, see figure 94$)$ for medium risk species, and is a probable pathway for angiosperms $(\mathrm{N}=20)$, arthropods $(\mathrm{N}=4)$ and fungi $(\mathrm{N}=2)$.

Figure 94: Pathways of introduction of species that are of medium risk (B) of having an impact in the Nordic region

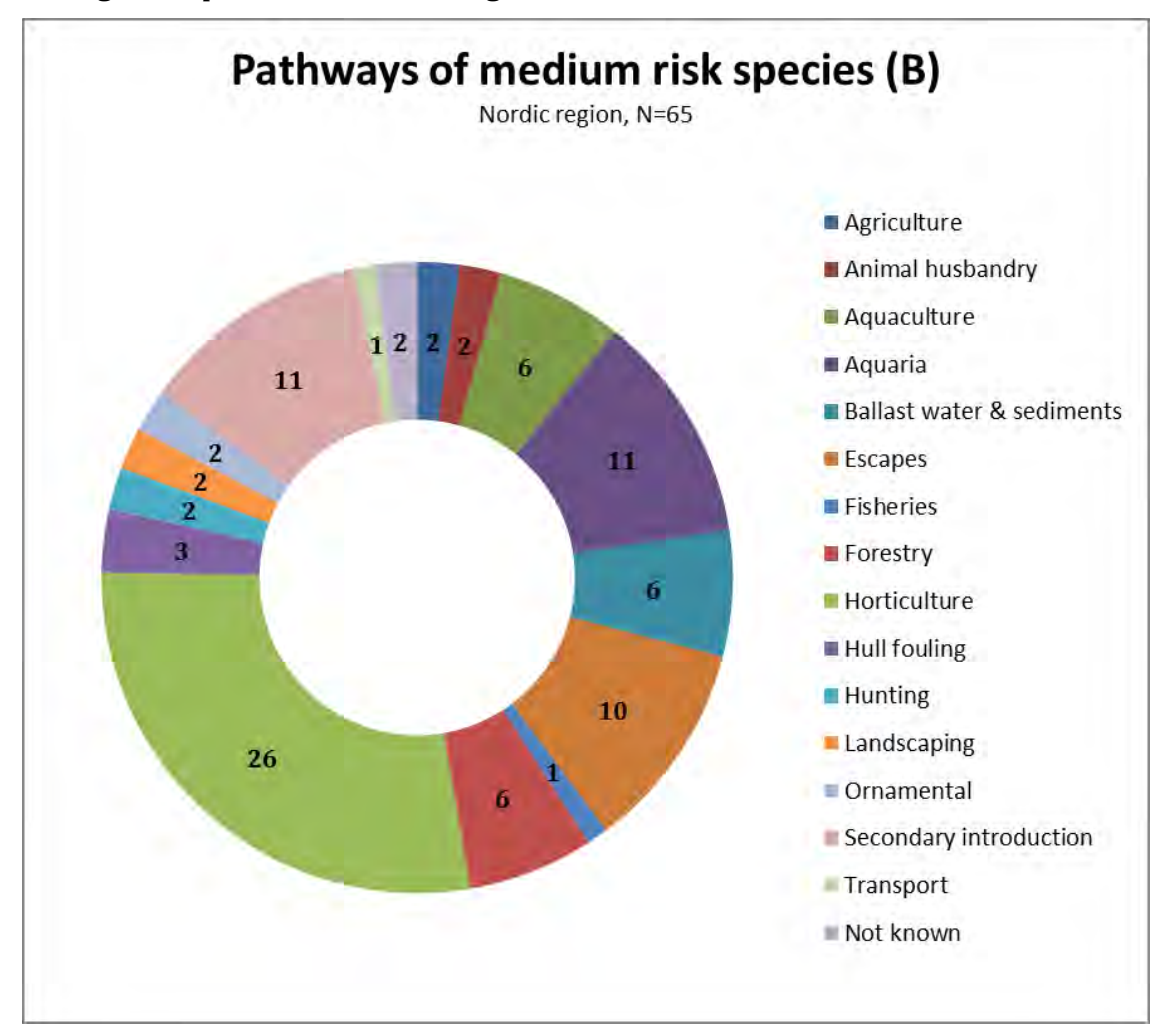

Another likely used pathway by the medium risk species is aquaria $(\mathrm{N}=11)$ which is a probable pathway for angiosperms $(\mathrm{N}=8)$ and arthropods $(\mathrm{N}=3$, freshwater crayfish). Secondary introduction $(\mathrm{N}=11)$ which is a probable pathway for arthropods $(\mathrm{N}=6)$, molluscs $(\mathrm{N}=2)$, fish $(\mathrm{N}=1)$, fungi $(\mathrm{N}=1)$ and reptiles $(\mathrm{N}=1)$ is another likely used pathway for medium risk species. 
Escapes is a probable pathway for 10 of the species here, which are reptiles $(\mathrm{N}=3)$, birds $(\mathrm{N}=2)$, mammals $(\mathrm{N}=2)$, amphibians $(\mathrm{N}=2)$ and arthropods $(\mathrm{N}=1)$.

\subsection{Baltic region}

\subsubsection{High risk species (A)}

26 species are categorised as high risk (A) of having a negative impact in the Baltic region (see list in appendix 11). The species originate from 8 taxonomic groups (see figure 95).

Figure 95: Taxonomic groups of species that are of high risk (A) of having a negative impact in the Baltic region

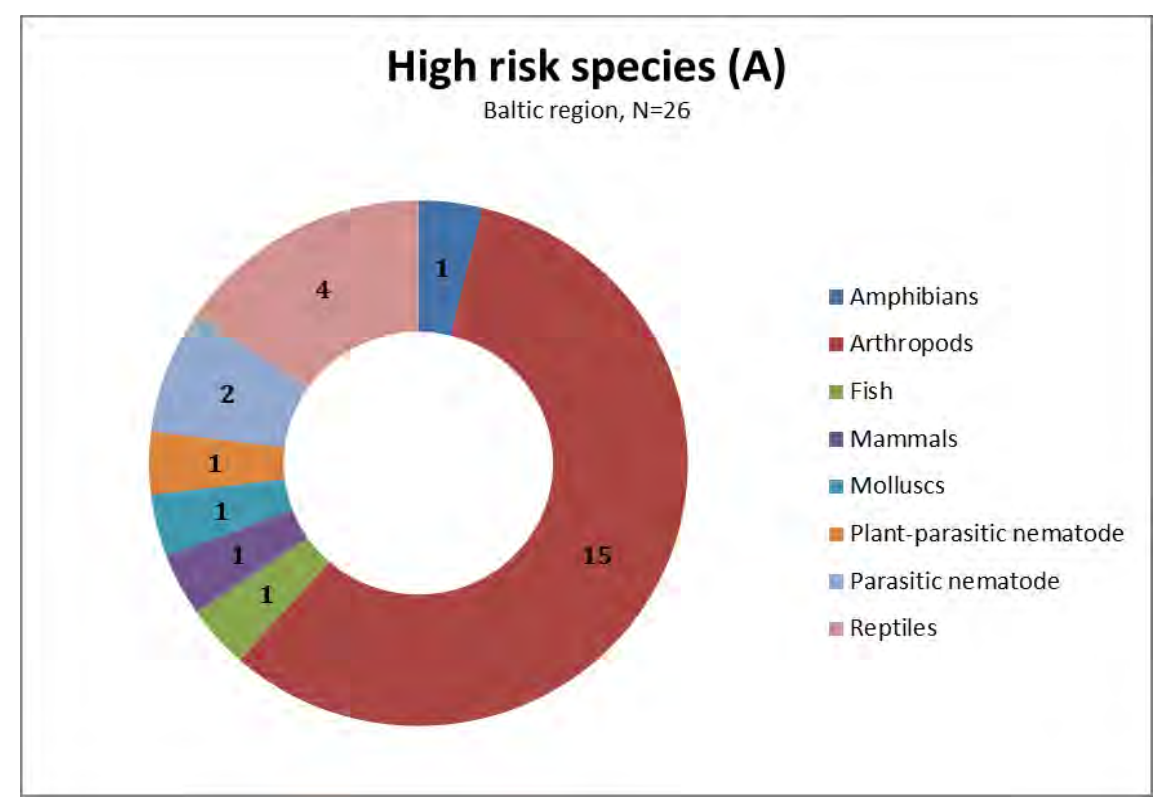

The majority of the high risk species are arthropods $(\mathrm{N}=15)$, where most are coleoptera $(\mathrm{N}=6)$ and diptera $(\mathrm{N}=3)$. Most of the coleopteran have horticulture $(\mathrm{N}=4)$ as a propable pathway ${ }^{6}$, while the species of diptera have transport $(\mathrm{N}=2)$.

${ }^{6}$ The pathways that are assigned to each species in the horizon scanning are from expert assessments or from the NOBANIS database. The assigned pathways are either a known pathway for the species, a known pathway for closely related species or the best estimate for potential pathway. 
The second largest group is reptiles $(\mathrm{N}=4)$, where all the species have escape as the probable pathway of introduction.

The high risk species for the Baltic region have 11 different pathways. Transport is the most likely pathway for high risk species in the Baltic region ( $\mathrm{N}=8$ see figure 96 ) to use. Especially species of arthropods $(\mathrm{N}=5)$ may use transport as the most likely pathway of introduction, but also for one species of molluscs and one parasitic nematode it is a possible pathway of introduction.

Horticulture is also a pathway for many high risk species in the Baltic region ( $N=7$, see figure 96$)$, and is a probable pathway for species of arthropods $(\mathrm{N}=5)$, as well as plant-parasitic nematodes $(\mathrm{N}=1)$ and mol$\operatorname{luscs}(\mathrm{N}=1)$.

Figure 96: Pathways of introduction of species that are of high risk (A) of having a negative impact in the Baltic region

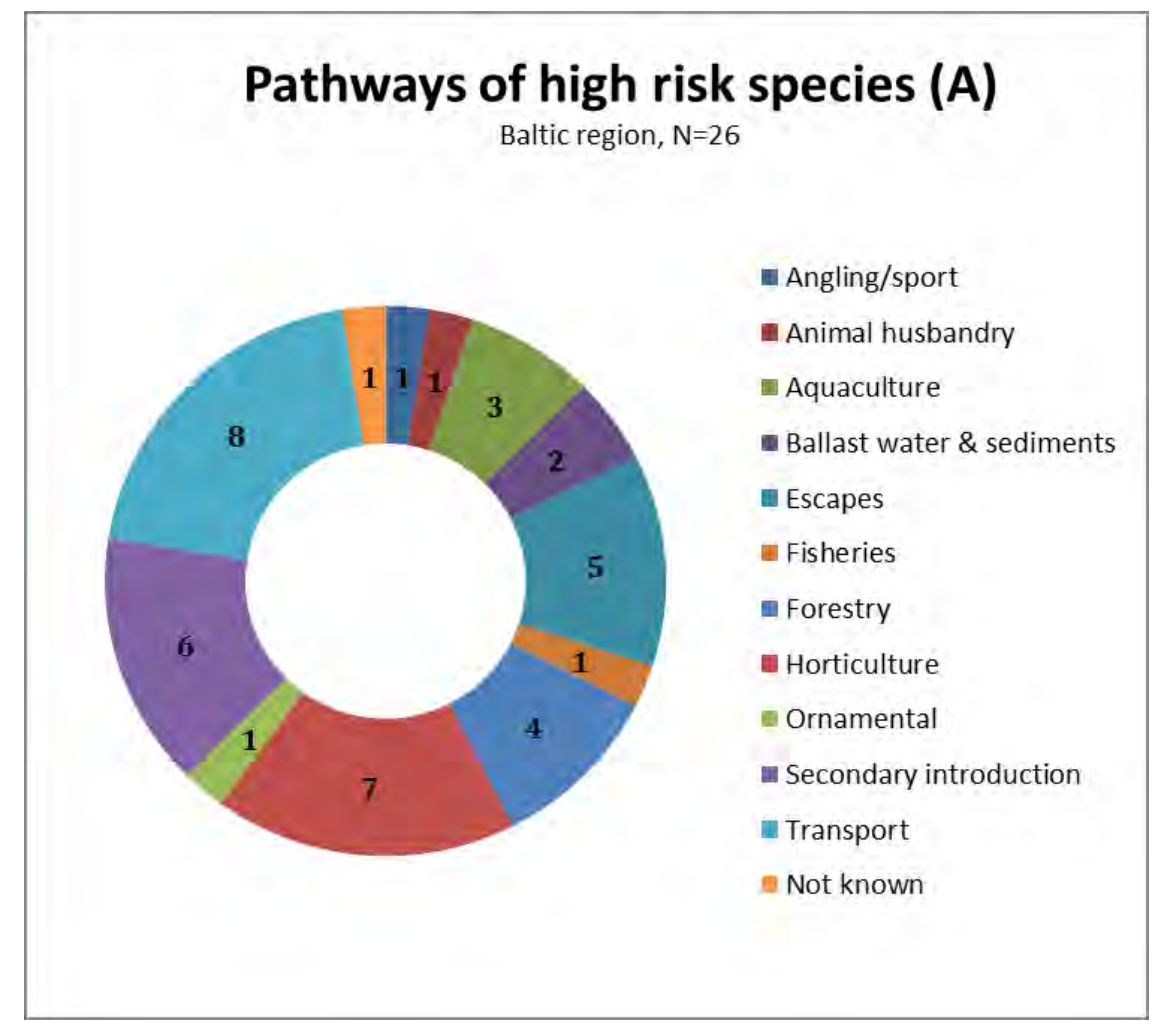

Secondary introduction is a pathway of introduction for 6 species: 5 arthropods and one species of amphibians. Another likely used pathway by the high risk species is escape $(\mathrm{N}=5)$ which is a probable pathway of introduction for four species of reptiles and one species of mammals. 


\subsubsection{Medium risk species $(B)$}

33 species are categorised as medium risk (B) of having a negative impact in the Baltic region (see list in appendix 12). The species originate from 8 taxonomic groups (see figure 97).

Figure 97: Taxonomic groups of species that are of medium risk (B) of having an impact in the Baltic region

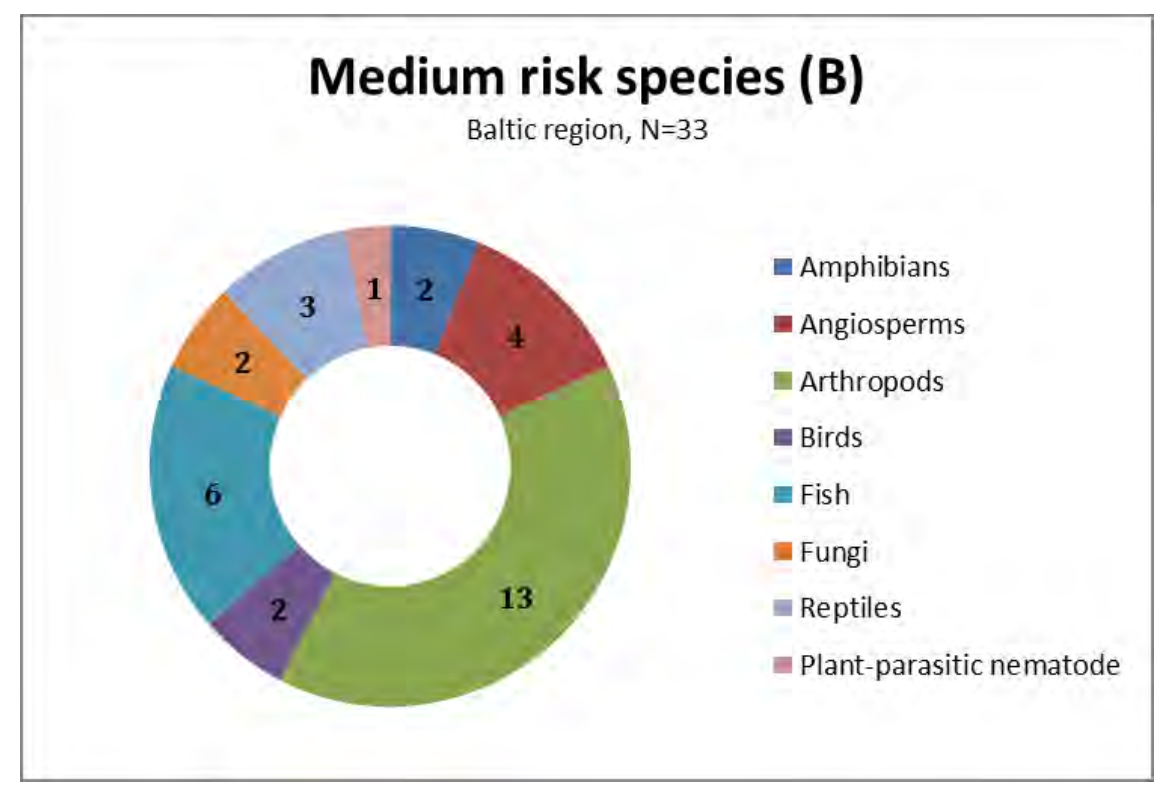

The majority of the medium risk species are arthropods ( $\mathrm{N}=13)$, where most are lepidoptera $(\mathrm{N}=4)$ and diptera $(\mathrm{N}=3)$. Most of the species of lepidoptera and diptera may use horticulture $(\mathrm{N}=3, \mathrm{~N}=1)$ as a propable pathway. For two of the diptera species, no pathway of introduction into the Baltic region was suggested.

The second largest group is fish $(\mathrm{N}=6)$, where the most probable pathways are ballast water and sediments $(\mathrm{N}=3)$ and secondary introduction $(\mathrm{N}=3)$.

The medium risk species for the Baltic region have 14 different pathways. Horticulture is the most likely pathway for medium risk species to use ( $\mathrm{N}=12$, see figure 98$)$ and is a probable pathway for arthropods $(\mathrm{N}=6)$, angiosperms $(\mathrm{N}=3)$ and fungi $(\mathrm{N}=2)$. 
Figure 98: Pathways of introduction of species that are of medium risk (B) of having an impact in the Baltic region

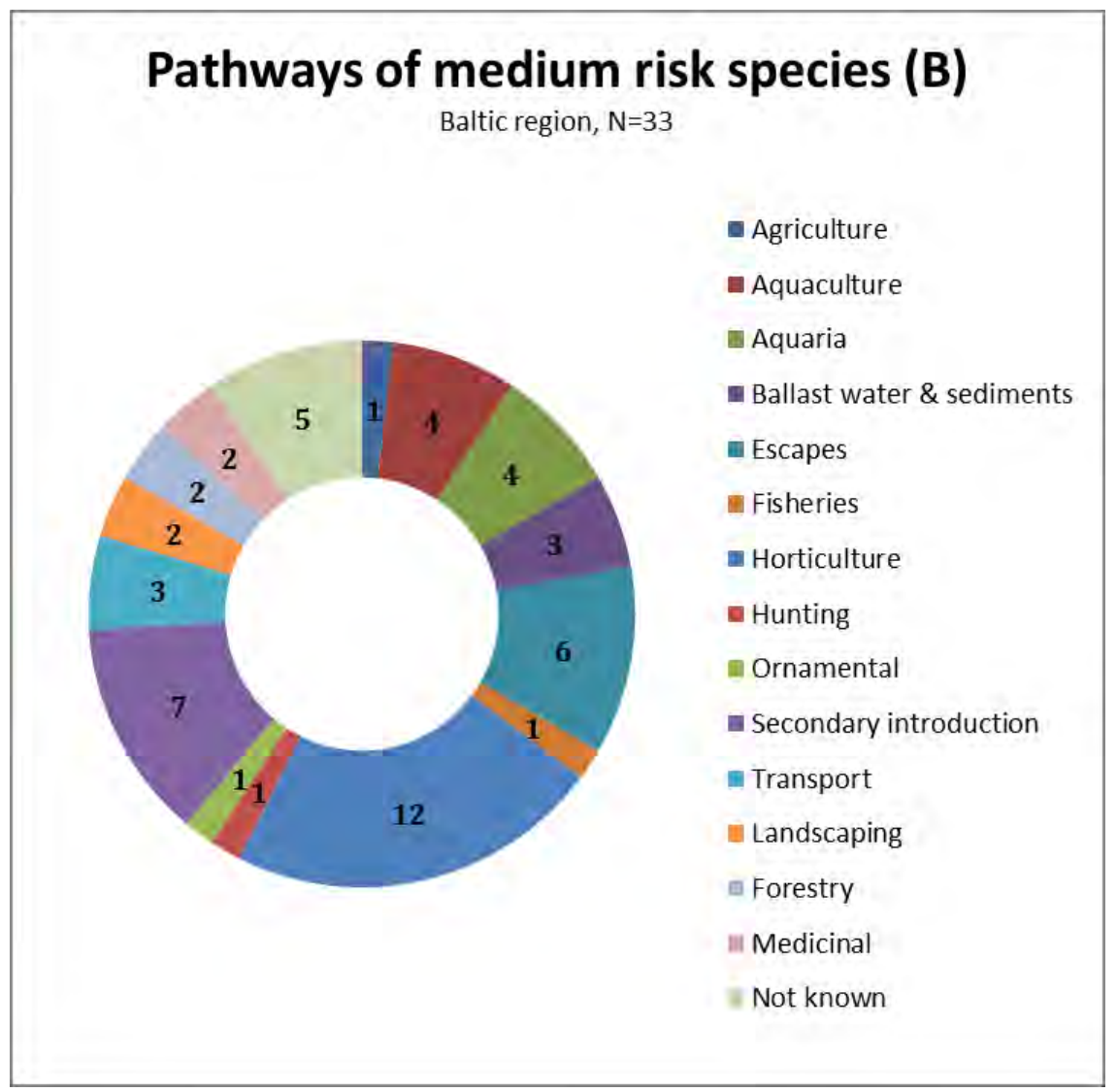

Secondary introduction is a propable pathway for 7 species. Particulary arthropods $(\mathrm{N}=3)$, fish $(\mathrm{N}=3)$ and one species of reptile may be introduced by secondary introduction, while escape is a propable pathway for 6 species: 3 reptiles, 2 amphibians and one species of arthropod.

\subsection{Islands of the North Atlantic Ocean}

\subsubsection{High risk species $(A)$}

Only two species are categorised as high risk (A) of having a negative impact in the Islands of the North Atlantic Ocean (see list in table 20 or appendix 13). The species originate from two taxonomic groups which are using two pathways each. 
The arthropod (Vespa velutina) has transport and secondary introduction as its pathway ${ }^{7}$, while the mammal (Sciurus carolinensis) has escapes and ornamental as a probable pathway of introduction.

Table 20: High risk species (A) of the Islands of the North Atlantic Ocean

\begin{tabular}{lll} 
Taxonomic group & Species & Pathway \\
Mammals & Sciurus carolinensis & Ornamental, Escapes \\
Arthropods/wasp & Vespa velutina & Secondary introduction, Transport \\
\hline
\end{tabular}

\subsubsection{Medium risk species $(B)$}

9 species are categorised as medium risk (B) of having a negative impact in the Islands of the North Atlantic Ocean (see list in appendix 14). The species originate from three taxonomic groups (see figure 99).

Figure 99: Taxonomic groups of species that are of medium risk (B) of having an impact in the Islands of the North Atlantic Ocean

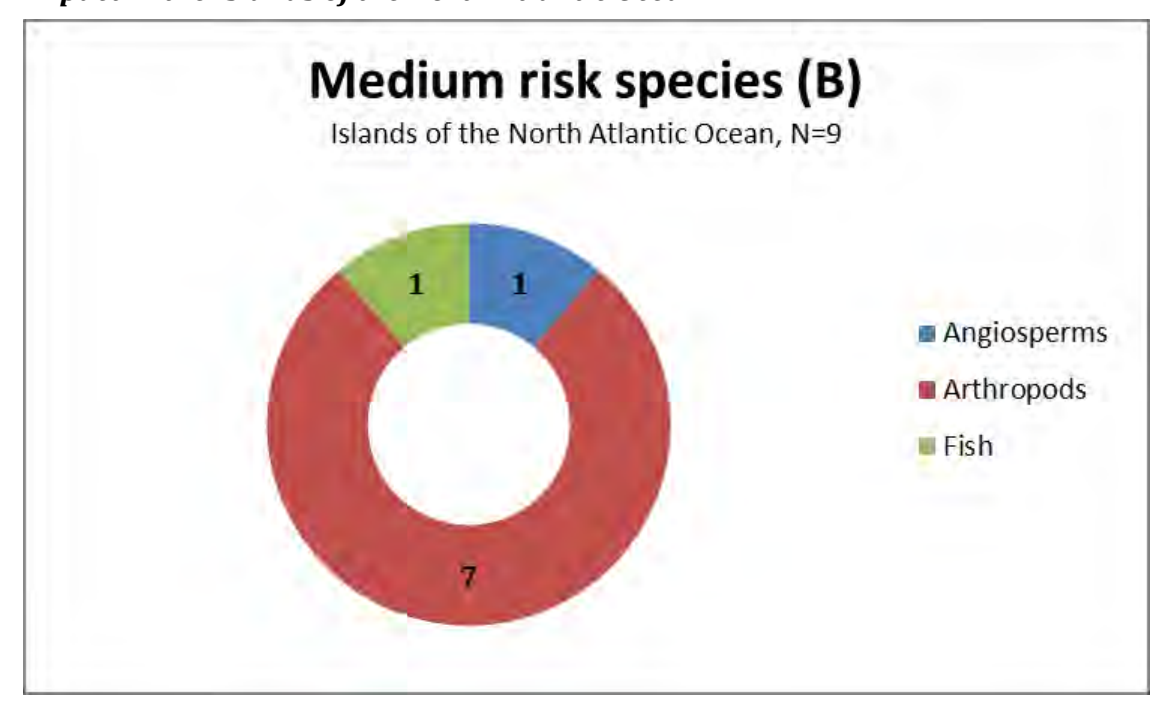

The majority of the medium risk species are arthropods $(\mathrm{N}=7)$, where most are species of diptera $(\mathrm{N}=5)$. The other two organisms are an angiosperm and a fish.

7 The pathways that are assigned to each species in the horizon scanning are from expert assessments or from the NOBANIS database. The assigned pathways are either a known pathway for the species, a known pathway for closely related species or the best estimate for potential pathway. 
The medium risk species for the Islands of the North Atlantic Ocean has 8 different pathways. Horticulture $(\mathrm{N}=2$, see figure 100) and transport $(\mathrm{N}=2)$ are the most likely used pathways, and the main species probable to be introduced by these are arthropods.

Figure 100: Pathways of introduction of species that are of medium risk (B) of having an impact in the Islands of the North Atlantic Ocean

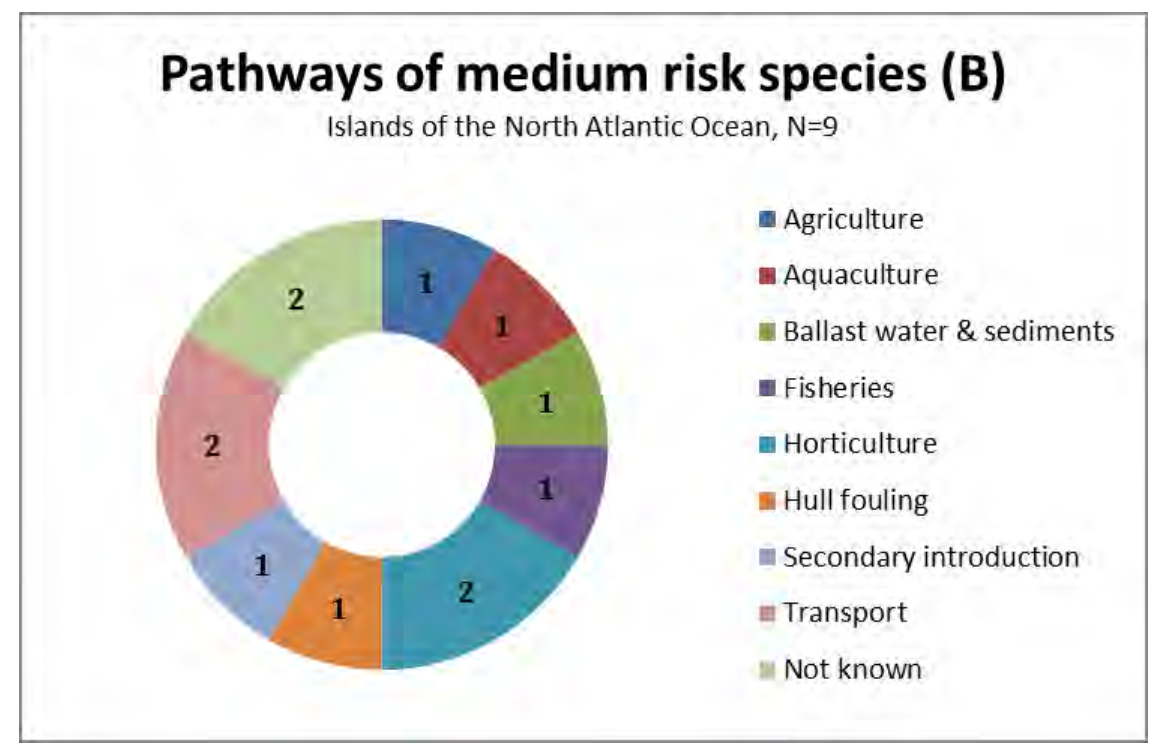

\subsection{Summary}

The number of different high risk species (A) for the three regions combined is 43, while the Number of medium risk species (B) is 78 .

In the Nordic and Baltic region the arthropods are the largest group of the high risk species (A), and in the Islands of the North Atlantic Ocean one of the two high risk species is an arthropod. The most probable pathways for them to use are horticulture, secondary introduction and transport, but a number of other pathways are also likely to be used by the high risk species.

The medium risk species (B) in the regions are mostly angiosperms and arthropods. The most probable pathway for them to use is also horticulture, along with secondary introduction. 


\subsubsection{Nordic region}

41 species are categorised as high risk (A) of having a negative impact in the Nordic region. The largest group is arthropods, followed by pathogenic fungi and reptiles.

The high risk species for the Nordic region may use 14 different pathways. Horticulture is the most likely pathway, followed by secondary introductions, transport, escape, forestry and ballast water \& sediments.

65 species are categorised as medium risk (B) of having an impact in the Nordic region. The largest group is angiosperms, followed by arthropods.

The medium risk species for the Nordic region may use 15 different pathways. Horticulture is the most probable used pathway, but also aquaria, secondary introduction and escape are likely to be used by several species.

\subsubsection{Baltic region}

26 species are categorised as high risk (A) of having a negative impact in the Baltic region. The majority of the high risk species are arthropods, followed by reptiles.

The high risk species for the Baltic region may use 11 different pathways. Transport is the most probable used pathway, along with horticulture and secondary introduction.

33 species are categorised as medium risk (B) of having an impact in the Baltic region. The majority of the species are arthropods $(\mathrm{N}=13)$, followed by fish $(\mathrm{N}=6)$.

The medium risk species for the Baltic region may use 14 different pathways. Horticulture is the most probable pathway to be used, but also secondary introduction and escape are likely to be used by several species.

\subsubsection{Islands of the North Atlantic Ocean}

Two species are categorised as high risk (A) of having a negative impact in the Islands of the North Atlantic Ocean. The species are an arthropod (Vespa velutina) which most likely will be introduced by transport and secondary introduction, and a mammal (Sciurus carolinensis) which most likely will be introduced by escape and ornamental use.

9 species are categorised as medium risk (B) of having a negative impact in the Islands of the North Atlantic Ocean. The majority of these are arthropods, while the others are an angiosperm and a fish.

The medium risk species for the region may use 8 different pathways of introduction, where horticulture and transport are the most likely used pathways. 



\section{Discussions}

\subsection{Pathway analysis}

The results from the pathway analysis are based on the current data available in the NOBANIS database, and since the environment and the species within it are dynamic, the information available will change over time. The new species and information that will be registered in the database are not definitive, but rather a current view, so further studies should be made.

\subsubsection{Pathways of introduced species}

This analysis shows that the main pathway of introduction in all three regions is horticulture, followed by agriculture, transport, forestry and ballast water \& sediments, but also that there are variations between the regions. The differences may reflect the difference in the countries' or territories' political history and trade traditions that can affect the use of pathways due to differences in import policy, trading relations and the handling of goods.

For some species with known pathways of introduction, it could be suitable to define the pathway of introduction on a smaller scale, or revise the pathway classifications as globalisation increases and new trading relations evolve (Essl et al. (in revision)). These initiatives may facilitate more thorough registration and management of certain pathways, to reduce introduction of invasive alien species of concern.

The analysis also shows that the majority of species introduced has an unidentified pathway of introduction. The missing information may reflect the challenge of identifying pathway of introduction for species that are unintentionally introduced. Furthermore, differences in percentage of unknown pathways between the regions may be caused by differences in method and degree of data collection. 


\subsubsection{Invasiveness of introduced species}

When examining the results of this analysis the groups with the highest number of invasive or potentially invasive species are angiosperms and arthropods. But looking at the percentage distribution, the groups with the highest degree of invasive or potentially invasive species differ between the regions. In the Nordic region microorganisms, flatworms and fungi are the groups with highest percentage of invasive species, while for the Baltic region it is species of annelids and fish. For Islands of the North Atlantic Ocean it was not possible, due to limited dataset, to identify the taxonomic groups with most invasive species present, but birds and mammals were the groups with most introductions of potentially invasive species. This inconsistency among the three regions may be due to differences in trading and import.

Looking at the pathways with the most introductions of species with high invasiveness, horticulture is again the main pathway of concern, followed by agriculture, transport, ballast water \& sediments and forestry. These results correspond with the results in Pathways of introduced species (chapter 4.1) and the result from the Danish study by Madsen et al. (2014), where horticulture also was the main pathway of introduction for nonnative species. On the other hand, when looking at the percentage of introductions that are invasive, the numbers are low for horticulture and agriculture, showing that the pathways with the highest number of introductions not always are the ones with the largest number of invasive alien species. This shows that the most frequently used pathways not necessarily contribute with the highest number of invasive species.

\subsubsection{Taxonomic groups of introduced species}

In this analysis, angiosperms are the group with the highest number of alien introductions and arthropods are the group with the second highest number of introductions in all three regions. The high number of introductions of angiosperms, which is primarily by horticulture, and as seen in the subanalysis Temporal development of pathways (chapter 4.4), introduction by horticulture has increased markedly since the 1700 , which corresponds to the high number of introductions of angiosperms.

For the arthropods, the high number of introductions may reflect that the group is highly diverse and therefore, has a wide range of pathways for dispersal. This means that prioritising pathways of concern can be challenging and costly and further studies of arthropods and specific subgroups and their pathways of introductions are needed. This is also the case for the molluscs representing marine, freshwater and terrestrial 
species, making it difficult to prioritise pathways of concern, when dealing with the different types of habitats and environment. Prioritisation of pathways when dealing with diverse groups of species with a high number of pathways can therefore be facilitated by using the results from the other analyses in this project, e.g. percentage of invasive species with each pathway and door knocker species.

Microorganisms and phytoplankton have been registered with a relatively few species in the participating countries and territories and in the NOBANIS database in general. Many small organisms can be challenging to detect, due to their small size and perhaps their use of vectors or hosts (primarily microorganisms), and it is possible that some of these species of smaller organisms already are present, but not registered in the NOBANIS database. In general, plant and animal pathogens are believed not to be fully represented in the NOBANIS database, due to these being in a grey zone between influence on plant and animal health and impact on biodiversity. Many of these organisms are identified in databases focusing on plant and animal health. The lack of consistency regarding registrations of plant and animal pathogens in the NOBANIS database can be minimized by defining clear guidelines for which species is registered in which database.

The type of introduction (intentional or unintentional) varies between the different groups, and knowledge on these differences is an important element when planning measures of control. Many introductions of species are intentional, for example for most introductions of coniferous plants, fish, and mammals. In these cases information campaigns can be part of the preventive initiatives applied. On the other hand, unintentional introductions are more challenging to prevent, because there are uncertainties about where to apply preventive initiatives.

Many species are registered in the NOBANIS database as introduced both intentionally and unintentionally, as they may be of different type within a country or of different type in each of the countries in the regions. These introductions should be managed like both types, to ensure that all new introductions are prevented or reduced.

Secondary introduction is a pathway, which is difficult to manage in order to prevent further introduction and spread of species across borders, due to the fact that these introductions are unintentional. In these cases, an early warning system (see the chapter 8 Recommendations) can assist in reducing these introductions, by neighbouring countries alerting each other (see chapter 8.2 Early warning system later in the report) regarding new species of concern (NOBANIS 2010). 


\subsubsection{Temporal development of pathways}

The registrations of introductions of alien species are increasing in all three regions. Especially the pathways horticulture, aquaculture, transport and forestry are increasing in the regions. The overall increase in registered introductions may reflect both the increase in globalisation, but also the global awareness concerning invasive alien species and the negative impact they have on native biodiversity, socio-economic concerns and in some cases human health.

There is, however a decrease in registrations over time for some of the pathways of introduction. Introductions by agriculture, medicinal and ballast water \& sediments have decreased in the Nordic region while agriculture, escapes and landscaping have decreased in Iceland.

The decrease in introductions by agriculture in the Nordic region may reflect that import of crops for food consumption etc. has expanded over the last 100 years. So instead of cultivating crops on the field, we import cultivated food items from outside the region. More restrictions when importing seed mixtures (Commission Regulation (EU) 2011) and seed in general for cultivation etc. may prevent some species of stowaways, and also the use of certain hybrid species (F1) for cultivation may prevent/minimize the spread of crops from fields into the wild.

The reductions in the number of registrations of the medicinal pathway may be caused by new knowledge and development in the medical field, and that the use of animals and plants in medicine is closely monitored.

The reduction in the use of ballast water \& sediments as a pathway of introduction can indicate an increase in awareness in recent years. Hopefully the reduction in alien species entering with ballast water \& sediments will continue with the convention "International Convention for the Control and Management of Ships Ballast Water \& Sediments" of 2004. In Iceland, restrictions on import of all animals may cause the decrease in introduction of alien species by escapes.

The current period from the year 2000 and until now is not finished and therefore not comparable to the other periods. It is therefore not shown in the graphs. If we also look at the data from 2000-2014 (shown in appendices 4 and 5) we can see the currently active pathways, but not whether there is an increase or decrease in introductions in recent times. However, there is a tendency for development in the landscaping pathway. The number of registrations for landscaping in the Nordic region from 2000 and until now is already higher than the sum from the previous fifty year periods, so it is certain that there is now an increase, which may further accelerate in the future. 


\subsubsection{Species origin and the pathways of introduction}

Most of the non-native species registered in the participating countries and territories originate from Europe and Asia, followed by North America, which primarily is due to the similarities in the biogeographic zones between Europe, Asia and North America, making it possible for alien species to establish. The high number of introduction of European species may also be due to the closeness of the area of origin to the area of introduction, and the high degree of trading within the European countries and territories.

The high number of introduction of Asian species, which is primarily by horticulture and agriculture, can be explained by the high percentage of import of Asian goods to the participating countries and territories. There is also a high degree of import from North America e.g. coniferous plants, which may explain the introductions of species native to North America (WTO 2014).

Looking at the different taxonomic groups and their areas of origin, and comparing them with the results obtained in Invasiveness of introduced species (chapter 4.2), the majority of the taxonomic groups with many invasive or potentially invasive species originates from Europe, Asia and North America. This again reflects the high degree of import from these parts of the world, which leads to a high number of introductions where some species may become invasive.

For all countries and territories in this study there are species where information regarding pathway of introduction, invasiveness etc. is missing. This missing information may mean that pathways of introductions are undetected, that new pathways may need to be defined, or that the degree of invasiveness is unclear. Additional studies and scientifically validated data are needed in order to identify pathways of introduction, as well as to clarify the invasive status of some non-native species registered in the regions. Further study of those particular species may increase the amount of information, and give us a more comprehensive understanding of invasive alien species to help prevent introduction, and to manage and eradicate the species. However, it will never be possible to obtain all relevant information due to the unpredictability of species in new environments etc. 


\subsection{Horizon scanning}

The large number of arthropods that are of high risk of arriving, establishing and having an impact on native biodiversity etc. in the regions, reflects the high diversity of the group. Several probable pathways of introduction make management initiatives a challenging task. There are some pathways that are more likely to be used by several species than others, and these can form the basis for management plans.

The medium risk species in the regions are mostly angiosperms and arthropods. The angiosperms, as well as the arthropods, are also a relatively diverse group with both terrestrial and aquatic habitats. The main pathway of introduction for the high and medium risk species of angiosperms is horticulture. For medium risk species of arthropods, horticulture and secondary introduction are the main pathways of introduction.

Making management initiatives for horticulture in general is likely to have a significant effect towards preventing high risk species and medium risk species of angiosperms and arthropods to be introduced in the regions.

Introductions by secondary introductions may be more challenging to manage. For the management of the secondary introductions an early warning system may be the best option. Here countries in the regions can warn each other about new invasive species and share information regarding prevention, management etc.

\subsubsection{Nordic region}

The Nordic region has a large group of high risk arthropods. The different types of arthropods have different probable pathways of introduction to the region, but primarily secondary introductions, ballast water \& sediments and horticulture are pathways of importance. These differ from the historic pathways seen for arthropods in the Nordic region in Taxonomic groups of introduced species (chapter 4.3), where the pathways horticulture, transport and forestry stand out. This indicates that there is a need for continuously adapting management initiatives to the current situation. Reduction of high risk arthropods may also reduce the introductions of medium risk arthropods.

The Nordic region has the largest number of medium risk angiosperms, which are introduced primarily by horticulture. The history of introductions of angiosperms by horticulture is supported by the subanalysis Taxonomic groups of introduced species (see chapter 4.3), although the invasiveness of these species is relatively low, compared to the other taxonomic groups in Invasiveness of introduced species (see 
chapter 4.2). Furthermore, in the subanalysis Temporal development of introductions (see chapter 4.4) there has been an increase of introductions by horticulture over time.

Management of introductions by horticulture in the Nordic region may also reduce the introductions of other groups, i.e. non-pathogenic fungi, pathogenic fungi and plant-parasitic nematodes, depending on the type of initiatives.

\subsubsection{Baltic region}

As seen in the Nordic region, the Baltic region also has a large group of high risk arthropods. The different types of arthropods have different pathways, but mostly secondary introductions, transport and horticulture are pathways of importance.

If we look at the historic pathways seen for arthropods in the Baltic region in Taxonomic groups of introduced species (chapter 4.3), the majority of the introductions are by unknown pathway. Also the invasiveness is unknown for the majority of the arthropods introduced to the Baltic, reflecting that knowledge concerning non-native arthropods in the Baltic is limited, and that further studies need to be made. This analysis of the most probable pathways of door knocker species, along with the historic pathways of introduction to the other regions, gives us valuable information regarding pathways of introduction for arthropods that can form the basis for management initiatives.

Management of the pathways for the high risk arthropods (horticulture and transport) may also reduce the introductions of the medium risk arthropods and other groups of door knocker species, e.g. medium risk angiosperms, fungi, fish and nematodes.

Attention on escapes in the Baltic region may also contribute to reduction of both high and medium risk species. This is due to the presence of four reptiles and one mammal on the high risk list, and three reptiles and one arthropod on the medium risk list. These 9 species are most likely to be introduced by escapes, and awareness campaigns on the negative effect of releasing pets and exotic animals into the wild might prevent some introductions.

\subsubsection{Islands of the North Atlantic Ocean}

Only two species are categorised as high risk (A) for the Islands of the North Atlantic Ocean. The species are an arthropod (Vespa velutina) most likely to be introduced by transport and secondary introduction, 
and a mammal (Sciurus carolinensis) most likely to be introduced by escapes and ornamental use. Therefore, only four pathways are important for management of the high risk species.

Even though the formerly introduced species of arthropods have had a low invasiveness (see chapter 4.2 Invasiveness of introduced species), the arthropod mentioned above is categorised as a high risk species. Furthermore, managing transport to prevent the introduction of the species may handle some species on the medium risk list as well. The invasiveness of the formerly introduced mammals is relatively high, although the results are based on only a few species.

The other medium risk species (primarily arthropods) might use a number of probable pathways, but with horticulture and transport as pathways of high importance. Horticulture is also a pathway of importance in the historic data on arthropods in Taxonomic groups of introduced species (chapter 4.3) and an increasingly important pathway in Temporal development of introductions (chapter 4.4), so initiatives towards horticulture may reduce further and new introductions of invasive and alien species of arthropods in the region.

\subsubsection{Methods}

For some species it was not possible for the expert(s) to make the assessments, due to the lack of knowledge and/or information on the particular species. The unassessed species may become threats in the future, because their invasiveness and pathways are unknown and therefore unmanaged, so new knowledge is continuously needed to evaluate the potential door knocker species.

The species that are assessed as low risk (C) are not considered to be immediate threats right now, but they may become threats in future (near, medium and long term). In the near future we might see changes in the type of goods transported, trading relations, habitats and dispersal of species etc. On a longer term we may expect changes in our climate which may change our environments to a great extent. This change in factors may be beneficial for some species, which then may be able to arrive, establish and become invasive.

In the horizon scanning the species are assigned pathways based on registrations in the NOBANIS database, along with expert assessments of known or probable pathways of the species or closely related species. These assigned pathways may not be all the pathways the species may use. Therefore, focus on the pathways is still needed as they may change over time. 
The horizon scanning was designed to be sensitive to species with a risk of having a negative impact, to prevent invasive species from receiving a too low risk assessment. Therefore, two species that scored high in arrival and establishment, but low in each of the three impact scores were assessed as high risk species, despite their low impact scores.

Making measures to control potential door knocker species in the marine environment may pose a great challenge in the future, and the assessment of some of the marine species in this project may have some uncertainties due to the difference in the coastal environment among the countries. E.g. Finland is part of the Nordic region in this analysis, due to terrestrial parameters, but the marine environment is more similar to the Baltic Sea than the marine environment along the coast of Denmark and Norway. Therefore, the marine environment in Finland has more in common with the countries in the Baltic region, i.e. brackish water with low salinity (Matz Berggren, pers. comm.).

The division of the three regions, where countries and territories, with different positions both regarding geographical position and climate are joined together, could give some uncertainty in the assessments results for the potentially door knocker species. But as mentioned in the methods, the division of the participation countries and territories is based on several attributes, and not only the geographical position and climate. Also topography, political history and the trading/import of goods (indirect influence the pathway of introduction) has been taking into account.

Potential door knocker species were eliminated from the final list when established in one or more of the participating countries and territories. By doing this, we may have excluded alien species on the final list that may be important door knockers for some participating countries and territories.

The environment and the species within it are dynamic and the assessments made by experts are based on the presently available information. The results in this analysis are therefore based on the current situation and experts' best estimates. We therefore recommend that the species on the horizon list are further examined, and by several experts, to get broader assessments of the species ability to arrive, establish and the impact they may have on biodiversity, human health and socio economic concerns. 



\section{Prioritisation of pathways}

In the process of prioritising pathways of concern, we looked at the results from the pathway analysis. The prioritisation was done based on:

- Number of introduced invasive species by the pathway.

- Number of introductions through the pathway.

Subsequently, other parameters from the pathway analysis and the horizon scanning were taken into account to make adjustments to the prioritisation of the pathways:

- Invasive introductions (\%). ${ }^{8}$

- Number of high risk (A) door knocker species that is assigned to the pathway.

- Number of medium risk (B) door knocker species that is assigned to the pathway.

- Number of potentially invasive introductions.

- Temporal development of pathways.

Pathways with less than 25 registrations of introduction were not considered to be pathways of concern in this report, and were therefore not included in the prioritised list, unless other of the parameters above showed that the pathway was of concern.

The list of prioritised pathways is the guideline for future management, and is presented for each region while the arguments for the prioritisation are described afterwards.

${ }^{8}$ Invasive introductions $(\%)=$ (invasive introductions by that pathway/all introductions by that pathway) $\mathrm{x} 100$ ). 


\subsection{Nordic region}

The prioritised list of pathways of concern for the Nordic region is presented in table 21 .

Table 21: Prioritised list of pathways of concern for the Nordic region

\begin{tabular}{|c|c|c|}
\hline Priority & Pathway & \\
\hline \multirow[t]{6}{*}{1} & Horticulture & \\
\hline & Invasive introductions & $282(16 \%)$ \\
\hline & Number of introductions & 1763 \\
\hline & High risk species (A) & 16 \\
\hline & Medium risk species (B) & 26 \\
\hline & Number of potentially invasive introductions & 251 \\
\hline \multirow[t]{6}{*}{2} & Transport & \\
\hline & Invasive introductions & $109(32 \%)$ \\
\hline & Number of introductions & 342 \\
\hline & High risk species $(A)$ & 8 \\
\hline & Medium risk species (B) & 1 \\
\hline & Number of potentially invasive introductions & 61 \\
\hline \multirow[t]{6}{*}{3} & Ballast water \& sediments & \\
\hline & Invasive introductions & $72(29 \%)$ \\
\hline & Number of introductions & 250 \\
\hline & High risk species $(A)$ & 6 \\
\hline & Medium risk species (B) & 6 \\
\hline & Number of potentially invasive introductions & 57 \\
\hline \multirow[t]{6}{*}{4} & Agriculture & \\
\hline & Invasive introductions & $86(15 \%)$ \\
\hline & Number of introductions & 561 \\
\hline & High risk species $(\mathrm{A})$ & 2 \\
\hline & Medium risk species (B) & 2 \\
\hline & Number of potentially invasive introductions & 63 \\
\hline \multirow[t]{6}{*}{5} & Secondary introduction & \\
\hline & Invasive introductions & $43(40 \%)$ \\
\hline & Number of introductions & 108 \\
\hline & High risk species $(A)$ & 9 \\
\hline & Medium risk species (B) & 11 \\
\hline & Number of potentially invasive introductions & 23 \\
\hline \multirow[t]{6}{*}{6} & Forestry & \\
\hline & Invasive introductions & 48 (21\%) \\
\hline & Number of introductions & 225 \\
\hline & High risk species $(\mathrm{A})$ & 6 \\
\hline & Medium risk species (B) & 6 \\
\hline & Number of potentially invasive introductions & 39 \\
\hline \multirow[t]{6}{*}{7} & Landscaping & \\
\hline & Invasive introductions & $41(35 \%)$ \\
\hline & Number of introductions & 117 \\
\hline & High risk species $(A)$ & 2 \\
\hline & Medium risk species (B) & 2 \\
\hline & Number of potentially invasive introductions & 27 \\
\hline
\end{tabular}




\begin{tabular}{|c|c|c|}
\hline Priority & Pathway & \\
\hline \multirow[t]{6}{*}{8} & Aquaculture & \\
\hline & Invasive introductions & $30(42 \%)$ \\
\hline & Number of introductions & 71 \\
\hline & High risk species $(\mathrm{A})$ & 2 \\
\hline & Medium risk species (B) & 6 \\
\hline & Number of potentially invasive introductions & 11 \\
\hline \multirow[t]{6}{*}{9} & Escapes & \\
\hline & Invasive introductions & $22(32 \%)$ \\
\hline & Number of introductions & 68 \\
\hline & High risk species $(\mathrm{A})$ & 8 \\
\hline & Medium risk species (B) & 10 \\
\hline & Number of potentially invasive introductions & 11 \\
\hline \multirow[t]{6}{*}{10} & Hull fouling & \\
\hline & Invasive introductions & $19(54 \%)$ \\
\hline & Number of introductions & 35 \\
\hline & High risk species $(\mathrm{A})$ & 4 \\
\hline & Medium risk species (B) & 3 \\
\hline & Number of potentially invasive introductions & 11 \\
\hline \multirow[t]{6}{*}{11} & Aquaria & \\
\hline & Invasive introductions & $8(30 \%)$ \\
\hline & Number of introductions & 27 \\
\hline & High risk species (A) & 1 \\
\hline & Medium risk species (B) & 11 \\
\hline & Number of potentially invasive introductions & 3 \\
\hline \multirow[t]{6}{*}{12} & Angling/sport & \\
\hline & Invasive introductions & $16(52 \%)$ \\
\hline & Number of introductions & 31 \\
\hline & High risk species $(A)$ & 1 \\
\hline & Medium risk species (B) & 0 \\
\hline & Number of potentially invasive introductions & 8 \\
\hline
\end{tabular}

Horticulture is a pathway of concern in the Nordic region. The highest number of known introductions of both invasive and potentially invasive species to the Nordic region is introduced through horticulture (see chapter 4.2 Invasiveness of introduced species). It is also a pathway of importance for many of the taxonomic groups (see chapter 4.3 Taxonomic groups of introduced species), and is historically the most frequently used pathway for all of the three regions (see chapter 4.1 Pathways of introduced species). Furthermore, there has been an increase in introductions by horticulture since the year 1750 (see chapter 4.4 Temporal development of pathways). 
A range of species may be targeted by management of horticulture. 16 of the $41^{9}$ high risk species (A) for the Nordic region have horticulture as a pathway (see appendix 9). These species are angiosperms, arthropods, pathogenic fungi, molluscs and plant-parasitic nematodes. Also a range of medium risk species (B) can be targeted when managing horticulture. These medium risk species are angiosperms, arthropods and non-pathogenic fungi.

Transport and ballast water \& sediments are also pathways of concern in the Nordic region with high numbers of introductions of invasive and potentially invasive alien species. Transport and ballast water \& sediments are also pathways used by many different taxonomic groups (see chapter 4.3 Taxonomic groups of introduced species), and a range of high risk species and medium risk species may be targeted by management of these pathways (see appendix 9 and 10).

Ballast water \& sediments is already a pathway of concern on an international scale, and through implementation of the "International Convention for Control and Management of Ships' Ballast Water and Sediments" it will be a pathway where action has been taken, while transport in general may result in more non-native introductions due to increasing globalisation.

The pathways agriculture, forestry and landscape are present on the prioritised list due to the high number of invasive introductions and the high and medium risk species related to the pathways. The three pathways have many alien species in common, i.e. many non-native species that are introduced to the Nordic region are registered for more than one of these three pathways.

The marine and freshwater pathways aquaculture, hull fouling, aquaria and angling/sport are pathways of concern. This is due to the number of invasive species introduced and the high percentage of invasive introductions. Furthermore, there are specific challenges in managing non-native marine and freshwater species when they are established, due to the limitations in eradication measures (see chapter 8 Recommendations).

Secondary introduction is also a challenging pathway, due to dispersal of non-native species from neighbouring countries (see chapter 8 Recommendations). The pathway is of concern for the Nordic region due to the high number of invasive introductions and high and medium risk

${ }^{9}$ Door knocker species may have been assigned multiple pathways of introduction, and therefore the numbers of high risk and medium risk species in the tables are higher than the total number of door knockers for the regions. 
species. Furthermore, it is a pathway that is increasingly registered over time (see chapter 4.4 Temporal development of pathways).

The list contains a number of pathways related to release and escape, e.g. aquaculture, escapes, aquaria and angling/sport, which have high numbers of invasive introductions and an increasing number of introductions of non-native species in the past 50 years (see chapter 4.4 Temporal development of pathways).

These pathways are registered for many of the taxonomic groups e.g. birds, fish, flatworms, macroalgae, mammals and reptiles \& amphibians (see chapter 4.3 Taxonomic groups of introduced species), where flatworms, macroalgae and mammals have a high percentage of invasive alien species (see chapter 4.2 Invasiveness of introduced species).

Medicinal is not part of the prioritised list of pathways for the Nordic region, though the number of introductions is relatively high, along with a relatively high number of invasive species registered. This is due to the results in the Temporal development of pathways (see chapter 4.4) which show that the use of medicinal as a pathway has declined over the last 100 years, and is no longer a pathway of concern. This decline may be due to the development and restrictions in the medical field.

\subsection{Baltic region}

The prioritised list of pathways of concern for the Baltic region is presented in table 22.

\begin{tabular}{llr} 
Table 22: Prioritised list of pathways of concern for the Baltic region \\
Priority & Pathway & \\
\hline 1 & Horticulture & $67(12 \%)$ \\
& Invasive introductions & 551 \\
& Number of introductions & 7 \\
High risk species (A) & 12 \\
Medium risk species (B) & 81 \\
Number of potentially invasive introductions & \\
& Transport & 21 (11\%) \\
Invasive introductions & 196 \\
Number of introductions & 8 \\
High risk species (A) & 3 \\
Medium risk species (B) & 14 \\
Number of potentially invasive introductions & \\
& Forestry & \\
Invasive introductions & 23 (52\%) \\
Number of introductions & 44 \\
High risk species (A) & 4 \\
Medium risk species (B) & 2 \\
Number of potentially invasive introductions & 20
\end{tabular}




\begin{tabular}{|c|c|c|}
\hline Priority & Pathway & \\
\hline \multirow[t]{6}{*}{4} & Agriculture & \\
\hline & Invasive introductions & $34(10 \%)$ \\
\hline & Number of introductions & 336 \\
\hline & High risk species $(\mathrm{A})$ & 0 \\
\hline & Medium risk species (B) & 1 \\
\hline & Number of potentially invasive introductions & 30 \\
\hline \multirow[t]{6}{*}{5} & Aquaculture & \\
\hline & Invasive introductions & $16(33 \%)$ \\
\hline & Number of introductions & 48 \\
\hline & High risk species $(A)$ & 3 \\
\hline & Medium risk species (B) & 4 \\
\hline & Number of potentially invasive introductions & 22 \\
\hline \multirow[t]{6}{*}{6} & Landscaping & \\
\hline & Invasive introductions & $21(47 \%)$ \\
\hline & Number of introductions & 45 \\
\hline & High risk species $(A)$ & 0 \\
\hline & Medium risk species (B) & 2 \\
\hline & Number of potentially invasive introductions & 9 \\
\hline \multirow[t]{6}{*}{7} & Ballast water \& sediments & \\
\hline & Invasive introductions & 7 (25\%) \\
\hline & Number of introductions & 28 \\
\hline & High risk species $(A)$ & 2 \\
\hline & Medium risk species (B) & 3 \\
\hline & Number of potentially invasive introductions & 17 \\
\hline \multirow[t]{6}{*}{8} & Secondary introduction & \\
\hline & Invasive introductions & $3(43 \%)$ \\
\hline & Number of introductions & 7 \\
\hline & High risk species $(A)$ & 6 \\
\hline & Medium risk species (B) & 7 \\
\hline & Number of potentially invasive introductions & 5 \\
\hline \multirow[t]{6}{*}{9} & Escapes & \\
\hline & Invasive introductions & $4(31 \%)$ \\
\hline & Number of introductions & 13 \\
\hline & High risk species $(A)$ & 5 \\
\hline & Medium risk species (B) & 6 \\
\hline & Number of potentially invasive introductions & 3 \\
\hline
\end{tabular}

In the Baltic region horticulture is also the main pathway of concern. The highest number of known introductions of both invasive and potentially invasive species to the Baltic region is introduced through horticulture (see chapter 4.2 Invasiveness of introduced species). It is also a pathway of importance for many of the taxonomic groups (see chapter 4.3 Taxonomic groups of introduced species), and is historically the most frequently used pathway for all three regions (see chapter 4.1 Pathways of introduced species). Furthermore, there has been an increase in introductions by horticulture in the Baltic region over the past 150 years (see chapter 4.4 Temporal development of pathways). Depending on the specific measures applied, management of horticulture may target a range 
of high and medium risk species of angiosperms, arthropods, fungi, molluscs and nematodes (see appendix 11 and 12).

Transport is also a pathway of concern for the Baltic region, since there are a high number of introductions by transport (see chapter 4.1 Pathways of introduced species) and a high number of introductions of both invasive and potentially invasive species. It is also a pathway of importance for many of the taxonomic groups (see chapter 4.3 Taxonomic groups of introduced species). Furthermore, there has been an increase in introductions by transport to the Baltic region over the past 100 years (see chapter 4.4 Temporal development of pathways). As for horticulture, managing transport could target many high and medium risk door knocker species from the following groups: Amphibians, arthropods, fish, molluscs and parasitic nematodes.

Agriculture, forestry and landscaping are also pathways of concern for the Baltic region, based on the number of introductions of non-native species and the number of introductions of invasive and potentially invasive species. For all three pathways the number of registrations has increased over the past 100 years (see chapter 4.4 Temporal development of pathways). Agriculture is a main pathway for many of the taxonomic groups, while forestry and landscape are mostly connected to species of angiosperms and coniferous plants (see chapter 4.3 Taxonomic groups of introduced species). Furthermore, the number of high and medium risk species that would most likely use these pathways has contributed to the prioritisation.

The pathway aquaculture is a pathway of concern, due to the number of introductions of invasive species, the number of introductions and the number of high and medium risk species. Furthermore, there are specific challenges in managing both marine and freshwater alien species when they are established, due to the limitations in eradication measures (see chapter 8 Recommendations).

Ballast water \& sediments is already a pathway of concern on an international scale, and through implementation of the "International Convention for Control and Management of Ships' Ballast Water and Sediments" it will be a pathway where action has been taken.

For the Baltic region we have chosen to prioritize secondary introduction and escapes as pathways of concern, despite the low number of introduced alien species and invasive species. This is due to the high number of high and medium risk species that would most likely use these pathways for introduction (see appendix 11 and 12). 
The registrations of medicinal has not been declining over time, but has been relatively static since the first registrations around 1750-1800. However, medicinal is not on the prioritised list of pathways for the Baltic region, due to the developments in the medical field that will most likely decrease the importance of the medicinal pathway, as for the Nordic region. 


\subsection{Islands of the North Atlantic Ocean}

The prioritised list of pathways of concern for the islands of the North Atlantic Ocean is presented in table 23.

\section{Table 23: Prioritised list of pathways of concern for the islands of the North Atlantic Ocean}

\begin{tabular}{|c|c|c|}
\hline Priority & Pathway & \\
\hline \multirow[t]{6}{*}{1} & Horticulture & \\
\hline & Invasive introductions & $3^{10}$ \\
\hline & Number of introductions & 65 \\
\hline & High risk species $(A)$ & 0 \\
\hline & Medium risk species (B) & 2 \\
\hline & Number of potentially invasive introductions & 8 \\
\hline \multirow[t]{6}{*}{2} & Transport & \\
\hline & Invasive introductions & 1 \\
\hline & Number of introductions & 27 \\
\hline & High risk species $(\mathrm{A})$ & 1 \\
\hline & Medium risk species (B) & 2 \\
\hline & Number of potentially invasive introductions & 0 \\
\hline \multirow[t]{6}{*}{3} & Secondary introduction & \\
\hline & Invasive introductions & 1 \\
\hline & Number of introductions & 9 \\
\hline & High risk species $(\mathrm{A})$ & 1 \\
\hline & Medium risk species (B) & 1 \\
\hline & Number of potentially invasive introductions & 4 \\
\hline \multirow[t]{6}{*}{4} & Escapes & \\
\hline & Invasive introductions & 1 \\
\hline & Number of introductions & 3 \\
\hline & High risk species $(A)$ & 1 \\
\hline & Medium risk species (B) & 0 \\
\hline & Number of potentially invasive introductions & 1 \\
\hline \multirow[t]{6}{*}{5} & Ornamental & \\
\hline & Invasive introductions & 0 \\
\hline & Number of introductions & 1 \\
\hline & High risk species $(\mathrm{A})$ & 1 \\
\hline & Medium risk species (B) & 0 \\
\hline & Number of potentially invasive introductions & 1 \\
\hline
\end{tabular}

Five pathways out of 14 registered pathways for the region are on the prioritised list. Horticulture has the highest number of introductions, invasive introductions and potentially invasive introductions, while transport has the second highest number of introductions, one high risk species and two medium risk species.

10 The percentages of the registered introductions of each invasiveness category for each pathway have not been calculated for the islands of the North Atlantic Ocean, due to the small amount of data available for this region. 
The pathways secondary introduction, escapes and ornamental have only few introductions, invasive introductions and potentially invasive introductions registered, but are present on the prioritised list due to the high risk door knocker species (see appendix 13). In Iceland, the current restrictions on import of all animals may prevent the introduction of high risk species that has escape and ornamental as a probable pathway. 


\section{Recommendations}

\subsection{Pathways of concern}

In this chapter we present general recommendations for further work on reducing alien introductions by the pathways of concern (see chapter 7 prioritisation of pathways). The recommendations are shown in table 24 and described afterwards.

\begin{tabular}{|c|c|}
\hline Challenges & Recommendations \\
\hline All & $\begin{array}{l}\text { Gathering of new knowledge } \\
\text { Early warning system } \\
\text { Horizon scannings on a regular basis }\end{array}$ \\
\hline Intentional introductions & $\begin{array}{l}\text { Restrictions on import and trade } \\
\text { Restrictions on release } \\
\text { Information campaigns }\end{array}$ \\
\hline Unintentional introductions & $\begin{array}{l}\text { Obligations to importers or exporters } \\
\text { Restrictions on import } \\
\text { Sample control or screening } \\
\text { Quarantines } \\
\text { Treatments }\end{array}$ \\
\hline Secondary introduction & $\begin{array}{l}\text { Early warning system } \\
\text { Reduction of introductions in general } \\
\text { Reduction of individuals introduced by other pathways }\end{array}$ \\
\hline Marine ecosystems & $\begin{array}{l}\text { Prevention of introduction by ballast water \& sediments } \\
\text { Reduction of introductions by angling/sport and aquaculture. }\end{array}$ \\
\hline
\end{tabular}

In the continuing work towards reducing alien introductions, new knowledge on alien species and pathways is needed to keep management initiatives up-to-date and effectful. Furthermore, an early warning system (see chapter 8.2 Early warning system later in the report) and completion of a horizon scanning on a regular basis are important tools for staying updated on potential threats. 
This analysis shows that horticulture is the main pathway of concern in all three regions. Many alien species from different taxonomic groups are registered with horticulture as a pathway, and introductions by horticulture are registered as both intentional and unintentional. Another pathway of concern in all three regions seems to be transport, which is also registered as a pathway for many different taxonomic groups. The majority of the introductions by transport are registered as unintentional.

\subsubsection{Intentional introductions}

Reduction of intentional and unintentional introductions of alien species requires different measures. To reduce intentional introduction of invasive alien species, e.g. angiosperms and reptiles, a costeffective measure can be implementation of restrictions on import and trade by implementing the EU regulations on invasive alien species. The restrictions can target certain non-native species that are known to be invasive in other parts of the world with a compatible climate, or species that have a habitat range that includes habitats found in the importing region. Restrictions on release of non-native organisms into the wild could benefit management if coupled with information campaigns regarding the probable negative impact of the species. Angling/sport, aquaculture, escapes, horticulture and landscaping are the pathways of concern that mostly facilitate intentional introductions.

\subsubsection{Unintentional introductions}

When reducing unintentional introductions, e.g. arthropods and molluscs by horticulture, other measures are appropriate. A way of reducing unintentional introductions is to impose obligations on importers or exporters of commodities. The obligations can be reduction or elimination of the species or groups of organisms of concern that can be found in certain commodities as stowaways. Another measure of reducing unintentional introductions can be restrictions of import of goods or organisms that can act as hosts or vectors of the species of concern. Also sample control or screening of imported commodities may reduce unintentional introduction, as well as imposing the use of quarantine when dealing with import of certain living organisms. Quarantine periods can also be coupled with treatment procedures for some goods or organisms, e.g. treatment of im- 
ported wooden items to eradicate potential stowaways. Agriculture, aquaria, forestry, horticulture and transport are pathways of concern that mostly facilitate unintentional introductions.

\subsubsection{Secondary introduction}

Other pathways of concern may require other management measures. Secondary introduction of non-native species dispersing from neighbouring countries is challenging to reduce or prevent. This is due to the fact that the introduction can happen without human interference, and is therefore not a result of specific activities that can be targeted. With secondary introduction, an early warning system is a way of alerting other countries about possible introductions, so countermeasures can be implemented. Furthermore, keeping the overall number of introductions low, as well as the number of individuals, may reduce secondary introduction.

\subsubsection{Marine ecosystems}

Alien species in the marine ecosystem can be challenging to manage, because measures to control them after introduction are limited or nonexisting. Therefore, prevention is the most appropriate tool for reducing introductions of marine alien species by ballast water \& sediments and hull fouling, e.g. by ratifying and implementing the "International Convention for Control and Management of Ships' Ballast Water and Sediments", which focuses on preventing introduction of marine alien species. Further measures to reduce introduction of marine alien species might be reduction of introductions from angling/sport and aquaculture as mentioned above.

\subsection{Early warning system}

An early warning system for introductions of species can have a range of layers. The NOBANIS collaboration of 20 countries and territories has an early warning system with an alert mechanism, a database on introduced species, and mechanisms of dialogue with scientific experts, environmental managers and policy makers.

The alert mechanism is activated when a participating country becomes aware that a new alien species has been found in their country, and a warning is sent to the other participating countries and posted on the NOBANIS website. This is an efficient way for countries to warn and 
inform each other of new species of concern, making it possible for the countries and territories to have a rapid response and to take measures to prevent the introduction and possible spread of high risk species.

Unlike the horizon scanning in this project, the early warning system in itself does not inform about the newly introduced species' ability to become established, become invasive or what the risks to biodiversity might be in the countries where it is not yet present. This is information that is necessary in order to assess the risks of an introduced species, what measures are possible and respond to the possible invasion in an effective and feasible way.

The NOBANIS database contains information on invasive alien species already present in the NOBANIS region. The information on alien species in the NOBANIS database includes: distribution, frequency, invasive status, pathway of introduction, reported impact and other relevant information. It is a dynamic database that is frequently updated and under continuous development. To keep the database updated, NOBANIS has been in close cooperation with scientific communities across Europe over the years. In this way the database is continuously updated and can improve our ability to predict if an alien species will become established and invasive, and assist the participating countries and territories in reducing introductions of the non-native species.

The NOBANIS contact persons in each of the participating countries or territories are scientific experts or environmental managers, and are able to act on incoming alerts. Also in the NOBANIS steering committee, researchers, environmental managers and policy makers form a network to actively integrate new knowledge in the management of alien species in the membering countries and territories across Europe.

On the basis of the horizon scanning in this report, new aspects of the alert mechanism might be relevant to implement. When communicating a species alert, the NOBANIS secretariat can inform the participating countries and territories about whether the new species is listed as a high or medium risk species in one of the regions. Furthermore, the species alert can contain information on where the introductions may occur and therefore where measures of prevention are appropriate.

Other parts of the NOBANIS collaboration can be improved. In the NOBANIS database there are challenges in standardization of the data, e.g. in the invasiveness status terminology, species names and species synonyms. To increase the standardization in the database a "Technical manual for the NOBANIS database" has been developed, where the protocols and standards for the data are described. Furthermore, the NOBANIS homepage and database is now undergoing improvement 
during which some of the standardization challenges are handled, the update and search mechanisms are improved, and a range of other functions are improved or added.

To ensure that an early warning system is active in the future, we need to make sure that mechanisms of species alerts, the databases and continuous accumulation of relevant knowledge are active and contemporary. Furthermore, we need to maintain, and perhaps improve, the dialogue between the countries and territories, and between researchers, environmental managers and policy makers. 



\section{Acknowledgements}

We would like to thank all participating countries and territories for collaborating on the project and for updating data in the NOBANIS database, and also assisting with locating experts for the horizon scanning and for their invaluable comments to the content of this report.

We are very grateful to the various experts that have taken on the task of filling out the assessment tables for the potential door knocker species, and for comments on this report. See appendix 2 for the full list of experts.

We would also like to thank Peter Wind ${ }^{11}$ (vascular plants), Nicolaj Scharff' ${ }^{12}$ (arachnida) and Torbjörn Ebenhard ${ }^{13}$ (mammals) for their input in the process of making the final list for the Horizon scanning and Ole Karsholt ${ }^{14}$ \& Nils Ryrholm ${ }^{15}$ for their national (DK \& SE) assessments of potential door knocker species of Lepidoptera.

Furthermore, we would like to thank Henrik Enghoff 16 for helping with the categorisation of some of the arthropods (species of Hemiptera), Sanne Raahauge Rasmussen ${ }^{17}$ for research on certain species (species of Coleoptera, Diptera and Angiosperms), and Julie Koch Sheard ${ }^{18}$ and Line Laursen for assisting with proofreading of this report. Also thanks to Helene Nyegaard Hvid ${ }^{19}$, Hans Peter Ravn ${ }^{20}$ and Max Emil Lenchler-Hübertz for commenting on this report.

\footnotetext{
11 Institute for Bioscience -Biodiversity, Aarhus University, Denmark.

12 Zoological Museum, Natural History Museum of Denmark, University of Copenhagen.

${ }^{13}$ Swedish Biodiversity Center, Swedish University of Agriculture and Sciences.

${ }^{14}$ Zoological Museum, Natural History Museum of Denmark, University of Copenhagen.

15 Department of Electronics, Mathematics and Natural Sciences, University of Gävle, Sweden.

16 Zoological Museum, Natural History Museum of Denmark, University of Copenhagen.

17 The Danish Nature Agency, Ministry of the Environment, Denmark.

18 The Danish Nature Agency, Ministry of the Environment, Denmark.

19 The Danish Nature Agency, Ministry of the Environment, Denmark.

${ }^{20}$ Forest \& Landscape, Department of Geosciences and Natural Ressource Management,University of Copenhagen, Denmark.
} 



\section{References}

\section{For the report}

Commission Regulation (EU) (2011). Commission Regulation (EU) No. 574/2011 of 16; June 2011 amending Annex I to Directive 2002/32/EC of the European Parliament and of the Council as regards maximum levels for nitrite, melamine, Ambrosia spp. and carry-over of certain coccidiostats and histomonostats and consolidating Annexes I and II thereto. http://eur-lex.europa.eu/LexUriServ/LexUriServ.do?uri= OJ:L:2011:159:0007:0024:EN:PDF

Essl, F., Bacher, S., Blackburn, T., Booy, O. et al. (in revision). Crossing Frontiers in Tackling Pathways of Biological Invasions. Bioscience.

Gederaas, L., Moen, T. L., Skjelseth, S. \& Larsen, L. K. (2012). Alien species in Norway with the Norwegian Black List 2012. The Norwegian Biodiversity Information Centre, Norway.

ISCC (Invasive Species Council of California) (2013). Invasive Species Pathway Risk Analysis for California, Prepared by Christina Conser, pp. 97. Available at: http://www.iscc.ca.gov/docs/reports/CISAC-Pathway-Report-July-2013-web.pdf Date of access 29-07-2014.

Kelly, J., O’Flynn, C., \& Maguire, C. (2013). Risk analysis and prioritisation for invasive and non-native species in Ireland and Northern Ireland. A report prepared for the Northern Ireland Environment Agency and National Parks and Wildlife Services as a part of Invasive Species Ireland.

NISC (National Invasive Species Council) (2007). Training and Implementation Guide for a Pathway Definition, Risk Analysis and Risk Prioritization. Developed jointly by the Aquatic Nuisance Species Task Force (ANSTF) and The National Invasive Species Council (NISC) Prevention Committee via the Pathways Work Team. USDAAPHIS. Riverdale, MD, pp. 59.

Madsen, C. L., Dahl, C. M., Thirslund, K. B., Grousset, F., Johannsen, V. K. \& Ravn, H. P. (2014). Pathways for non-native species in Denmark. Department of Geosciences and Natural Resource Management, University of Copenhagen, Frederiksberg, pp. 131.

Rabitsch, W., Gollasch, S., Isermann, M., Starfinger, U. \& Nehring, S. (2013). Erstelling einer Warliste in Deutschland noch nicht vorkommendee invasiver Tiere und Pflanzen. BfN-Skripten 331.

Sutherland, W.J. et al. (2008). Future novel threats and opportunities facing UK biodiversity identified by horizon scanning. J. Appl. Ecol. 2008; 45: pp. 821-833. DOI: http://dx.doi.org/10.1111/j.1365-2664.2008.01474.x

Roy, H. E., Peyton, J., Aldridge, D. C., Bantock et al. (2014). Horizon scanning for invasive alien species with the potential to threaten biodiversity in Great Britain. Global Change Biology. DOI: http://dx.doi.org/10.1111/gcb.12603

Secretariat of NOBANIS (2010). Developing an early warning system for invasive alien species (IAS) based on the NOBANIS database. NOBANIS. 


\section{For the information search on Angiosperms, Coleoptera and Diptera}

Agroatlas: www.agroatlas.ru

Barnard, P. (2011). Royal Entomological Society Book of British Insects. WileyBlackwell. DOI: http://dx.doi.org/10.1002/9781444344981

Barnes, J. (1990). Life History of Dohrniphora cornuta (Bigot) (Diptera: Phoridae), a Filth-inhabiting Humpbacked Fly. New York Entemological Society, vol. 88 (4), pp. 474-483.

Bioweb: http://bioweb.uwlax.edu

Bugguide: http://bugguide.net

CABI/ISC: www.cabi.org/isc

Chandler, P. (1999). Micropygus vagans Parent (Diptera: Dolichopodidae), a New Zealand fly in the British Isles. British Journal of Entomology and Natural History, vol. 12, pp. 215-220.

DAISIE: www.europe_aliens.org

Danish Red List: http://redlist.dmu.dk

Dep. of Agriculture, Food and the Marine: www.agriculture.gov.ie

Diptera.info: www.diptera.info

Dobson, J. (1999). A 'bee-louse' Braula schmitzi Orosi-Pal (Diptera: Braulidae) new to the British Isles, and the status of Braula spp. in England and Wales. British Journal of Entomology and Natural History, vol. 11, pp. 139-148.

EPPO: www.eppo.int

GBIF: www.gbif.org

Habib, R. et al. (2007). Biological Characteristics of the Cypress Bark Beetle Phloeosinus aubei in the Kessra Forest, Center of Tunisia. Tunisian Journal of Plant Protection, vol. 2 (2).

IPM Online: www.ipm.ucdavis.edu

Invasive Alien Species in Northern Ireland: www.habitas.org.uk

IUCN/ISSG: www.issg.org

Moraal, L. (2010). Infestations of the cypress bark beetles Phloeosinus rudis, P. bicolor and P. thujae in The Netherlands (Coleoptera: Curculionidae: Scolytinae). Entomologische Berichten, vol. 70 (4), pp. 140-145.

Naturespot: www.naturespot.org.uk

Pest Insects of our Cultural Heritage: www.ensam.inra.fr

PFAF: www.pfaf.org

Plantwise: www.plantwise.org

Sukontason, K. et al. (2003). Mouthparts of Megaselia scalaris (Loew) (Diptera: Phoridae). Micron, vol. 34 (8), pp. 345-350. DOI: http://dx.doi.org/10.1016/j.micron.2003.08.003 


\section{Summary (NO)}

En av de viktigste driverne bak tapet av biologisk mangfold er invaderende fremmede arter. For å planlegge kostnadseffektive tiltak for å hindre introduksjon av skadelige invaderende fremmede arter, må vi vite på hvilken måte de blir introdusert. Hittil har tiltak for å forhindre skade på naturlige miljøer og biologisk mangfold i de nordiske og baltiske landene, inkl. Island og Færøyene, i hovedsak har vært reaktive metoder basert på kunnskap om invaderende fremmede arter som allerede finnes. Denne tilnærmingen har vist seg å være en kostbar og ineffektiv måte å håndtere invaderende fremmede arter.

Forebygging av introduksjon av nye invaderende fremmede arter kan forbedres gjennom å samle ny kunnskap om invasive og potensielt invaderende arter og deres spredningsveier. Dette inkluderer også planlegging og gjennomføring av hensiktsmessige kontroll tiltak, slik som: overvåking, tidlig oppdagelse og varsling, og umiddelbar iverksettelse av tiltak mot arten.

Formålet med dette prosjektet var å gjennomføre en spredningsveianalyse og en "horizon scanning". Analysen ble gjort for å identifisere og prioritere spredningsveier i forhold til hvilke fremmede arter (særlig invasive fremmede arter) som har blitt innført til Norden og Baltikum, i tillegg til Island og Færøyene. "Horizon scanningen" ble gjennomført for å identifisere potensielle dørstokkarter som i fremtiden kan bli introdusert over de viktigste spredningsveiene.

NOBANIS Nettverket ble initiert med finansiering fra Nordisk ministerråd. NOBANIS databasen inneholder informasjon over fremmede arter i 20 land og territoriene i Nord- og Sentral-Europa, som har samarbeidet med å dele informasjon om fremmede arter. 10 av disse landene og territoriene har deltatt i dette prosjektet: Danmark, Estland, Færøyene, Finland, Island, Latvia, Litauen, Norge (inkludert Svalbard) og Sverige. Dataene i NOBANIS databasen har dannet grunnlaget for spredningsveianalysen, og hvert deltakende land har oppdatert sine nasjonale data med relevant informasjon ved hjelp av relevant litteratur og artikler, samt gjennom bruk av nasjonale eksperter. 
Spredningsveianalysen og "horizon scanningen" i dette prosjektet er gjennomført på et regionalt nivå, hvor de deltakende land og territorier ble delt inn i tre regioner:

- En nordisk region bestående av Danmark, Finland, Norge og Sverige (for spredningsveianalysen også Svalbard).

- En baltisk region bestående av Estland, Latvia og Litauen.

- En region bestående av øyene i Nord-Atlanteren representert ved Island og Færøyene.

I tillegg inneholder spredningsveianalysen følgende delanalyser for de introduserte artene:

- Spredningsvei.

- Invasivitet.

- Taksonomiske gruppe.

- Utvikling av spredningsveien over tid.

- Opprinnelsesområde og spredningsvei.

Resultatene viste at den viktigste veien for introduksjon var hagebruk, etterfulgt av landbruk, transport, skogbruk og ballastvann og sedimenter, men det var variasjoner mellom regionene.

For å undersøke hvilke nye arter som kan bli introdusert og etablert i de tre regionene i fremtiden, ble en rekke potensielle dørstokkarter vurdert.

Eksperter fra de deltakende land og territorier vurderte listen over 414 potensielle dørstokkarter. Av de 414 artene, så ble 43 vurdert som arter med høy risiko og 78 som middels risiko i regionene.

I denne rapporten så blir også en prioritert liste over spredningsveier presentert, sammen med retningslinjer og generelle anbefalinger på mulige tiltak ovenfor ulike spredningsveier i regionen, samt råd for et tidlig varslingssystem. 


\section{Summary (FI)}

Yksi keskeinen syy luonnon monimuotoisuuden vähenemiselle ovat haitalliset vieraslajit - Invasive Alien species (IAS), jotka leviävät ja aiheuttavat negatiivisia vaikutuksia kotoperäisille lajeille ja elinympäristöille. Haitallisten vieraslajien kustannustehokkaan torjunnan suunnittelu ja toteutus edellyttää sitä, että tiedämme mahdollisimman paljon niiden leviämisväylistä ja saapumistavoista.

Tähän mennessä torjuntatoimet haitallisten lajien biodiversiteettiin ja luonnonympäristöön kohdistuvien vaikutusten estämiseksi Pohjoismaissa ja Baltian maissa mukaan lukien Islanti ja Färsaaret on aloitettu ja toteutettu vasta kun lajit ovat jo saapuneet ja niiden vaikutukset on tunnistettu. Tämä lähestymistapa on sekä kallis että tehoton. Torjunnat tulisi aloittaa ennen kun lajit saapuvat ja muodostavat pysyvän kannan.

Uusien haitallisten vieraslajien saapuminen voidaan torjua tehokkaammin tunnistamalla ja keräämällä uutta tietoa haitallisista sekä tarkkailtavista ja paikallisesti haitallisista vieraslajeista sekä niiden leviämisväylistä. Lisäksi ennaltaehkäisy-, torjunta- ja valvontatoimet on suunniteltava ja toimeenpantava. Keskeisiä toimia ovat seuranta, ennakkovaroitus, aikainen havaitseminen ja haitallisen vieraslajin välitön poistaminen.

Tämän hankkeen tavoitteena oli tunnistaa ja asettaa tärkeysjärjestykseen leviämisväylät, joiden kautta haitalliset vieraslajit saapuvat Pohjoismaihin, Baltiaan sekä Islantiin ja Färsaariin. Toinen keskeinen tavoite oli kartoittaa ja tunnistaa (horizontal scanning) lajit, jotka ovat tulossa jo tunnistettujen tärkeiden leviämisväylien kautta.

NOBANIS-verkosto perustettiin Pohjoismaisen ministerineuvoston rahoituksella. NOBANIS tietokanta sisältää tietoja vieraslajeista 20 maasta ja alueesta Pohjois- ja Keski-Euroopassa. NOBANIS-verkostoon kuuluvat maat ovat tehneet yhteistyötä haitallisten vieraslajien aiheuttamien haittavaikutusten vähentämiseksi jakamalla toisilleen NOBANIStietokannan aineistoja vieraslajien esiintymisestä eri maissa.

Yhteensä 10 "NOBANIS- maata" (Tanska, Eesti, Latvia, Liettua, Norja Suomi, Islanti ja Färsaaret (mukaan lukien Huippuvuoret) sekä Ruotsi osallistuivat hankkeeseen, jossa arvioitiin leviämisväyliä NOBANIStietokannan pohjalta. Nämä maat päivittivät tietokannan kansalliset lajitiedot keräämällä tietoja kirjallisuudesta ja ottamalla yhteyttä kansallisiin asiantuntijoihin. 
Tässä projektissa tehdyt arviot toteutettiin kolmella eri alueella:

- Pohjoismaissa: Tanska, Suomi, Norja (mukaan lukien Huippuvuoret) ja Ruotsi.

- Baltian alue: Eesti, Latvia ja Liettua.

- Pohjoisatlantin saaret: Islanti ja Färsaaret.

Leviämisväyläselvitys koostui seuraavista osista:

- Saapuneiden lajien leviämisväylät.

- Saapuneiden lajien invasiivisuus.

- Saapuneiden lajien taksonomiset ryhmät.

- Leviämisväylien muutos ajassa.

- Lajien alkuperät ja saapumisreitit.

Leviämisväylien kartoitus osoitti, että vieraslajien keskeisin saapumisreitti on puutarhaviljely ja seuraavaksi tärkeimpiä ovat maatalous, liikenne, metsätalous ja painolastinvesi sekä sedimentit, mutta leviämisväylät vaihtelevat alueiden välillä.

Jotta voitaisiin ennakoida mahdolliset uudet vieraslajit, jotka ovat tulossa ja voisivat tulevaisuudessa muodostaa pysyvän kannan alueelle, kartoitettiin keskeiset leviämisväylät ja arvioitiin potentiaaliset uudet tulokkaat nk. "door knocker species". Osallistujamaiden asiantuntijat kartoittivat yhteensä 414 lajia, jotka voisivat aiheuttaa haittaa tulevaisuudessa. Näistä 43 lajia arvioitiin korkean riskin ja 78 keskimääräisen riskin lajeiksi.

Raportissa on luettelo haitallisten vieraslajien leviämisväylistä tärkeysjärjestyksessä ja siinä annetaan suosituksia sekä esitetään keinoja keskeisten Pohjoismaihin ja Baltian maihin suuntautuvien leviämisreittien valvomiseksi. Raportissa annetaan myös suosituksia alueellisen ennakkovaroitusjärjestelmän perustamiseksi. 


\section{Appendices}

\section{Appendix 1: Classification of pathways in Norway}

\begin{tabular}{|c|c|c|}
\hline Intentional introductions & Unintentional spread - from & Unintentional introductions - with \\
\hline Aesthetic planting & Agriculture & Animal foodstuff \\
\hline $\begin{array}{l}\text { Animals used for increased } \\
\text { possibilities of hunting and } \\
\text { catching }\end{array}$ & Aquaculture & Ballast sand/soil \\
\hline Biological pest control & Aquaria & Ballast water \\
\hline For production of honey & Botanical gardens & Bark \\
\hline $\begin{array}{l}\text { Illegal dumping/ introduction into } \\
\text { the wild }\end{array}$ & Construction and building & Construction materials \\
\hline $\begin{array}{l}\text { Management actions towards } \\
\text { other species }\end{array}$ & Export/trade & Corn products \\
\hline Plants used for shelter or shade & Fisheries & Dried fruit/fruit in general \\
\hline Production of green decorations & Forestry & Filings \\
\hline Restoration attempts & Garden centers & Fish \\
\hline \multirow{10}{*}{$\begin{array}{l}\text { Species for cultivation, in gardens, } \\
\text { indoors and game animals }\end{array}$} & Gardening & Food \\
\hline & Greeneries & $\begin{array}{l}\text { Goods from garden centers and } \\
\text { nurseries }\end{array}$ \\
\hline & Hunting and fishing & Holiday and leisure equipment \\
\hline & Industry & Imported production material \\
\hline & Leisure boats & Invertebrates \\
\hline & Nurseries & Leisure boats \\
\hline & Private gardens & Mammals \\
\hline & Private individuals' activities & Masses \\
\hline & Research & Means of transportation \\
\hline & $\begin{array}{l}\text { Secondary spread from neigh- } \\
\text { boring countries }\end{array}$ & Nuts \\
\hline
\end{tabular}




\begin{tabular}{lll} 
Intentional introductions & Unintentional spread - from & Unintentional introductions - with \\
Tourism & Soil \\
Unknown pathway & Packaging \\
Zoological gardens & Plants \\
& Plants from gardens \\
& Plants with soil/potted plants \\
& Private vehicles \\
& Processed wood \\
& Refugees from garden centers and \\
nurseries & Round timber without bark \\
& Seeds and cones etc. \\
& Ship fouling \\
& Textiles and shoes \\
& Trains \\
& Transport by road \\
& Timber \\
Unknown & Vegetables \\
& Wood chippings \\
\hline
\end{tabular}




\section{Appendix 2: List of experts}

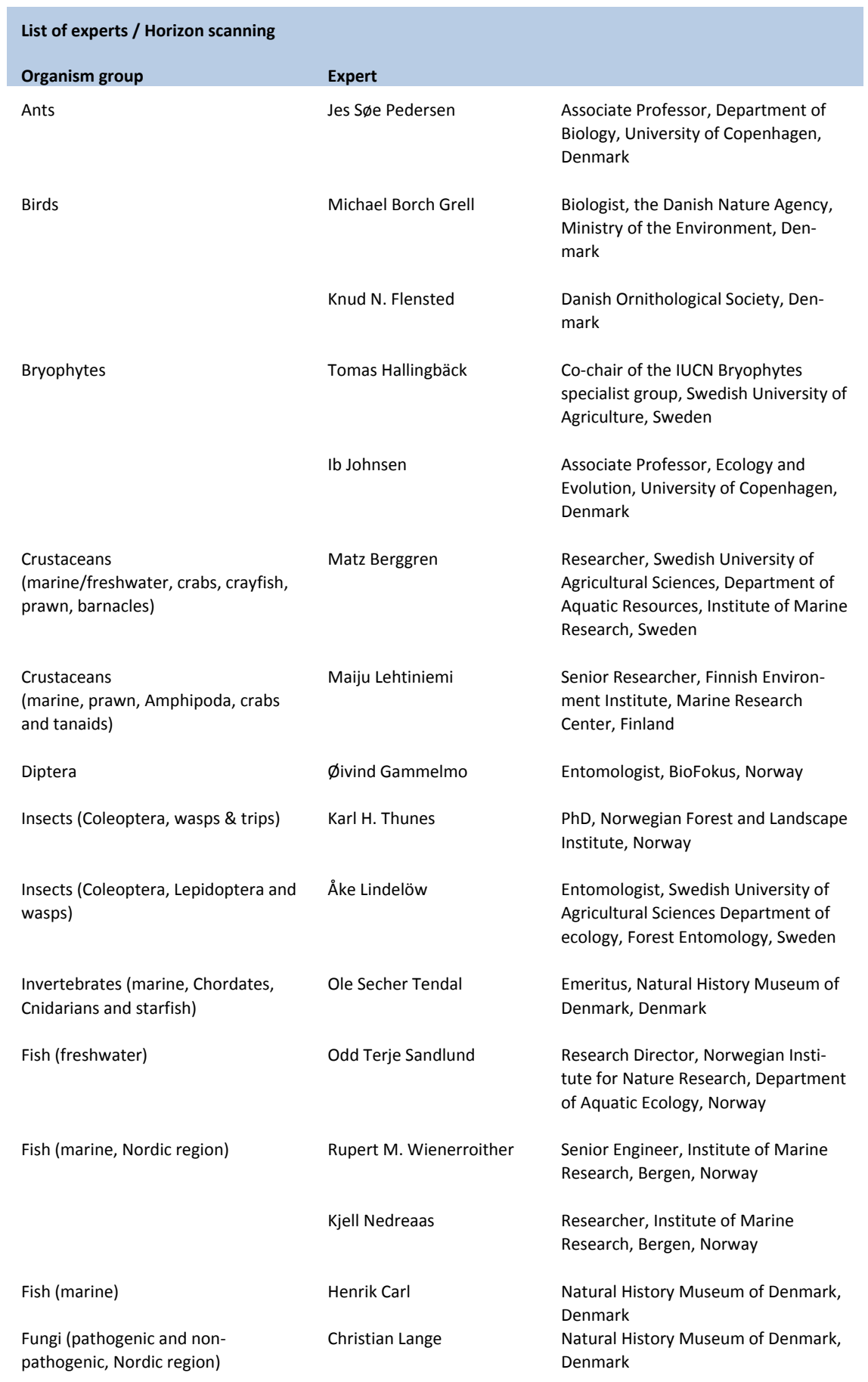




\begin{tabular}{|c|c|c|}
\hline $\begin{array}{l}\text { List of experts / Horizon scanning } \\
\text { Organism group }\end{array}$ & Expert & \\
\hline \multirow[t]{3}{*}{$\begin{array}{l}\text { Fungi } \\
\text { (non-pathogenic, Baltic region) }\end{array}$} & Teele Jairus & $\begin{array}{l}\text { Researcher, Department of Botany, } \\
\text { Institute of Ecology and Earth Scienc- } \\
\text { es, University of Tartu, Estonia }\end{array}$ \\
\hline & Inita Daniele & $\begin{array}{l}\text { Head of Botanical department, } \\
\text { mycologist, Museum of Natural } \\
\text { History, Latvia }\end{array}$ \\
\hline & Ernestas Kutorga & $\begin{array}{l}\text { Vilnius University, Department of } \\
\text { Botany and Genetics, Lithuania }\end{array}$ \\
\hline Gastropoda (terrestrial) & Ted Von Proschwitz & $\begin{array}{l}\text { Göteborgs Naturhistoriska Museum, } \\
\text { Sweden }\end{array}$ \\
\hline Lepidoptera & Jan Fischer Rasmussen & $\begin{array}{l}\text { Biologist, Oddsherred Kommune, } \\
\text { Denmark }\end{array}$ \\
\hline Macroalgae & Ruth Nielsen & $\begin{array}{l}\text { Lector emeritus, Natural History } \\
\text { Museum of Denmark, Denmark }\end{array}$ \\
\hline $\begin{array}{l}\text { Mammals } \\
\text { (Nordic region and IS \& FO) }\end{array}$ & Thomas Secher Jensen & $\begin{array}{l}\text { Researcher, Natural History Museum } \\
\text { Aarhus, Denmark }\end{array}$ \\
\hline Mammals & Linas Balčiauskas & $\begin{array}{l}\text { Leading Researcher, Nature Research } \\
\text { Centre, Laboratory of Mammalian } \\
\text { Ecology, Lithuania }\end{array}$ \\
\hline $\begin{array}{l}\text { Molluscs (marine/freshwater, } \\
\text { mussels and snails) }\end{array}$ & Kathe Jensen & $\begin{array}{l}\text { Researcher, Natural History Museum } \\
\text { of Denmark, Denmark }\end{array}$ \\
\hline $\begin{array}{l}\text { Nematodes (plant--parasitic nema- } \\
\text { todes) }\end{array}$ & Christer Magnusson & $\begin{array}{l}\text { Senior Researcher, Norwegian Insti- } \\
\text { tute for Agriculture and Environmen- } \\
\text { tal Research, Norway }\end{array}$ \\
\hline Nematodes (parasitic) & Tor Atle Mo & $\begin{array}{l}\text { Head of Section of Parasitology, } \\
\text { Norwegian Veterinary Institute, } \\
\text { Norway }\end{array}$ \\
\hline \multirow[t]{2}{*}{ Reptiles and amphibians } & Merike Linnamagi & $\begin{array}{l}\text { Senior Officer, Ministry of Environ- } \\
\text { ment of Estonia, Estonia }\end{array}$ \\
\hline & $\begin{array}{l}\text { Thorbjørn Koch } \\
\text { Christoffersen }\end{array}$ & $\begin{array}{l}\text { The Danish Nature Agency, Ministry of } \\
\text { the Environment, Denmark }\end{array}$ \\
\hline Tanaids & Dr. Kim Larsen (DK) & $\begin{array}{l}\text { Aquatic, Ecology and Evolution } \\
\text { Department CIIMAR in Portugal }\end{array}$ \\
\hline \multirow[t]{2}{*}{ Vascular plants } & Arto Kurtto & $\begin{array}{l}\text { Curator, Finnish Museum of Natural } \\
\text { History in Helsinki, Finland }\end{array}$ \\
\hline & Paweł Wąsowicz & $\begin{array}{l}\text { Botanist, the Icelandic Institute of } \\
\text { Natural History, Iceland }\end{array}$ \\
\hline Wasps & Lars Vilhelmsen & $\begin{array}{l}\text { Associate Professor, the Natural } \\
\text { History Museum of Denmark, Den- } \\
\text { mark }\end{array}$ \\
\hline
\end{tabular}




\section{Appendix 3: Assessment scores and criteria}

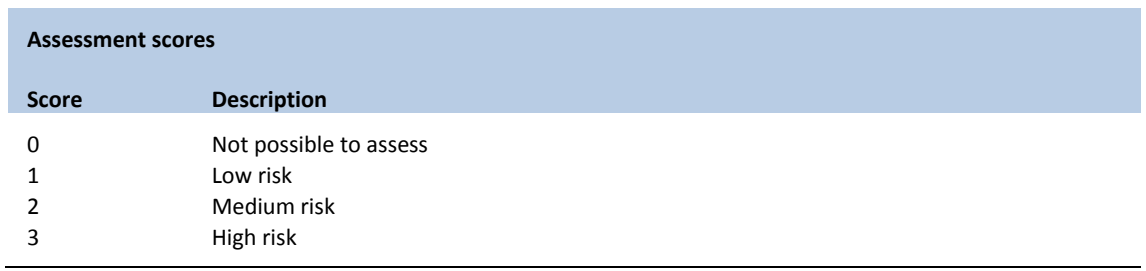

Assessment criteria and scoring system for potential door knocker species not yet established in DK, $\mathrm{FI}, \mathrm{NO}, \mathrm{SE}, \mathrm{IS}, \mathrm{FO}, \mathrm{LV}, \mathrm{LT} \& \mathrm{EE}$

\begin{tabular}{|c|c|c|c|c|c|}
\hline \multicolumn{6}{|c|}{ Assessment form } \\
\hline \multicolumn{6}{|l|}{ Species name } \\
\hline \multicolumn{6}{|l|}{$\begin{array}{l}\text { Pathway of } \\
\text { introduction }\end{array}$} \\
\hline \multirow[t]{2}{*}{ Factor } & \multirow[t]{2}{*}{ Assessment criteria } & & Score & & Comments \\
\hline & & $D K, F I, N O \& S E$ & $I S \& F O$ & $\angle V, L T \& E E$ & $\begin{array}{l}\text { and/or } \\
\text { references }\end{array}$ \\
\hline Arriving & $\begin{array}{l}\text { What is the possibility that } \\
\text { the species will arrive? }\end{array}$ & & & & \\
\hline Establishment & $\begin{array}{l}\text { What is the possibility that } \\
\text { the species will become } \\
\text { established? }\end{array}$ & & & & \\
\hline \multirow[t]{3}{*}{$\begin{array}{l}\text { Impact } \\
\text { assessment }\end{array}$} & $\begin{array}{l}\text { Does the species pose a } \\
\text { threat to biodiversity? }\end{array}$ & & & & \\
\hline & $\begin{array}{l}\text { Does the species pose a risk } \\
\text { to human health? }\end{array}$ & & & & \\
\hline & $\begin{array}{l}\text { Does the species pose a risk } \\
\text { regarding socio-economic } \\
\text { concerns? }\end{array}$ & & & & \\
\hline
\end{tabular}


Appendix 4: Temporal development of pathways in the Nordic region

\begin{tabular}{|c|c|c|c|c|c|c|c|}
\hline \multicolumn{8}{|c|}{ Temporal development of pathways / Nordic region } \\
\hline Pathway & $1700-1750$ & $1750-1800$ & $1800-1850$ & $1850-1900$ & 1900-1950 & 1950-2000 & $2000-$ \\
\hline Agriculture & 30 & 12 & 65 & 151 & 132 & 81 & 12 \\
\hline Angling/sport & 0 & 0 & 2 & 8 & 4 & 16 & 5 \\
\hline Animal husbandry & 0 & 0 & 1 & 1 & 2 & 3 & c \\
\hline Aquaculture & 0 & 0 & 1 & 7 & 16 & 50 & 11 \\
\hline Aquaria & 1 & 0 & 0 & 3 & 10 & 8 & $\varepsilon$ \\
\hline Ballast water \& sediments & 7 & 4 & 44 & 71 & 55 & 41 & 35 \\
\hline Biological control & 0 & 0 & 0 & 1 & 0 & 6 & 1 \\
\hline Escapes & 3 & 0 & 0 & 2 & 10 & 28 & $\epsilon$ \\
\hline Fisheries & 0 & 0 & 0 & 1 & 0 & 4 & $c$ \\
\hline Forestry & 0 & 5 & 15 & 39 & 40 & 97 & 13 \\
\hline Horticulture & 40 & 39 & 140 & 336 & 403 & 515 & 131 \\
\hline Hull fouling & 0 & 0 & 2 & 4 & 11 & 10 & 11 \\
\hline Hunting & 1 & 0 & 0 & 2 & 6 & 6 & 2 \\
\hline Landscaping & 4 & 4 & 9 & 24 & 28 & 19 & 39 \\
\hline Medicinal & 13 & 8 & 10 & 17 & 10 & 4 & c \\
\hline Ornamental & 0 & 0 & 1 & 3 & 5 & 7 & 4 \\
\hline Reintroduction & 1 & 0 & 0 & 0 & 4 & 6 & c \\
\hline Secondary introduction & 1 & 0 & 0 & 3 & 25 & 60 & 22 \\
\hline Transport & 3 & 4 & 101 & 74 & 80 & 83 & 18 \\
\hline Not known & 60 & 14 & 125 & 457 & 705 & 755 & 306 \\
\hline Total & 164 & 90 & 516 & 1,204 & 1,546 & 1,799 & 624 \\
\hline
\end{tabular}




\section{Appendix 5: Temporal development of pathways in the Baltic region}

\begin{tabular}{|c|c|c|c|c|c|c|c|}
\hline \multirow[t]{2}{*}{ Temporal develop } & Iways / Baltic & gion & & ne periods & & & \\
\hline & $1700-1750$ & $1750-1800$ & $1800-1850$ & $1850-1900$ & $1900-1950$ & $1950-2000$ & $2000-$ \\
\hline Agriculture & 1 & 28 & 77 & 29 & 97 & 163 & 0 \\
\hline Angling/sport & 0 & 0 & 0 & 0 & 0 & 0 & 0 \\
\hline Animal husbandry & 0 & 0 & 0 & 0 & 0 & 5 & 0 \\
\hline Aquaculture & 0 & 0 & 0 & 6 & 7 & 39 & 4 \\
\hline Aquaria & 0 & 0 & 0 & 1 & 1 & 0 & 1 \\
\hline Ballast water \& sediments & 0 & 0 & 7 & 5 & 6 & 12 & 2 \\
\hline Biological control & 0 & 0 & 0 & 0 & 0 & 1 & 0 \\
\hline Escapes & 0 & 0 & 0 & 1 & 3 & 10 & 1 \\
\hline Fisheries & 0 & 0 & 0 & 0 & 0 & 1 & 0 \\
\hline Forestry & 0 & 4 & 11 & 5 & 7 & 16 & 0 \\
\hline Horticulture & 4 & 108 & 154 & 81 & 97 & 213 & 2 \\
\hline Hull fouling & 0 & 1 & 4 & 4 & 3 & 3 & 2 \\
\hline Hunting & 0 & 0 & 0 & 1 & 2 & 1 & 0 \\
\hline Landscaping & 0 & 3 & 0 & 10 & 8 & 28 & 0 \\
\hline Medicinal & 0 & 7 & 7 & 6 & 5 & 8 & 0 \\
\hline Ornamental & 0 & 1 & 1 & 1 & 4 & 13 & 0 \\
\hline Reintroduction & 0 & 0 & 0 & 0 & 0 & 0 & 0 \\
\hline Secondary introduction & 0 & 0 & 0 & 0 & 1 & 4 & 0 \\
\hline Transport & 0 & 2 & 6 & 45 & 76 & 66 & 1 \\
\hline Not known & 0 & 36 & 64 & 59 & 94 & 147 & 7 \\
\hline Total & 5 & 190 & 331 & 254 & 411 & 730 & 20 \\
\hline
\end{tabular}




\section{Appendix 6: High risk species for all regions}

\begin{tabular}{ll}
\hline $\begin{array}{l}\text { Amphibia (Taxonomic group) } \\
\text { Species }\end{array}$ & Pathway \\
\hline Alytes obstetricans & Secondary introduction, Transport \\
\hline & \\
\hline $\begin{array}{l}\text { Angiosperms (Taxonomic group) } \\
\text { Species }\end{array}$ & Pathway \\
$\begin{array}{l}\text { Gunnerpha fructicosa } \\
\text { Pueraria montana var. lobata } \\
\text { (Syn. P. lobata) }\end{array}$ & $\begin{array}{l}\text { Horticulture, Landscaping } \\
\text { Horticulture }\end{array}$ \\
\hline
\end{tabular}

Arthropods / Prawn (Taxonomic group)

\begin{tabular}{ll} 
Species & Pathway \\
\hline Palaemon macrodactylus & Ballast water \& sediments, Secondary introduction \\
\hline
\end{tabular}

Arthropods / Amphipods (Taxonomic group)

\begin{tabular}{ll} 
Species & Pathway \\
\hline Dikerogammarus villosus & Ballast water \& sediments \\
\hline
\end{tabular}

Arthropods / Ants (Taxonomic group)

Species Pathway

Lasius neglectus

Horticulture, Landscaping

Arthropods / Coleoptera (Taxonomic group)

Species Pathway

Agrilus planipennis $\quad$ Forestry

Diabrotica virgifera Agriculture, Transport, Secondary introduction

Luperomorpha xanthodera Horticulture

Otiorhynchus liguricus Horticulture

(Syn. O. salicicola)

Phloeosinus aubei Horticulture

Phloeosinus rudis Horticulture

Arthropods / Diptera (Taxonomic group)

$\begin{array}{ll}\text { Species } & \text { Pathway } \\ \begin{array}{l}\text { Aedes albopictus } \\ \text { Coenosia attenuata }\end{array} & \text { Transport } \\ \text { Ochlerotatus japonicus } & \text { Transport }\end{array}$


Arthropods / Freshwater crayfish (Taxonomic group)

\begin{tabular}{ll} 
Species & Pathway \\
\hline Orconectes virilis & Aquaculture, Aquaria with Secondary introduction \\
\hline
\end{tabular}

\section{Arthropods / Lepidoptera (Taxonomic group)}

\begin{tabular}{ll}
\hline Species & Pathway \\
\hline Dendrolimus sibiricus & Horticulture, Forestry \\
\hline
\end{tabular}

Arthropods / Marine crab (Taxonomic group)

\begin{tabular}{ll} 
Species & Pathway \\
$\begin{array}{ll}\text { Hemigrapsus penicillatus } \\
\text { Hemigrapsus takanoi } \\
\text { Hemigrapsus sanguineus }\end{array}$ & $\begin{array}{l}\text { Ballast water \& sediments, Hull fouling, Secondary introduction } \\
\text { Ballast water \& sediments, Hull fouling, Secondary introduction } \\
\text { Ballast water \& sediments, Hull fouling, Secondary introduction }\end{array}$ \\
\hline $\begin{array}{l}\text { Arthropods / Tanaidacea (Taxonomic group) } \\
\text { Species }\end{array}$ & Pathway \\
\hline Sinelobus stanfordi & Ballast water \& sediments, Hull fouling \\
\hline
\end{tabular}

Arthropods / Wasp (Taxonomic group)

Species Pathway

Sirex ermak Forestry, Transport, Seconday introduction

Vespa velutina Seconday introduction, Transport

Birds (Taxonomic group)

\begin{tabular}{ll} 
Species & Pathway \\
\hline Myiopsitta monachus & Escapes, Ornamental \\
\hline
\end{tabular}

Fish / Freshwater (Taxonomic group)

\begin{tabular}{|c|c|}
\hline Species & Pathway \\
\hline Ameiurus melas & Angling/sport, Aquaculture, Fisheries \\
\hline \multicolumn{2}{|c|}{ Fungus / Pathogen (Taxonomic group) } \\
\hline Species & Pathway \\
\hline Ceratocystis fagacearum & Forestry \\
\hline Cryphonectria parasitica & Horticulture \\
\hline Cryptostroma corticale & Forestry, Horticulture \\
\hline Monilinia fructicola & Horticulture \\
\hline splanchnonema platani & Horticulture \\
\hline
\end{tabular}


Mammal (Taxonomic group)

Species Pathway

Callosciurus erythraeus Secondary introduction, Escapes

Muntiacus reevesi Escapes

Sciurus carolinensis Ornamental, Escapes

Mollusca / Terrestrial gastropoda (Taxonomic group)

Species Pathway

Tandonia budapestensis Horticulture, Transport

Plant-parasitic nematode (Taxonomic group)

Species Pathway

Meloidogyne chitwoodi Horticulture

Meloidogyne fallax Horticulture

Parasitic nematode (Taxonomic group)

\begin{tabular}{ll} 
Species & Pathway \\
\hline $\begin{array}{l}\text { Ashworthius sidemi } \\
\text { Bursaphelenchus xylophilus }\end{array}$ & $\begin{array}{l}\text { Animal husbandry } \\
\text { Forestry, Transport }\end{array}$ \\
\hline
\end{tabular}

Reptilia (Taxonomic group)

Species

Pathway

Chelydra serpentina

Escapes

Chrysemys picta

Craptemys pseudogeographica -

Macrochelys temminckii Escapes 


\section{Appendix 7: Medium risk species for all regions}

$\begin{array}{ll}\text { Amphibia (Taxonomic group) } & \\ \text { Medium risk species (B) / All regions combined } & \\ \text { Species } & \text { Pathway } \\ \begin{array}{ll}\text { Bufo marinus } & \text { Escapes } \\ \text { Xenopus laevis } & \text { Escapes } \\ \hline\end{array}\end{array}$

\section{Angiosperms (Taxonomic group)}

Medium risk species (B) / All regions combined

\section{Species}

Pathway

Acacia melanoxylon

Akebia quinata

Horticulture

Allium triquetrum

Horticulture

Amorpha fructicosa

Horticulture

Cortaderia selloana

Horticulture, Landscaping

Gaultheria mucronata (Syn. Pernettya muc-

Horticulture

ronata)

Gymnocoronis spilanthoides

Horticulture

Hakea sericea

Hedychium gardnerianum

Hydrocotyle ranunculoides

Aquaria

Landscaping, Horticulture

Horticulture

Aquaria

Hygrophila polysperma

Aquaria

Imperata cylindrica

Lagarosiphon major

Horticulture

Aquaria

Lemna minuta

Aquaria

Libertia chilensis (Syn. Libertia Formosa) Horticulture

Ligustrum lucidum

Horticulture

Ligustrum sinense

Horticulture

Morella faya

Horticulture

Myriophyllum aquaticum

Aquaria

Paulownia tomentosa Horticulture

Phormium tenax Horticulture

Pistia stratiotes Aquaria

Pittosporum undulatum Horticulture

Rhus radicans (Syn. Toxicodendron radicans) Horticulture, Landscaping

Rosa bracteata

Sagittaria graminea

Horticulture

Sasa palmata

Aquaria

Sicyos angulatus

Horticulture

Spathodea campanulata

Horticulture

Arthropods / Ants (Taxonomic group)

Medium risk species (B) / All regions combined

Species

Pathway

Lasius neglectus

Horticulture, Landscaping 


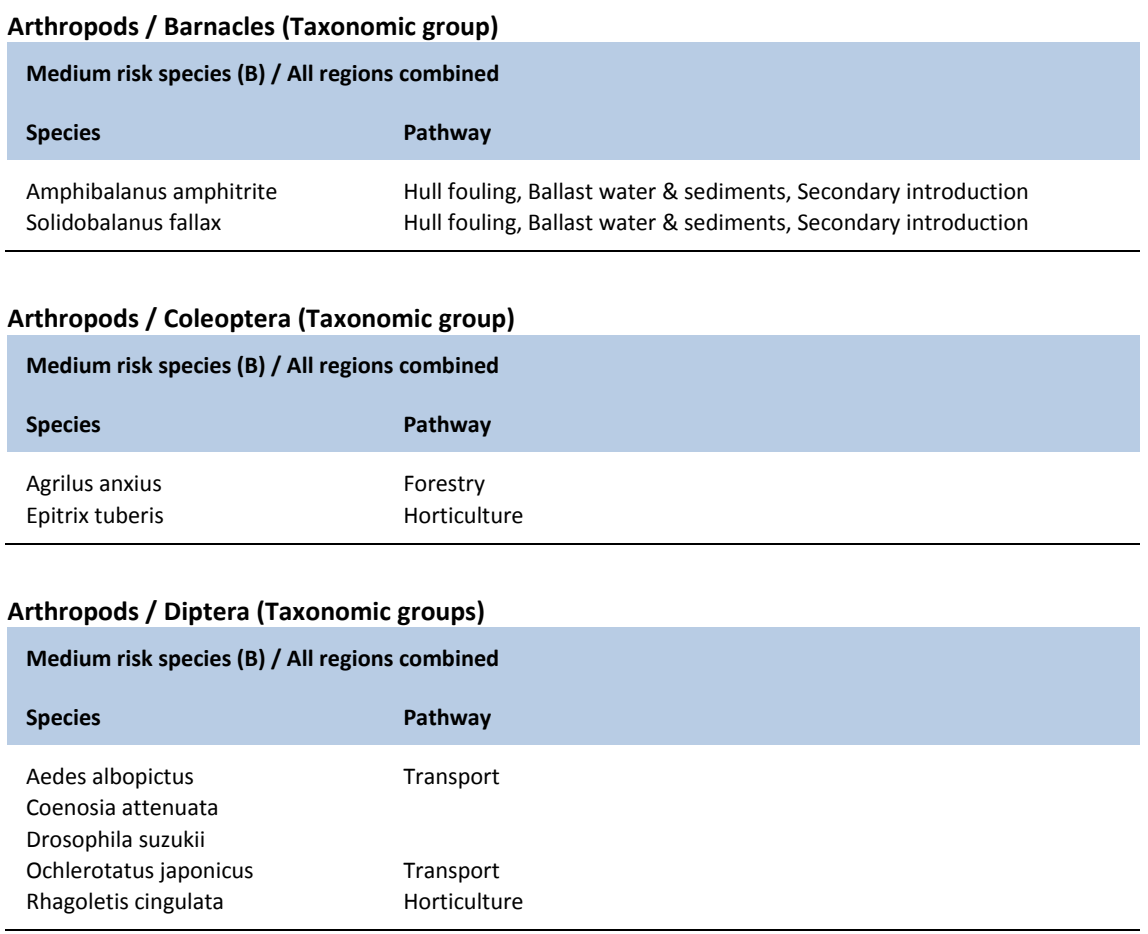

\section{Athropods / Freshwater crayfish (Taxonomic group)}

Medium risk species (B) / All regions combined

Species

Pathway

Orconectes rusticus

Procambarus clarkii

Aquaculture, Aquaria with Secondary introduction

Procambarus fallax $\mathrm{f}$ virginalis

Aquaculture, aquaria, secondary introduction

Aquaria, Escapes

\section{Athropods / Lepidoptera (Taxonomic group)}

Medium risk species (B) / All regions combined

Species Pathway

Cacoecimorpha pronubana Horticulture, Secondary introduction

Dendrolimus superans Horticulture, Forestry

Hyphantria cunea

Lymantria mathura Horticulture, Forestry, Transport

Arthropods / Marine crab (Taxonomic group)

Medium risk species (B) / All regions combined

Species

Pathway

Callinectes sapidus

Ballast water \& sediments

Charybdis japonica

Ballast water \& sediments, Secondary introduction 
Arthropods / Marine prawn (Taxonomic group)

Medium risk species (B) / All regions combined

Species

Pathway

Marsupenaeus japonicus

Aquaculture, Ballast water \& sediments

Arthropods / Trips (Taxonomic group)

Medium risk species (B) / All regions combined

Species

Pathway

Thrips palmi Agriculture

Birds (Taxonomic group)

Medium risk species (B) / All regions combined

Species

Pathway

Callonetta leucophrys

Chrysolophus pictus

Escapes

Falco biarmicus

Hunting

Lophura nycthemera

Escapes

Nymphicus hollandicus

Hunting

\section{Fish / Freshwater (Taxonomic group)}

Medium risk species (B) / All regions combined

Species

Pathway

Coregonus muksun

Neogobius fluviatilis

Aquaculture

Neogobius gymnotrachelus

Ballast water \& sediments, Transport, Secondary introduction

Neogobius kessleri

Ballast water \& sediments, Secondary introduction

Romanogobio belingi

Ballast water \& sediments, Transport, Secondary introduction

\section{Fish / Marine (Taxonomic group)}

Medium risk species (B) / All regions combined

Species

Pathway

Anguilla rostrata

Fisheries, Aquaculture

Fungi (Taxonomic group)

Medium risk species (B) / All regions combined

Species

Pathway

Gymnopus luxurians

Panaeolus cyanescens

Horticulture, Forestry

Psilocybe cubensis

Horticulture, (Medicinal)

Suillus placidus

Horticulture, (Medicinal)

Forestry, Horticulture, Secondary introduction 
Fungus / Pathogen (Taxonomic group)

Medium risk species (B) / All regions combined

Species Pathway

Endocronartium harknessii Forestry

Ophiostoma wageneri Forestry

Mammal (Taxonomic group)

Medium risk species (B) / All regions combined

Species Pathway

Herpestes javanicus Ornamental, Escapes

Mustela furo Animal husbandry, Escapes

Mollusca / Marine mollusca (Taxonomic group)

Medium risk species (B) / All regions combined

Species Pathway

Musculista senhousia

Hull fouling, Secondary introduction

Mollusca / Marine snail (Taxonomic group)

Medium risk species (B) / All regions combined

Species

Pathway

Rapana venosa

Aquaculture, Secondary introduction

Plant-parasitic nematode (Taxonomic group)

Medium risk species (B) / All regions combined

Species Pathway

Meloidogyne fallax Horticulture

Parasitic Nematode (Taxonomic group)

Medium risk species (B) / All regions combined

Species Pathway

Ashworthius sidemi Animal husbandry

Reptilia (Taxonomic group)

Medium risk species (B) / All regions combined

Species

Pathway

Apalone spinifera

Ecapes

Boa constrictor imperator

Elaphe schrenckil

Escapes, Ornamental, Secondary introduction 


\section{Appendix 8: Species not assessed}

\begin{tabular}{|c|c|}
\hline \multicolumn{2}{|c|}{ Species not assessed / All regions combined } \\
\hline Group & Species \\
\hline Angiosperms & Verbena brasiliensis \\
\hline Angiosperms & Sorghum $\mathrm{x}$ almum \\
\hline Angiosperms & Cyperus esculentus \\
\hline Angiosperms & Malus asiatica \\
\hline Arthropods & Chelicorophium robustum \\
\hline Arthropods & Crematogaster auberti \\
\hline Arthropods & Crematogaster osakensis \\
\hline Arthropods & Crematogaster rogenhoferi \\
\hline Arthropods & Pheidole pallidula \\
\hline Arthropods & Crematogaster auberti \\
\hline Arthropods & Crematogaster osakensis \\
\hline Arthropods & Crematogaster rogenhoferi \\
\hline Arthropods & Pheidole pallidula \\
\hline Arthropods & Anopheles quadrimaculatus \\
\hline Arthropods & Aphidoletes abietis \\
\hline Arthropods & Micropygus vagans \\
\hline Arthropods & Tephritis praecox \\
\hline Arthropods & Thoracochaeta johnsoni \\
\hline Arthropods & Blepharipa schineri \\
\hline Arthropods & Orconectes juvenilis \\
\hline Arthropods & Ammothea hilgendorfi \\
\hline Birds & Chloephaga picta \\
\hline Bryozoan & Watersipora subtorquata \\
\hline Bryozoan & Tricellaria inopinata \\
\hline Bryozoan & Bugula stolonifera \\
\hline Cnidarians & Garveia franciscana \\
\hline Cnidarians & Blackfordia virginica \\
\hline Fish/Marine & Platichthys stellatus \\
\hline Fish/Marine & Sebastes schlegelii \\
\hline Fish/Marine & Trinectes maculatus \\
\hline Fish/Marine & Micropogonias undulatus \\
\hline Fish/Marine & Paralichthys olivaceus \\
\hline Macroalgae & Asperococcus scaber \\
\hline Macroalgae & Botrytella pacifica \\
\hline Macroalgae & Botrytella parva \\
\hline Macroalgae & Caulerpa racemosa \\
\hline Macroalgae & Codium fragile ssp. atlanticum \\
\hline Macroalgae & Codium textile \\
\hline Macroalgae & Corynophlaea verruculiformis \\
\hline Macroalgae & Cryptonemia hibernica \\
\hline Macroalgae & Goniotrichopsis sublittoralis \\
\hline Macroalgae & Grateloupia subpectinata \\
\hline Macroalgae & Myriactula areschougii \\
\hline Macroalgae & Myriactula clandestina \\
\hline Macroalgae & Polyopes lancifolius \\
\hline Macroalgae & Polysiphonia atlantica \\
\hline Macroalgae & Scytosiphon dotyi \\
\hline Macroalgae & Solieria chordalis \\
\hline Macroalgae & Ulva pertusa \\
\hline Macroalgae & Asparagopsis armata \\
\hline Macroalgae & Grateloupia doryphore (Syn. Grateloupia turuturu) \\
\hline
\end{tabular}




$\begin{array}{ll}\begin{array}{l}\text { Species not assessed / All regions combined } \\ \text { Group }\end{array} & \text { Species } \\ \text { Mollusca } & \text { Rangia cuneata } \\ \text { Plant-parasitic nematode } & \text { Meloidogyne minor } \\ \text { Other Chordates } & \text { Corella eumyota } \\ \text { Other Chordates } & \text { Perophora japonica } \\ \text { Other Chordates } & \text { Didemnum vexillum } \\ \text { Other invertebrates } & \text { Celtodoryx ciocalyptoides } \\ \text { Sea urchins \& starfish } & \text { Asterias amurensis }\end{array}$




\section{Appendix 9: High risk species for the Nordic region}

\begin{tabular}{ll} 
Angiosperms (Taxonomic group) & \\
High risk species (A) / Nordic region & Pathway \\
Species & $\begin{array}{l}\text { Horticulture } \\
\text { Horticulture, Agriculture, Transport } \\
\text { Hunnera tinctoria } \\
\begin{array}{l}\text { Pueraria montana var. lobata (Syn. P. lobata) } \\
\text { Amorpha fructicosa }\end{array}\end{array}$ \\
\hline $\begin{array}{l}\text { Arthropods / Prawn (Taxonomic group) } \\
\text { High risk species (A) / Nordic region }\end{array}$ & $\begin{array}{l}\text { Pathway } \\
\text { Species }\end{array}$ \\
\hline Palaemon macrodactylus & Ballast water \& sediments, Secondary introduction \\
\hline
\end{tabular}

Arthropods / Amphipods (Taxonomic group)

High risk species (A) / Nordic region

Species

Pathway

Dikerogammarus villosus

Ballast water \& sediments

Arthropods / Ants (Taxonomic group)

\begin{tabular}{ll} 
High risk species (A) / Nordic region & \\
Species & Pathway \\
\hline Lasius neglectus & Horticulture, Landscaping \\
\hline
\end{tabular}

Arthropods / Coleoptera (Taxonomic group)

High risk species (A) / Nordic region

Species

Diabrotica virgifera

Agrilus planipennis

Luperomorpha xanthodera

Otiorhynchus liguricus (Syn. O. salicicola)

Phloeosinus aubei

Phloeosinus rudis
Pathway

Agriculture, Transport, Secondary introduction

Forestry

Horticulture

Horticulture

Horticulture

Horticulture

Arthropods / Diptera (Taxonomic group)

High risk species (A) / Nordic region

Species

Pathway

Aedes albopictus

Transport

Ochlerotatus japonicus

Transport

Coenosia attenuata 


Arthropods / Freshwater crayfish (Taxonomic group)
\begin{tabular}{ll} 
High risk species (A) / Nordic region & \\
Species & Pathway \\
\hline Orconectes virilis & Aquaculture, Aquaria with Secondary introduction \\
\hline
\end{tabular}

Arthropods / Lepidoptera (Taxonomic group)
\begin{tabular}{ll} 
High risk species (A) / Nordic region & \\
Species & Pathway \\
\hline Dendrolimus sibiricus & Horticulture, Forestry \\
\hline
\end{tabular}

\begin{tabular}{|c|c|}
\hline High risk species $(A) /$ Nor & \\
\hline Species & Pathway \\
\hline Hemigrapsus penicillatus & Ballast water \& sediments, Hull fouling, Secondary introduction \\
\hline Hemigrapsus takanoi & Ballast water \& sediments, Hull fouling, Secondary introduction \\
\hline Hemigrapsus sanguineus & Ballast water \& sediments, Hull fouling, Secondary introduction \\
\hline
\end{tabular}

\begin{tabular}{l} 
Arthropods / Tanaidacea (Taxonomic groups) \\
\begin{tabular}{ll} 
High risk species (A) / Nordic region \\
Species & Pathway \\
\hline Sinelobus stanfordi & Ballast water \& sediments, Hull fouling
\end{tabular} \\
\hline
\end{tabular}

\section{Arthropods / Wasp (Taxonomic group)}

\begin{tabular}{ll} 
High risk species (A) / Nordic region & \\
Species & Pathway \\
\hline $\begin{array}{l}\text { Sirex ermak } \\
\text { Vespa velutina }\end{array}$ & $\begin{array}{l}\text { Forestry, Transport, Seconday introduction } \\
\text { Seconday introduction, Transport }\end{array}$ \\
\hline
\end{tabular}

\begin{tabular}{ll} 
Birds (Taxonomic group) & \\
High risk species (A) / Nordic region & \\
Species & Pathway \\
\hline Myiopsitta monachus & Escapes, Ornamental \\
\hline
\end{tabular}

Fish / Freshwater (Taxonomic group)

\begin{tabular}{ll} 
High risk species (A) / Nordic region & \\
Species & Pathway \\
\hline Ameiurus melas & Angling/sport, Aquaculture, Fisheries \\
\hline
\end{tabular}




\begin{tabular}{ll} 
Fungus / Pathogen (Taxonomic group) \\
High risk species (A) / Nordic region & \\
Species & Pathway \\
Ceratocystis fagacearum & Forestry \\
Cryptostroma corticale & Forestry, Horticulture \\
Cryphonectria parasitica & Horticulture \\
Monilinia fructicola & Horticulture \\
Splanchnonema platani & Horticulture \\
\hline
\end{tabular}

\begin{tabular}{ll} 
Mammal (Taxonomic group) & \\
High risk species (A) / Nordic region & \\
Species & Pathway \\
Muntiacus reevesi & Escapes \\
Callosciurus erythraeus & Secondary introduction, Escapes \\
Sciurus carolinensis & Ornamental, Escapes \\
\hline
\end{tabular}

Mollusca / Terrestrial gastropoda (Taxonomic group)

High risk species (A) / Nordic region

Species Pathway

Tandonia budapestensis Horticulture, Transport

Plant-parasitic nematode (Taxonomic group)

\begin{tabular}{ll} 
High risk species (A) / Nordic region & \\
Species & Pathway \\
Meloidogyne chitwoodi & Horticulture \\
Meloidogyne fallax & Horticulture \\
\hline
\end{tabular}

Parasitic Nematode (Taxonomic group)

High risk species (A) / Nordic region

Species Pathway

Bursaphelenchus xylophilus Forestry, Transport

Reptilia (Taxonomic group)

High risk species (A) / Nordic region

Species Pathway

Chelydra serpentina Escapes

Chrysemys picta Escapes

Graptemys pseudogeographica Escapes

Macrochelys temminckii Escapes 


\section{Appendix 10: Medium risk species for the Nordic region}

\begin{tabular}{ll} 
Amphibial (Taxonomic group) & \\
Medium risk species (B) / Nordic region & \\
Species & Pathway \\
\begin{tabular}{ll} 
Bufo marinus & Escapes \\
Xenopus laevis & Escapes \\
\hline
\end{tabular} \\
\hline
\end{tabular}

\begin{tabular}{|c|c|}
\hline Medium risk species (B) / Nordic region & \\
\hline Species & Pathway \\
\hline Sicyos angulatus & Agriculture, Horticulture \\
\hline Sagittaria graminea & Aquaria \\
\hline Pistia stratiotes & Aquaria \\
\hline Myriophyllum aquaticum & Aquaria \\
\hline Lemna minuta & Aquaria \\
\hline Lagarosiphon major & Aquaria \\
\hline Hygrophila polysperma & Aquaria \\
\hline Hydrocotyle ranunculoides & Aquaria \\
\hline Gymnocoronis spilanthoides & Aquaria \\
\hline Spathodea campanulata & Horticulture \\
\hline Rosa bracteata & Horticulture \\
\hline Pittosporum undulatum & Horticulture \\
\hline Phormium tenax & Horticulture \\
\hline Paulownia tomentosa & Horticulture \\
\hline Morella faya & Horticulture \\
\hline Ligustrum sinense & Horticulture \\
\hline Ligustrum lucidum & Horticulture \\
\hline Libertia chilensis (Syn Libertia Formosa) & Horticulture \\
\hline Imperata cylindrica & Horticulture \\
\hline Hedychium gardnerianum & Horticulture \\
\hline $\begin{array}{l}\text { Gaultheria mucronata (Syn. Pernettya } \\
\text { mucronata) }\end{array}$ & Horticulture \\
\hline Sasa palmata & Horticulture \\
\hline Acacia melanoxylon & Horticulture \\
\hline Akebia quinata & Horticulture \\
\hline Allium triquetrum & Horticulture \\
\hline Cortaderia selloana & Horticulture \\
\hline Rhus radicans (Syn. Toxicodendron radicans) & Horticulture, Landscaping \\
\hline Hakea sericea & Landscaping, Horticulture \\
\hline
\end{tabular}

Arthropods / Barnacles (Taxonomic group)

Medium risk species (B) / Nordic region

Species

Pathway

Amphibalanus amphitrite

Hull fouling, Ballast water \& sediments, Secondary introduction Solidobalanus fallax Hull fouling, Ballast water \& sediments, Secondary introduction 


Arthropods / Coleoptera (Taxonomic group)
\begin{tabular}{ll} 
Medium risk species (B) / Nordic region \\
Species & Pathway \\
Agrilus anxius & Forestry \\
Epitrix tuberis & Horticulture \\
\hline
\end{tabular}

\begin{tabular}{|c|c|}
\hline \multicolumn{2}{|c|}{ Medium risk species (B) / Nordic region } \\
\hline Species & Pathway \\
\hline Rhagoletis cingulata & Horticulture \\
\hline
\end{tabular}

\begin{tabular}{|c|c|}
\hline \multicolumn{2}{|c|}{ Medium risk species (B) / Nordic region } \\
\hline Species & Pathway \\
\hline Orconectes rusticus & Aquaculture, Aquaria with Secondary introduction \\
\hline Procambarus clarkii & Aquaculture, aquaria, secondary introduction \\
\hline Procambarus fallax $f$ virginalis & Aquaria, Escapes \\
\hline
\end{tabular}

Arthropods / Lepidoptera (Taxonomic group)

Medium risk species (B) / Nordic region

Species

Pathway

Dendrolimus superans

Horticulture, Forestry

Cacoecimorpha pronubana

Horticulture, Secondary introduction

Hyphantria cunea

Arthropods / Marine crab (Taxonomic group)

Medium risk species (B) / Nordic region

Species Pathway

Charybdis japonica

Ballast water \& sediments, Secondary introduction

Arthropods / Marine prawn (Taxonomic group)

Medium risk species (B) / Nordic region

Species Pathway

Marsupenaeus japonicus Aquaculture, Ballast water \& sediments

Arthropods / Trips (Taxonomic group)

Medium risk species (B) / Nordic region

Species Pathway

Thrips palmi Agriculture 


\begin{tabular}{ll} 
Birds (Taxonomic group) & \\
Medium risk species (B) / Nordic region \\
Species & Pathway \\
Callonetta leucophrys & Escapes \\
Falco biarmicus & Escapes \\
Chrysolophus pictus & Hunting \\
Lophura nycthemera & Hunting \\
Nymphicus hollandicus & \\
\hline
\end{tabular}

Fish / Freshwater (Taxonomic group)

Medium risk species (B) / Nordic region

Species Pathway

Coregonus muksun Aquaculture

Neogobius kessleri Ballast water \& sediments, Transport, Secondary introduction

\section{Fish / Marine (Taxonomic group)}

Medium risk species (B) / Nordic region

Species Pathway

Anguilla rostrata

Fisheries, Aquaculture

Fungus (Taxonomic group)

Medium risk species (B) / Nordic region

Species

Pathway

Suillus placidus

Forestry, Horticulture, Secondary introduction

Gymnopus luxurians Horticulture, Forestry

Fungus / Pathogen (Taxonomic group)

Medium risk species (B) / Nordic region

Species Pathway

Endocronartium harknessii Forestry

Ophiostoma wageneri Forestry

\section{Mammal (Taxonomic group)}

Medium risk species (B) / Nordic region

Species

Pathway

Mustela furo

Animal husbandry, Escapes

Herpestes javanicus

Ornamental, Escapes 
Mollusca / Marine mollusca (Taxonomic group)

Medium risk species (B) / Nordic region

Species

Potamocorbula amurensis

Musculista senhousia

Pathway

Ballast water \& sediments

Hull fouling, Secondary introduction

Mollusca / Marine Snail (Taxonomic group)

Medium risk species (B) / Nordic region

Species Pathway

Rapana venosa

Aquaculture, Secondary introduction

Parasitic Nematode (Taxonomic group)

Medium risk species (B) / Nordic region

Species

Pathway

Ashworthius sidemi

Animal husbandry

Reptilia (Taxonomic group)

Medium risk species (B) / Nordic region

Species

Pathway

Apalone spinifera

Escapes

Boa constrictor imperator

Escapes

Elaphe schrencki

Escapes, Ornamental, Secondary introduction 


\section{Appendix 11: High risk species for the Baltic region}

\begin{tabular}{ll}
$\begin{array}{l}\text { Amphibia (Taxonomic group) } \\
\text { High risk species (A) / Baltic region }\end{array}$ \\
Species & Pathway \\
\hline Alytes obstetricans & Secondary introduction, Transport \\
\hline & \\
\hline Arthropods / Prawn (Taxonomic group) & \\
\hline High risk species (A) / Baltic region & Pathway \\
Species & Ballast water \& sediments, Secondary introduction \\
\hline Palaemon macrodactylus
\end{tabular}

\begin{tabular}{l} 
Arthropods / Amphipods (Taxonomic group) \\
\begin{tabular}{ll} 
High risk species (A) / Baltic region & Pathway \\
Species & Ballast water \& sediments \\
\hline Dikerogammarus villosus &
\end{tabular} \\
\hline
\end{tabular}

\begin{tabular}{ll} 
Arthropods / Coleoptera (Taxonomic group) \\
High risk species (A) / Baltic region & \\
Species & Pathway \\
\hline Diabrotica virgifera & Agriculture, Transport, Secondary introduction \\
Agrilus planipennis & Forestry \\
Luperomorpha xanthodera & Horticulture \\
Otiorhynchus liguricus (Syn. O. salicicola) & Horticulture \\
Phloeosinus aubei & Horticulture \\
Phloeosinus rudis & Horticulture \\
\hline
\end{tabular}

\begin{tabular}{|c|c|}
\hline High risk species (A) / B & \\
\hline Species & Pathway \\
\hline Aedes albopictus & Transport \\
\hline Ochlerotatus japonicus & Transport \\
\hline Coenosia attenuata & \\
\hline
\end{tabular}

\begin{tabular}{l} 
Arthropods / Freshwater crayfish (Taxonomic group) \\
\begin{tabular}{ll} 
High risk species (A) / Baltic region & Pathway \\
Species & Aquaculture, Aquaria with Secondary introduction \\
\hline Orconectes virilis &
\end{tabular} \\
\hline
\end{tabular}




Athropods / Lepidoptera (Taxonomic group)
\begin{tabular}{ll} 
High risk species (A) / Baltic region & \\
Species & Pathway \\
\hline Dendrolimus sibiricus & Horticulture, Forestry \\
\hline
\end{tabular}

Arthropods / Wasp (Taxonomic group)

High risk species (A) / Baltic region

Species Pathway

Sirex ermak Forestry, Transport, Seconday introduction

Vespa velutina Seconday introduction, Transport

Fish / Freshwater (Taxonomic group)

High risk species (A) / Baltic region

Species

Pathway

Ameiurus melas

Angling/sport, Aquaculture, Fisheries

Mammal (Taxonomic group)

High risk species (A) / Baltic region

Species Pathway

Sciurus carolinensis

Ornamental, Escapes

Mollusca / Terrestrial Gastropoda (Taxonomic group)

High risk species (A) / Baltic region

Species

Pathway

Tandonia budapestensis

Horticulture, Transport

Plant-parasitic nematode (Taxonomic group)

High risk species (A) / Baltic region

Species Pathway

Meloidogyne chitwoodi Horticulture

Parasitic Nematode (Taxonomic group)

High risk species (A) / Baltic region

Species

Pathway

Ashworthius sidemi

Animal husbandry

Bursaphelenchus xylophilus Forestry, Transport 
Reptilia (Taxonomic group)

High risk species (A) / Baltic region

Species

Pathway

Chelydra serpentina

Macrochelys temminckii

Escapes

Chrysemys picta

Escapes

Graptemys pseudogeographica 


\section{Appendix 12: Medium risk species for the Baltic region}

\begin{tabular}{ll} 
Amphibia (Taxonomic group) & \\
Medium risk species (B) / Baltic region & Pathway \\
Species & Escapes \\
$\begin{array}{l}\text { Bufo marinus } \\
\text { Xenopus laevis }\end{array}$ \\
\hline
\end{tabular}

\begin{tabular}{ll} 
Angiosperms (Taxonomic group) & \\
Medium risk species (B) / Baltic region & \\
Species & Pathway \\
\hline $\begin{array}{l}\text { Gymnocoronis spilanthoides } \\
\text { Gaultheria mucronata (Syn. Pernettya mucronata) } \\
\text { Cortaderia selloana }\end{array}$ & $\begin{array}{l}\text { Aquaria } \\
\text { Amorpha fructicosa }\end{array}$ \\
\hline
\end{tabular}

Arthropods / Ants (Taxonomic group)
\begin{tabular}{ll} 
Medium risk species (B) / Baltic region & \\
Species & Pathway \\
\hline Lasius neglectus & Horticulture, Landscaping \\
\hline
\end{tabular}

\begin{tabular}{ll} 
Athropods / Coleoptera (Taxonomic group) & \\
Medium risk species (B) / Baltic region & \\
Species & Pathway \\
\hline Epitrix tuberis & Horticulture \\
\hline
\end{tabular}

\begin{tabular}{ll} 
Arthropods / Diptera (Taxonomic group) & \\
Medium risk species (B) / Baltic region & \\
Species & Pathway \\
\hline $\begin{array}{l}\text { Rhagoletis cingulata } \\
\text { Drosophila suzukii } \\
\text { Coenosia attenuata }\end{array}$ & Horticulture \\
\hline
\end{tabular}

\begin{tabular}{ll} 
Arthropods / Freshwater crayfish (Taxonomic group) \\
$\begin{array}{ll}\text { Medium risk species (B) / Baltic region } & \text { Pathway } \\
\text { Species } & \text { Aquaculture, Aquaria with Secondary introduction } \\
\text { Orconectes rusticus } & \text { Aquaculture, aquaria, secondary introduction } \\
\text { Procambarus clarkii } & \text { Aquaria, Escapes } \\
\text { Procambarus fallax } \mathrm{f} \text { virginalis } & \end{array}$ \\
\hline
\end{tabular}


Arthropods / Lepidoptera (Taxonomic group)

Medium risk species (B) / Baltic region

Species

Pathway

Dendrolimus superans

Horticulture, Forestry

Lymantria mathura

Horticulture, Forestry, Transport

Cacoecimorpha pronubana

Horticulture, Secondary introduction

Hyphantria cunea

Arthropods / Trips (Taxonomic group)

Medium risk species (B) / Baltic region

Species Pathway

Thrips palmi Agriculture

Birds (Taxonomic group)

Medium risk species (B) / Baltic region

Species

Pathway

Chrysolophus pictus

Hunting

Nymphicus hollandicus

Fish / Freshwater (Taxonomic group)

Medium risk species (B) / Baltic region

Species

Pathway

Coregonus muksun

Neogobius gymnotrachelus

Aquaculture

Neogobius fluviatilis

Ballast water \& sediments, Secondary introduction

Neogobius kessleri

Ballast water \& sediments, Transport, Secondary introduction

Ballast water \& sediments, Transport, Secondary introduction

Romanogobio belingi

\section{Fish / Marine (Taxonomic group)}

Medium risk species (B) / Baltic region

Species Pathway

Anguilla rostrata

Fisheries, Aquaculture

Fungi (Taxonomic group)

Medium risk species (B) / Baltic region

Species

Pathway

Panaeolus cyanescens

Horticulture, (Medicinal)

Psilocybe cubensis Horticulture, (Medicinal) 
Plant-parasitic nematode (Taxonomic group)

Medium risk species (B) / Baltic region

Species

Pathway

Meloidogyne fallax

Horticulture

Reptilia (Taxonomic group)

Medium risk species (B) / Baltic region

Species

Pathway

Boa constrictor imperator

Ecapes

Apalone spinifera

Ecapes

Elaphe schrenckil

Escapes, Ornamental, Secondary introduction 
Appendix 13: High risk species for the Islands of the North Atlantic Ocean

\begin{tabular}{l} 
Arthropods / Wasp (Taxonomic group) \\
$\begin{array}{l}\text { High risk species (A) / Islands of the North Atlantic Ocean } \\
\text { Species } \\
\text { Vespa velutina }\end{array}$ \\
$\begin{array}{l}\text { Mammal (Taxonomic group) } \\
\text { High risk species (A) / Islands of the North Atlantic Ocean introduction, Transport }\end{array}$ \\
Species $\quad$ Pathway \\
\hline Sciurus carolinensis $\quad$ Ornamental, Escapes \\
\hline
\end{tabular}




\section{Appendix 14: Medium risk species for the Islands of the North Atlantic Ocean}

\begin{tabular}{|c|c|}
\hline \multicolumn{2}{|c|}{ Angiosperms (Taxonomic group) } \\
\hline \multicolumn{2}{|c|}{ Medium risk species (B) / Islands of the North Atlantic Ocean } \\
\hline Species & Pathway \\
\hline $\begin{array}{l}\text { Gaultheria mucronata } \\
\text { (Syn. Pernettya mucronata) }\end{array}$ & Horticulture \\
\hline \multicolumn{2}{|c|}{ Athropods / Barnacles (Taxonomic group) } \\
\hline \multicolumn{2}{|c|}{ Medium risk species (B) / Islands of the North Atlantic Ocean } \\
\hline Species & Pathway \\
\hline Solidobalanus fallax & Hull fouling, Ballast water \& sediments, Secondary introduction \\
\hline \multicolumn{2}{|c|}{ Arthropods / Diptera (Taxonomic group) } \\
\hline \multicolumn{2}{|c|}{ Medium risk species (B) / Islands of the North Atlantic Ocean } \\
\hline Species & Pathway \\
\hline \multicolumn{2}{|l|}{ Coenosia attenuata } \\
\hline Aedes albopictus & Transport \\
\hline Ochlerotatus japonicus & Transport \\
\hline Drosophila suzukii & \\
\hline Rhagoletis cingulata & Horticulture \\
\hline
\end{tabular}

Arthropods / Trips (Taxonomic group)

\begin{tabular}{ll} 
Medium risk species (B) / Islands of the North Atlantic Ocean \\
Species & Pathway \\
Thrips palmi & Agriculture \\
\hline
\end{tabular}

Fish / Marine (Taxonomic group)

Medium risk species (B) / Islands of the North Atlantic Ocean

Species Pathway

Anguilla rostrata Fisheries, Aquaculture 


\section{Appendix 15: Low risk species for the Nordic region}

\begin{tabular}{ll} 
Amphibia (Taxonomic group) & \\
Low risk species $(\mathbf{C})$ / Nordic region & \\
\hline Species & Pathway \\
\hline Eleutherodactylus coqui & Transport \\
Osteopilus septentrionalis & Transport \\
Pelophylax bedriagae & Escapes \\
\hline
\end{tabular}

\begin{tabular}{|c|c|}
\hline \multicolumn{2}{|l|}{ Low risk species (C) / Nordic region } \\
\hline Species & Pathway \\
\hline Zostera japonica & Transport \\
\hline Ziziphus mauritiana & Horticulture, Agriculture \\
\hline Vitex rotundifolia & Landscaping, Horticulture \\
\hline Triadica sebifera & Horticulture \\
\hline Solidago nemoralis & Horticulture, Landscaping \\
\hline Sisyrinchium californicum & Horticulture \\
\hline Sesbania punicea & Horticulture \\
\hline Salvinia molesta & Aquaria \\
\hline Psidium guajava & Agriculture \\
\hline Prosopis glandulosa & Agriculture, Landscaping \\
\hline Polygonum perfoliatum (Syn. Persicaria perfoliata) & Horticulture, Agriculture \\
\hline Plantago serpentina & Agriculture \\
\hline Paspalum distichum (Syn. Paspalum paspalodes) & Agriculture \\
\hline Nassella trichotoma & Agriculture \\
\hline Nassella neesiana & Horticulture \\
\hline Myriophyllum heterophyllum & Aquaria \\
\hline Mimosa pigra & Horticulture \\
\hline Microstegium vimineum & Agriculture, Transport \\
\hline Dolichandra unguis-cati (Syn. Macfadyena unguis-cati) & Horticulture \\
\hline Ludwigia peploides & Aquaria \\
\hline Ludwigia grandiflora & Aquaria \\
\hline \multicolumn{2}{|l|}{ Juncus planifolius } \\
\hline Ipomoea aquatica & Horticulture \\
\hline \multicolumn{2}{|l|}{ Hydrocotyle ramiflora } \\
\hline Hiptage benghalensis & Horticulture \\
\hline Cyperus rotundus & Agriculture, Transport \\
\hline Acacia dealbata & Horticulture \\
\hline Acaena ovaliflolia & Horticulture \\
\hline Alternanthera philoxeroides & Aquaria \\
\hline Andropogon virginicus & Horticulture, Secondary introduction \\
\hline Araujia sericifera & Horticulture \\
\hline Ardisia elliptica & Horticulture \\
\hline Artemisia tournefortiana & Agriculture, Forestry, Transport \\
\hline Baccharis halimifolia & Horticulture, Secondary introduction \\
\hline Calystegia inflate (Syn .C. sepium subsp. Americana) & Horticulture \\
\hline Carpobrotus acinaciformis & Horticulture \\
\hline Carpobrotus edulis & Horticulture \\
\hline Cenchrus pauciflorus (Syn. Cenchrus pauciflorus, C. incertus) & Transport \\
\hline \multicolumn{2}{|l|}{ Chromolaena odorata } \\
\hline Clidemia hirta & Horticulture \\
\hline Cuscuta tinei & Agriculture \\
\hline Urtica cannabina & \\
\hline
\end{tabular}




\begin{tabular}{|c|c|}
\hline \multicolumn{2}{|c|}{ Low risk species (C) / Nordic region } \\
\hline Species & Pathway \\
\hline Crangonyx pseudogracilis & Ballast water \& sediments \\
\hline Linepithema humile & Horticulture, Landscaping \\
\hline Wasmannia auropunctata & Horticulture, Landscaping \\
\hline Balanus eburneus & Hull fouling, Secondary introduction \\
\hline Balanus trigonus & Hull fouling, Ballast water \& sediments, Secondary introduction \\
\hline Balanus variegatus & Hull fouling, Secondary introduction \\
\hline Megabalanus coccopoma & Hull fouling \\
\hline Megabalanus tintinnabulum & Hull fouling \\
\hline Megabalanus tulipiformis & Hull fouling \\
\hline Dendroctonus ponderosae & Forestry \\
\hline Enaphalodes rufulus & Forestry \\
\hline Hesperophanes campestris & Forestry, Transport \\
\hline Ips hauseri & Forestry \\
\hline Ips pini & Forestry \\
\hline Monochamus carolinensis & Forstry \\
\hline Monochamus marmoratus & Forstry \\
\hline Monochamus mutator & Forstry \\
\hline Monochamus nitens & Forstry \\
\hline Monochamus notatus & Forstry \\
\hline Monochamus obtusus & Forstry \\
\hline Monochamus scutellatus & Forstry \\
\hline Oemona hirta & Forestry, Horticulture, Landscaping \\
\hline Pissodes nemorensis & Forestry, Horticulture, Landscaping \\
\hline Pissodes strobi & Forestry, Horticulture, Landscaping \\
\hline Pissodes terminalis & Forestry, Horticulture, Landscaping \\
\hline Popillia japonica & Horticulture \\
\hline Saperda candida & Forestry, Horticulture, Landscaping \\
\hline Scolytus moravitzi & Forestry \\
\hline Tetropium gracilicorne & Forestry \\
\hline Xylosandrus crassiusculus & Forestry, Horticulture, Landscaping \\
\hline \multicolumn{2}{|l|}{ Braula schmitzi } \\
\hline Rhagoletis fausta & Horticulture \\
\hline Rhagoletis indifferens & Horticulture \\
\hline Rhagoletis pomonella & Horticulture \\
\hline Strobilomyia viaria & Transport \\
\hline Potamon ibericum & Aquaculture, aquaria \\
\hline Cherax destructor & Aquaculture, Aquaria with Secondary introduction \\
\hline Cherax quadricarinatus & Aquaculture, Aquaria with Secondary introduction \\
\hline Procambarus acutus & Aquaculture, aquaria, Angling/sport \\
\hline Lymantria mathura & Horticulture, Forestry, Transport \\
\hline Choristoneura fumiferana & Horticulture \\
\hline Choristoneura occidentalis & Horticulture \\
\hline Malacosoma americanum & Horticulture, Forestry \\
\hline Malacosoma disstria & Horticulture, Forestry \\
\hline Orgyia pseudotsugata & Horticulture, Forestry \\
\hline Acleris gloverana & Horticulture, Landscaping \\
\hline Acleris variana & Horticulture, Landscaping \\
\hline Cydia prunivora & Horticulture, Landscaping \\
\hline Spodoptera littoralis & Horticulture \\
\hline Callinectes sapidus & Ballast water \& sediments \\
\hline Percnon gibbesi & Hull fouling, Ballast water \& sediments, Secondary introduction \\
\hline Portunus pelagicus & Hull fouling, Ballast water \& sediments, Secondary introduction \\
\hline
\end{tabular}




\begin{tabular}{ll} 
Birds (Taxonomic group) & \\
Low risk species (C) / Nordic region & Pathway \\
Species & Escapes, Ornamental \\
Psittacula eupatria & Escapes, Ornamental \\
Threskiornis aethiopicus & \\
\hline Bryophytes (Taxonomic group) & \\
Low risk species (C) / Nordic region & Pathway \\
Species & \\
\hline
\end{tabular}

\section{Fish / Freshwater (Taxonomic group)}

Low risk species (C) / Nordic region

Species

Neogobius fluviatilis

Neogobius gymnotrachelus

Romanogobio belingi

Benthophilus durrelli

Benthophilus nudus

Catostomus commersonii

Channa argus

Cichla ocellaris

Clarias gariepinus

Clupeonella tscharchalensis

Cobitis bilineata

Gambusia affinis

Gambusia holbrooki

Ictalurus punctatus

Ictiobus niger

Knipowitschia longecaudata

Misgurnus anguillicaudatus

Monopterus albus

Neogobius gorlap

Neogobius pallasi

Parachondrostoma toxostoma

Pimephales promelas

Proterorhinus semilunaris

Pylodictis olivaris

\section{Pathway}

Ballast water \& sediments, Transport, Secondary introduction Ballast water \& sediments, Secondary introduction

Fisheries

Biological contro

Aquaculture, Fisheries

Aquaculture, Fisheries

\section{Fish / Marine (Taxonomic group)}

Low risk species (C) / Nordic region

Species

Anguilla rostrata*

Anguilla japonica

Neogobius eurycephalus (Syn. Ponticola eurycephalus)

Siganus rivulatus

Syngnathus nigrolineatus (Syn. Syngnathus abaster)

\section{Pathway}

Fisheries, Aquaculture

Fisheries, Aquaculture

Ballast water \& sediments
Angling/sport, Aquaria

Ballast water \& sediments, Transport, Secondary introduction 


\begin{tabular}{ll} 
Fungus (Taxonomic group) & \\
Low risk species (C) / Nordic region & \\
Species & Pathway \\
Panaeolus cyanescens & Horticulture, (Medicinal) \\
Psilocybe cubensis & Horticulture, (Medicinal) \\
Clathrus ruber & Horticulture, Secondary introduction \\
Leucocoprinus straminellus & Horticulture \\
Suillus ochraceoroseus & Forestry, Horticulture, Secondary introduction \\
\hline
\end{tabular}

\begin{tabular}{|c|c|}
\hline Low risk species (C) / Nordic region & \\
\hline Species & Pathway \\
\hline Atropellis pinicola & Forestry \\
\hline Atropellis piniphila & Forestry \\
\hline Chrysomyxa arctostaphyli & Forestry \\
\hline Davidiella populorum & Forestry, Horticulture \\
\hline Mycosphaerella laricis-leptolepidis & Forestry \\
\hline Phellinus weirii & Forestry, Transport \\
\hline Stegophora ulmea & Horticulture \\
\hline
\end{tabular}

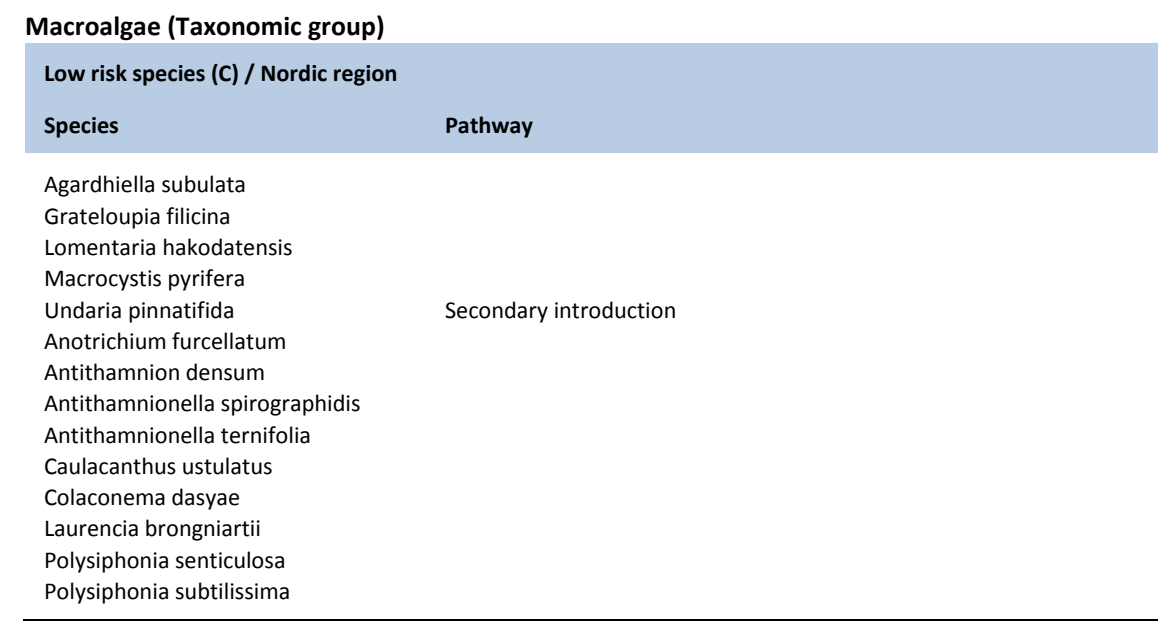

\begin{tabular}{ll} 
Mammal (Taxonomic group) & \\
Low risk species (C) / Nordic region & \\
Species & Pathway \\
Sus scrofa vittatus & Escapes, Hunting, Ornamental \\
Trichosurus vulpecula & Escapes \\
Tamias striatus & Ornamental \\
Sylvilagus floridanus & \\
Sciurus niger & \\
Sciurus anomalus & Ornamental, Escapes \\
Rusa timorensis & \\
Nasua nasua & Animal husbandry, Secondary introduction \\
Macropus rufogriseus & Escapes \\
Macaca fascicularis & Escapes \\
Callosciurus finlaysonii & Ornamental, Escapes \\
Axis axis & Ornamental, Escapes \\
\hline
\end{tabular}




\begin{tabular}{ll} 
Mollusca (Taxonomic group) & \\
Low risk species (C) / Nordic region & \\
Species & Pathway \\
Brachidontes pharaonis & Hull fouling, Ballast water \& sediments \\
Mercenaria mercenaria & Ballast water \& sediments, Escapes \\
Ruditapes philippinarum & Aquaculture, Secondary introduction \\
Urosalpinx cinerea & Aquaculture, Secondary introduction \\
Corbicula fluminea & Ballast water \& sediments, Aquaculture \\
Corbicula fluminalis & Hull fouling, Ballast water \& sediments \\
Dreissena rostriformis bugensis & Ballast water \& sediments, Secondary introduction \\
Crassostrea virginica & Mollusca \\
Ostrea chilensis & Aquaculture \\
Pinctada radiata & Aquaculture, Hull fouling \\
Euglandina rosea & \\
Chilostoma cingulatum gobanzi & Ornamental \\
\hline
\end{tabular}

Other Chordates (Taxonomic group)

Low risk species (C) / Nordic region

Species Pathway

Corella eumyota Aquaculture, Hull fouling

Perophora japonica Hull fouling

Reptilia (Taxonomic group)

Low risk species (C) / Nordic region

Species

Pathway

Boiga irregularis

Escapes, Transport

Mauremys leprosa

Escapes, Ornamenta

*Comment from expert: "the species spawns in the Sargasso Sea and will never become established in European waters". 


\section{Appendix 16: Low risk species for the Baltic region}

\begin{tabular}{ll} 
Amphibia (Taxonomic group) & \\
Low risk species (C) / Baltic region & Pathway \\
Species & Transport \\
Eleutherodactylus coqui & Transport \\
Osteopilus septentrionalis & Escapes \\
Pelophylax bedriagae & Page \\
\hline
\end{tabular}

\begin{tabular}{|c|c|}
\hline \multicolumn{2}{|l|}{ Low risk species (C) / Baltic region } \\
\hline Species & Pathway \\
\hline Zostera japonica & Transport \\
\hline Ziziphus mauritiana & Horticulture, Agriculture \\
\hline Vitex rotundifolia & Landscaping, Horticulture \\
\hline Triadica sebifera & Horticulture \\
\hline Spathodea campanulata & Horticulture \\
\hline Solidago nemoralis & Horticulture, Landscaping \\
\hline Sisyrinchium septentrionale & Horticulture \\
\hline Sisyrinchium californicum & Horticulture \\
\hline Sicyos angulatus & Agriculture, Horticulture \\
\hline Sesbania punicea & Horticulture \\
\hline Salvinia molesta & Aquaria \\
\hline Sagittaria graminea & Aquaria \\
\hline Rosa bracteata & Horticulture \\
\hline Rhus radicans (Syn. Toxicodendron radicans) & Horticulture, Landscaping \\
\hline Pueraria montana var. lobata (Syn. P. lobata) & Horticulture, Agriculture, Transport \\
\hline Psidium guajava & Agriculture \\
\hline Prosopis glandulosa & Agriculture, Landscaping \\
\hline Polygonum perfoliatum (Syn. Persicaria perfoliata) & Horticulture, Agriculture \\
\hline Plantago serpentina & Agriculture \\
\hline Pittosporum undulatum & Horticulture \\
\hline Pistia stratiotes & Aquaria \\
\hline Phormium tenax & Horticulture \\
\hline Paulownia tomentosa & Horticulture \\
\hline Paspalum distichum (Syn. Paspalum paspalodes) & Agriculture \\
\hline Nassella trichotoma & Agriculture \\
\hline \multicolumn{2}{|l|}{ Nassella tenuissima } \\
\hline Nassella neesiana & Horticulture \\
\hline Myriophyllum heterophyllum & Aquaria \\
\hline Myriophyllum aquaticum & Aquaria \\
\hline Morella faya & Horticulture \\
\hline Mimosa pigra & Horticulture \\
\hline Microstegium vimineum & Agriculture, Transport \\
\hline Dolichandra unguis-cati (Syn. Macfadyena unguis-cati) & Horticulture \\
\hline Ludwigia peploides & Aquaria \\
\hline Ludwigia grandiflora & Aquaria \\
\hline Ligustrum sinense & Horticulture \\
\hline Ligustrum lucidum & Horticulture \\
\hline Libertia chilensis (Syn. Libertia Formosa) & Horticulture \\
\hline Lemna minuta & Aquaria \\
\hline Lagarosiphon major & Aquaria \\
\hline \multicolumn{2}{|l|}{ Juncus planifolius } \\
\hline Ipomoea aquatica & Horticulture \\
\hline Imperata cylindrica & Horticulture \\
\hline Hygrophila polysperma & Aquaria \\
\hline Hydrocotyle ranunculoides & Aquaria \\
\hline Hydrocotyle ramiflora & \\
\hline
\end{tabular}




\begin{tabular}{|c|c|}
\hline $\begin{array}{l}\text { Low risk species (C) / Baltic region } \\
\text { Species }\end{array}$ & Pathway \\
\hline Hiptage benghalensis & Horticulture \\
\hline Hedychium gardnerianum & Horticulture \\
\hline Hakea sericea & Landscaping, Horticulture \\
\hline Gunnera tinctoria & Horticulture \\
\hline Cyperus rotundus & Agriculture, Transport \\
\hline Sasa palmata & Horticulture \\
\hline Acacia dealbata & Horticulture \\
\hline Acacia melanoxylon & Horticulture \\
\hline Acaena ovaliflolia & Horticulture \\
\hline Akebia quinata & Horticulture \\
\hline Allium triquetrum & Horticulture \\
\hline Alternanthera philoxeroides & Aquaria \\
\hline Andropogon virginicus & Horticulture, Secondary introduction \\
\hline Araujia sericifera & Horticulture \\
\hline Ardisia elliptica & Horticulture \\
\hline Artemisia tournefortiana & Agriculture, Forestry, Transport \\
\hline Baccharis halimifolia & Horticulture, Secondary introduction \\
\hline Calystegia inflate (Syn. C. sepium subsp. Americana) & Horticulture \\
\hline Carpobrotus acinaciformis & Horticulture \\
\hline Carpobrotus edulis & Horticulture \\
\hline Cenchrus pauciflorus (Syn. Cenchrus pauciflorus, C. incertus) & Transport \\
\hline \multicolumn{2}{|l|}{ Chromolaena odorata } \\
\hline Clidemia hirta & Horticulture \\
\hline Cuscuta tinei & Agriculture \\
\hline Urtica cannabina & \\
\hline
\end{tabular}

\begin{tabular}{|c|c|}
\hline \multicolumn{2}{|c|}{ Low risk species (C) / Baltic region } \\
\hline Species & Pathway \\
\hline Crangonyx pseudogracilis & Ballast water \& sediments \\
\hline Linepithema humile & Horticulture, Landscaping \\
\hline Wasmannia auropunctata & Horticulture, Landscaping \\
\hline Amphibalanus amphitrite & Hull fouling, Ballast water \& sediments, Secondary introduction \\
\hline Balanus eburneus & Hull fouling, Secondary introduction \\
\hline Balanus trigonus & Hull fouling, Ballast water \& sediments; Secondary introduction \\
\hline Balanus variegatus & Hull fouling, Secondary introduction \\
\hline Megabalanus coccopoma & Hull fouling \\
\hline Megabalanus tintinnabulum & Hull fouling \\
\hline Megabalanus tulipiformis & Hull fouling \\
\hline Solidobalanus fallax & Hull fouling, Ballast water \& sediments, Secondary introduction \\
\hline Agrilus anxius & Forestry \\
\hline Dendroctonus ponderosae & Forestry \\
\hline Enaphalodes rufulus & Forestry \\
\hline Hesperophanes campestris & Forestry, Transport \\
\hline Ips hauseri & Forestry \\
\hline Ips pini & Forestry \\
\hline Monochamus carolinensis & Forstry \\
\hline Monochamus marmoratus & Forstry \\
\hline Monochamus mutator & Forstry \\
\hline Monochamus nitens & Forstry \\
\hline Monochamus notatus & Forstry \\
\hline Monochamus obtusus & Forstry \\
\hline Monochamus scutellatus & Forstry \\
\hline Oemona hirta & Forestry, Horticulture, Landscaping \\
\hline Pissodes nemorensis & Forestry, Horticulture, Landscaping \\
\hline Pissodes strobi & Forestry, Horticulture, Landscaping \\
\hline Pissodes terminalis & Forestry, Horticulture, Landscaping \\
\hline Popillia japonica & Horticulture \\
\hline
\end{tabular}




\begin{tabular}{|c|c|}
\hline \multicolumn{2}{|c|}{ Low risk species (C) / Baltic region } \\
\hline Species & Pathway \\
\hline Saperda candida & Forestry, Horticulture, Landscaping \\
\hline Scolytus moravitzi & Forestry \\
\hline Tetropium gracilicorne & Forestry \\
\hline Xylosandrus crassiusculus & Forestry, Horticulture, Landscaping \\
\hline \multicolumn{2}{|l|}{ Braula schmitzi } \\
\hline Rhagoletis fausta & Horticulture \\
\hline Rhagoletis indifferens & Horticulture \\
\hline Rhagoletis pomonella & Horticulture \\
\hline Strobilomyia viaria & Transport \\
\hline Potamon ibericum & Aquaculture, aquaria \\
\hline Cherax destructor & Aquaculture, Aquaria with Secondary introduction \\
\hline Cherax quadricarinatus & Aquaculture, Aquaria with Secondary introduction \\
\hline Procambarus acutus & Aquaculture, aquaria, Angling/sport \\
\hline Choristoneura fumiferana & Horticulture \\
\hline Choristoneura occidentalis & Horticulture \\
\hline Malacosoma americanum & Horticulture, Forestry \\
\hline Malacosoma disstria & Horticulture, Forestry \\
\hline Orgyia pseudotsugata & Horticulture, Forestry \\
\hline Acleris gloverana & Horticulture, Landscaping \\
\hline Acleris variana & Horticulture, Landscaping \\
\hline Cydia prunivora & Horticulture, Landscaping \\
\hline Spodoptera littoralis & Horticulture \\
\hline Charybdis japonica & Ballast water \& sediments, Secondary introduction \\
\hline Hemigrapsus penicillatus & Ballast water \& sediments, Hull fouling, Secondary introduction \\
\hline Hemigrapsus takanoi & Ballast water \& sediments, Hull fouling, Secondary introduction \\
\hline Hemigrapsus sanguineus & Ballast water \& sediments, Hull fouling, Secondary introduction \\
\hline Percnon gibbesi & Hull fouling, Ballast water \& sediments, Secondary introduction \\
\hline Portunus pelagicus & Hull fouling, Ballast water \& sediments, Secondary introduction \\
\hline Marsupenaeus japonicus & Aquaculture, Ballast water $\&$ sediments \\
\hline Sinelobus stanfordi & Ballast water \& sediments, Hull fouling \\
\hline
\end{tabular}

\begin{tabular}{|c|c|}
\hline \multicolumn{2}{|c|}{ Low risk species (C) / Baltic region } \\
\hline Species & Pathway \\
\hline Callonetta leucophrys & Escapes \\
\hline Lophura nycthemera & Hunting \\
\hline Myiopsitta monachus & Escapes, Ornamental \\
\hline Psittacula eupatria & Escapes, Ornamental \\
\hline Threskiornis aethiopicus & Escapes, Ornamental \\
\hline
\end{tabular}

\section{Bryophytes (Taxonomic group)}

Low risk species (C) / Baltic region

Species

Pathway

Lophocolea semiteres

\section{Fish / Freshwater (Taxonomic group)}

\section{Low risk species (C) / Baltic region}

Species

Pathway

Benthophilus durrell

Benthophilus nudus

Catostomus commersonii 


\section{Low risk species (C) / Baltic region}

Species

Channa argus

Cichla ocellaris

Clarias gariepinus

Clupeonella tscharchalensis

Cobitis bilineata

Gambusia affinis

Gambusia holbrooki

Ictalurus punctatus

Ictiobus niger

Knipowitschia longecaudata

Misgurnus anguillicaudatus

Monopterus albus

Neogobius gorlap

Neogobius pallasi

Parachondrostoma toxostoma

Pimephales promelas

Proterorhinus semilunaris

Pylodictis olivaris

\section{Pathway}

Fisheries

Biological control

Aquaculture, Fisheries

Aquaculture, Fisheries

Angling/sport

Angling/sport, Aquaria

Ballast water \& sediments, Transport, Secondary introduction

\section{Fish / Marine (Taxonomic group)}

\begin{tabular}{ll} 
Low risk species (C) / Baltic region & \\
Species & Pathway \\
\hline Anguilla rostrata* & Fisheries, Aquaculture \\
Anguilla japonica & Fisheries, Aquaculture \\
Neogobius eurycephalus (Syn. Ponticola eurycephalus) & Ballast water \& sediments \\
Siganus rivulatus & \\
Syngnathus nigrolineatus (Syn. Syngnathus abaster) & \\
\hline
\end{tabular}

\section{Fungus (Taxonomic group)}

Low risk species (C) / Baltic region

Species

Pathway

Clathrus ruber

Gymnopus luxurians

Leucocoprinus straminellus

Suillus ochraceoroseus
Horticulture, Secondary introduction

Horticulture, Forestry

Horticulture

Forestry, Horticulture, Secondary introduction

Macroalgae (Taxonomic group)

Low risk species (C) / Baltic region

Species

Pathway

Anotrichium furcellatum

Antithamnion densum

Antithamnionella spirographidis

Antithamnionella ternifolia

Caulacanthus ustulatus

Colaconema dasyae

Laurencia brongniarti

Polysiphonia senticulosa

Polysiphonia subtilissima 


\begin{tabular}{ll} 
Mammal (Taxonomic group) & \\
Low risk species (C) / Baltic region & \\
Species & Pathway \\
Sus scrofa vittatus & Escapes, Hunting, Ornamental \\
Trichosurus vulpecula & Escapes \\
Tamias striatus & Ornamental \\
Sylvilagus floridanus & \\
Sciurus niger & \\
Sciurus anomalus & Ornamental, Escapes \\
Rusa timorensis & \\
Nasua nasua & Animal husbandry, Secondary introduction \\
Mustela furo & Animal husbandry, Escapes \\
Muntiacus reevesi & Escapes \\
Macropus rufogriseus & Escapes \\
Macaca fascicularis & Escapes \\
Herpestes javanicus & Ornamental, Escapes \\
Callosciurus finlaysonii & Ornamental, Escapes \\
Callosciurus erythraeus & Secondary introduction, Escapes \\
Axis axis & Ornamental, Escapes \\
\hline
\end{tabular}

\begin{tabular}{ll} 
Mollusca (Taxonomic group) & \\
Low risk species (C) / Baltic region & \\
Species & Pathway \\
Mercenaria mercenaria & Ballast water \& sediments, Escapes \\
Musculista senhousia & Hull fouling, Secondary introduction \\
Ruditapes philippinarum & Aquaculture, Secondary introduction \\
Rapana venosa & Aquaculture, Secondary introduction \\
Urosalpinx cinerea & Aquaculture, Secondary introduction \\
Dreissena rostriformis bugensis & Ballast water \& sediments, Secondary introduction \\
Crassostrea virginica & \\
Ostrea chilensis & Aquaculture \\
Pinctada radiata & Aquaculture, Hull fouling \\
Euglandina rosea & \\
Chilostoma cingulatum gobanzi & Ornamental \\
\hline
\end{tabular}

\section{Reptilia (Taxonomic group)}

\begin{tabular}{ll} 
Low risk species (C) / Baltic region & \\
Species & Pathway \\
\hline Boiga irregularis & Escapes, Transport \\
Mauremys leprosa & Escapes, Ornamental \\
\hline
\end{tabular}

*Comment from expert: "the species spawns in the Sargasso Sea and will never become established in European waters". 


\section{Appendix 17: Low risk species for the Islands of the North Atlantic Ocean}

\begin{tabular}{ll} 
Amphibia (Taxonomic group) & \\
Low risk species (C) / Islands of the North Atlantic Ocean & \\
Species & Pathway \\
& \\
Alytes obstetricans & Secondary introduction, Transport \\
Bufo marinus & Escapes \\
Xenopus laevis & Escapes \\
Eleutherodactylus coqui & Transport \\
Osteopilus septentrionalis & Transport \\
Pelophylax bedriagae & Escapes \\
\hline
\end{tabular}

\begin{tabular}{|c|c|}
\hline \multicolumn{2}{|l|}{ Low risk species (C) / Islands of the North Atlantic Ocean } \\
\hline Species & Pathway \\
\hline Gymnocoronis spilanthoides & Aquaria \\
\hline Amorpha fructicosa & Horticulture, Landscaping \\
\hline Cortaderia selloana & Horticulture \\
\hline Zostera japonica & Transport \\
\hline Ziziphus mauritiana & Horticulture, Agriculture \\
\hline Vitex rotundifolia & Landscaping, Horticulture \\
\hline Triadica sebifera & Horticulture \\
\hline Spathodea campanulata & Horticulture \\
\hline Solidago nemoralis & Horticulture, Landscaping \\
\hline Sisyrinchium septentrionale & Horticulture \\
\hline Sisyrinchium californicum & Horticulture \\
\hline Sicyos angulatus & Agriculture, Horticulture \\
\hline Sesbania punicea & Horticulture \\
\hline Salvinia molesta & Aquaria \\
\hline Sagittaria graminea & Aquaria \\
\hline Rosa bracteata & Horticulture \\
\hline Rhus radicans (Syn. Toxicodendron radicans) & Horticulture, Landscaping \\
\hline Pueraria montana var. lobata (Syn. P. lobata) & Horticulture, Agriculture, Transport \\
\hline Psidium guajava & Agriculture \\
\hline Prosopis glandulosa & Agriculture, Landscaping \\
\hline Polygonum perfoliatum (Syn. Persicaria perfoliata) & Horticulture, Agriculture \\
\hline Plantago serpentina & Agriculture \\
\hline Pittosporum undulatum & Horticulture \\
\hline Pistia stratiotes & Aquaria \\
\hline Phormium tenax & Horticulture \\
\hline Paulownia tomentosa & Horticulture \\
\hline Paspalum distichum (Syn. Paspalum paspalodes) & Agriculture \\
\hline Nassella trichotoma & Agriculture \\
\hline \multicolumn{2}{|l|}{ Nassella tenuissima } \\
\hline Nassella neesiana & Horticulture \\
\hline Myriophyllum heterophyllum & Aquaria \\
\hline Myriophyllum aquaticum & Aquaria \\
\hline Morella faya & Horticulture \\
\hline Mimosa pigra & Horticulture \\
\hline Microstegium vimineum & Agriculture, Transport \\
\hline Dolichandra unguis-cati (Syn. Macfadyena unguis-cati) & Horticulture \\
\hline Ludwigia peploides & Aquaria \\
\hline Ludwigia grandiflora & Aquaria \\
\hline Ligustrum sinense & Horticulture \\
\hline Ligustrum lucidum & Horticulture \\
\hline Libertia chilensis (Syn. Libertia formosa) & Horticulture \\
\hline
\end{tabular}




\begin{tabular}{|c|c|}
\hline \multicolumn{2}{|l|}{ Low risk species (C) / Islands of the North Atlantic Ocean } \\
\hline Species & Pathway \\
\hline Lemna minuta & Aquaria \\
\hline Lagarosiphon major & Aquaria \\
\hline \multicolumn{2}{|l|}{ Juncus planifolius } \\
\hline Ipomoea aquatica & Horticulture \\
\hline Imperata cylindrica & Horticulture \\
\hline Hygrophila polysperma & Aquaria \\
\hline Hydrocotyle ranunculoides & Aquaria \\
\hline \multicolumn{2}{|l|}{ Hydrocotyle ramiflora } \\
\hline Hiptage benghalensis & Horticulture \\
\hline Hedychium gardnerianum & Horticulture \\
\hline Hakea sericea & Landscaping, Horticulture \\
\hline Gunnera tinctoria & Horticulture \\
\hline Cyperus rotundus & Agriculture, Transport \\
\hline Sasa palmata & Horticulture \\
\hline Acacia dealbata & Horticulture \\
\hline Acacia melanoxylon & Horticulture \\
\hline Acaena ovaliflolia & Horticulture \\
\hline Akebia quinata & Horticulture \\
\hline Allium triquetrum & Horticulture \\
\hline Alternanthera philoxeroides & Aquaria \\
\hline Andropogon virginicus & Horticulture, Secondary introduction \\
\hline Araujia sericifera & Horticulture \\
\hline Ardisia elliptica & Horticulture \\
\hline Artemisia tournefortiana & Agriculture, Forestry, Transport \\
\hline Baccharis halimifolia & Horticulture, Secondary introduction \\
\hline Calystegia inflata (Syn.C. sepium subsp. Americana) & Horticulture \\
\hline Carpobrotus acinaciformis & Horticulture \\
\hline Carpobrotus edulis & Horticulture \\
\hline Cenchrus pauciflorus (Syn. Cenchrus pauciflorus, C. incertus) & Transport \\
\hline \multicolumn{2}{|l|}{ Chromolaena odorata } \\
\hline Clidemia hirta & Horticulture \\
\hline Cuscuta tinei & Agriculture \\
\hline Urtica cannabina & \\
\hline
\end{tabular}

Arthropods (Taxonomic group)

\begin{tabular}{ll} 
Low risk species (C) / Islands of the North Atlantic Ocean \\
Species & Pathway \\
\hline Palaemon macrodactylus & Ballast water \& sediments, Secondary introduction \\
Dikerogammarus villosus & Ballast water \& sediments \\
Lasius neglectus & Horticulture, Landscaping \\
Linepithema humile & Horticulture, Landscaping \\
Wasmannia auropunctata & Horticulture, Landscaping \\
Amphibalanus amphitrite & Hull fouling, Ballast water \& sediments, Secondary introduction \\
Balanus eburneus & Hull fouling, Secondary introduction \\
Balanus trigonus & Hull fouling, Ballast water \& sediments; Secondary introduction \\
Balanus variegatus & Hull fouling, Secondary introduction \\
Megabalanus coccopoma & Hull fouling \\
Megabalanus tintinnabulum & Hull fouling \\
Megabalanus tulipiformis & Hull fouling \\
Agrilus planipennis & Forestry \\
Diabrotica virgifera & Agriculture, Transport, Secondary introduction \\
Luperomorpha xanthodera & Horticulture \\
Otiorhynchus liguricus (Syn. O. salicicola) & Horticulture \\
Phloeosinus aubei & Horticulture \\
Phloeosinus rudis & Horticulture \\
Epitrix tuberis & Horticulture \\
Agrilus anxius & Forestry \\
Dendroctonus ponderosae & Forestry \\
& \\
&
\end{tabular}




\begin{tabular}{|c|c|}
\hline \multicolumn{2}{|c|}{ Low risk species (C) / Islands of the North Atlantic Ocean } \\
\hline Species & Pathway \\
\hline Enaphalodes rufulus & Forestry \\
\hline Hesperophanes campestris & Forestry, Transport \\
\hline Ips hauseri & Forestry \\
\hline Ips pini & Forestry \\
\hline Monochamus carolinensis & Forstry \\
\hline Monochamus marmoratus & Forstry \\
\hline Monochamus mutator & Forstry \\
\hline Monochamus nitens & Forstry \\
\hline Monochamus notatus & Forstry \\
\hline Monochamus obtusus & Forstry \\
\hline Monochamus scutellatus & Forstry \\
\hline Oemona hirta & Forestry, Horticulture, Landscaping \\
\hline Pissodes nemorensis & Forestry, Horticulture, Landscaping \\
\hline Pissodes strobi & Forestry, Horticulture, Landscaping \\
\hline Pissodes terminalis & Forestry, Horticulture, Landscaping \\
\hline Popillia japonica & Horticulture \\
\hline Saperda candida & Forestry, Horticulture, Landscaping \\
\hline Scolytus moravitzi & Forestry \\
\hline Tetropium gracilicorne & Forestry \\
\hline Xylosandrus crassiusculus & Forestry, Horticulture, Landscaping \\
\hline \multicolumn{2}{|l|}{ Braula schmitzi } \\
\hline Rhagoletis fausta & Horticulture \\
\hline Rhagoletis indifferens & Horticulture \\
\hline Rhagoletis pomonella & Horticulture \\
\hline Strobilomyia viaria & Transport \\
\hline Potamon ibericum & Aquaculture, aquaria \\
\hline Orconectes virilis & Aquaculture, Aquaria with Secondary introduction \\
\hline Procambarus fallax $f$ virginalis & Aquaria, Escapes \\
\hline Procambarus clarkii & Aquaculture, aquaria, secondary introduction \\
\hline Orconectes rusticus & Aquaculture, Aquaria with Secondary introduction \\
\hline Cherax destructor & Aquaculture, Aquaria with Secondary introduction \\
\hline Cherax quadricarinatus & Aquaculture, Aquaria with Secondary introduction \\
\hline Procambarus acutus & Aquaculture, aquaria, Angling/sport \\
\hline Dendrolimus sibiricus & Horticulture, Forestry \\
\hline \multicolumn{2}{|l|}{ Hyphantria cunea } \\
\hline Cacoecimorpha pronubana & Horticulture, Secondary introduction \\
\hline Dendrolimus superans & Horticulture, Forestry \\
\hline Lymantria mathura & Horticulture, Forestry, Transport \\
\hline Choristoneura fumiferana & Horticulture \\
\hline Choristoneura occidentalis & Horticulture \\
\hline Malacosoma americanum & Horticulture, Forestry \\
\hline Malacosoma disstria & Horticulture, Forestry \\
\hline Orgyia pseudotsugata & Horticulture, Forestry \\
\hline Acleris gloverana & Horticulture, Landscaping \\
\hline Acleris variana & Horticulture, Landscaping \\
\hline Cydia prunivora & Horticulture, Landscaping \\
\hline Spodoptera littoralis & Horticulture \\
\hline Callinectes sapidus & Ballast water \& sediments \\
\hline Charybdis japonica & Ballast water \& sediments, Secondary introduction \\
\hline Hemigrapsus penicillatus & Ballast water \& sediments, Hull fouling, Secondary introduction \\
\hline Hemigrapsus takanoi & Ballast water \& sediments, Hull fouling, Secondary introduction \\
\hline Hemigrapsus sanguineus & Ballast water \& sediments, Hull fouling, Secondary introduction \\
\hline Percnon gibbesi & Hull fouling, Ballast water \& sediments, Secondary introduction \\
\hline Portunus pelagicus & Hull fouling, Ballast water \& sediments, Secondary introduction \\
\hline Marsupenaeus japonicus & Aquaculture, Ballast water \& sediments \\
\hline Sinelobus stanfordi & Ballast water \& sediments, Hull fouling \\
\hline Sirex ermak & Forestry, Transport, Seconday introduction \\
\hline
\end{tabular}




\begin{tabular}{ll} 
Birds (Taxonomic group) & \\
Low risk species (C) / Islands of the North Atlantic Ocean \\
Species & Pathway \\
Chrysolophus pictus & Hunting \\
Nymphicus hollandicus & \\
Callonetta leucophrys & Escapes \\
Lophura nycthemera & Hunting \\
Myiopsitta monachus & Escapes, Ornamental \\
Psittacula eupatria & Escapes, Ornamental \\
Threskiornis aethiopicus & Escapes, Ornamental \\
\hline
\end{tabular}

\section{Bryophytes (Taxonomic group)}

Low risk species (C) / Islands of the North Atlantic Ocean
Species Pathway

Lophocolea semiteres

Fish / Freshwater (Taxonomic group)

Low risk species (C) / Islands of the North Atlantic Ocean

Species

Ameiurus melas

Coregonus muksun

Neogobius fluviatilis

Neogobius gymnotrachelus

Neogobius kessleri

Romanogobio belingi

Benthophilus durrelli

Benthophilus nudus

Catostomus commersonii

Channa argus

Cichla ocellaris

Clarias gariepinus

Clupeonella tscharchalensis

Cobitis bilineata

Gambusia affinis

Gambusia holbrooki

Ictalurus punctatus

Ictiobus niger

Knipowitschia longecaudata

Misgurnus anguillicaudatus

Monopterus albus

Neogobius gorlap

Neogobius pallasi

Parachondrostoma toxostoma

Pimephales promelas

Proterorhinus semilunaris

Pylodictis olivaris

\section{Pathway}

Angling/sport, Aquaculture, Fisheries

Aquaculture

Ballast water \& sediments, Transport, Secondary introduction

Ballast water \& sediments, Secondary introduction

Ballast water \& sediments, Transport, Secondary introduction

Fisheries

Biological contro

Aquaculture, Fisheries

Aquaculture, Fisheries

Angling/spor

Angling/sport, Aquaria

Ballast water \& sediments, Transport, Secondary introduction 
Fish / Marine (Taxonomic group)

Low risk species (C) / Islands of the North Atlantic Ocean

Species

Pathway

Anguilla rostrata*

Fisheries, Aquaculture

Anguilla japonica

Fisheries, Aquaculture

Neogobius eurycephalus (Syn. Ponticola eurycephalus) Ballast water \& sediments

Siganus rivulatus

Syngnathus nigrolineatus (Syn. Syngnathus abaster)

Macroalgae (Taxonomic group)

Low risk species (C) / Islands of the North Atlantic Ocean

Species

Pathway

Agardhiella subulata

Grateloupia filicina

Macrocystis pyrifera

Undaria pinnatifida

Anotrichium furcellatum

Secondary introduction

Antithamnion densum

Antithamnionella spirographidis

Antithamnionella ternifolia

Caulacanthus ustulatus

Colaconema dasyae

Laurencia brongniartii

Polysiphonia senticulosa

Polysiphonia subtilissima

\section{Mammal (Taxonomic group)}

Low risk species (C) / Islands of the North Atlantic Ocean

Species

Pathway

Sus scrofa vittatus

Trichosurus vulpecula

Escapes, Hunting, Ornamental

Tamias striatus

Escapes

Sylvilagus floridanus

Sciurus niger

Sciurus anomalus

Rusa timorensis

Nasua nasua

Mustela furo

Muntiacus reevesi

Ornamental

Macropus rufogriseus

Macaca fascicularis

Herpestes javanicus

Callosciurus finlaysonii

Callosciurus erythraeus

Axis axis

Ornamental, Escapes

Animal husbandry, Secondary introduction

Animal husbandry, Escapes

Escapes

Escapes

Escapes

Ornamental, Escapes

Ornamental, Escapes

Secondary introduction, Escapes

Ornamental, Escapes 


\begin{tabular}{ll} 
Mollusca (Taxonomic group) & \\
Low risk species (C) / Islands of the North Atlantic Ocean \\
Species & Pathway \\
Mercenaria mercenaria & Ballast water \& sediments, Escapes \\
Musculista senhousia & Hull fouling, Secondary introduction \\
Ruditapes philippinarum & Aquaculture, Secondary introduction \\
Rapana venosa & Aquaculture, Secondary Introduction \\
Urosalpinx cinerea & Aquaculture, Secondary introduction \\
Dreissena rostriformis bugensis & Ballast water \& sediments, Secondary introduction \\
Crassostrea virginica & Mollusca \\
Ostrea chilensis & Aquaculture \\
Pinctada radiata & Aquaculture, Hull fouling \\
Tandonia budapestensis & Horticulture, Transport \\
Euglandina rosea & \\
Chilostoma cingulatum gobanzi & Ornamental \\
\hline
\end{tabular}

Parasitic Nematode (Taxonomic group)

Low risk species (C) / Islands of the North Atlantic Ocean

Species Pathway

Ashworthius sidemi Animal husbandry

Bursaphelenchus xylophilus Forestry, Transport

\section{Reptilia (Taxonomic group)}

Low risk species (C) / Islands of the North Atlantic Ocean

Species

Pathway

Chelydra serpentina

Escapes

Macrochelys temminckii

Chrysemys picta

Escapes

Graptemys pseudogeographica Escapes

Boa constrictor imperator Ecapes

Apalone spinifera Ecapes

Elaphe schrenckii Escapes, Ornamental, Secondary introduction

Boiga irregularis Escapes, Transport

Mauremys leprosa Escapes, Ornamental

*Comment from expert: "the species spawns in the Sargasso Sea and will never become established in European waters". 


\section{Appendix 18: List of potential door knocker species}

\begin{tabular}{lll}
\hline $\begin{array}{l}\text { Amphibian (Taxonomic group) } \\
\text { Potential door knocker species / Horizon scanning }\end{array}$ & \\
\hline Species name & Family name & Order \\
\hline Alytes obstetricans & Discoglossidae & - \\
Bufo marinus & Bufonidae & - \\
Eleutherodactylus coqui & Leptodactylidae & - \\
Osteopilus septentrionalis & Hylidae & - \\
Pelophylax bedriagae & Ranidae & - \\
Xenopus laevis & Pipidae & - \\
\hline
\end{tabular}

\begin{tabular}{|c|c|c|}
\hline \multicolumn{3}{|c|}{ Potential door knocker species / Horizon scanning } \\
\hline Species name & Family name & Order \\
\hline Acacia dealbata & Fabaceae & - \\
\hline Acacia melanoxylon & Fabaceae & - \\
\hline Acaena ovaliflolia & Rosaceae & - \\
\hline Akebia quinata & Lardizabalaceae & - \\
\hline Allium triquetrum & Alliaceae & - \\
\hline Alternanthera philoxeroides & Amaranthaceae & - \\
\hline Amorpha fructicosa* & Fabaceae & - \\
\hline Andropogon virginicus & Poaceae & - \\
\hline Araujia sericifera & Apocynaceae & - \\
\hline Ardisia elliptica & Myrsinaceae & - \\
\hline Artemisia tournefortiana* & Asteraceae & - \\
\hline Baccharis halimifolia & Asteraceae & - \\
\hline Calystegia inflata & Convolvulaceae & - \\
\hline Carpobrotus acinaciformis & Aizoaceae & - \\
\hline Carpobrotus edulis* & Aizoaceae & - \\
\hline Cenchrus pauciflorus & Poaceae & - \\
\hline Chromolaena odorata & Asteraceae & - \\
\hline Clidemia hirta & Melastromataceae & - \\
\hline Cortaderia selloana & Poaceae & - \\
\hline Crepis aurea & Asteraceae & - \\
\hline Cuscuta tinei & Cuscutaceae & - \\
\hline Cyperus esculentus & Cyperaceae & - \\
\hline Cyperus rotundus & Cyperaceae & - \\
\hline Gaultheria mucronata & Ericacea & - \\
\hline Gunnera tinctoria & Gunneraceae & - \\
\hline Gymnocoronis spilanthoides & Asteraceae & - \\
\hline Hakea sericea & Proteaceae & - \\
\hline Hedychium gardnerianum & Asteraceae & - \\
\hline Hiptage benghalensis & Malpighiaceae & - \\
\hline Hydrocotyle ramiflora & Apiaceae & - \\
\hline Hydrocotyle ranunculoides & Apiaceae & - \\
\hline Hygrophila polysperma & Acanthaceae & - \\
\hline Imperata cylindrica & Poaceae & - \\
\hline Ipomoea aquatica & Convolvulaceae & - \\
\hline Juncus planifolius & Juncacea & - \\
\hline Lagarosiphon major & Hydrocharitaceae & - \\
\hline Lemna minuta* & Lemnaceae & - \\
\hline Libertia formosa & Iridacea & - \\
\hline Ligustrum lucidum & Oleaceae & - \\
\hline Ligustrum sinense & Oleaceae & - \\
\hline Ludwigia grandiflora & Onagraceae & - \\
\hline Ludwigia peploides & Onagraceae & - \\
\hline Macfadyena unguis-cati & Bignoniaceae & - \\
\hline
\end{tabular}




\begin{tabular}{|c|c|c|}
\hline \multicolumn{3}{|c|}{ Potential door knocker species / Horizon scanning } \\
\hline Species name & Family name & Order \\
\hline Malus asiatica & Rosaceae & - \\
\hline Microstegium vimineum & Poaceae & - \\
\hline Mimosa pigra & Fabaceae & - \\
\hline Morella faya & Myricaceae & - \\
\hline Myriophyllum aquaticum & Haloragaceae & - \\
\hline Myriophyllum heterophyllum & Haloragaceae & - \\
\hline Nassella neesiana & Poaceae & - \\
\hline Nassella tenuissima & Poaceae & - \\
\hline Nassella trichotoma & Poaceae & - \\
\hline Paspalum paspalodes & Poaceae & - \\
\hline Paulownia tomentosa & Scruphulariaceae & - \\
\hline Phormium tenax & Xanthorrhoeaceae & - \\
\hline Pistia stratiotes* & Araceae & - \\
\hline Pittosporum undulatum & Pittosporaceae & - \\
\hline Plantago serpentina & Plantaginaceae & - \\
\hline Polygonum perfoliatum & Polygonaceae & - \\
\hline Prosopis glandulosa & Fabaceae & - \\
\hline Psidium guajava & Myrtaceae & - \\
\hline Pueraria lobata & Fabaceae & - \\
\hline Rhus radicans & Anacardiaceae & - \\
\hline Rosa bracteata & Rosacea & - \\
\hline Sagittaria graminea & Alismataceae & - \\
\hline Salvinia molesta & Salviniaceae & - \\
\hline Sasa palmata & Poaceae & - \\
\hline Sesbania punicea & Fabaceae & - \\
\hline Sicyos angulatus* & Cucurbitaleae & - \\
\hline Sisyrinchium californicum & Iridacea & - \\
\hline Sisyrinchium septentrionale & Iridaceae & - \\
\hline Solidago nemoralis & Asteraceae & - \\
\hline Sorghum $\mathrm{x}$ almum & Poaceae & - \\
\hline Spathodea campanulata & Bignoniaceae & - \\
\hline Triadica sebifera & Euphorbiaceae & - \\
\hline Urtica cannabina & Urticaceae & - \\
\hline Verbena brasiliensis & Verbenaceae & - \\
\hline Vitex rotundifolia & Lamiaceae & - \\
\hline Ziziphus mauritiana & Rhamnaceae & - \\
\hline Zostera japonica & Zosteraceae & - \\
\hline
\end{tabular}

Annelids (Taxonomic group)

\begin{tabular}{lll} 
Potential door knocker species / Horizon scanning & \\
Species name & Family name & Order \\
\hline Hydroides dianthus & Serpulidae & - \\
Hydroides elegans & Serpulidae & - \\
Hydroides ezoensis & Serpulidae & - \\
Sabella spallanzanii & Sabellidae & - \\
\hline
\end{tabular}

Arthropods (Taxonomic group)

Potential door knocker species / Horizon scanning

Species name

Crematogaster auberti

Crematogaster osakensis

Crematogaster rogenhoferi

Lasius neglectus

Linepithema humile
Family name

Order

Formicidae

Formicidae

Formicidae

Formicidae

Formicidea
Hymenoptera Hymenoptera Hymenoptera

Hymenoptera Hymenoptera 


\begin{tabular}{|c|c|c|}
\hline \multicolumn{3}{|c|}{ Potential door knocker species / Horizon scanning } \\
\hline Species name & Family name & Order \\
\hline Pheidole pallidula & Formicidae & Hymenoptera \\
\hline Wasmannia auropunctata & Formicidae & Hymenoptera \\
\hline Vespa velutina & Vespidae & Hymenoptera \\
\hline Sirex ermak & Siricidae & Hymenoptera \\
\hline Agrilus anxius & Buprestidae & Coleoptera \\
\hline Agrilus planipennis & Buprestidae & Coleoptera \\
\hline Conotrachelus nenuphar & Curculionidae & Coleoptera \\
\hline Cryptophilus integer & Languriidae & Coleoptera \\
\hline Dendroctonus ponderosae & Curculionidae & Coleoptera \\
\hline Diabrotica virgifera & Chrysomelidae & Coleoptera \\
\hline Enaphalodes rufulus & Cerambycidae & Coleoptera \\
\hline Epitrix tuberis & Chrysomelidae & Coleoptera \\
\hline Glischrochilus quadrisignatus* & Nitidulidae & Coleoptera \\
\hline Hesperophanes campestris & Cerambycidae & Coleoptera \\
\hline Ips hauseri & Curculionidae & Coleoptera \\
\hline Ips pini & Curculionidae & Coleoptera \\
\hline Lissorhoptrus oryzophilus & Curculionidae & Coleoptera \\
\hline Luperomorpha xanthodera & Chrysomelidae & Coleoptera \\
\hline Monochamus carolinensis & Cerambycidae & Coleoptera \\
\hline Monochamus marmorator & Cerambycidae & Coleoptera \\
\hline Monochamus mutator & Cerambycidae & Coleoptera \\
\hline Monochamus nitens & Cerambycidae & Coleoptera \\
\hline Monochamus notatus & Cerambycidae & Coleoptera \\
\hline Monochamus obtusus & Cerambycidae & Coleoptera \\
\hline Monochamus scutellatus & Cerambycidae & Coleoptera \\
\hline Oemona hirta & Cerambycidae & Coleoptera \\
\hline Otiorhynchus liguricus & Curculionidae & Coleoptera \\
\hline Phloeosinus aubei & Scolytidae & Coleoptera \\
\hline Phloeosinus rudis & Scolytidae & Coleoptera \\
\hline Pissodes nemorensis & Curculionidae & Coleoptera \\
\hline Pissodes strobi & Curculionidae & Coleoptera \\
\hline Pissodes terminalis & Curculionidae & Coleoptera \\
\hline Popillia japonica & Scarabaeidae & Coleoptera \\
\hline Saperda candida & Cerambycidae & Coleoptera \\
\hline Scolytus morawitzi & Scolytidae & Coleoptera \\
\hline Sefrania bleusei & Dermesteidae & Coleoptera \\
\hline Tetropium gracilicorne & Cerambycidae & Coleoptera \\
\hline Xylosandrus crassiusculus & Scolytidae & Coleoptera \\
\hline Aedes albopictus & Culicidae & Diptera \\
\hline Anopheles quadrimaculatus & Culicidae & Diptera \\
\hline Aphidoletes abietis & Cecidomyiidae & Diptera \\
\hline Blepharipa schineri & Tachinidae & Diptera \\
\hline Braula schmitzi & Braulidae & Diptera \\
\hline Coenosia attenuata & Muscidae & Diptera \\
\hline Drosophila suzukii & Drosophilidae & Diptera \\
\hline Liriomyza huidobrensis & Agromyzidae & Diptera \\
\hline Micropygus vagans & Dolichopodidae & Diptera \\
\hline Ochlerotatus japonicus & Culicidae & Diptera \\
\hline Rhagoletis cingulata & Tephritidae & Diptera \\
\hline Rhagoletis fausta & Tephritidae & Diptera \\
\hline Rhagoletis indifferens & Tephritidae & Diptera \\
\hline Rhagoletis pomonella & Tephritidae & Diptera \\
\hline Strobilomyia viaria & Anthomyiidae & Diptera \\
\hline Tephritis praecox & Tephritidae & Diptera \\
\hline Thoracochaeta johnsoni & Sphaeroceridae & Diptera \\
\hline Diaphorina citri & Psyllidae & Hemiptera \\
\hline Homalodisca vitripennis & Cicadellidae & Hemiptera \\
\hline Metcalfa pruinosa & Flatidae & Hemiptera \\
\hline Scaphoideus titanus & Cicadellidae & Hemiptera \\
\hline Adelges tsugae & Adelgidae & Hemiptera \\
\hline Halyomorpha halys & Pentatomidae & Hemiptera \\
\hline
\end{tabular}




\begin{tabular}{|c|c|c|}
\hline \multicolumn{3}{|c|}{ Potential door knocker species / Horizon scanning } \\
\hline Species name & Family name & Order \\
\hline Lepidosaphes ussuriensis & Diaspididae & Hemiptera \\
\hline Margarodes vitis & Margarodidae & Hemiptera \\
\hline Nysius huttoni & Lygaeidae & Hemiptera \\
\hline Orius laevigatus & Anthocoridae & Hemiptera \\
\hline Oxycarenus lavaterae & Lygaeidae & Hemiptera \\
\hline Stephanitis takeyai & Tingidae & Hemiptera \\
\hline Stictocephala bubalis & Membracidae & Hemiptera \\
\hline Arocatus longiceps & Lygaeidae & Hemiptera \\
\hline Corythucha arcuata & Tingidae & Hemiptera \\
\hline Corythucha ciliata & Tingidae & Hemiptera \\
\hline Acleris gloverana & Tortricidae & Lepidoptera \\
\hline Acleris variana & Tortricidae & Lepidoptera \\
\hline Cydia prunivora & Tortricidae & Lepidoptera \\
\hline Hyphantria cunea* & Arctiidae & Lepidoptera \\
\hline Lymantria mathura & Lymantriidae & Lepidoptera \\
\hline Malacosoma americanum & Lasiocampidae & Lepidoptera \\
\hline Malacosoma disstria & Lasiocampidae & Lepidoptera \\
\hline Orgyia pseudotsugata & Lymantriidae & Lepidoptera \\
\hline Spodoptera littoralis & Noctuidae & Lepidoptera \\
\hline Cacoecimorpha pronubana* & Tortricidae & Lepidoptera \\
\hline Choristoneura fumiferana & Tortricidae & Lepidoptera \\
\hline Choristoneura occidentalis & Tortricidae & Lepidoptera \\
\hline Dendrolimus sibiricus & Lasiocampidae & Lepidoptera \\
\hline Dendrolimus superans & Lasiocampidae & Lepidoptera \\
\hline Opilio ruzickai & Phalangiidae & Opiliones \\
\hline Ammothea hilgendorfi & Ammotheidae & Pantopoda \\
\hline Frankliniella occidentalis & Tripidae & Thysanoptera \\
\hline Thrips palmi & Thripinae & Thysanoptera \\
\hline Obesogammarus obessus & Gammaridae & Amphipoda \\
\hline Dikerogammarus villosus & Gammaridae & Amphipoda \\
\hline Chelicorophium robustum & Corophiidae & Amphipoda \\
\hline Crangonyx pseudogracilis & Crangonyctidae & Amphipoda \\
\hline Amphibalanus amphitrite & Balanidae & Sessilia \\
\hline Balanus eburneus & Balanidae & Sessilia \\
\hline Balanus trigonus & Balanidae & Sessilia \\
\hline Balanus variegatus & Balanidae & Sessilia \\
\hline Megabalanus coccopoma & Balanidae & Sessilia \\
\hline Megabalanus tintinnabulum & Balanidae & Sessilia \\
\hline Megabalanus tulipiformis & Balanidae & Sessilia \\
\hline Solidobalanus fallax & Archaeobalanidae & Sessilia \\
\hline Acartia omori & Acartiidae & Calanoida \\
\hline Eurytemora americana & Temoridae & Calanoida \\
\hline Eurytemora pacifica & Temoridae & Calanoida \\
\hline Myicola ostrea & Myicolidae & Poecilostomatoida \\
\hline Pseudomyicola spinosus & Myicolidae & Poecilostomatoida \\
\hline Daphnia lumholtzi & Daphniidae & Cladocera \\
\hline Daphnia parvula & Anomopoda & Cladocera \\
\hline Callinectes sapidus* & Portunidae & Decapoda \\
\hline Charybdis japonica & Portunidae & Decapoda \\
\hline Hemigrapsus penicillatus & Varunidae & Decapoda \\
\hline Hemigrapsus takanoi* & Varunidae & Decapoda \\
\hline Hemigrapsus sanguineus* & Varunidae & Decapoda \\
\hline Percnon gibbesi & Plagusiidae & Decapoda \\
\hline Portunus pelagicus & Portunidae & Decapoda \\
\hline Potamon ibericum & Potamidae & Decapoda \\
\hline Procambarus fallax $\mathrm{f}$ virginalis* & Cambaridae & Decapoda \\
\hline Procambarus clarkii & Cambaridae & Decapoda \\
\hline Cherax destructor & Parastacidae & Decapoda \\
\hline Cherax quadricarinatus & Parastacidae & Decapoda \\
\hline Orconectes juvenilis & Cambaridae & Decapoda \\
\hline Orconectes rusticus & Cambaridae & Decapoda \\
\hline
\end{tabular}




\begin{tabular}{lll} 
Potential door knocker species / Horizon scanning & & \\
Species name & Family name & Order \\
Orconectes virilis & Cambaridae & Decapoda \\
Procambarus acutus & Cambaridae & Decapoda \\
Cordioniscus stebbingi & Styloniscidae & Isopoda \\
Porcellio dilatatus & Porcellionidae & Isopoda \\
Trichorhina tomentosa & Platyarthridae & Isopoda \\
Marsupenaeus japonicus & Penaeidae & Decapoda \\
Palaemon macrodactylus & Palaemonidae & Decapoda \\
Sinelobus stanfordi & Tanaidae & Tanaidacea \\
\hline
\end{tabular}

\section{Birds (Taxonomic group)}

\begin{tabular}{lll} 
Potential door knocker species / Horizon scanning & & \\
Species name & Family name & Order \\
Callonetta leucophrys & Anatidae & - \\
Chloephaga picta & Anatidae & - \\
Chrysolophus pictus* & Phasianidae & - \\
Falco biarmicus* & Falconidae & - \\
Lophura nycthemera & Phasianidae & - \\
Myiopsitta monachus & Psittacidae & - \\
Nymphicus hollandicus & Cacatuidae & - \\
Psittacula eupatria & Psittacidae & - \\
Threskiornis aethiopicus & Threskiornithida & - \\
\hline
\end{tabular}

\section{Bryophytes (Taxonomic group)}

\begin{tabular}{|c|c|c|}
\hline \multicolumn{3}{|c|}{ Potential door knocker species / Horizon scanning } \\
\hline Species name & Family name & Order \\
\hline Lophocolea semiteres & Geocalycaceae & - \\
\hline
\end{tabular}

\section{Bryozoan (Taxonomic group)}

\begin{tabular}{lll} 
Potential door knocker species / Horizon scanning & \\
Species name & Family name & Order \\
\hline $\begin{array}{l}\text { Watersipora subtorquata } \\
\text { Bugula stolonifera }\end{array}$ & Watersiporidae & - \\
Tricellaria inopinata & Bugulidae & - \\
\hline
\end{tabular}

Cnidarians (Taxonomic group)

Potential door knocker species / Horizon scanning

Species name

Family name

Order

Blackfordia virginica

Garveia franciscana

Blackfordiidae

Rhopilema nomadica

Bougainvilliidae

Rhizostomae 
Sea urchins \& starfish (Taxonomic group)

Potential door knocker species / Horizon scanning

Species name

Family name

Order

Asterias amurensis

Asteriidae

\section{Fish (Taxonomic group)}

Potential door knocker species / Horizon scanning

Species name

Family name

Order

Ameiurus melas*

Benthophilus durrelli

Ictaluridae

Benthophilus nudus

Catostomus commersonii

Channa argus

Cichla ocellaris

Clarias gariepinus

Clupeonella tscharchalensis

Cobitis bilineata

Coregonus muksun*

Gambusia affinis

Gambusia holbrooki

Ictalurus punctatus*

Ictiobus niger*

Knipowitschia longecaudata

Misgurnus anguillicaudatus

Monopterus albus

Neogobius fluviatilis

Neogobius gorlap

Neogobius gymnotrachelus

Neogobius kessleri

Neogobius pallasi

Pimephales promelas

Proterorhinus semilunaris

Pylodictis olivaris

Romanogobio belingi

Parachondrostoma toxostoma

Gobiidae

Gobiidae

Catostomidae

Channidae

Cichlidae

Clariidae

Clupeidae

Cobitidae

Coregonidae

Poeciliidae

Poeciliidae

Ictaluridae

Catastomidae

Gobiidae

Cabitidae

Synbranchidae

Gobiidae

Gobiidae

Gobiidae

Gobiidae

Gobiidae

Cyprinidae

Gobiidae

Ictaluridae

Cyprinidae

Cyprinidae

Anguillidae

Anguillidae

Sciaenidae

Anguilla rostrata

Micropogonias undulatus

Paralichthyida

Pleuronectidae

Sebastidae

Platichthys stellatus

Sigaridae

Syngnathidae

Siganus rivulatus

Achiridae

Trinectes maculatus

Neogobius eurycephalus

Gobiidae

Flatworms (Taxonomic group)

Potential door knocker species / Horizon scanning

Species name

Bothriocephalus acheilognathi

Dactylogyrus lamellatus

Dendrocoelum romanodanubiale

Fascioloides magna

Platydemus manokwari
Family name

Order

Bothriocephalidae

Dactylogyridae

Dendrocoelidae

Fasciolidae

Geoplanidae 
Not pathogenic fungi (Taxonomic group)

\begin{tabular}{lll} 
Potential door knocker species / Horizon scanning & \\
Species name & Family name & Order \\
\hline Clathrus ruber & Phallaceae & - \\
Gymnopus luxurians* & Tricholomatacea & - \\
Leucocoprinus straminellus & Agaricaceae & - \\
Panaeolus cyanescens & Bolbitiaceae & - \\
Psilocybe cubensis & Hymenogastraceae & - \\
Suillus ochraceoroseus & Suillaceae & - \\
Suillus placidus* & Suillaceae & - \\
\hline
\end{tabular}

Pathogenic fungi (Taxonomic group)

\begin{tabular}{lll} 
Potential door knocker species / Horizon scanning & \\
Species name & Family name & Order \\
Atropellis pinicola & Dermateaceae & - \\
Atropellis piniphila & Dermateaceae & - \\
Ceratocystis fagacearum & Ceratocystidaceae & - \\
Chrysomyxa arctostaphyli & Coleosporiaceae & - \\
Cryphonectria parasitica & Valsaceae & - \\
Cryptostroma corticale & Not assigned & - \\
Davidiella populorum & Davidiellaceae & - \\
Endocronartium harknessii & Cronartiaceae & - \\
Monilinia fructicola & Sclerotiniaceae & - \\
Mycosphaerella laricis-leptolepidis & Mycosphaerellaceae & - \\
Ophiostoma wageneri & Ophiostomataceae & - \\
Phellinus weirii & Hymenochaetaceae & - \\
splanchnonema platani & Pleomassariaceae & - \\
Stegophora ulmea & Gnomoniaceae & - \\
\hline
\end{tabular}

Macroalgae (Taxonomic group)

Potential door knocker species / Horizon scanning

Species name

Family name

Order

Agardhiella subulata

Anotrichium furcellatum

Antithamnion densum

Antithamnionella spirographidis

Antithamnionella ternifolia

Asparagopsis armata

Asperococcus scaber

Botrytella pacifica

Botrytella parva

Caulacanthus ustulatus

Caulerpa racemosa

Codium fragile ssp. atlanticum

Codium textile

Colaconema dasyae

Corynophlaea verruculiformis

Cryptonemia hibernica

Goniotrichopsis sublittoralis

Grateloupia filicina

Grateloupia subpectinata

Grateloupia turuturu

Laurencia brongniartii

Lomentaria hakodatensis

Macrocystis pyrifera

Areschougiaceae

Ceramiaceae

Ceramiaceae

Ceramiaceae

Ceramiaceae

Bonnemaisoniaceae

Chordariaceae

Chordariaceae

Chordariaceae

Caulacanthaceae

Caulerpacea

Codiaceae

Codiaceae

Colaconemataceae

Chordariaceae

Halymeniaceae

Stylonemataceae

Halymeniaceae

Halymeniaceae

Halymeniaceae

Rhodomelaceae

Lomentariaceae

Laminariaceae

Myriactula areschougi

Chordariaceae 


\begin{tabular}{lll}
\multicolumn{2}{l}{ Potential door knocker species / Horizon scanning } & \\
Species name & Family name & Order \\
Myriactula clandestina & Chordariaceae & - \\
Polyopes lancifolius & Halymeniaceae & - \\
Polysiphonia atlantica & Rhodomelaceae & - \\
Polysiphonia senticulosa & Rhodomelaceae & - \\
Polysiphonia subtilissima & Rhodomelaceae & - \\
Scytosiphon dotyi & Scytosiphonaceae & - \\
Solieria chordalis & Solieriaceae & - \\
Ulva pertusa & Ulvaceae & - \\
Undaria pinnatifida & Alariaceae & - \\
\hline
\end{tabular}

\section{Mammal (Taxonomic group)}

Potential door knocker species / Horizon scanning

Species name

Family name

Order

Axis axis

Callosciurus erythraeus

Callosciurus finlaysonii

Cervidae
Sciuridae

Herpestes javanicus

Macaca fascicularis

Macropus rufogriseus

Muntiacus reevesi

Mustela furo

Nasua nasua

Rusa timorensis

Sciurus anomalus

Sciurus carolinensis

Sciurus niger

Sylvilagus floridanus

Tamias striatus

Trichosurus vulpecula

Sus scrofa bittatus

Sciuridae

Herpestidae

Cercopithecideae

Macropodidae

Cervidae

Mustelidae

Procyonidae

Cervidae

Sciuridae

Sciuridae

Sciuridae

Leporidae

Sciuridae

Phalangeridae

Suidae

Microorganisms (Taxonomic group)

Potential door knocker species / Horizon scanning

Species name

Family name

Order

Clavibacter michiganensis ssp. insidiosus

Clavibacter michiganensis ssp. michiganensis

Leptosphaeria maculans

Rabbit haemorrhagic disease virus

Tobacco ringspot nepovirus

Microbacteriaceae

Microbacteriaceae

Phaeosphaeriaceae

Caliciviridae

Secoviridae

Phytophthora kernoviae

Erwinia amylovora

Pepino mosaic virus

Pythiaceae

Enterobacteriaceae

Ph. cambivora $x$ Ph. fragariae

Flexiviridae

Phytophthoraceae

Mollusca (Taxonomic group)

Potential door knocker species / Horizon scanning

Species name

Family name

Order

Brachidontes pharaonis

Chilostoma cingulatum gobanzi

Corbicula fluminalis

Corbicula fluminea

Mytilidae

Helicidae

Corbiculidae

Corbiculidae 


\begin{tabular}{lll}
\multicolumn{2}{l}{ Potential door knocker species / Horizon scanning } & \\
Species name & Family name & Order \\
\hline Crassostrea virginica* & Ostreidae & - \\
Dreissena bugensis & Dreissenidae & - \\
Euglandina rosea & Spiraxidae & - \\
Mercenaria mercenaria & Veneridae & - \\
Musculista senhousia & Mytilidae & - \\
Ostrea chilensis & Ostreidae & - \\
Pinctada radiata & Pteriidae & - \\
Potamocorbula amurensis & Cardiidae & - \\
Rangia cuneata & Mactridae & - \\
Rapana venosa & Muricidae & - \\
Ruditapes philippinarum & Veneridae & - \\
Tandonia budapestensis & Milacidae & - \\
Urosalpinx cinerea & Muricidae & - \\
\hline
\end{tabular}

\section{Plant-parasitic nematode (Taxonomic group)}

\begin{tabular}{lll} 
Potential door knocker species / Horizon scanning & \\
Species name & Family name & Order \\
Meloidogyne chitwoodi & Meloidogynidae & - \\
Meloidogyne fallax & Meloidogynidae & - \\
Meloidogyne minor & Meloidogynidae & - \\
Angiostrongylus vasorum & Metastrongylidae & - \\
\hline
\end{tabular}

\section{Paracitic nematode (Taxonomic group)}

\begin{tabular}{|c|c|c|}
\hline \multicolumn{3}{|c|}{ Potential door knocker species / Horizon scanning } \\
\hline Species name & Family name & Order \\
\hline Ashworthius sidemi & Trichostrongylidae & - \\
\hline Bursaphelenchus xylophilus & Parasitaphelenchidae & - \\
\hline
\end{tabular}

Other chordates (Taxonomic group)

\begin{tabular}{lll} 
Potential door knocker species / Horizon scanning & \\
Species name & Family name & Order \\
\hline $\begin{array}{l}\text { Didemnum vexillum } \\
\text { Perophora japonica }\end{array}$ & Didemnidae \\
Corella eumyota & $\begin{array}{l}\text { Perophoridae } \\
\text { Corellidae }\end{array}$ & - \\
\hline
\end{tabular}

\section{Other invertebrates (Taxonomic group)}

\begin{tabular}{lll} 
Potential door knocker species / Horizon scanning & \\
Species name & Family name & Order \\
\hline $\begin{array}{l}\text { Celtodoryx ciocalyptoides } \\
\text { Botrylloides violaceus }\end{array}$ & $\begin{array}{l}\text { Coelosphaeridae } \\
\text { Botryllidae }\end{array}$ & - \\
\hline
\end{tabular}


Phytoplankton (Taxonomic group)

Potential door knocker species / Horizon scanning

Species name

Family name

Order

Alexandrium catenella

Alexandrium leei

Gonyaulacaceae

Goniodomataceae

Goniodomataceae

Asterolampraceae

Asteromphalus sarcophagus

Chaetocerotaceae

Chaetoceros peruvianus

etoceros rostratus

Chacetore

Eucampia cornuta

Hemiaulaceae

Isochrysis glaban

Isochrysidaceae

Isochrysidaceae

Neoceratium candelabrum

Ceratiaceae

Olisthodiscus luteus

Chattonellacea

Pleurosigma planctonicum

Pleurosigmataceae

Protist (Taxonomic group)

Potential door knocker species / Horizon scanning

Family name

Order

Plasmodium relictum

Plasmodiidae

Reptile (Taxonomic group)

Potential door knocker species / Horizon scanning

Species name

Family name

Order

Apalone spinifera

Boa constrictor imperator

Boiga irregularis

Chelydra serpentina

Chrysemys picta

Elaphe schrenckii

Graptemys pseudogeographica

Macrochelys temminckii

Trionychidae

Boidea

Colubridae

Chelydridae

Emydidae

Colubridae

Emydidae

Mauremys leprosa

Chelydridae

Geoemydidae

*Species observed but not established in one or more of the participating countries and territories. 
Ved Stranden 18

DK-1061 Copenhagen K

www.norden.org

\section{Invasive Alien Species}

Invasive alien species are one of the main drivers of biodiversity loss, due to their ability to disperse and cause negative effects on native species and the environment. To reduce the introduction of invasive alien species in the future, preventive measures need to be implemented, and knowledge about pathways of introduction of new and potentially invasive alien species can facilitate tailor-made measures.

The aim of this project is to contribute to the fulfilment of obligations in the CBD Aichi target 9 and the EU Biodiversity Strategy 2020 target 5, by identifying and prioritising the most significant pathways of introduction for invasive alien species by conducting a pathway analysis and horizon scanning. This identification and prioritisation is done for 10 participating countries and territories part of the NOBANIS network to assist them in minimising and preventing further introductions and establishment of invasive alien species.

Based on the results from the pathway analysis and horizon scanning, this report presents a prioritised list of pathways of interest, general recommendations on measures to control pathways of interest, and advice on development of an early warning system for invasive alien species.

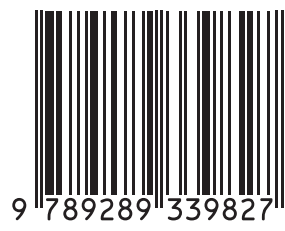

